\title{
HEAT PUMP WATER HEATER FOR COLD CLIMATE - CANADA
}

\author{
By \\ Afarin Amirirad \\ B.Sc. (Mechanical Engineering) \\ Isfahan University of Technology, Iran, 2007 \\ A thesis \\ presented to Ryerson University \\ in partial fulfillment of the \\ requirements for the degree of \\ Master of Applied Science \\ In the Program of
}

Mechanical and Industrial Engineering

Toronto, Ontario, Canada, 2016

(C)Afarin Amirirad 2016 


\section{Author's Declaration}

I hereby declare that I am the sole author of this thesis. This is a true copy of the thesis, including any required final revisions, as accepted by my examiners.

I authorize Ryerson University to lend this thesis to other institutions or individuals for the purpose of scholarly research.

I further authorize Ryerson University to reproduce this thesis by photocopying or by other means, in total or in part, at the request of other institutions or individuals for the purpose of scholarly research.

I understand that my thesis may be made electronically available to the public. 


\title{
HEAT PUMP WATER HEATER FOR COLD CLIMATE - CANADA
}

\author{
Afarin Amirirad \\ Master of Applied Science \\ Program of Mechanical Engineering \\ Ryerson University, Toronto, Ontario, Canada, 2016
}

\section{Abstract}

Considering the large energy consumption of conventional water heaters in residential buildings, the performance of a new type of water heater has been characterized through conducting experiments and numerical modelling. The specific water heater investigated in this work benefits from heat absorption from the indoor air, denoted as the air source heat pump water heater (ASHPWH), and is located in the Archetype Sustainable Twin House B in Toronto. The experiments have been conducted under three different indoor conditions associated with temperature and humidity. The coefficient of performance (COP), which quantifies the ratio of heating capacity to the consumed power of ASHPWH, ranges between 1.5 and 5, depending on the indoor dry bulb and water inlet temperatures. A TRNSYS model of ASHPWH has been constructed based on the obtained experimental results and has subsequently been integrated with a TRNSYS model of the Archetype Sustainable House (ASH). The numerical results were verified with the experimental data. The model results suggests that after employing ASHPWH, the domestic hot water energy consumption reduces by $60.3 \%$ and $53.2 \%$ compared to the electric water heater in summer and winter respectively. Due to the energy absorption of ASHPWH from the indoor environment, the heating load of the ASH house increases while its cooling load decreases. Furthermore, the annual electricity consumption of the ASH house due to the required heating and cooling as well as the domestic hot water demand is reduced by $21.3 \%$. Finally, as a consequence of employing ASHPWH, the energy cost and GHG emission were reduced respectively by $22 \%$ and $21.7 \%$. By investigating the system in four other Canadian cities, it appears that Vancouver and Edmonton would have the maximum and minimum energy savings respectively. 


\section{Acknowledgements}

I appreciate the kind support of my supervisor Dr. Alan Fung and his guidance and encouragement throughout the course of my project. I would also like to thank my colleagues Rakesh Kumar, Kajen Ethirveerasingham, Raghad Kamel and Navid Ekrami for many helpful discussions. I appreciate the funding support of the AO Smith and NSERC which provided the equipment required for my experiments. I am also very grateful to Erik Janssen, Ricardo Brown, Gil Amdurski and Aidan Brookson from Toronto and Region Conservation Authority (TRCA) for their help and support during the course of my experiments. I also acknowledge the Queen Elizabeth II graduate scholarship and the IESO student assistantship award from Center for Urban Energy. 
This work is dedicated to my husband who has been my support in all time and my dear parents, who encouraged me in every decision of my life. 


\section{Table of Contents}

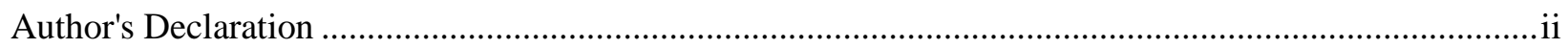

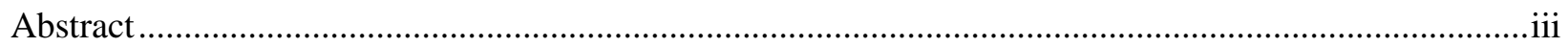

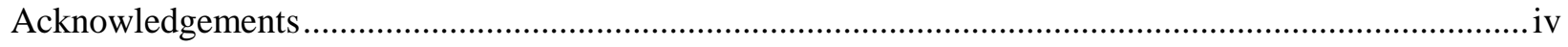

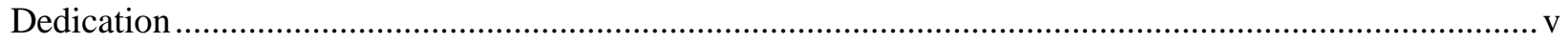

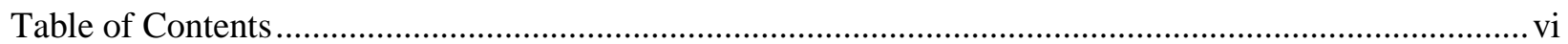

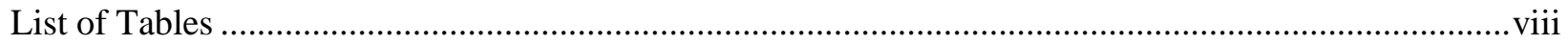

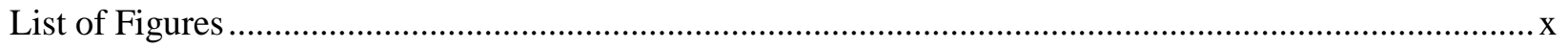

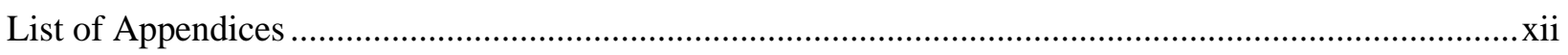

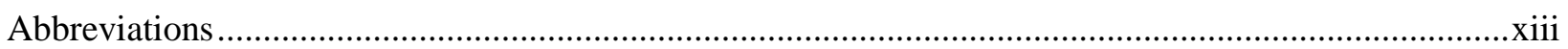

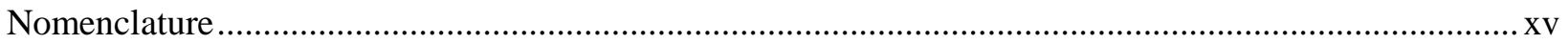

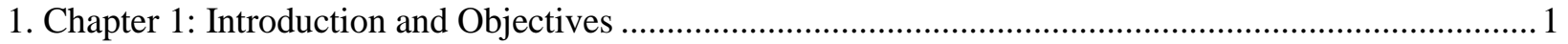

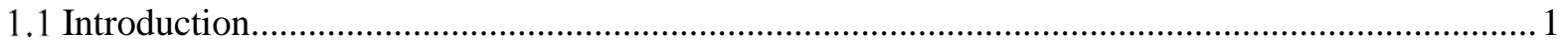

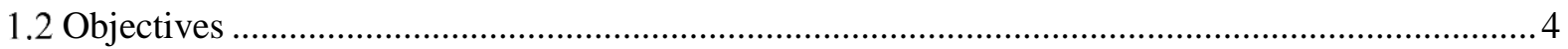

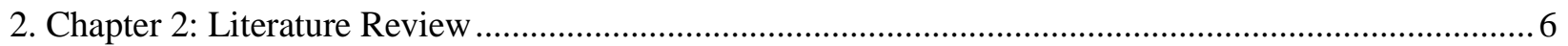

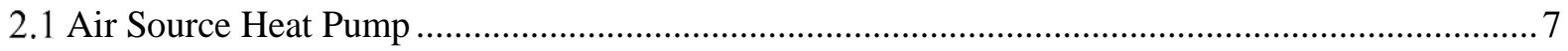

2.2 Different Types of Air Source Heat Pump .............................................................................. 9

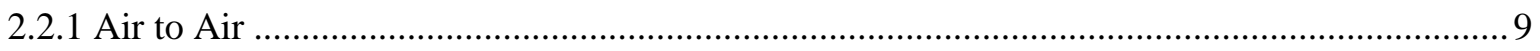

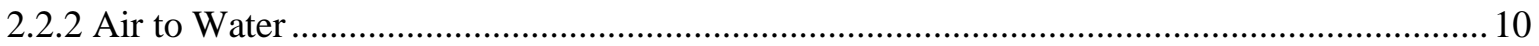

2.3 Different Applications of Air Source Heat Pump..................................................................... 11

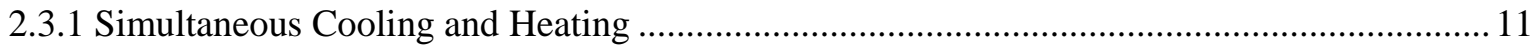

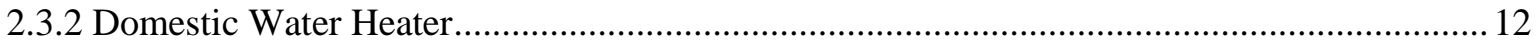

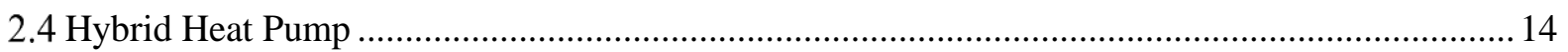

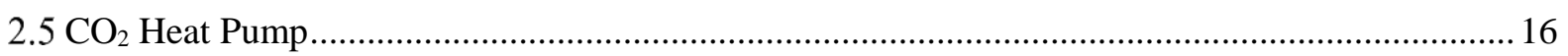

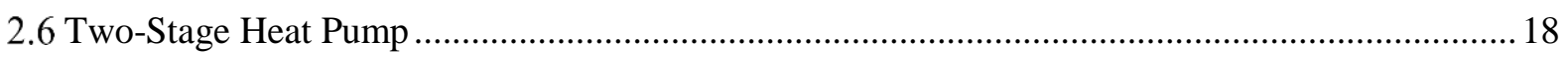

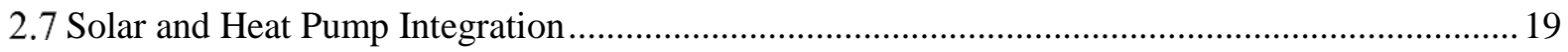

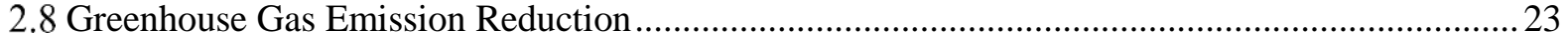

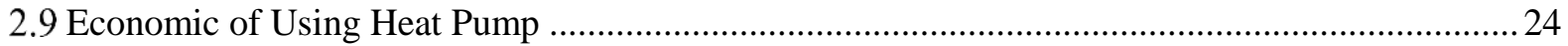

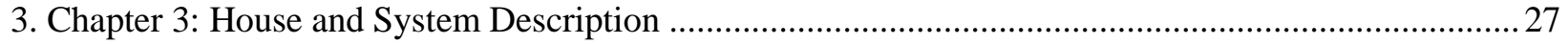

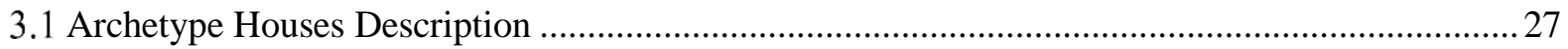

3.2 A.O. Smith Air Source Heat Pump Water Heater ...................................................................... 28

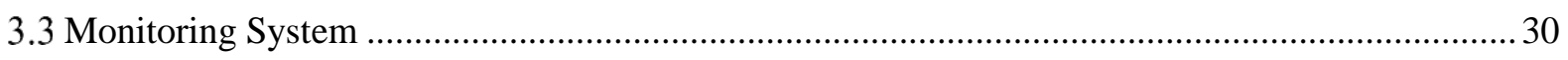




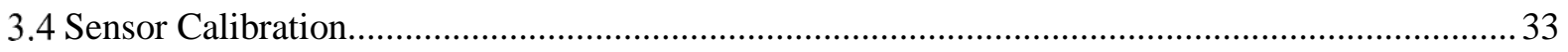

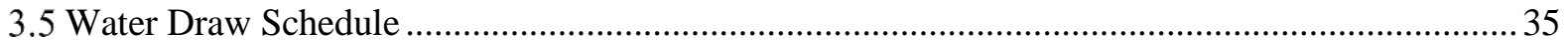

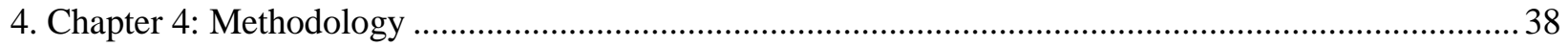

4.1 Energy Consumption, Generation and COP Equations …........................................................... 38

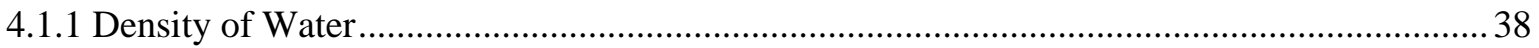

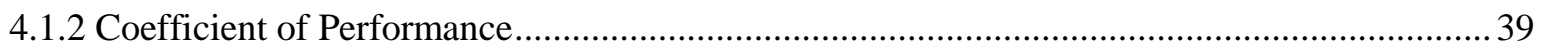

4.2 Calculating Tank Heat Transfer Coefficient (U-value) .............................................................. 45

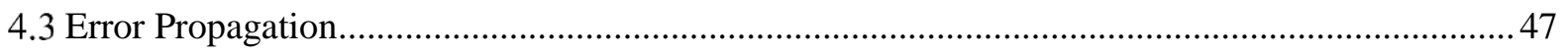

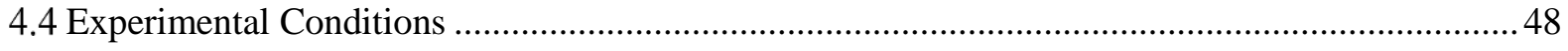

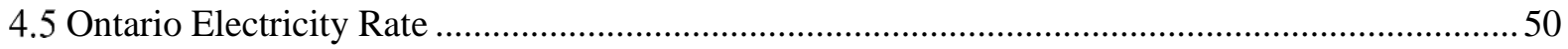

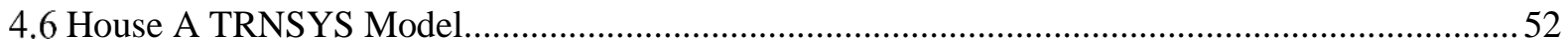

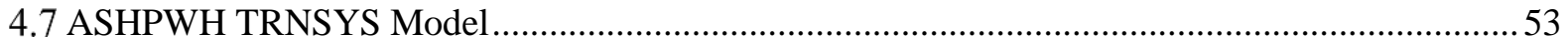

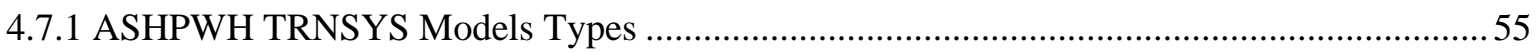

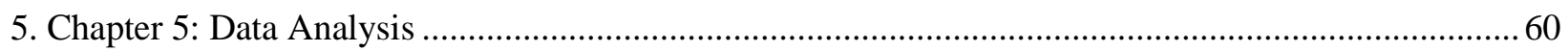

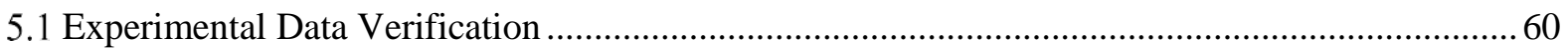

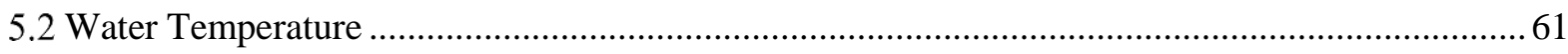

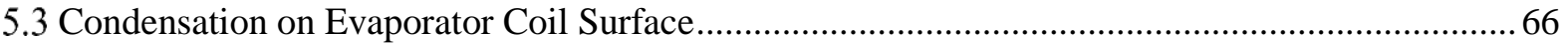

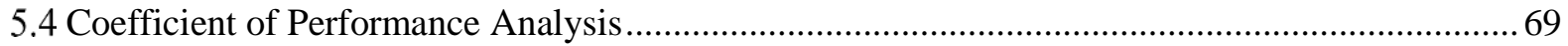

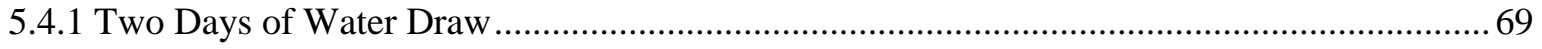

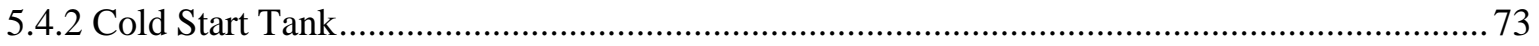

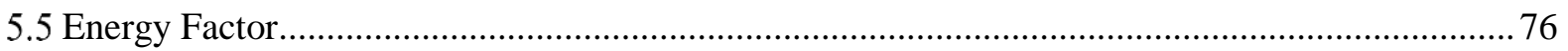

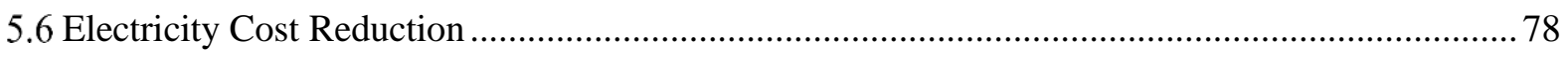

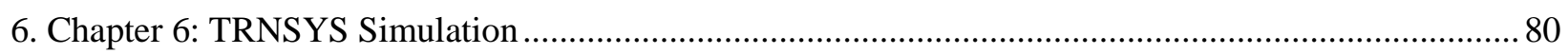

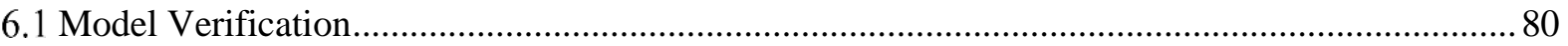

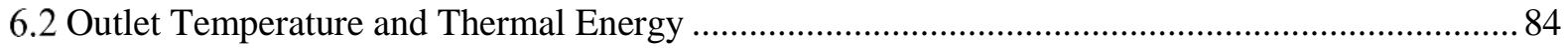

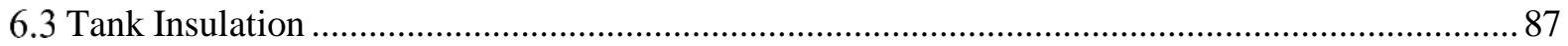

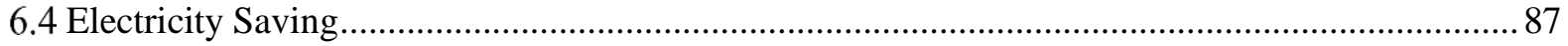

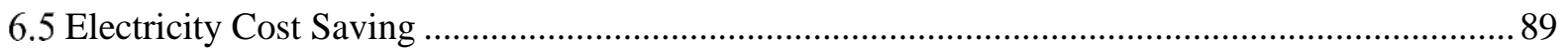

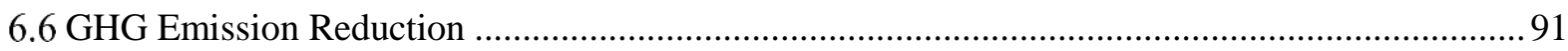

6.7 System Performance in Major Canadian Cities ...................................................................... 92

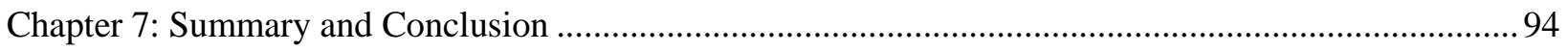

References 


\section{List of Tables}

Table 2-1: Overview of GHG emission from HPs (Amponsah et al., 2014) ..........................................24

Table 3-1: Technical specifications of mechanical systems installed in House A (Safa et al., 2015) ........28

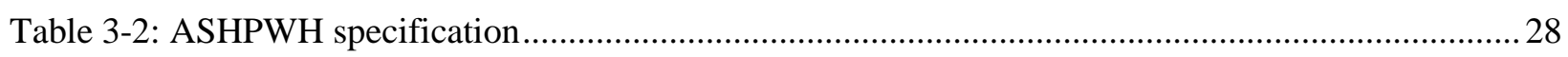

Table 3-3: Distribution of heat exchanger coil around the tank...........................................................29

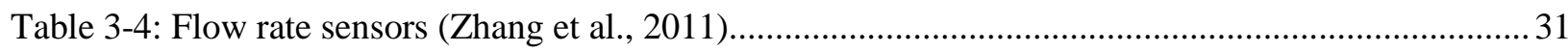

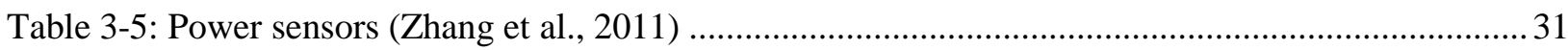

Table 3-6: Temperature and relative humidity sensors (Zhang et al., 2011) ............................................31

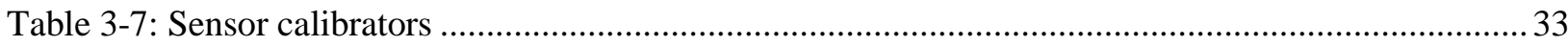

Table 3-8: List of events and different flow rates used for the water draw schedule in winter (Tanha, 2012)

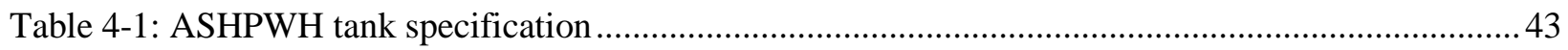

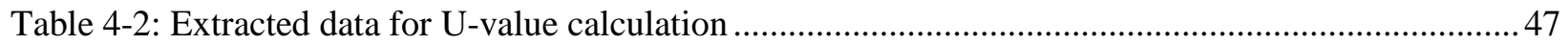

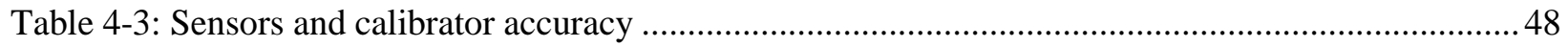

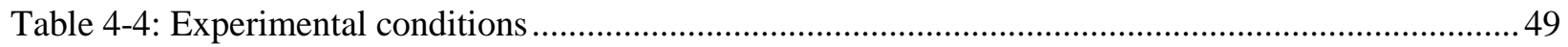

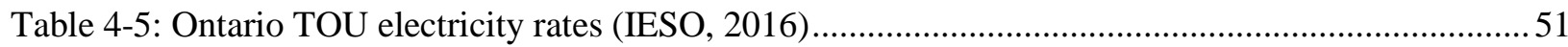

Table 4-6: Electricity delivery rate (Hydro One, 2016) .........................................................................51

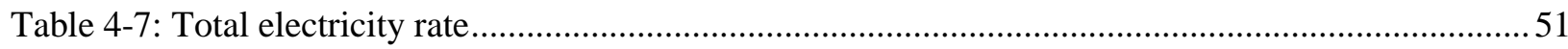

Table 4-8: Model's specification of House A (Safa et al., 2015) ............................................................53

Table 4-9: Properties of refrigerant and water in $\mathrm{T}=27^{\circ} \mathrm{C}$ (Moran and Shapiro, 2006)..........................54

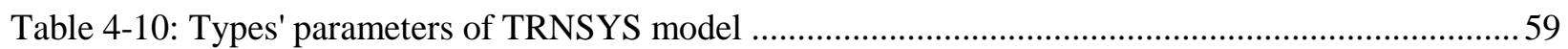

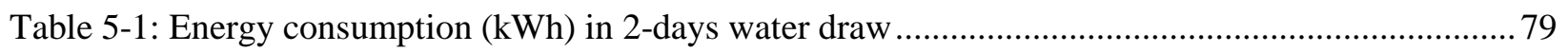

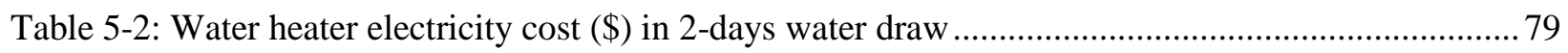

Table 6-1: Percentages of HP and electric heaters operation time in one year ......................................... 86

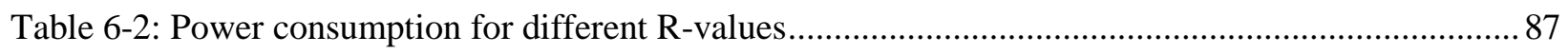

Table 6-3: Power consumption reduction due to increased R-value...................................................... 87

Table 6-4: House A electricity consumption breakdown in Toronto weather ............................................ 88

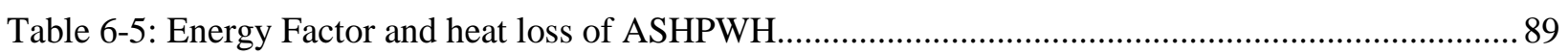

Table 6-6: Energy Factor and heat loss of electric water heater ........................................................... 89

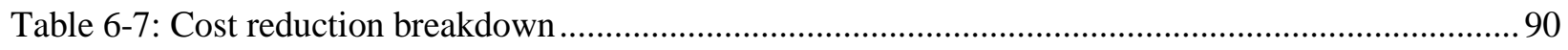

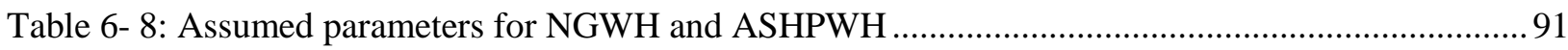

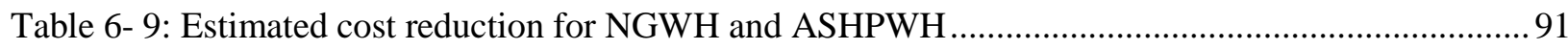

Table 6-10: Monthly average GHG emission factors in Ontario ........................................................... 91 
Table 6-11: GHG emission analysis

Table 6-12: Annual saved electricity in five major Canadian cities .....................................................93

Table 6-13: Annual electricity cost reduction in five major Canadian cities ...........................................93

Table 6-14: Annual GHG emission reduction in five major Canadian cities ..........................................93

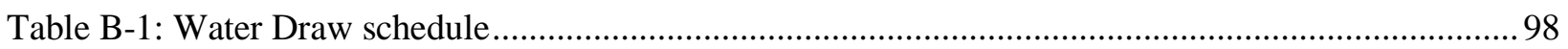

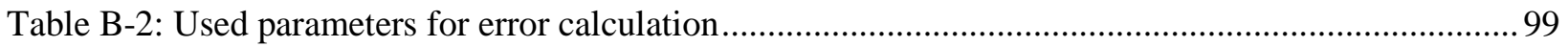




\section{List of Figures}

Figure 1-1: Energy use and GHG emission by sector in 2009 in Canada (NRCan, 2011) ........................ 1

Figure 1-2: Water heating energy use by fuel type, 1990 and 2009 in Canada ........................................2

Figure 1-3: Installed A.O. Smith ASHPWH at Archetype House B ..................................................... 4

Figure 2-1: A schematic of ASHP (Greening and Azapagic, 2012) ...................................................... 7

Figure 2-2: An improved ASHP cycle (Ding et al., 2004) .................................................................. 8

Figure 2-3: New design for air-air reversible HP (Renedo et al., 2007) .................................................. 9

Figure 2-4: Schematic of a rooftop, air-to-air HP working with $\mathrm{CO}_{2}($ Calabrese et al., 2015)................. 10

Figure 2-5: Hybrid HP system (ground water/air source) (Nam et al., 2010).......................................... 15

Figure 2-6: Hybrid HP system (solar energy, wind energy, HP) (Poulet and Outbib, 2015) .................... 16

Figure 2-7: An integrated residential $\mathrm{CO}_{2} \mathrm{HP}$ system (Stene, 2005) ................................................... 18

Figure 2-8: Schematic of the new solar assisted air source HP heating system (Liang et al., 2011) ..........20

Figure 2-9: Outline schematic diagram of the experiment (Jie et al., 2008) ...........................................21

Figure 2-10: Schematic diagram of the PV-SAHP/HP test (Fu et al., 2012) ...........................................22

Figure 2-11: Ground source air HP (Mattinen et al., 2015) ................................................................2

Figure 3-1: Southwest view of Archetype Sustainable Houses (Tanha et al., 2015) ................................22

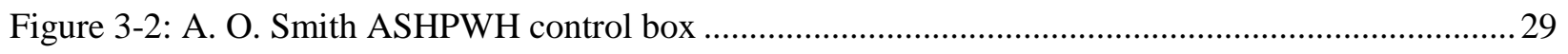

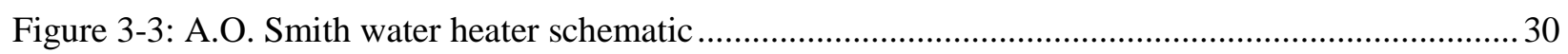

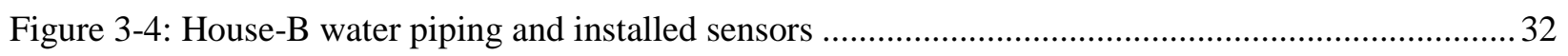

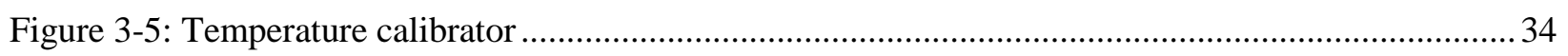

Figure 3-6: Water draw profile based on 1-minute time step (Knight et al., 2007) .................................. 35

Figure 3-7: Water draw profile based on 5-minutes time step........................................................... 36

Figure 3-8: Average monthly water supply temperature …................................................................ 37

Figure 4-1: Water density trend based on the temperature …................................................................ 39

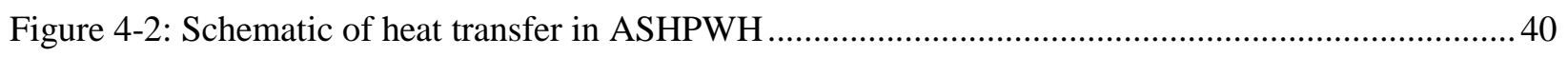

Figure 4-3: Schematic view of ASHPWH with related sensors of House-B ........................................... 41

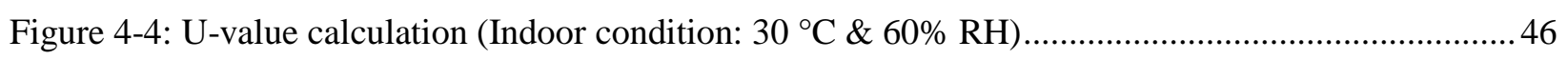

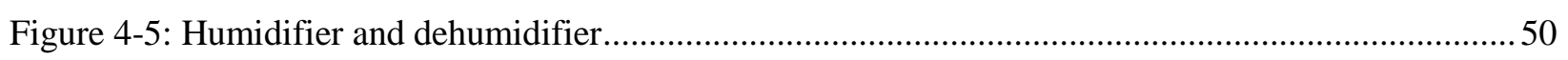

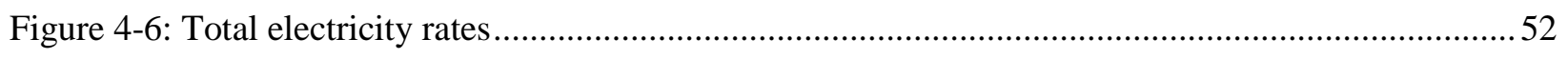

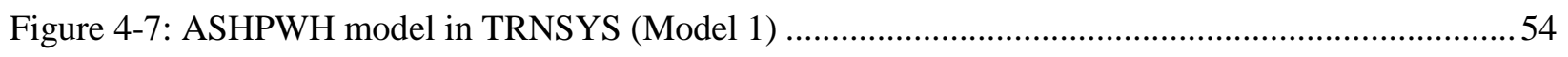

Figure 4-8: Electric water heater model in TRNSYS (Model 2) .........................................................5

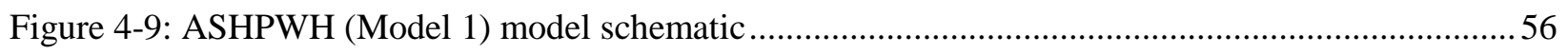

Figure 4-10: Electric water heater (Model 2) model schematic.............................................................56 
Figure 5-1: Manufacturer and experimental result in cold start tank stage of $19.7^{\circ} \mathrm{C}$ and $50 \%$ RH.........61

Figure 5-2: Tank nodes temperature for electric mode during water draw stage .....................................62

Figure 5-3: Tank nodes temperature for HP mode during water draw stage ........................................... 64

Figure 5-4: Tank nodes temperature for hybrid mode during water draw stage ......................................65

Figure 5-5: Visualization of (a) the actual temperature of the coil surface and (b) the sensor temperature66

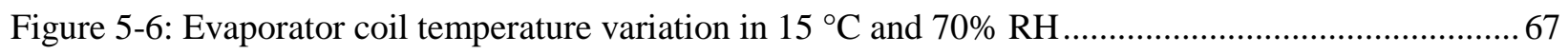

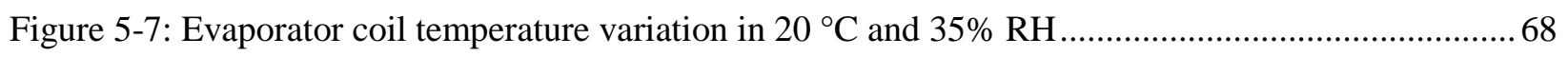

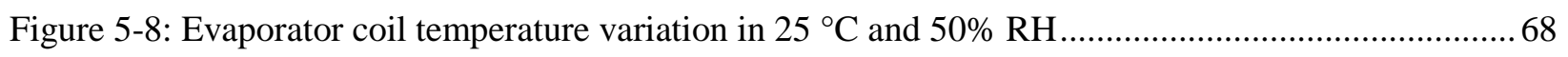

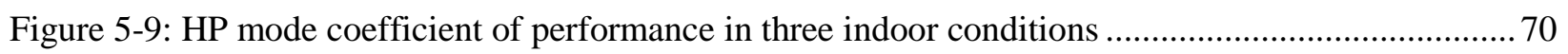

Figure 5-10: Tank inlet temperature for three indoor conditions in HP mode......................................... 71

Figure 5-11: Hybrid mode coefficient of performance in two indoor conditions ..................................... 72

Figure 5-12: Tank inlet temperature for two indoor condition in hybrid mode ........................................ 72

Figure 5-13: Performance curve for heat pump mode during heating up the tank from $16{ }^{\circ} \mathrm{C} \ldots \ldots \ldots \ldots \ldots \ldots . . . . . .74$

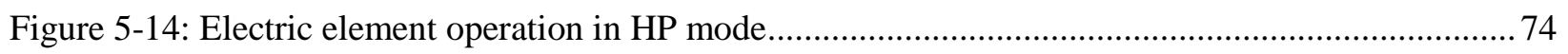

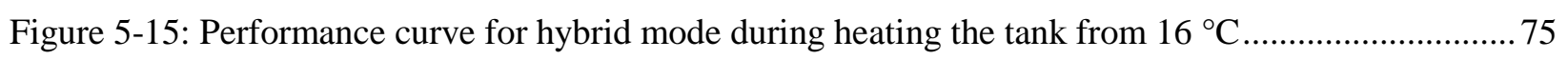

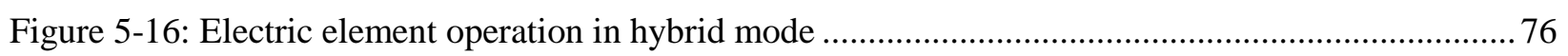

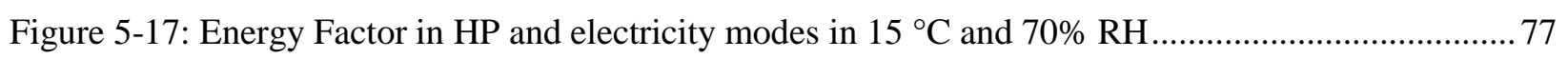

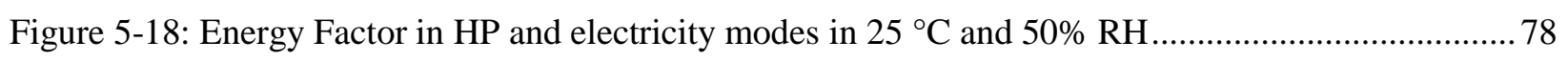

Figure 5-19: The price distribution of the experiment's water draw schedule .......................................... 79

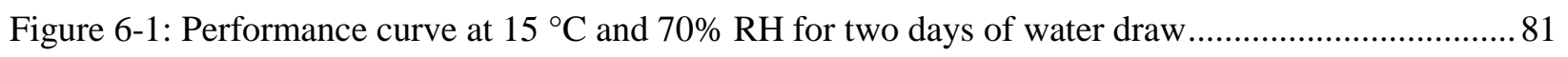

Figure 6-2: Performance curve at $20^{\circ} \mathrm{C}$ and $35 \% \mathrm{RH}$ for two days of water draw.................................. 81

Figure 6-3: Performance curve at $25^{\circ} \mathrm{C}$ and $50 \% \mathrm{RH}$ for two days of water draw.................................. 82

Figure 6-4: Temperature of outlet water at $15^{\circ} \mathrm{C}$ and $70 \% \mathrm{RH}$ for two days of water draw ....................8 83

Figure 6-5: Temperature of outlet water at $20^{\circ} \mathrm{C}$ and $35 \% \mathrm{RH}$ for two days of water draw ....................83

Figure 6-6: Temperature of outlet water at $25^{\circ} \mathrm{C}$ and $50 \% \mathrm{RH}$ for two days of water draw .................... 84

Figure 6-7: Tank outlet temperature and control signals in March......................................................... 85

Figure 6-8: Tank outlet temperature and control signals in September ................................................. 85

Figure 6-9: ASHPWH thermal energy generation and electrical energy consumption ............................. 86

Figure 6-10: Monthly water main temperature (Tanha et al., 2015) ...................................................... 92 


\section{List of Appendices}

Appendix A: Water Draw Profile ................................................... 98

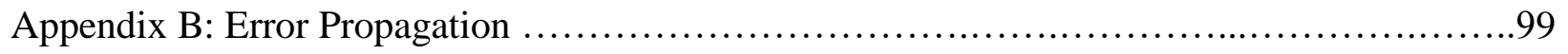

Appendix C: MATLAB Code for Analyzing Experimental Data..............................101 


\section{Abbreviations}

\begin{tabular}{|c|c|}
\hline ASHRAE & $\begin{array}{l}\text { American Society of Heating, Refrigerating and Air-Conditioning } \\
\text { Engineers }\end{array}$ \\
\hline BILD & Building Industry and Land Development Association \\
\hline BTU & British Thermal Unit \\
\hline $\mathrm{COP}$ & Coefficient of Performance \\
\hline DAQ & Data Acquisition System \\
\hline DHW & Domestic Hot Water \\
\hline DWH & Domestic Water Heating \\
\hline GAL & U.S. Gallon (3.78 LITERS) \\
\hline GHG & Greenhouse Gas \\
\hline GPM & Gallon Per Minute \\
\hline HP & Heat Pump \\
\hline ASHPWH & Air Source Heat Pump Water Heater \\
\hline HVAC & Heating, Ventilating and Air Conditioning \\
\hline IEA & International Energy Agency \\
\hline $\mathrm{kW}$ & Kilowatt \\
\hline $\mathrm{kWh}$ & Kilowatt Hour \\
\hline NRCan & Natural Resources Canada \\
\hline
\end{tabular}


TOU

TRCA

ZNEH
Time-of-use

Toronto and Region Conservation Authority

Zero Net Energy Home 


\section{Nomenclature}

\begin{tabular}{|c|c|}
\hline$A$ & Total area of the tank wall $\left(\mathrm{m}^{2}\right)$ \\
\hline$A_{\text {Sen }}$ & Sensor accuracy \\
\hline$A_{\text {Cal }}$ & Calibrator accuracy \\
\hline$C_{p}$ & Specific heat of the water $\left(\mathrm{kJ} / \mathrm{kg}_{-}{ }^{\circ} \mathrm{C}\right)$ \\
\hline COP & ASHPWH coefficient of performance \\
\hline$E_{\text {sys }}$ & Systematic error \\
\hline$F L_{2}$ & Tank inlet flow rate (U.S.Gallon Per Minute) \\
\hline$m$ & Water mass $(\mathrm{kg})$ \\
\hline$\dot{m}$ & Mass flow rate of the tank water (kg/min) \\
\hline$q$ & Volumetric flow rate $\left(\mathrm{m}^{3} / \mathrm{min}\right)$ \\
\hline$Q_{A S H P}$ & The rate of thermal energy supplied by ASHP (kJ/min) \\
\hline$Q_{\text {Elec }}$ & The rate of thermal energy supplied by electric heaters $(\mathrm{kJ} / \mathrm{min})$ \\
\hline$Q_{\text {loss }}$ & The rate of tank heat loss $(\mathrm{kJ} / \mathrm{min})$ \\
\hline$Q_{\text {Tank }}$ & The rate of water draw thermal energy ( $\mathrm{kJ} / \mathrm{min})$ \\
\hline$P_{1}$ & ASHPWH power input (kJ/min) \\
\hline$P_{2}$ & Electric elements power input (kJ/min) \\
\hline$\frac{\partial E_{\text {Tank }}}{\partial t}$ & The rate of change of tank thermal energy $(\mathrm{kJ} / \mathrm{min})$ \\
\hline
\end{tabular}


$r$

$T_{4}^{t}$

$T_{26}^{t}$

$T_{\text {avg }}^{t+\Delta t}$

$T_{a v g}^{t}$

$T_{75}^{t}$

$U$

$U_{X_{i}}$

\section{Greek Symbols:}

$\rho_{\text {water }} \quad$ Density of water $\left(\mathrm{kg} / \mathrm{m}^{3}\right)$

$\eta$
Experimental result function based on measured variables $X_{i}$

Tank outlet temperature at time $\mathrm{t}\left({ }^{\circ} \mathrm{C}\right)$

Tank inlet temperature at time $\mathrm{t}\left({ }^{\circ} \mathrm{C}\right)$

Average water temperature at time $t+\Delta t\left({ }^{\circ} \mathrm{C}\right)$

Average water temperature at time $t\left({ }^{\circ} \mathrm{C}\right)$

Ambient temperature at time $\mathrm{t}\left({ }^{\circ} \mathrm{C}\right)$

Heat transfer coefficient $\left(\mathrm{W} / \mathrm{m}^{2 \circ} \mathrm{C}\right)$

Uncertainty in the measured variables $X_{i}$

Electric elements efficiency (\%) 


\section{Chapter 1: Introduction and Objectives}

\subsection{Introduction}

Energy use by the building sector continues to increase mainly due to population growth and fewer people per household. Based on Energy Efficiency Trends report (NRCan, 2011), these factors contributed to an $11 \%$ increase in residential energy use from 1990 to 2009 in Canada. As a result, the residential sector accounts for $17 \%$ of total energy use and $15 \%$ of total GHG emission as demonstrated in Figure 1-1.

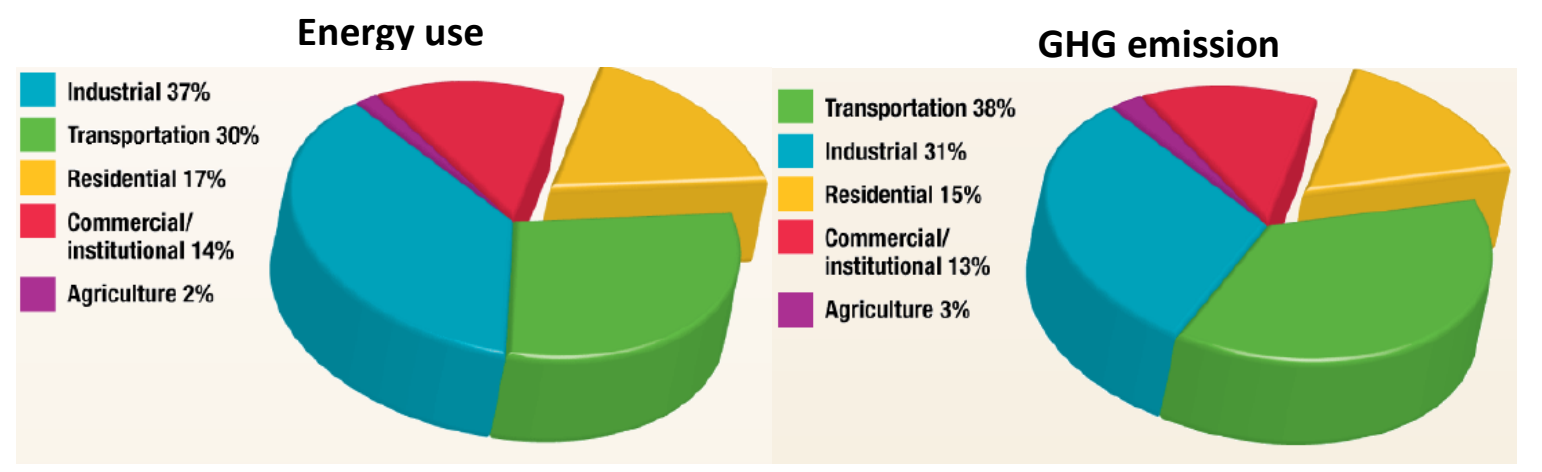

Figure 1-1: Energy use and GHG emission by sector in 2009 in Canada (NRCan, 2011)

Among all the energy consumer in residential sector, approximately 22\% (110.5 Petajoule) of the total energy is allocated to domestic water heating in Ontario (NRCan, 2016). This is the second, after space heating, major cause of energy consumption in the residential sector which results in about 4.9 Megatonnes of $\mathrm{CO}_{2}$ emission. The conventional systems of water heating consume considerable amounts of electricity and natural gas as sources of heat production. Considering Ontario's climate goals of greenhouse gas emission reduction from 1990 levels of $15 \%$ by 2020 and $80 \%$ by 2050 (Ministry of the Environment and Climate Change, 2014), these conventional systems are ideal candidates for replacement with more advanced and energy efficient alternatives such as the Air Source Heat Pump Water Heater (ASHPWH).

In Canada, various energy resources such as natural gas, electricity and heating oil are used for domestic water heating. The amount of energy consumption in the residential sector for each category is shown in Figure 1-2 (NRCan, 2011). Electric water heaters are convenient for 
installation and operation, however, the overall efficiency in converting a potential energy of fossil fuels into electric energy, then into thermal energy is quite low. Compared to the electric, gas and solar water heaters, the heat pump water heater has several advantages due to its energy savings, and low running costs. Furthermore, in contrast to conventional heaters, this type of water heater is safe and supplies more heat with the same amount of electric input (Zhang et al., 2007, Kim et al., 2004, Hepbasli and Kalinci, 2009).

Gill and Fung (2011) simulated seventeen different domestic hot water (DHW) systems to study their corresponding fuel consumption, greenhouse gas (GHG) emissions and 30-year lifecycle costs in Ontario. These systems include two-panel solar-based systems with electric and gas backup tanks, modulating gas combo boilers, on-demand gas water heaters, and conventional electric and gas hot water tanks. Their results showed that a DHW system with solar preheat with time-of-use electric backup (0.94) with timers has the lowest energy consumption and GHG emissions. This system uses $1.22 \mathrm{MWh}$ of electricity and produces $266 \mathrm{~kg}(586 \mathrm{lb})$ of GHG emissions. A DHW system with a high-efficiency on-demand modulating gas combo boiler with gray-water heat recovery is the best option in terms of 30-year life-cycle cost with the cost of CAD 12,332 .

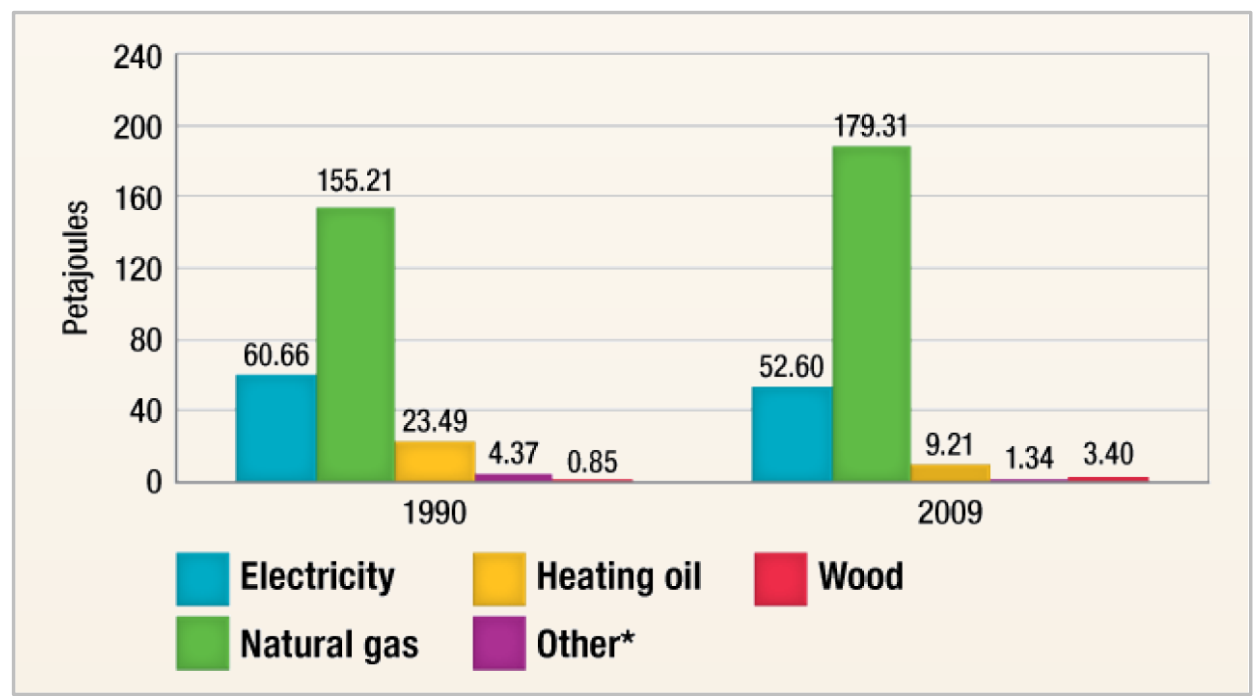

Figure 1-2: Water heating energy use by fuel type, 1990 and 2009 in Canada (Other includes coal and propane.)

The air source heat pump uses a refrigerant cycle in order to transfer the heat from cold surrounding air to the hot sink. ASHPWH is a type of air source heat pump which transfers the 
mentioned heat from surrounding air by the evaporator to heat water via the condenser. ASHPWH usually has been used in the hotter climates (such as the southern US) where space heating is minimum to none. In these climates, these systems are installed in the unconditioned garage/porch and/or outside, and provide excellent performance year-round. However, the climatic conditions are different in most part of Canada, where for a large part of the year temperature of ambient air is well below the freezing temperature for several months and space heating is needed.

In an effort to demonstrate sustainable housing technologies in Ontario, the Toronto and Region Conservation Authority (TRCA) along with the Building Industry and Land Development (BILD) Association have implemented the "Archetype Sustainable House" project at the Living City Campus at Kortright Centre in Vaughan, Ontario, Canada. This prototype twin-house is designed to demonstrate energy efficient housing technologies through research, education, training, market transformation and partnership programs (Zhang et al., 2011). Amongst a variety of state of the art technologies within the twin houses, an ASHPWH has been installed in House B shown in Figure 1-3. This equipment was donated by the industrial partner A.O. Smith.

Generally, the indoor temperature of the house is maintained by the central heating system (based on natural gas or electricity). In order to investigate the application of the ASHPWH system in the cold climate of Canada, in this study the ASHPWH was installed in the indoor space (conditioned basement) in a semi-detached Archetype Sustainable House. The heat is extracted from the house, and as a result, the presence of this water heater alters the heating and cooling demands of the house. 


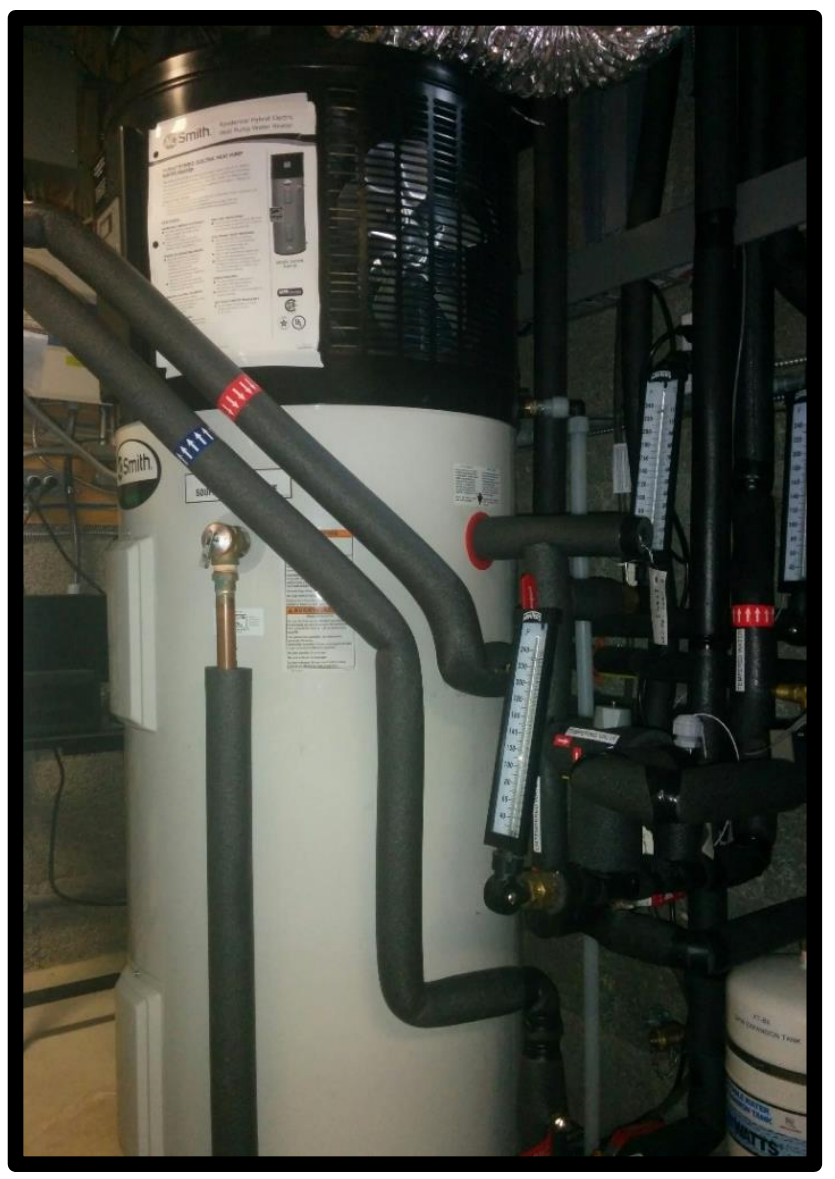

Figure 1-3: Installed A.O. Smith ASHPWH at Archetype House B

\subsection{Objectives}

This research involves a detailed performance analysis, through experimental and numerical investigation, of relatively new water heating technology. The detailed objectives of this thesis are given in the following:

- Establish performance of this technology in a sustainable Canadian house by systematic testing and collect the required data.

- Examine the fluctuation in the water set point temperature $\left(55^{\circ} \mathrm{C}\right)$ through a series of predefined indoor test conditions and water draw profiles.

- Determine the values of coefficient of performance (COP) and key performance indicators (heating capacity, energy consumption, Energy Factor, etc.) for a range of indoor conditions 
(room temperature and relative humidity) and in different modes (hybrid, HP and electric) during two stages (cold start tank and two days of water draw).

- Investigate the potential condensation on the evaporator coil in different indoor conditions by measuring the coil temperature.

- Model and simulate the ASHPWH in TRNSYS using the performance curve derived from the experimental analysis and validate the model by experimental results.

- Evaluate the impact of ASHPWH on the overall heating/cooling as well as domestic water heating energy consumption, GHG emission and financial benefits using TRNSYS energy modeling in summer and winter by comparing the ASHPWH with conventional electric water heater.

- Investigate the effects of tank R-value increase in ASHPWH electrical consumption in summer and winter.

- Assessing the overall energy consumption reduction, GHG emission reduction and energy cost reduction of the ASHPWH in five Canadian cities with different weather condition namely Toronto, Montreal, Halifax, Vancouver and Edmonton. 


\section{Chapter 2: Literature Review}

Considering the increase in the fuel cost and also the persistence of global warming, significant interest has grown over the recent past in studying heat pumps (HP) which transfer the wasted heat into useful heat (Chua et al., 2010). It is estimated that the use of HPs in providing thermal energy would be tripled from its 2010 level in the European Union countries by 2020 (Mattinen et al., 2015). Based on the increasing application of the HP system, this chapter serves as a thorough review of various aspects of this technology.

In Section 2.1, air source heat pump, as one of the most popular types of HPs, will be presented. Different types and applications of air source HP will be explained in Sections 2.2 and 2.3, respectively. Beside the advantages of a HP system which made it a popular system around the world, there are some disadvantages that can limit its usage. One method for minimizing the disadvantages of different kinds of HPs is to hybridize the equipment's heat source. The available literature about hybrid HPs will be reviewed in Section 2.4.

Global warming is one of the important issues around the world and refrigerants are one of the threats leading to the global warming. Since $\mathrm{CO}_{2}$ is a non-toxic and non-flammable fluid, it can be used as a refrigerant in HPs without threatening ozone depletion or global warming caused by leakage (Neksa, 2002). In a following section, Section 2.5, $\mathrm{CO}_{2} \mathrm{HP}$ will be reviewed. One of the solutions in order to overcome the downside of decreasing COP of HP in winter is employing twostage compression, although it must be considered that the cost of two-stage air source HP is higher than the single-stage air source HP but less than ground source HP. Two-stage HP is the topic of Section 2.6.

In Section 2.7, the integration of two important technologies of HP and solar energy, that enable the energy efficient or net zero energy building targets, will be presented. Section 2.8 explores the potential of different types of HPs in greenhouse gas emission reduction. Finally, the research efforts on the financial aspects of using HP will be summarized at the end of this chapter. 


\subsection{Air Source Heat Pump}

Generally HP includes evaporator, compressor, condenser and expansion valve where evaporator absorbs and condenser rejects the heat as shown in Figure 2-1. In fact, since this technology transferring heat between different environments instead of generating the heat so the coefficient of performance (COP) of HP is more than 1 which means more energy can be delivered to the higher temperature sink than electricity used. This advantage makes it a suitable option for Net Zero Energy Buildings. Another considerable benefit of employing air source heat pump (ASHP) is low installation cost compared to other kind of HPs namely ground source HP (Greening and Azapagic, 2012).

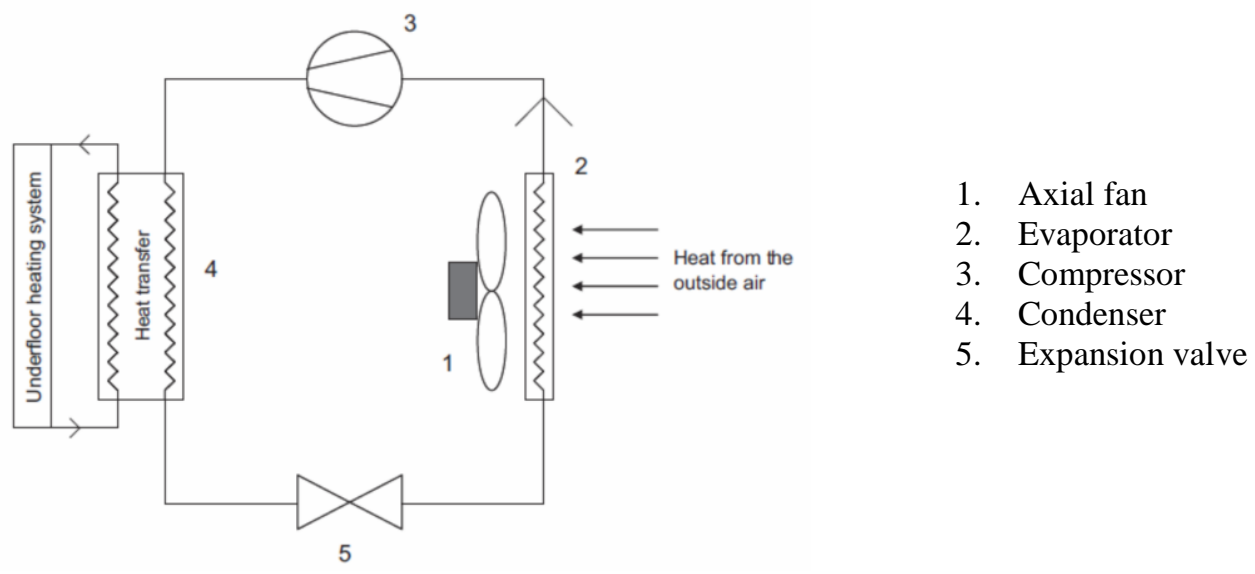

Figure 2-1: A schematic of ASHP (Greening and Azapagic, 2012)

Despite the advantages of ASHP, there are some disadvantages that need to consider more discretion in applying ASHP in some conditions. The HP can be oversized for regular weather condition due to cold weather condition in winter therefore, the compressor will generally operate in part load which result in efficiency reduction. Four major problems of using HPs operating at low ambient temperatures are: (1) high compressor discharge temperatures, (2) decreased COP, (3) reduced heating capacity, and (4) increased on/off cycling when a HP designed for low ambient temperatures operating at higher ambient temperatures (Bertsch and Groll, 2008).

In order to overcome these drawbacks, some methods have been investigated. Ma et al. (2003) investigated an improved HP cycle which has high efficiency in outdoor temperature $-10^{\circ} \mathrm{C}$ to $15^{\circ} \mathrm{C}$. In this improved HP, a scroll compressor economizer was applied in the HP cycle and the 
thermodynamic analysis of the new HP has been carried out. Finally performance of the improved HP system with a scroll compressor of $64 \mathrm{~cm}^{3}$ displacement was calculated. The measured results of the HP prototype showed that it could provide high temperature and high-capacity water supply even in temperature below $-10^{\circ} \mathrm{C}$ to $-15^{\circ} \mathrm{C}$.

Since ASHP cannot run efficiently in severe low ambient temperature during winter time due to drop in the evaporator inlet air temperature and consequently drop in HP performance. In order to eliminate this deficiency, Ding et al. (2004) proposed an improved ASHP which includes a scroll compressor with supplementary refrigerant injections as presented in Figure 2-2. After developing the prototype, the ASHP was verified and the relevant dynamic performance was tested. The results of this research show that the performance of this new kind of ASHP can be improved effectively under severe weather condition.

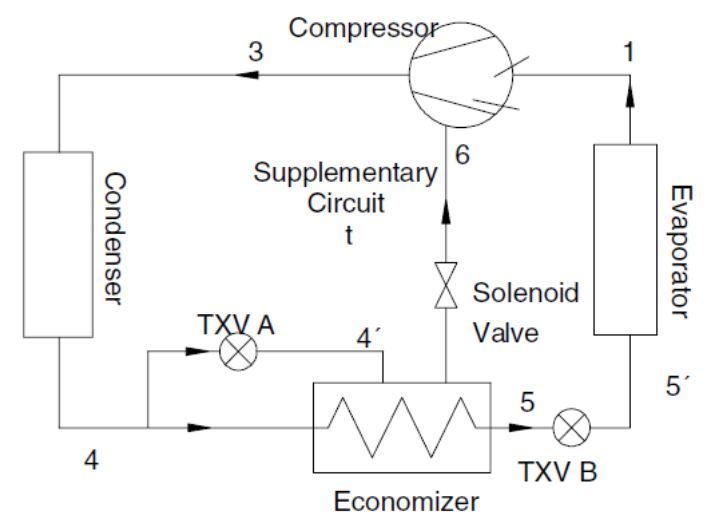

Figure 2-2: An improved ASHP cycle (Ding et al., 2004)

Jenkins et al. (2008) have investigated the effect of replacing existing boilers and airconditioning systems with ASHPs in $\mathrm{CO}_{2}$ emission in two typical UK offices. One of the offices is representative of ' 2005 ' UK office, with typical equipment/lighting usage, fabric and internal gains, and the other one is a representative of '2030' UK office (an improved version of the '2005' building with equipment/lighting, fabric glazing and boiler adjustment). This study shows that ASHP will be more beneficial if energy efficiency can be improved and also electrical generation can be decarbonized in office buildings. Ultimately, a brief economic analysis suggested that ASHPs are likely to provide significantly cheaper energy bills to the user than the defined baseline scenario of boiler with conventional air-conditioning. 


\subsection{Different Types of Air Source Heat Pump}

\subsubsection{Air to Air}

Heat pump is a refrigeration machine with reversing refrigerant flow inside the cycle. One of the most common types of the ASHP is air to air HP which transfers heat from cold air to warm air, therefore based on the season it will extract the heat from inside or outside of the building. Renedo et al. (2007) have proposed a new design for air-air reversible HPs. This design is based on the inverse air flow in the ducts done by a damper system. In this equipment, the condenser and the compressor are in one of the ducts, just as the evaporator and the expansion device are in the other duct shown in Figure 2-3. This design allows any air-air machine to be transformed into a reversible HP, whether they are small devices or large-scale equipment. By using this method, the initial investment for HP will be reduced as much as the price of chiller.

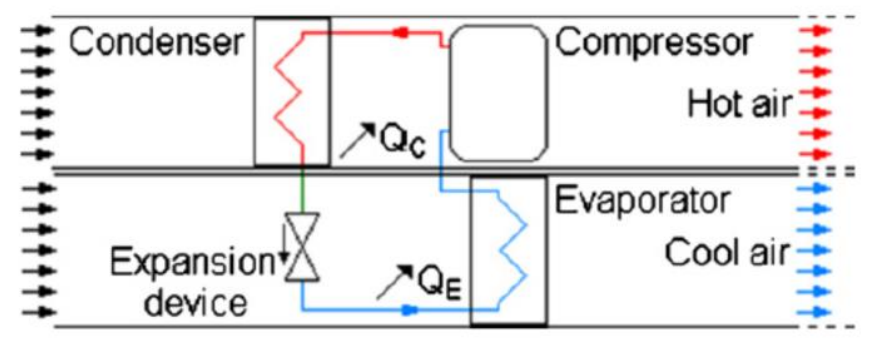

Figure 2-3: New design for air-air reversible HP (Renedo et al., 2007)

Most of the HP systems work with hydrofluorocarbon (HFC) as a refrigerant. As an example, R134a has a global warming potential (GWP100) equal to 1300 which means it traps heat 1300 times more compared to the $\mathrm{CO}_{2}$ over 100 years. This fact makes $\mathrm{R} 134 \mathrm{a}$ a significant threat for the environment. In order to eliminate this refrigerant application, Calabrese et al. (2015) explored the suitable operating condition shown in Figure 2-4 for applying roof top air to air system working with trans-critical carbon dioxide cycle during the heating season. Based on the experimental results which was set up in Rome, Italy, the heating power and the COP are affected by the air temperature at the gas cooler inlet as well as part load working conditions. In addition, thermodynamic analysis in this research indicates the direct and indirect effects of fan speed and air flow temperature on the performance. It is comprehensible from the final result that the COP of the HP is less than or close to the performance of similar HFC systems. 


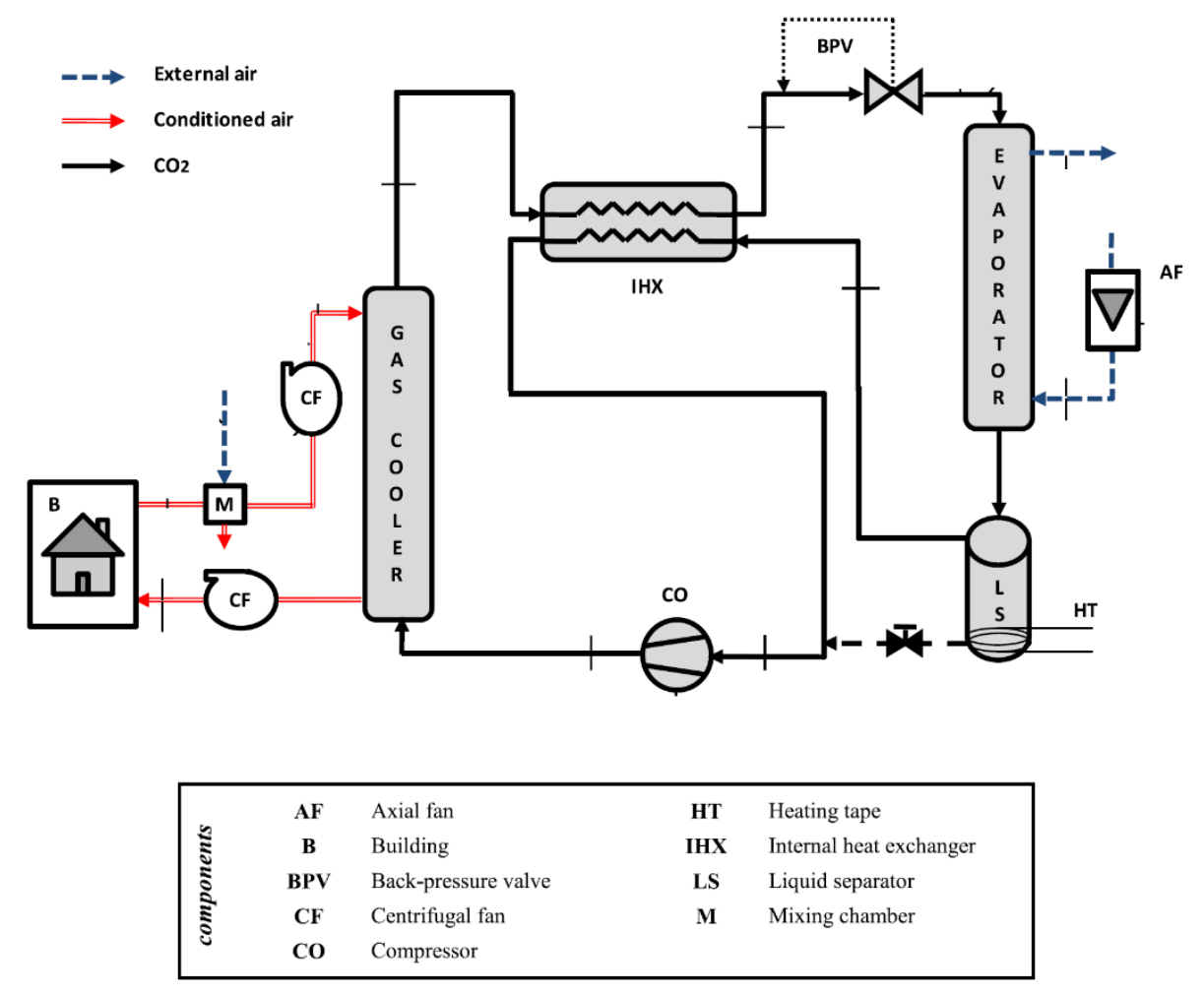

Figure 2-4: Schematic of a rooftop, air-to-air $\mathrm{HP}$ working with $\mathrm{CO}_{2}$ (Calabrese et al., 2015)

\subsubsection{Air to Water}

Another type of ASHP is air to water HP which this device absorb the heat from the external air and heat the building environment using a hydronic system. During heating and cooling season, HP performance is influenced by some external factors like local climate, settings and building characteristics. Madonna et al. (2013) explored these effects for a small air to water HP used for small residential space cooling and heating in different cities in Italy. In order to evaluate annual performance of a reversible HP, a mathematical model for hourly performance of unit using the data collected from the field monitoring has been developed. Results of this paper demonstrate variation of annual and seasonal performances for 14 cases with different conditions (old or new) and climate (cold or hot) and category (single family or twoflat). It shows that climate has the most important effect on annual performance. However the ratio of heating and cooling peak load has the same significance and it can reduce the seasonal efficiency by up to $25 \%$ because of excessive cycling in milder season.

Selecting the correct HP size has an important role in extracting the maximum performance from air to water HP in different seasons. Dongellini et al. (2015) have studied the seasonal performances of air-to-water HPs combined with a radiant floor heating system and presented a 
mathematical model which showed the impact of the design on the seasonal energy consumption. This mathematical model computes HP performance indicators (i.e., heating capacity and COP) for each partial load working condition then estimates the seasonal efficiency of the system. Different models for different types of HPs including mono-compressor HPs, multi-compressor HPs and variable-speed mono-compressor HPs have been considered. The numerical results confirm that the modulation characteristics of the different HPs strongly affect the optimal sizing of the system. Therefore, down-sizing mono-compressor HP, over-sizing multi-compressor, and adapting inverter-driven models enhance system efficiency.

\subsection{Different Applications of Air Source Heat Pump}

\subsubsection{Simultaneous Cooling and Heating}

In the interval between winter and summer, some part of buildings facing south can demand cooling and some faces north can require heating. Since HP supplies simultaneously heating in condenser and cooling in evaporator, therefore in the case of dual energy demand, HP for simultaneous (HPS) cooling and heating is a good solution. Byrne et al. (2012) presented the TRNSYS model of a HP that can fulfill fluctuating cooling and heating needs simultaneously. The model has been verified using the results of experimental study on a $15 \mathrm{~kW}$ heating capacity HPS prototype using R407C. Simulation has been run for three different cities with different weathers: Rennes, Marseille, and Brussels. The result shows that the annual COP is improved by $6 \%$ in Marseille, $13 \%$ in Rennes and up to $19 \%$ in Brussels (the coldest).

Ghoubali et al. (2014) investigated the performance of HPS in three kinds of buildings (a lowenergy residential building, an office building, and a retail space) under three different climatic conditions in France. Models for small-to-medium HPS using R407C, R290 and HFO1234yf as refrigerant were developed in TRNSYS. Afterward the results from numerical models have been verified by the results of experimental tests on a $15 \mathrm{~kW}$-heating-capacity HPS working with $\mathrm{R} 407 \mathrm{C}$. The ratio of simultaneous needs (RSN) is defined as the minimum of the ratio between the heating needs (sum of space heating and domestic hot water) and the cooling needs during a day and inverse. This indicator has been defined to show the most suitable house with HPS. The higher the RSN is, the more simultaneous heating and cooling throughout the year will be needed. 
The result shows that the low-energy residential buildings have the best RSN compared to two other buildings (around 28\% in the oceanic climate and 30\% in the Mediterranean climate).

\subsubsection{Domestic Water Heater}

Domestic hot water (DHW) heating is the fourth largest energy consumers in commercial building sector after heating, air conditioning, and lighting. For residential sector DHW heating accounts for $17 \%$ of all residential site energy use in the United States and Canada which makes it the third and second largest energy user in homes respectively (Hepbasli and Kalinci, 2009; NRCan, 2011). These percentages for other countries are: $20 \%$ for Brazil, $25 \%$ for UK, $26 \%$ for Spain and 30\% for Australia (Vieira et al., 2015). Although this value might be different for the average home in different states and provinces but still can shows the importance of using HP water heating in energy saving regardless of its impact on heating and cooling application.

Vieira et al. (2015) has analyzed energy performance (annual energy consumption and energy intensity) and provided hot water temperature for air source heat pump water heater (ASHPWH). These analyses have been performed across nine cities in Australia under different conditions: weather, cold water supply temperature, hot water set point temperature, consumption pattern, and energy time distribution. Moreover, different parameters which have been explored include: COP, water heating capacities, hot water tank insulation, size, and set point temperature. In order to calibrate the simulation, experimental analysis has been done to specify the practical operational performance of systems in different conditions. The results show that the energy consumption of ASHPWH have been affected mostly by the COP and storage tank capacity. Besides that, in cities with warmer weather condition because of the less influence of technical conditions and sitespecific conditions, a wider range of ASHPWHs can be applied.

Morrison et al. (2004) presented seasonal performance evaluation methods for water heaters as well as method for rating air source HP water heaters. Two air-source HP water heaters have been tested and the results show that the integral condenser system (56\% of energy saving) and external condenser system (44\% of energy saving) had significantly lower energy saving compared to the typical solar water heaters or solar-boosted HP water heaters (65-75\%. of energy saving), although the installation flexibility of these products makes them a good option where solar water heaters cannot be employed. 
Tran et al. (2016) have proposed a simplified model of coefficient of performance and examines its predictive capability. The model variables are air temperature and COP and derived from the test data, using regression techniques. After developing the model, the average COP performance for a standard test has been calculated and compared to the measured values. Finally the expected COP in accordance with other international standard test procedures (the US, Japanese and European test standards and the steady-state Korean test standard) was estimated and compared to experimental data. The simulation result from this model is in complete agreement with the experimental data and therefore this model can eliminate the necessity of performing experiment for different standards.

Ibrahim et al. (2014) presented a dynamic simulation model to predict the performance of an ASHPWH using MATLAB. The developed model was used to assess equipment's performance in four Lebanese climate zones. Based on model result the expected monthly values of the average COP varies from 2.9 to 5 , which is higher than conventional electric water heaters efficiency. Assuming that the constant electricity tariff and hot water loads, the high COP leads to significant savings in end-use electrical energy consumption (69\%-82\%), GHG emissions and operating costs.

Tanha et al. (2015) investigated the performance of drain water heat recovery (DWHR) system used with two solar domestic water heaters (SDWH) in order to evaluate the significance of DWHR system in annual energy saving. The first SDWH system in House A which located in Archetype Sustainable Twin Houses at Kortright Center, Vaughan, Ontario includes a flat plate solar thermal collector with a gas boiler and a DWHR unit. The second SDWH system was installed in House B including an evacuated tube solar collector, an electric tank and a DWHR unit. The experimental study results show that DWHR unit has resulted an annual heat recovery of $789 \mathrm{kWh}$ and overall effectiveness of about $50 \%$. In addition, SDWH with flat plate has generated an annual thermal energy output of $2038 \mathrm{kWh}$ and SDWH with evacuated tubes collectors an annual thermal energy output of $1383 \mathrm{kWh}$.

The usual products that being used in producing domestic hot water are gas water heater, electric water heater and solar water heater. Compared to the three other types of water heater, ASHPWH has several advantages such as energy saving, safety, low running expense (Zhang et al., 2007). Zhang et al. (2007) suggested some optimization methods for air source heat pump 
water heater. This ASHPWH consists of a HP, water tank and connecting pipes. They proposed the following considerations in order to optimize the system:

1. Refrigerant filling quantity coupling with the thermal expansion valve opening degree

2. The length of condensing coil pipe

3. Fluctuation of compressor power indicates the instability of system running

4. Suitable compatibility of HP capacity and water tank size

Bursill and Cruickshank (2016) conducted an experiment and model in order to modify the controls system for a commercially available ASHPWH. The experiments has been performed based on different hot water demand as well as different HP and electric booster set point temperatures. Finally using calibrated TRNSYS model, an optimal control strategy and tank set point temperature for cold climate was determined. The result shows that the system energy consumption can be decreased by minimizing the temperature difference between the electric booster and HP.

\subsection{Hybrid Heat Pump}

A proper way to minimize the disadvantages of different kinds of HPs is to hybridize the HP which could use dual heat sources. Ground water HP has relatively stable source (ground water) temperature throughout the year although it might not be completely efficient during intermediate seasons (spring and autumn) according to temperature condition. As it was mentioned in previous sections, performance of air source heat pump diminishes remarkably in extremely low ambient temperature during severe winter weather. Considering these two system's deficiencies, Nam et al. (2010) have developed a system which utilizes both groundwater and air source based on temperature conditions and building loads. The annual performance of the system was evaluated by several case studies which have been conducted on the various conditions of source location, refrigerant and pumping rate. Their developed system presented in Figure 2-5, is located in Chiba (east of Tokyo) with the average annual air temperature of about $15.4^{\circ} \mathrm{C}$. From the outcome of this research, it was found that the annual performance factor of the hybrid system improved by $2-7 \%$ compared to water cooling system, and by 4-18\% compared to air cooling system. Moreover, cooling experiments using real-scale equipment shows that the seasonal coefficient of performance (SCOP) of the developed hybrid system is higher than ASHP system and is equal to 5.86. 


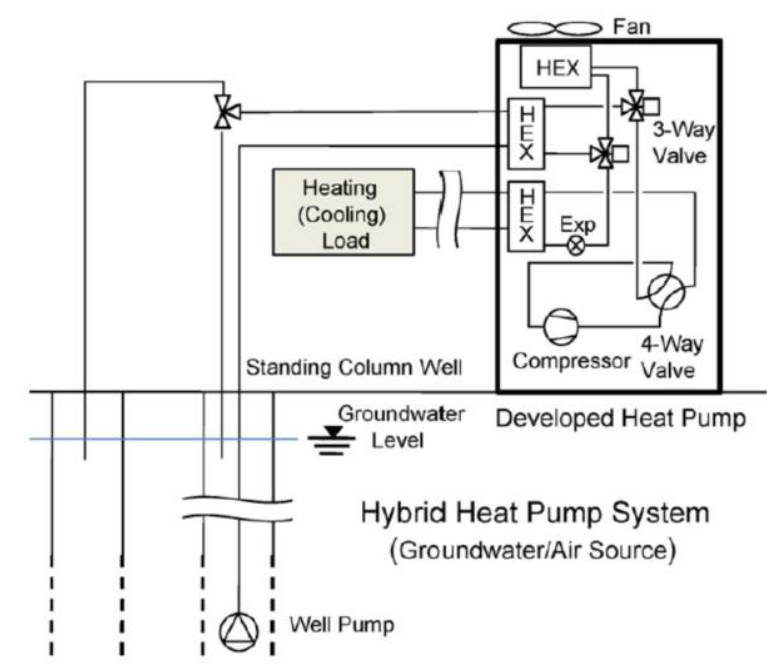

Figure 2-5: Hybrid HP system (ground water/air source) (Nam et al., 2010)

Poulet and Outbib (2015) analysed the system that uses two different alternatives for thermal energy production and verified it by experimental results. As Figure 2-6 shows, the first alternative is the HP thermal energy production consumes electrical energy produced by solar thermal and/or wind generator and the second alternative is electricity production from photovoltaic panels and then its conversion to thermal energy by using air/water HP. Finally a case study in France has been performed for dwellings in order to validate the alternatives based on energy conversion and hybridization fundamental at a scale of a country. The results show that by using system based on electrical energy conversion, thermal energy production can be improved by up to $50 \%$. Furthermore, electrical energy production can be improved by up to $90 \%$ for some locations. 


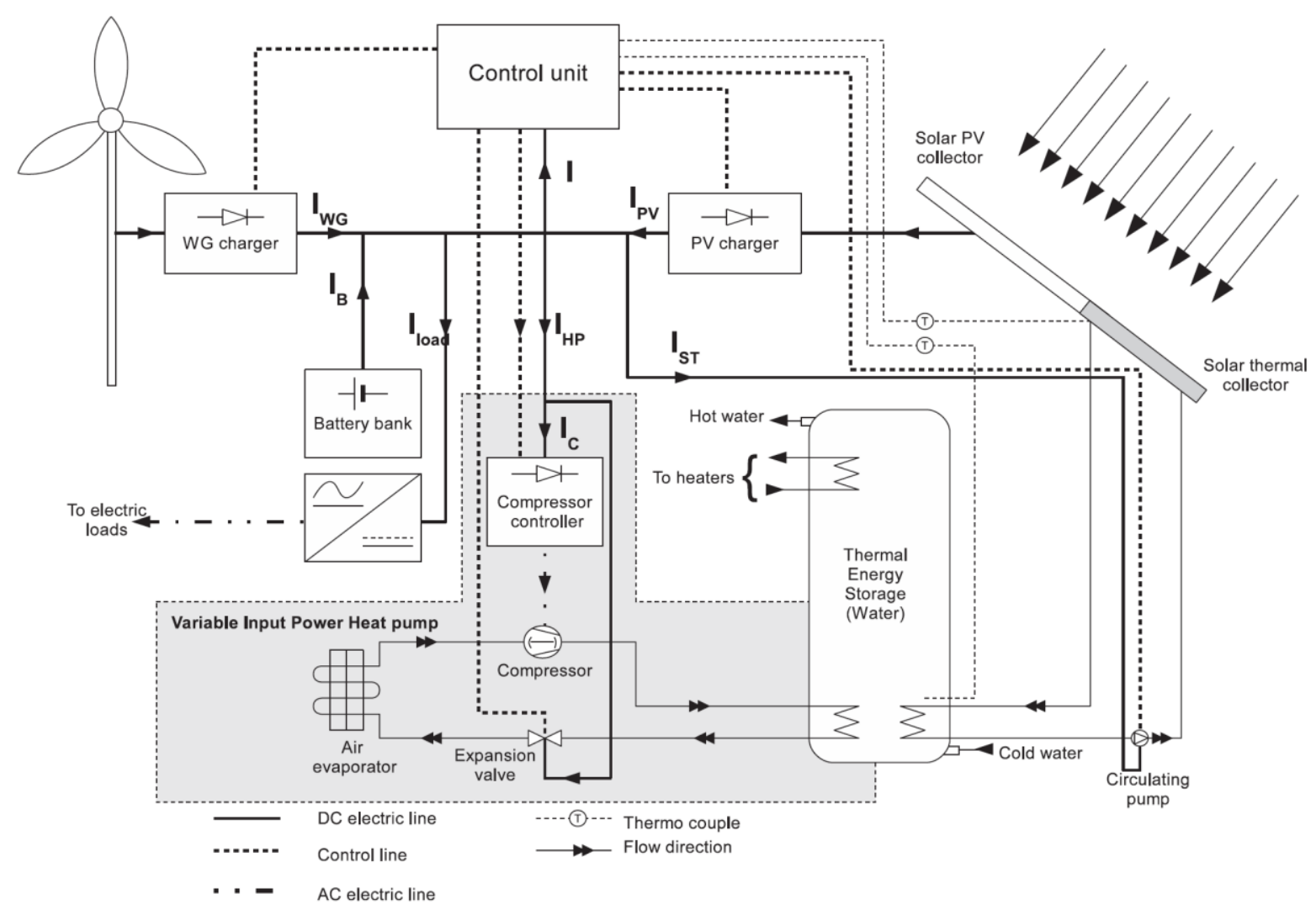

Figure 2-6: Hybrid HP system (solar energy, wind energy, HP) (Poulet and Outbib, 2015)

\section{5 $\mathrm{CO}_{2}$ Heat Pump}

After abolishing the use of CFCs and HCFCs in the Montreal Protocol, two replacement categories were hydrofluorocarbons (HFC) and natural refrigerants. A release of one kilogram of an HFC gas has 1000-3000 times more contribution to global warming than release of one kilogram of $\mathrm{CO}_{2}$. Due to high global warming potential (GWP) of HFCs, these gases have been included in the Kyoto Agreement to be regulated (Neksa, 2002). Among all natural gases, $\mathrm{CO}_{2}$ has ozone depletion potential (ODP) equal to zero and global warming potential equal to one. It is not toxic, flammable or corrosive (Papadaki et al., 2015).There is a net surplus of $\mathrm{CO}_{2}$ in the world that can be used in the refrigeration cycle, therefore it is widely available and inexpensive (Neksa, 2002).

Despite all the mentioned benefits, two factors must be considered while employing $\mathrm{CO}_{2}$ in $\mathrm{HP}$ refrigerant cycle: 1) low critical temperature, and 2) high working pressure. $\mathrm{CO}_{2}$ become super critical fluid at temperature $31.1^{\circ} \mathrm{C}$ and pressure 73.7 bar. Therefore this low critical temperature 
limits the operating temperature range for subcritical cycles (Austin et al., 2011). High pressure can cause design challenges but by today technology and knowledge progress, this challenge has been transformed to an advantage of decreasing component sizes due to high volumetric capacity (Neksa, 2002).

Due to low efficiency, $\mathrm{CO}_{2}$ systems could have higher energy consumption than HFC systems hence they can indirectly contribute to global warming. Because this contribution depends on the real working condition of each application, there are some research which investigate the correlation between working condition and output efficiency. Yang et al. (2010) developed a mathematical model for transcritical water to water $\mathrm{CO}_{2} \mathrm{HP}$. The model results which were verified by the experimental data, demonstrated that by decreasing inlet temperature and increasing mass flow rate of cooling water, the system performance increased and the optimal heat rejection pressure reduced.

Stene (2005) explored a residential brine-to-water $\mathrm{CO}_{2} \mathrm{HP}$ system through theoretical and experimental study. In order to proceed experimental studies, a $6.5 \mathrm{~kW}$ prototype HP unit has been constructed then the performance and system behavior have been tested in different operating conditions. The schematic of an integrated residential $\mathrm{CO}_{2} \mathrm{HP}$ is illustrated in Figure 2-7 and it operates in three different modes: 1) space heating only, 2) domestic hot water only, and 3) simultaneous space heating and domestic hot water heating. The research conclusion shows that an integrated residential brine-to-water $\mathrm{CO}_{2} \mathrm{HP}$ system may achieve the same or higher seasonal performance factor compared to the most energy efficient brine-to-water HPs, whenever:

1. The heating demand for hot water production is more than $25 \%$ of the total annual heating demand of the building,

2. The return temperature in the space heating system is equal to or less than $30^{\circ} \mathrm{C}$,

3. The city water temperature is equal to or less than $10^{\circ} \mathrm{C}$,

4. The exergy losses in the DHW tank are small. 


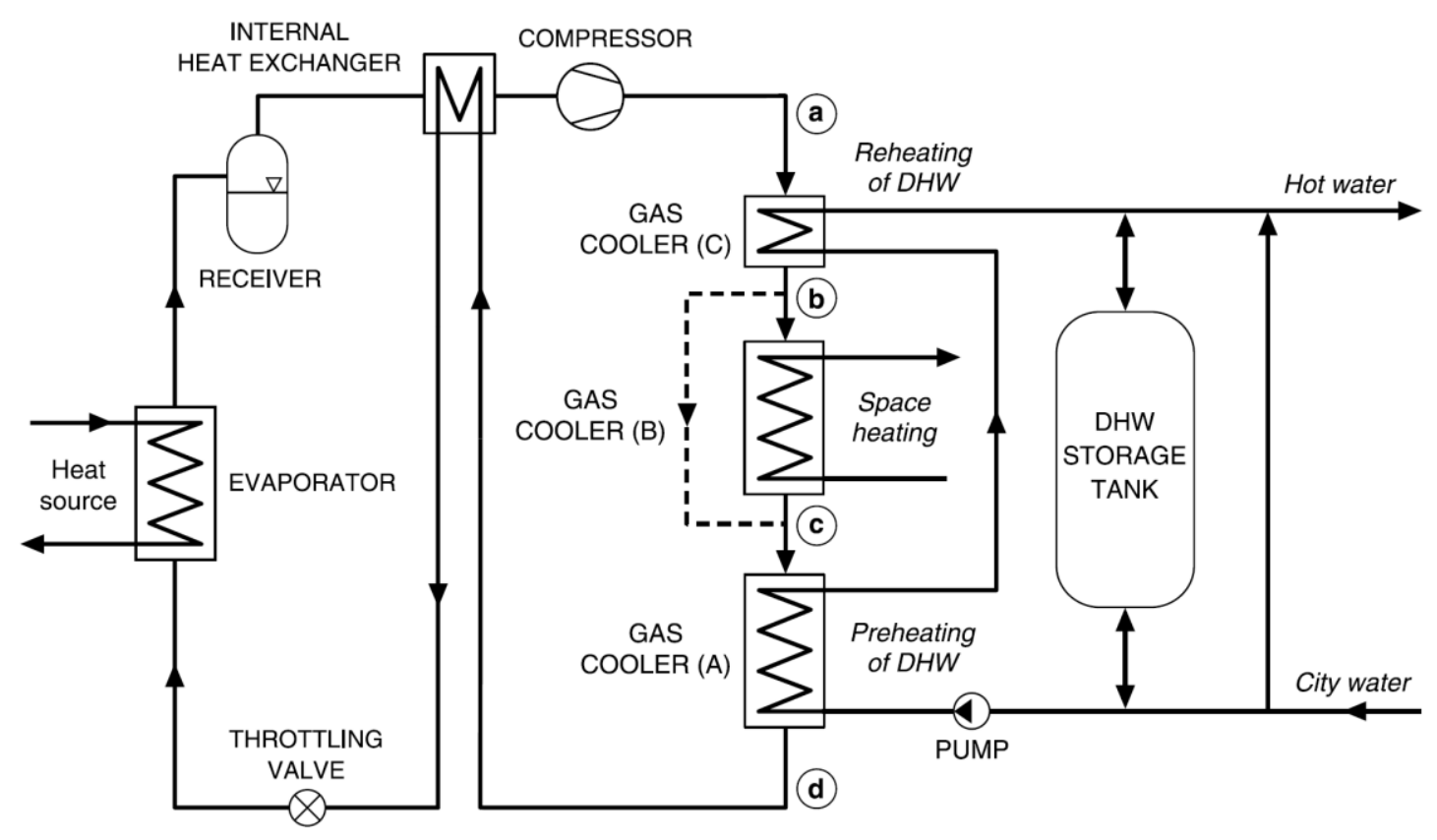

Figure 2-7: An integrated residential $\mathrm{CO}_{2} \mathrm{HP}$ system (Stene, 2005)

Neksa et al. (1998) investigated $\mathrm{CO}_{2}$ heat pump water heating system characteristics by developing prototype design and performing experimental analysis. Based on experimental results, the energy consumption can be reduced by $75 \%$ compared to electrical and gas fired system, therefore $\mathrm{CO}_{2}$ can be a well suited alternative for water heating heat pump refrigerant. Since $\mathrm{CO}_{2}$ $\mathrm{HP}$ can produce DHW with the temperature of $90^{\circ} \mathrm{C}$ compare to $55^{\circ} \mathrm{C}$ in traditional HPs, therefore it can be used in a wide range of residential and commercial buildings as well as industrial applications.

\subsection{Two-Stage Heat Pump}

One of the solutions in order to overcome the decreased COP of HP in cold climate is to employ two-stage HPs, although it must be considered that the cost of two-stage air source HP is higher than the single-stage air source HP but less than ground source HP. The main challenge of applying this system is the appropriate design of control for the system. Bertsch and Groll (2008) designed and tested a two-stage air source HP for water and air heating which uses R410A as a refrigerant. In this study three cycles: 1) two-stage HP with intercooler, 2) two-stage HP with economizer, and 3) cascade cycle have been investigated. Two-stage HP has approximately double heating capacity compared to single stage and it has been verified that two-stage HP is able to 
operate at ambient temperatures between $-30^{\circ} \mathrm{C}$ to $10^{\circ} \mathrm{C}$ and supply water temperature of up to $50^{\circ} \mathrm{C}$.

Safa et al. (2015) developed a two-stage variable capacity ASHP and building models using TRNSYS. Then the models have been verified by experimental data from data acquisition system installed in the Sustainable Houses located in Vaughan, Canada. Results show that in heating mode, the ASHP performed suitably at milder winter temperature, and poorly at temperatures below $-19^{\circ} \mathrm{C}$. By analyzing the part load performance, it was noted that the ASHP operated in both single and two-stage operation in the region of 54-103\% of the rated capacity. Nevertheless in the cooling mode, the ASHP performed very well with a COP range of 4.7 at $34^{\circ} \mathrm{C}$ to 5.7 at around $15^{\circ} \mathrm{C}$ and it operates only in single stage.

\subsection{Solar and Heat Pump Integration}

Two important technologies that enable the energy efficient or net zero energy building targets are $\mathrm{HP}$ and solar energy. As known from previous section the COP of the HP will reduce in severe cold weather because of the low ambient temperature that enters evaporator. Therefore by increasing the evaporator input temperature, this drawback can be minimized. One of the methods is integration of HP and solar technologies. Despite that, this integration can improve the performance of solar technologies by overcoming the irregular intensity of solar irradiance. A series of experimental and analytical analyses for various solar assisted HPs have been performed which some of them have been explained briefly in following.

The potential advantage of using integration of solar collector and HP is decreasing collector temperature as well as boosting the HP evaporator temperature which consequently will enhance the performance of both systems. Kamel et al. (2015) have presented the literature review on solar systems and their integration with HPs in order to review the fundamentals of PV, solar thermal collectors, PV/T collectors and their classification. The result shows that the dominant source of solar assisted HP is a liquid-based system with water thermal storage. The challenges for this integration are related to the design of the control system, which should work optimally under all conditions. In most of the developed systems in review liquid has been used as working fluid since 
it has higher thermal capacity, and it can be employed as a medium to store thermal energy in thermal energy storage when heating is not required.

A new solar assisted air source HP system as it is presented in the Figure 2-8, have been designed by Liang et al. (2011). A mathematical model for a solar assisted air source HP with the heating capacity of $10 \mathrm{~kW}$ has been developed for the heating mode. In order to validate the model, experimental tests have been carried out in weather conditions of Nanjing, China. Finally, the correlation between solar collector size and system performance has been investigated. Based on the results, by increasing the size of solar collector from $0 \mathrm{~m}^{2}$ to $40 \mathrm{~m}^{2}$ the COP can be increased by $11.22 \%$ and energy saving of the system can be improved by $24 \%$ in a typical sunny day during heating season.

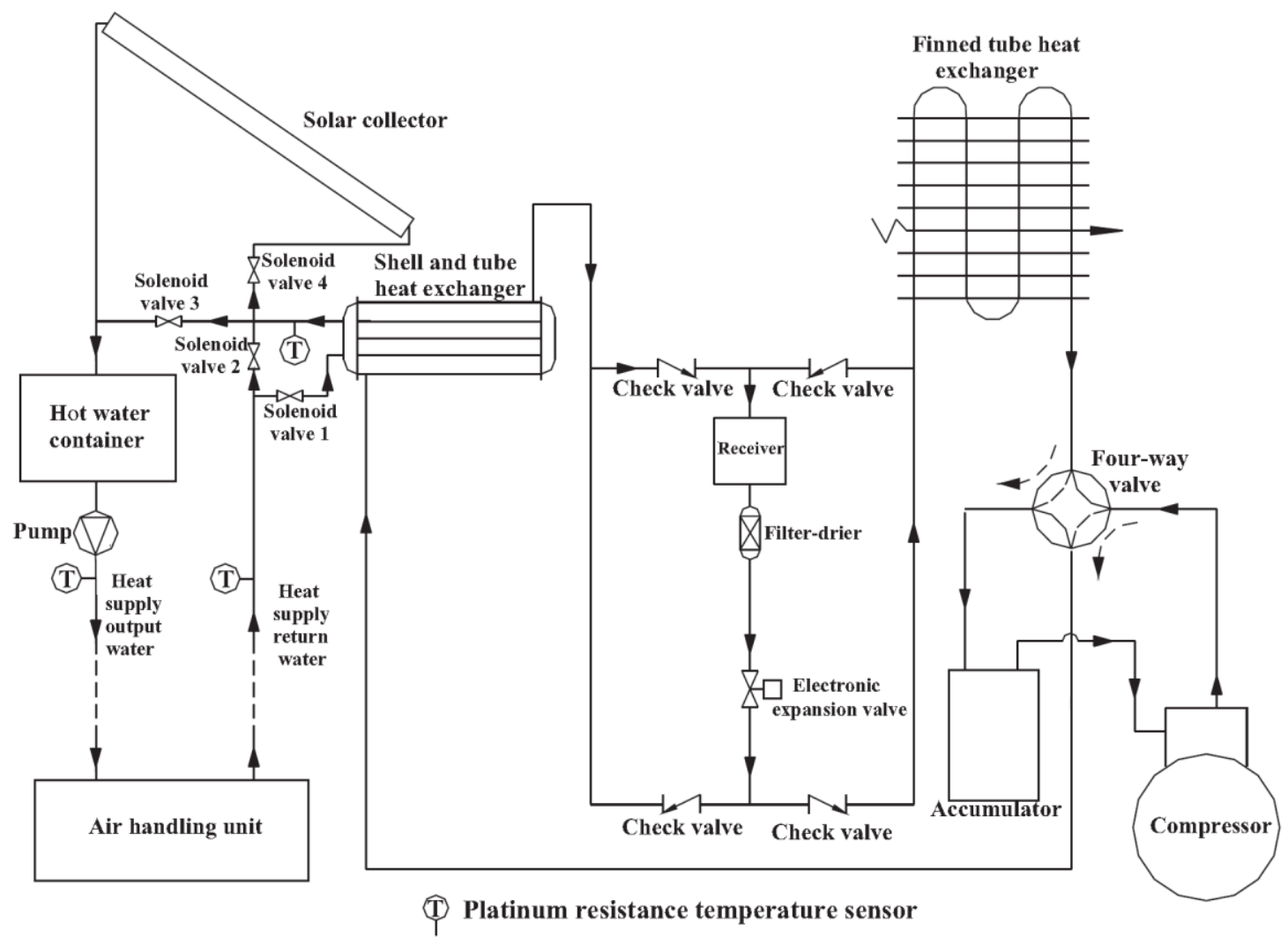

Figure 2-8: Schematic of the new solar assisted air source HP heating system (Liang et al., 2011)

Li et al. (2014) have proposed a new system consisting of solar thermal and HP with seasonal energy storage for both application of space and water heating in cold region. In order to compare the new system with a conventional space heating system as well as investigation of major 
parameters influencing on system performance, a model has been developed by employing TRNSYS. Based on the analysis, the average seasonal performance of the system during heating season is 3.7 which is $40 \%$ more than of the conventional air-to-water HP. While considering the space heating load, the monthly energy saving is about $52 \%$.

A model composed of PV evaporator and solar assisted HP has been suggested by Jie et al. (2008) as it is shown in Figure 2-9. This system has been called photovoltaic solar assisted HP (PV-SAHP) and is included four major components: PV evaporator, variable-frequency compressor, water-cooled condenser, and electronic expansion valve. In order to analyze the system, the mathematical model and numerical simulation have been proposed and ultimately the experiments have been done in Hefei, China to verify the numerical simulation. The results show that PV-SAHP has higher energy performance than conventional HP with the maximum COP value of 8.4 and the average of 6.5 (the hot water temperature: $30^{\circ} \mathrm{C}$, the averaged solar radiation intensity: $603 \mathrm{~W} / \mathrm{m}^{2}$, and the averaged ambient temperature: $15.8^{\circ} \mathrm{C}$ ).

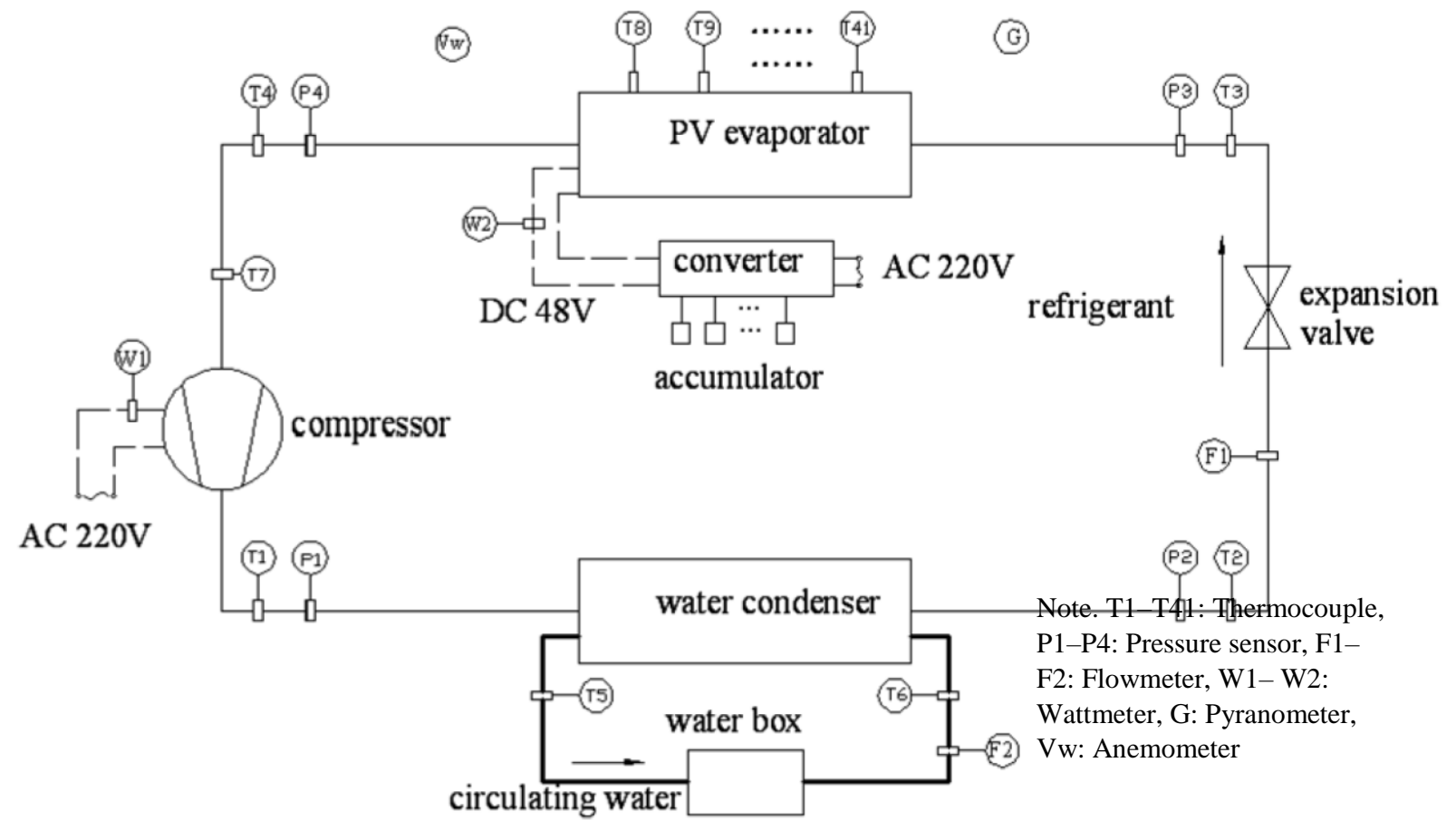

Figure 2-9: Outline schematic diagram of the experiment (Jie et al., 2008)

$\mathrm{Fu}$ et al. (2012) have developed a practical design for integration of HP with heat pipe photovoltaic thermal collector called photovoltaic solar-assisted HP/heat-pipe (PV-SAHP/HP) as shown in Figure 2-10. When the solar energy is sufficient, the heat pipes would be engaged in the 
system and the water inside collectors absorb the thermal energy otherwise HP would start to work and refrigerant absorbs the thermal energy by passing through collector. This thermal energy then will be released to the water in condenser. PV-SAHP/HP is capable of operating in three different modes: the heat-pipe only, solar-assisted HP, and air-source heat-pump only modes. After designing the system, a series of experiments in Hong Kong, China have been conducted in order to study the performance of the system while operating under the heat-pipe and the solar-assisted heat-pump modes. Under strong solar radiation condition, in the heat pipe mode the daily average system energy and exergy efficiencies are 36.5-38.4\% and 7.4-7.8\% respectively but in the solar assisted mode, system energy and exergy efficiencies are 61.1-82.1\% and 8.3-9.1\% respectively. Therefore the PV-SAHP/HP system in the HP mode is more efficient in energy saving than the heat pipe mode.

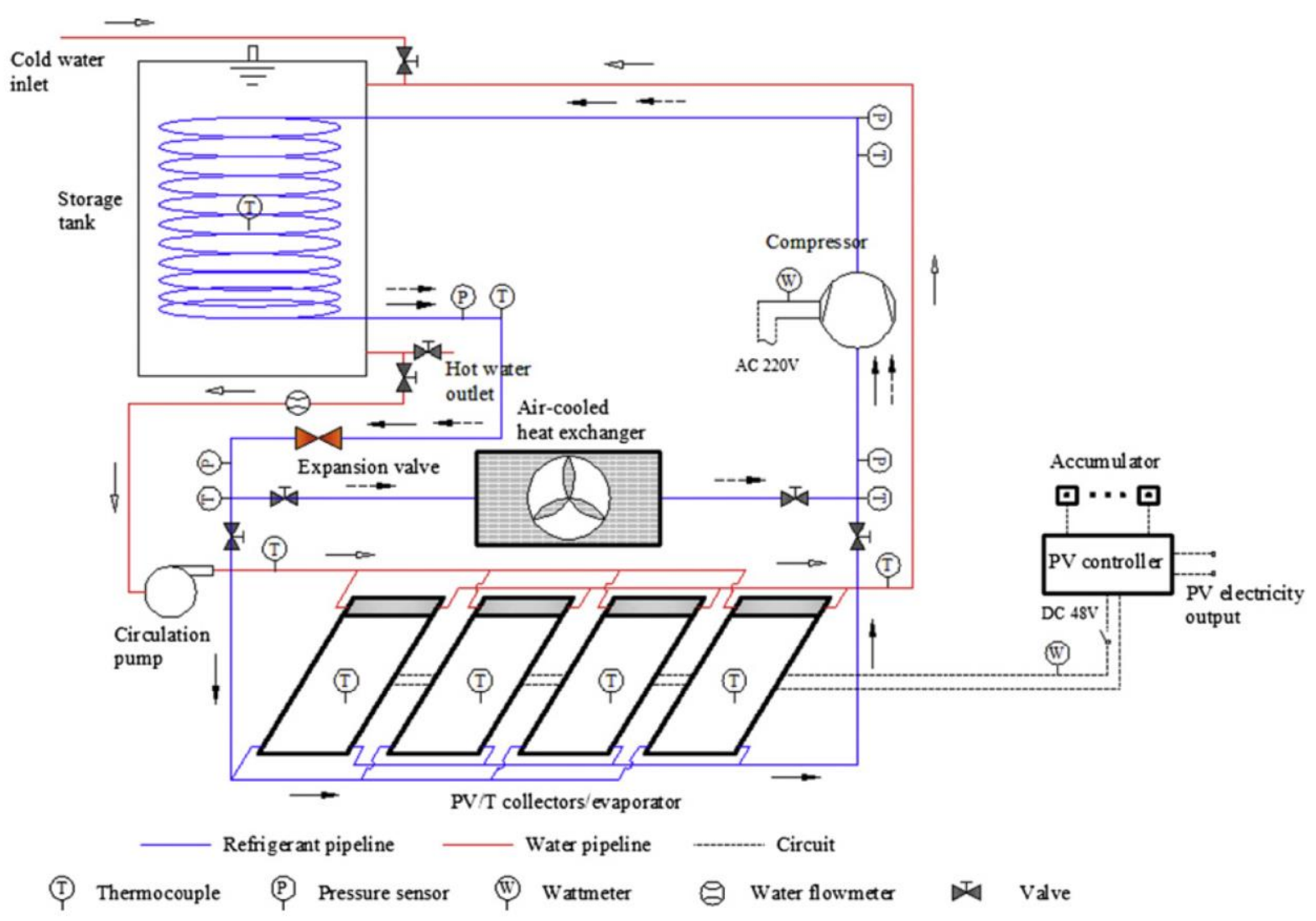

Figure 2-10: Schematic diagram of the PV-SAHP/HP test (Fu et al., 2012)

Increasing evaporator inlet temperature reduces the temperature difference between condenser and evaporator and consequently increasing the COP. Coupling building integrated photovoltaic/thermal collector (BIPV/T) and ASHP is one of the method of increasing evaporator 
temperature especially in severe winter condition. Kamel and Fung (2014) developed a TRNSYS model in order to investigate this integration. In their model the heat pump uses the warm air generated in BIPV/T as the source for heat production and the result from model were used to investigate the toal saving in energy and cost as well as GHG emission reduction. The results demonstrated that the annual GHG emission due to electricity demand by ASHP was reduced by $225 \mathrm{~kg} \mathrm{CO}_{2}$ for the new system.

\subsection{Greenhouse Gas Emission Reduction}

Gill and Fung (2011) have studied the fuel consumption, greenhouse gas (GHG) emissions, and 30-year life-cycle costs of seventeen different domestic hot water (DHW) systems including two-panel solar-based systems with electric and gas backup tanks, modulating gas combo boilers, on-demand gas water heaters, and conventional electric and gas hot water tanks. In the first part of the study, the simulation using the TRNSYS performed for the systems and the results showed that a DHW system with solar preheat with TOU electric backup (0.94) with timers has less energy consumption and GHG emissions. In additions, DHW system with a high-efficiency on-demand modulating gas combo boiler with gray-water heat recovery has the lowest life-cycle cost. In the second part of the study, a hybrid water heating system for the Net Zero Energy Healthy Housing project located in Toronto was simulated, and sensitivity analysis about the effects of various components in the hybrid model on electricity consumption and GHG emission per year was performed. Based on the results of second part, a graywater heat recovery unit can save $80 \%$ of electricity cost and GHG emissions of hybrid systems.

Mattinen et al. (2015) have assessed the potential of reducing GHG emission as well as energy consumption of a new type of HP in Finnish households. This new type of HP is a ground source air HP (GSAHP) which integrates a conventional ASHP with a heat collector (horizontal or vertical collector pipes) that are placed in the ground. A GSAHP uses a fan to transfer the heat to the indoor air and does not require a hydronic heating system. Their results indicate that GSAHP consumes less electricity and has lower GHG emission compared to the conventional ASHP. GSAHP has higher COP and it becomes even more beneficial for a colder building location. 


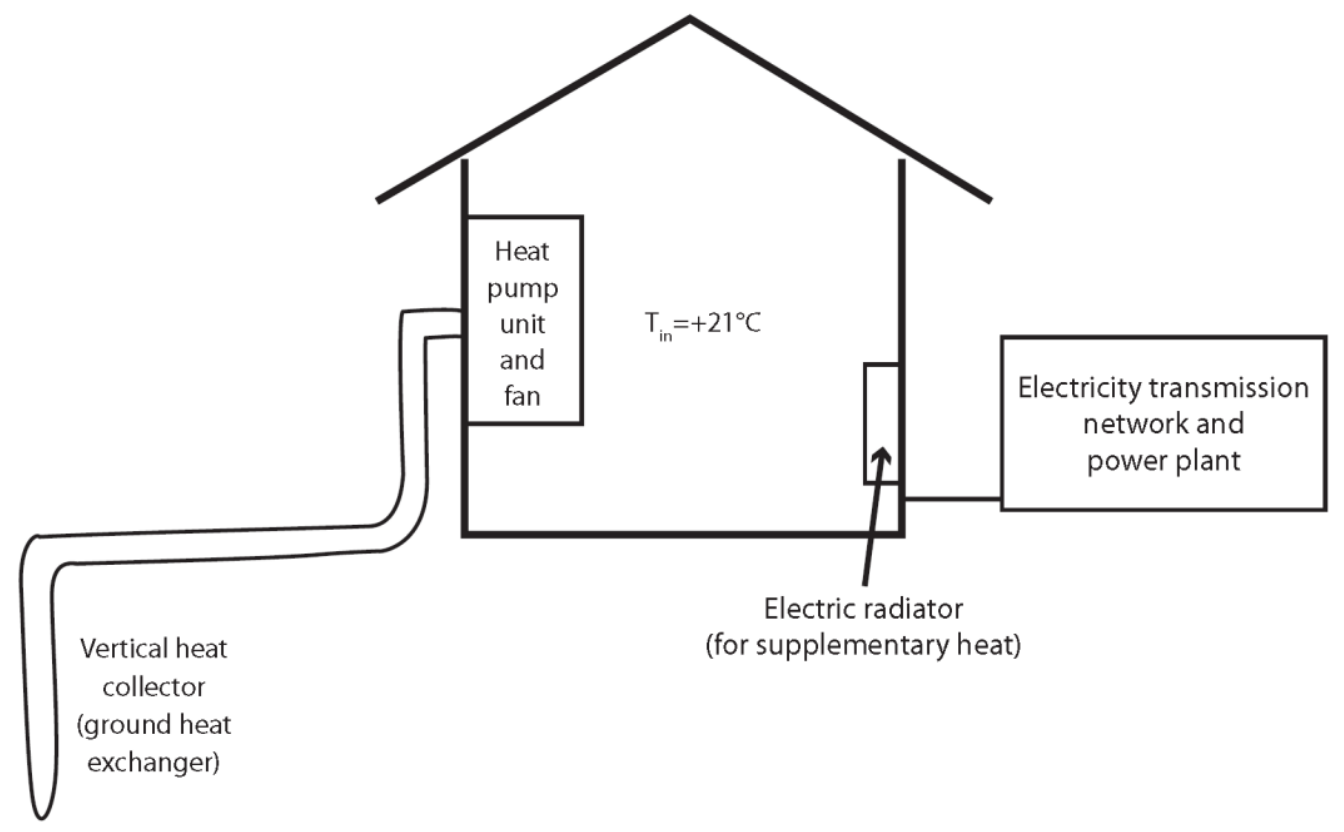

Figure 2-11: Ground source air HP (Mattinen et al., 2015)

Amponsah et al. (2014) discussed the electricity and heat generation of renewable energy technologies and calculated the GHG emission from different renewable technologies. These new technologies included: onshore wind, offshore wind, hydropower, wave power and tidal energy, geothermal, photovoltaic, solar thermal, dedicated biomass, energy from waste, HPs. In this article GHG emissions of different kind of HP (air/ground/water source) have been reviewed from different studies and it has been summarized in Table 2-1.

Table 2-1: Overview of GHG emission from HPs (Amponsah et al., 2014)

\begin{tabular}{|c|c|c|l|}
\hline \multicolumn{2}{|c|}{ gCO2eq/kWh (heat) } & \multirow{2}{*}{ Comments } \\
\cline { 1 - 3 } Mean & Min & Max & \\
\hline 207 & 150 & 264 & ASHP: with different efficiencies \\
\hline 276 & 138 & 276 & ASHP: Lower values is for an electricity mix based on 80\% contribution from renewable \\
\hline 189 & 90 & 189 & $\begin{array}{l}\text { GSHP and WSHP: Lower values is for an electricity mix based on 80\% contribution from } \\
\text { renewable }\end{array}$ \\
\hline & 65 & 149 & GSHP: German estimates for GSHP for different electricity mix (national and regional) \\
\hline
\end{tabular}

\subsection{Economic of Using Heat Pump}

The optimal cost is an important criteria for the equipment prevalence between customers as well as establishment of large scale policies for energy efficient equipment of buildings. Aste et 
al. (2013) evaluated the performance of five different heating and cooling systems in three reference residential buildings located in Italy. The systems include boiler-chiller, air to air HP, air to water HP, ground source HP and ground water HP. The evaluation involves comparison of performance indicators such as primary energy consumption, $\mathrm{CO}_{2}$ emission and net present cost. The results demonstrate that air source HP systems is a better solution in cities with mild climate like Rome and Palermo. However in cities with more severe climate condition like Milan by using storage system, ASHP can still be a competitive solution compared to the ground source and ground water HP.

Thygesen and Karlsson (2013) have simulated and analyzed three different systems considering energy and economics. These systems included: alternative 1) a PV-system and a ground source HP, alternative 2) a solar thermal system and a ground source HP, alternative 3) a PV-system, a solar thermal system, and a ground source HP. The annuity method is used for economic analysis because of its ability to compare systems with different economic lifespan. Finally, a sensitivity analysis has been done in order to assess the impact of different electricity prices on systems profitability. Nevertheless, the results show that alternative 1 with instantaneous metering is not profitable, alternative 1 with daily and monthly metering are more profitable and yield solar electricity fraction of $43.5 \%$ and $50 \%$ respectively. Alternative 2 and 3 are nonprofitable with solar electricity fraction less than alternative 1. In conclusion, a system integrated with a ground source HP and a PV-system is the most effective system considering energy and economics.

Honari et al. (2014) compared the energy use intensity (EUI) and energy cost intensity (ECI) of GSHP, conventional natural gas furnaces and air conditioners (NGF A/Cs), and ASHP for different types of buildings located in North Carolina. In order to compare the systems, different parameters including energy consumption and savings, itemized cost, average installed cost, simple payback period, net present value, and cost of saved energy have been calculated. The study reveal that GSHP save in energy cost intensity about $48.3 \%$ and $37 \%$ more than ASHP and $16.7 \%$ and $46.6 \%$ more than NGF A/Cs for residential and commercial sectors respectively. Based on a payback period calculation, GSHP had $22 \%$ and $64 \%$ higher payback period than NGF A/Cs and $45 \%$ and $88 \%$ higher payback period than ASHP for residential and light commercial buildings respectively. 
In spite of tremendous improvements in our understanding of HPs, a careful investigation concerning the suitability of an air source heat pump water heater that absorbs heat from the surrounding air in extremely cold climates of Canada has been lacking hitherto. This study is therefore primarily motivated to analyze such systems, for the first time, in the cold climate of Toronto. For this purpose, as will be elaborated in the following chapters, we have conducted a series of experiments and numerical modelling in order to characterize the performance of this equipment in the energy-efficient Archetype house B. The numerical findings have been extended to analyze the performance of such systems in other major Canadian cities. 


\section{Chapter 3: House and System Description}

In this chapter, at first the house used for installing experiment setup will be briefly explained. Afterward, the A.O. Smith air source heat pump water heater (ASHPWH) with all the applied specification and schematic in this research is described further. For each experiment, the required sensors were calibrated before installation. Therefore, Section 3.4 discusses the procedure of sensors calibration and the required sensors for the experiment followed by the detail explanation of water draw schedule.

\subsection{Archetype Houses Description}

The Archetype Sustainable House, located in Vaughan, Ontario represents a semi-detached home with two units, named "House A" and "House B". House A shown on the left side of Figure 3-1, is equipped with energy efficient technologies which are practical today and House B includes advanced and innovative technologies displayed on the right side of Figure 3-1. The main purpose of developing these houses was to transform the current housing market, as well as future buildings to low energy houses with a small ecological footprint (Dembo et al., 2010). House B is a three story house with three washrooms including a lavatory and shower, one kitchen including sink, clothes washer and dishwasher. An ASHPWH from A.O. Smith has been installed in the basement of House B and the required modifications, which will be described in Section 3.3, were done in the plumbing and monitoring system.

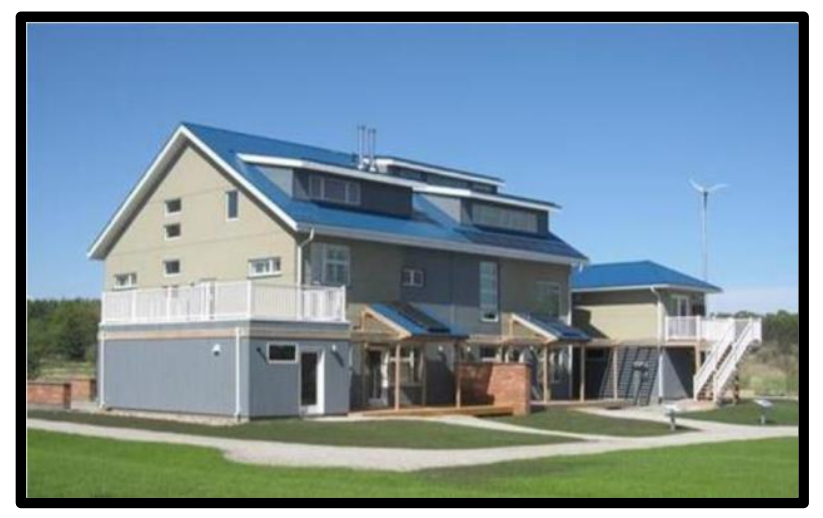

Figure 3-1: Southwest view of Archetype Sustainable Houses (Tanha et al., 2015) 
House A was equipped with a two-stage variable capacity ASHP with a direct expansion coil Air Handling Unit (AHU) for delivery of conditioned air in summer and winter. The total conditioned floor area and volume of the house including basement are $3,714 \mathrm{ft}^{2}$ and $34,820 \mathrm{ft}^{3}$, respectively. The technical information about the heat pump and air handling unit is given in Table 3-1 (Safa et al., 2015). In this research the developed TRNSYS model of the ASHPWH is integrated with the House A model.

Table 3-1: Technical specifications of mechanical systems installed in House A (Safa et al., 2015)

\begin{tabular}{|c|c|}
\hline Equipment & Technical Information \\
\hline $\begin{array}{l}\text { Air source heat pump } \\
(\mathrm{ASHP})\end{array}$ & $\begin{array}{l}\text { Heating capacities-COP: } 3.27 \text {, heating } \\
\text { capacity: } 11.06 \mathrm{~kW}(38 \mathrm{MBH}) \text { at } 21.1^{\circ} \mathrm{C}\left(70{ }^{\circ} \mathrm{F}\right) \\
\text { DB and } 15.6{ }^{\circ} \mathrm{C}\left(60^{\circ} \mathrm{F}\right) \mathrm{WB} \text { indoor and } 8.3^{\circ} \mathrm{C} \\
\left(47^{\circ} \mathrm{F}\right) \mathrm{DB} \text { and } 6.1{ }^{\circ} \mathrm{C}\left(43{ }^{\circ} \mathrm{F}\right) \text { WB outdoor } \\
\text { Cooling capacities - COP: } 3.52 \text {, cooling } \\
\text { capacity: } 9.82 \mathrm{~kW}(33.5 \mathrm{MBH}) \text {, at } 26.7^{\circ} \mathrm{C}\left(80{ }^{\circ} \mathrm{F}\right) \\
\text { DB and } 19.4^{\circ} \mathrm{C}\left(67^{\circ} \mathrm{F}\right) \mathrm{WB} \text { indoor and } 35^{\circ} \mathrm{C} \\
\left(95^{\circ} \mathrm{F}\right) \mathrm{DB} \text { and } 23.9^{\circ} \mathrm{C}\left(75^{\circ} \mathrm{F}\right) \text { WB outdoor }\end{array}$ \\
\hline Air handling unit & $\begin{array}{l}\text { Multi-speed fan, airflow dry: } 705-810-920 \\
\text { CFM, airflow wet: } 635-730-830 \text {, cooling } \\
\text { capacity: } 8.73 \mathrm{~kW}(2.5 \mathrm{t}) \text {, heating capacity: } \\
16.73 \mathrm{~kW}(57.48 \mathrm{MBH}) \text { at } 800 \mathrm{CFM} \text { and } 82^{\circ} \mathrm{C} \\
\left(180^{\circ} \mathrm{F}\right) \text { EWT }\end{array}$ \\
\hline
\end{tabular}

\subsection{A.O. Smith Air Source Heat Pump Water Heater}

The tested air source heat pump water heater (ASHPWH), with the specification shown in Table 3-2, is a self-contained heat pump, integrated on the top of the water tank, which absorbs the heat from surrounding air and transfers it to the refrigerant (R134a) inside the heat pump. The condenser is a coil wrapped around the water tank as shown in Figure 3-3-a. Table 3-3 tabulated the distribution of the heat exchanger coil around the tank. The capacity of the system is 190 liters (50 gallons) of water intended for single family (2-3 people) residential use. The water temperature can be adjusted from $35^{\circ} \mathrm{C}$ to $60^{\circ} \mathrm{C}$ set point temperature.

Table 3-2: ASHPWH specification

\begin{tabular}{|l|l|c|c|c|c|c|c|}
\hline & & & \multicolumn{3}{|c|}{ Energy Factor } & \\
\cline { 3 - 6 } Model & Manufacturer & Gallon Capacity & HP Mode & Hybrid Mode & Electric Mode & Height (m) & Diameter (m) \\
\hline SHPT-50 & A.O.Smith & 50 & 2.78 & 2.75 & 0.89 & 1.60 & 0.56 \\
\hline
\end{tabular}


Table 3-3: Distribution of heat exchanger coil around the tank

\begin{tabular}{|l|c|c|c|c|c|c|}
\hline Nodes & $\begin{array}{c}1 \text { (Tank } \\
\text { Bottom) }\end{array}$ & 2 & 3 & 4 & 5 & $\begin{array}{c}6 \text { (Tank } \\
\text { Top Head) }\end{array}$ \\
\hline $\begin{array}{l}\text { Coil } \\
\text { percentage }\end{array}$ & $29 \%$ & $29 \%$ & $36 \%$ & $2 \%$ & $2 \%$ & $2 \%$ \\
\hline
\end{tabular}

The system operates in four different modes as illustrated in the system control box in Figure 3-2 which will be explained briefly in the following:

Heat Pump (Efficiency) mode: During this mode of operation, the HP would be utilized to heat up the water with a goal of minimal electric element heating.

Electric mode: Only the electric elements operate.

Hybrid mode: The HP is primarily utilized, but in case of high demand, electric heaters also operate in order to improve and accelerate hot water temperature recovery.

Vacation mode: This mode operates as the Hybrid mode in order to maintain the water temperature at $15.6^{\circ} \mathrm{C}$.

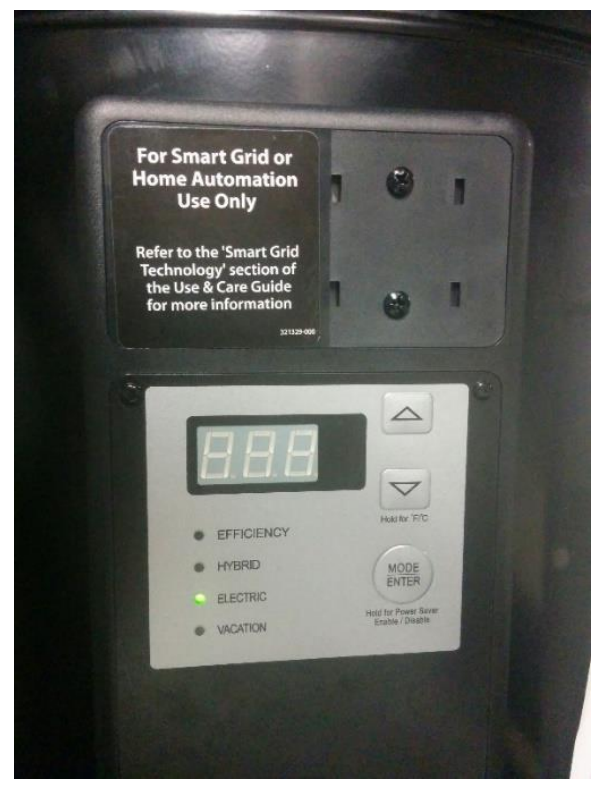

Figure 3-2: A. O. Smith ASHPWH control box

Based on the information provided by the manufacturer, this system includes two electric heaters and as illustrated in Figure 3-3-b, if water tank height is assumed to be divided in 6 nodes 
with equal spacing, electric heaters are located in nodes 2 and 5. According to the provided information by the manufacturer, the control temperature that activates HP and electric modes operations in hybrid mode is the average of two sensors' data in nodes 3 and 6 . The inlet and outlet of tank water are in nodes 1 and 6 , respectively.

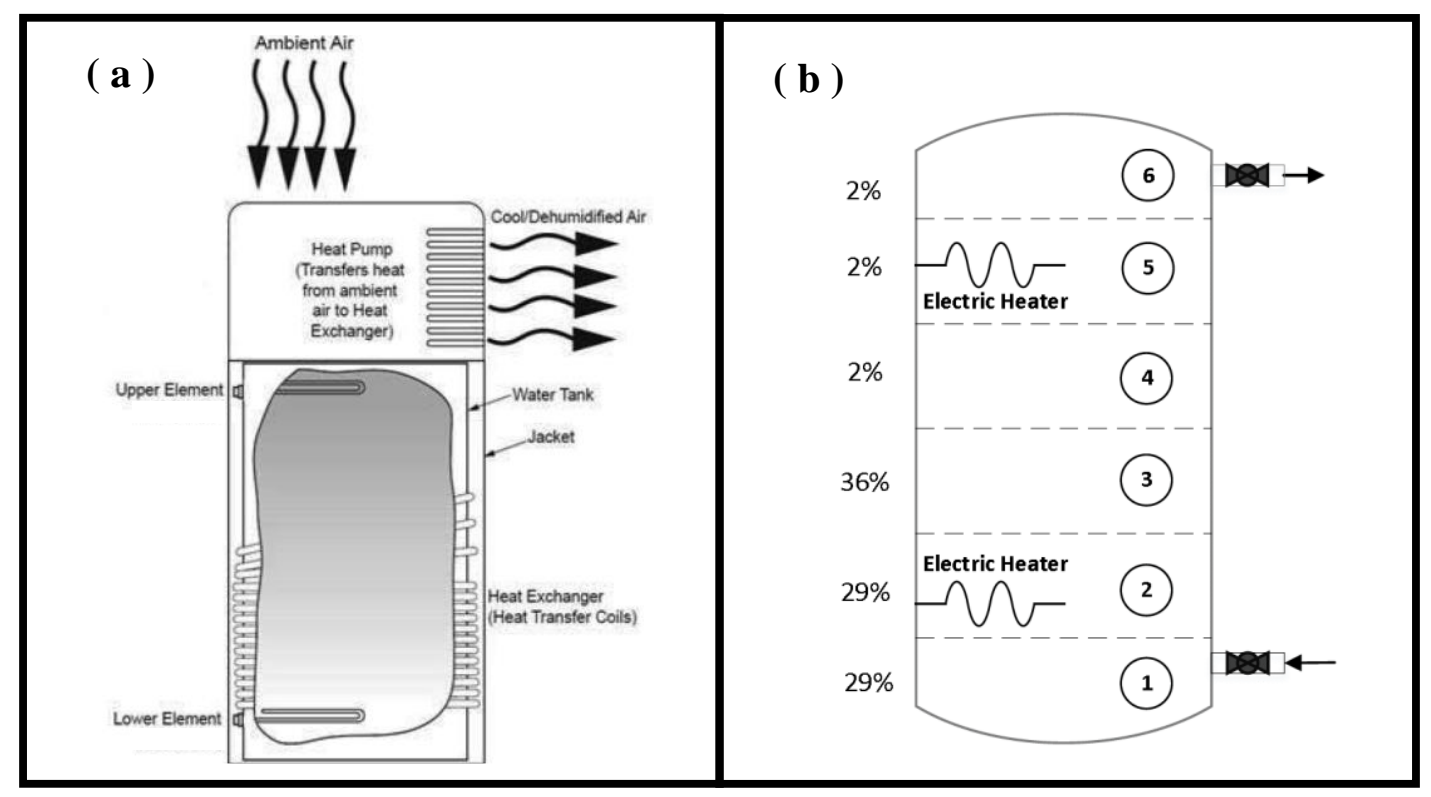

Figure 3-3: A.O. Smith water heater schematic

\subsection{Monitoring System}

The monitoring facility used in this project was previously developed for the performance monitoring of other mechanical equipment, house energy performance, and on-site renewable energy generation (Zhang et al., 2011). For this research, a modification was made in the existing data acquisitions (DAQ) system, which consisted of sensors, controllers, modules, connector blocks, power supplies, LabVIEW software platform and a central computer. The required experimental data such as indoor temperature and relative humidity, inlet water temperature and flow rate (provided water to the tank), outlet/supply water temperature (tank water to the service), electric element and heat pump power consumptions and tank temperatures were collected. In Tables 3-4, 3-5 and 3-6, a brief description of the sensors employed for measuring the flow rate, power, temperature and relative humidity are listed. 
Table 3-4: Flow rate sensors (Zhang et al., 2011)

\begin{tabular}{|c|l|c|c|l|}
\hline & Tag & Channel Address & Type & Description \\
\hline 1 & FL11 & B-CFP8-M7-CH1 & AI-110 & Cold water to tempering valve flow rate \\
\hline 2 & FL3 & B-CFP8-M7-CH-2 & AI-110 & Tempered water flow rate \\
\hline 3 & FL2 & B-CFP8-M7-CH-5 & AI-110 & Tank inlet flow rate \\
\hline
\end{tabular}

Table 3-5: Power sensors (Zhang et al., 2011)

\begin{tabular}{|l|l|c|c|l|}
\hline & Tag & Channel Address & Type & Description \\
\hline 17 & P1+P2 & B-CFP7-M1-CH7 & 4-P-1 & AO Smith DHW total power \\
\hline 18 & P2 & B-CFP7-M4-CH7 & $11-\mathrm{P}-1$ & AO Smith DHW electric resistanse power \\
\hline
\end{tabular}

Table 3-6: Temperature and relative humidity sensors (Zhang et al., 2011)

\begin{tabular}{|c|l|c|c|l|}
\hline & Tag & Channel Address & Type & Description \\
\hline 4 & T78 & B-CFP2-M8-CH-0 & RTD-122 & A.O. Smith tank temperature probe 1-42" from top \\
\hline 5 & T79 & B-CFP2-M8-CH-1 & RTD-122 & A.O. Smith tank temperature probe 2-35" from top \\
\hline 6 & T80 & B-CFP2-M8-CH-2 & RTD-122 & A.O. Smith tank temperature probe 3-28" from top \\
\hline 7 & T81 & B-CFP2-M8-CH-3 & RTD-122 & A.O. Smith tank temperature probe 4-21" from top \\
\hline 8 & T4 & B-CFP2-M8-CH-5 & RTD-122 & Tank outlet temperature \\
\hline 9 & T82 & B-CFP2-M8-CH-6 & RTD-122 & A.O. Smith tank temperature probe 5-14" from top \\
\hline 10 & T83 & B-CFP2-M8-CH-7 & RTD-122 & A.O. Smith tank temperature probe 6-7" from top \\
\hline 11 & T26 & B-CFP2-M1-CH-3 & RTD-122 & Tank inlet temperature \\
\hline 12 & T22 & B-CFP2-M1-CH-6 & RTD-122 & Tempered water temperature \\
\hline 13 & T2 & B-CFP2-M1-CH-7 & RTD-122 & Untempered water temperature \\
\hline 14 & T75 & B-CFP3-M1-CH6 & AI-111 & Ambient air temperature \\
\hline 16 & T77 & B-CFP2-M5-CH-4 & RTD-124 & Evaporator coil temperature \\
\hline 15 & RH28 & B-CFP3-M1-CH7 & AI-111 & Ambient air relative humidity \\
\hline
\end{tabular}

Figure 3-4 displays the schematic view of installed ASHPWH in the water heating cycle of House-B with all modified components and sensors for the monitoring system. The house was supplied with water from a local well. At the beginning of the piping system, the supplied water to the house is divided into two parts, one of them is directed towards the appliances and the other one goes to the ASHPWH water tank. The services that receive hot water inside House-B include shower, bathroom sink, kitchen sink, clothes washer (cold and tempered water) and dishwasher (un-tempered water). In order to investigate the temperature variation inside the tank during a time period and also calculate the water average temperature, 6 temperature sensors $\left(\mathrm{T}_{78}-\mathrm{T}_{83}\right)$ have been inserted inside the tank. The interval of all sensors are equal to 7 inches from the tank top, except the lowest sensor with a distance of 6 inches from the tank bottom. 
The ASHPWH absorbs the heat from the surrounding air inside the house, therefore the operation of HP in the system can affect the room temperature and relative humidity. Due to this influence, two sensors, $\mathrm{T}_{75}$ and $\mathrm{R}_{28}$, have been installed in the basement area close to the ASHPWH location to monitor the variation of indoor air dry bulb temperature and relative humidity during experiments. The temperature sensor has been placed on the evaporator to explore the condensation incidence on the evaporator coil during different experiments.

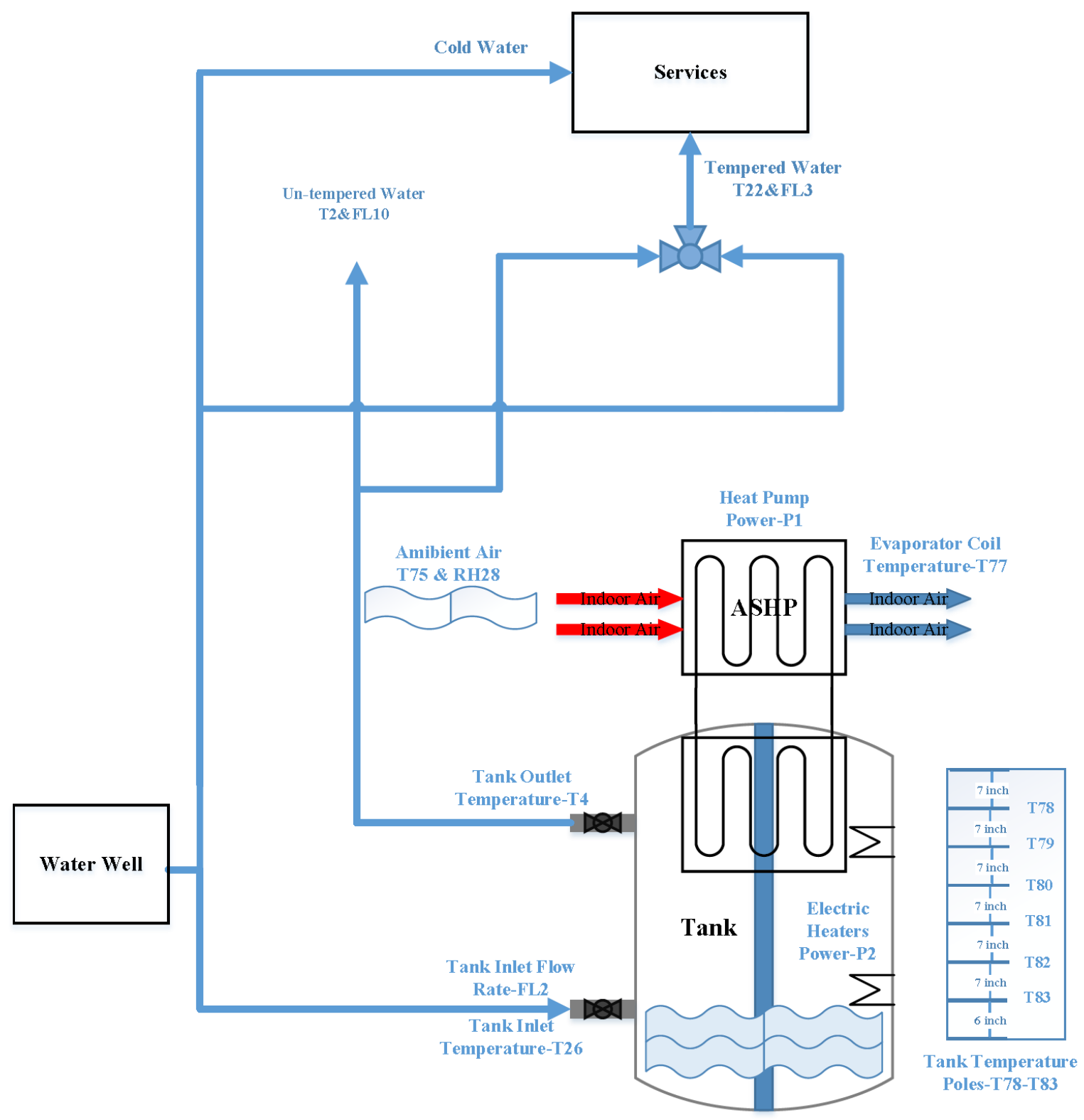

Figure 3-4: House-B water piping and installed sensors 


\subsection{Sensor Calibration}

Based on the ASHRAE Handbook (2009), calibration is defined as the process of adjusting the sensors for the purpose of reducing or eliminating the deviation between indicated values and their corresponding standard values. There are two kinds of error: (1) random (precision) error, and (2) systematic (bias) error. Random error is an estimate related to the repeatability of one specific measurement and unlike systematic error, it varies for different measurements. Systematic uncertainty is estimated by using calibrators and engineering judgement. Finally, the total uncertainty of the system is a square root of the sum of the squares of precision and systematic errors (Coleman and Steele, 2009). Three kinds of sensors, including temperature, water flow rate and power, and their calibrators that have been used in this research, are listed in Table 3-7.

Table 3-7: Sensor calibrators

\begin{tabular}{|l|l|}
\hline Sensors & \multicolumn{1}{|c|}{ Calibrators } \\
\hline $\begin{array}{l}\text { Proteus series water } \\
\text { flow rate sensors }\end{array}$ & Volume bucket and stop watch \\
\hline Wattnode & Factory calibrated but cross checked \\
\hline $\begin{array}{l}\text { RTD temperature } \\
\text { sensors }\end{array}$ & $\begin{array}{l}\text { Multifunction micro bath } \\
\text { Sika Electronics - Model: TPM165S }\end{array}$ \\
\hline
\end{tabular}

Temperature sensor calibration was performed using Sika temperature calibrator type TPM165S, shown in Figure 3-5. After labeling and connecting the sensors to the Compact Field Points (CFP) modules via wires, the sensors were set in the thermal well of the calibrator. When the calibrator started to work, after 5 minutes the temperature was stabilized inside the well and the data was recorded from National Instruments Measurements and Automation Explorer (NI/MAX). This process was repeated for temperatures between $0{ }^{\circ} \mathrm{C}$ to $70{ }^{\circ} \mathrm{C}$ for each $10{ }^{\circ} \mathrm{C}$ interval and compared to the calibrator set point temperature. After gathering all the data for each sensors, two lines had been developed, one for the data read from NI/MAX and the other one from the value of calibrator screen. Finally, by calculating the offset between these two data sets the calibration accuracy was determined. 


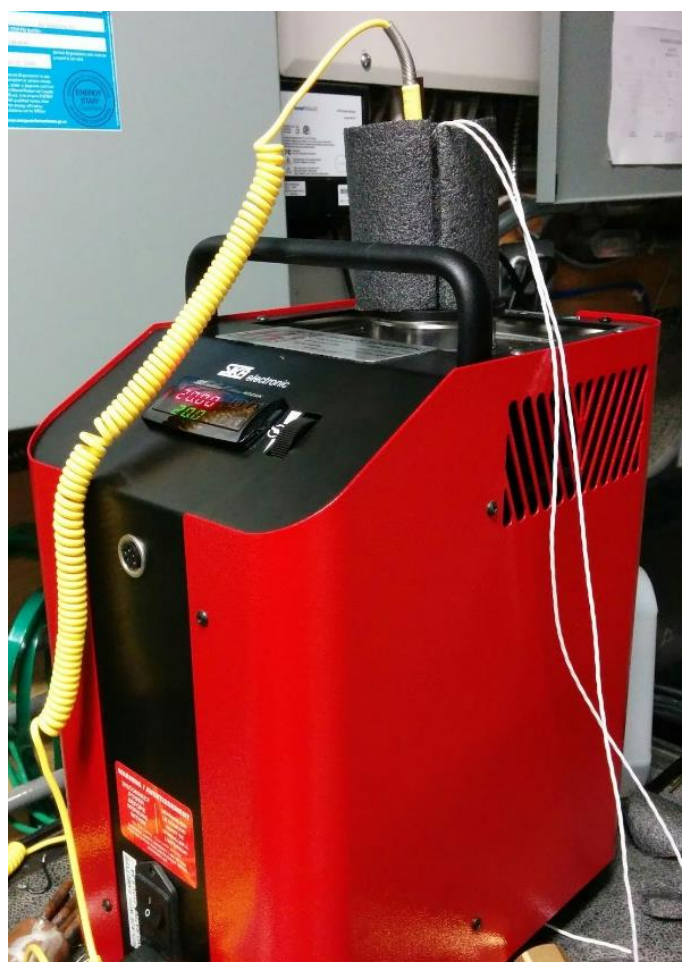

Figure 3-5: Temperature calibrator

Based on the water draw schedule and list of events in Table 3-8, the schedule of the three valves flow rate was determined. The volume bucket and stop watch technique was performed in order to calibrate the flow rate sensors. For each valve the flow rate was measured 5 times after getting to a steady state flow until the desired value was achieved by adjusting the valves. The remaining difference between measured data and desired value is the system accuracy which was used in total system error propagation. The power sensors were factory calibrated and the accuracy value was extracted from their manual.

Table 3-8: List of events and different flow rates used for the water draw schedule in winter (Tanha, 2012)

\begin{tabular}{|c|c|c|c|}
\hline Application & Cold \& Hot Water Flow Rate-Mixed (GPM) & Hot Water Flow Rate (GPM) & Cold Water Flow Rate (GPM) \\
\hline Shower & 1.9 & 1.6 & 0.3 \\
\hline Bathroom Sink & 1.2 & 1.0 & 0.2 \\
\hline Kitchen Sink & 1.2 & 1.0 & 0.2 \\
\hline Clothes Washer (CW) & 3.0 & 1.6 & 1.4 \\
\hline Dishwasher (DW) & 1.3 & 1.3 & 0 \\
\hline
\end{tabular}




\subsection{Water Draw Schedule}

The water draw profile employed in the experiments is 1-minute draw interval for 200 litre/day average draw schedule from the IEA Annex 42 by the International Energy Agency (Knight et al., 2007). This water draw is for 365 days of the year and the required water draw for this research is a 48 hours schedule, therefore some adjustments have been made in order to have a suitable schedule. Since averaging and normalizing the data to one day did not generate a feasible draw profile, therefore two separate days were chosen with the average of 200 litre/day. The final water draw schedule includes two days of water draw schedule, $1^{\text {st }}$ day 150 litre/day and $2^{\text {nd }}$ day 250 litre/day hot water demand. Figure 3-6 shows the 1-minute water draw profile in two days and the tabulated data can be found in Appendix A. Finally the schedule was entered in the LabVIEW program to run the experiments. In order to model the system in TRNSYS, the 5-minute water draw was developed in order to coincide the simulation time between heating/cooling system and water heater system as illustrated in Figure 3-7.

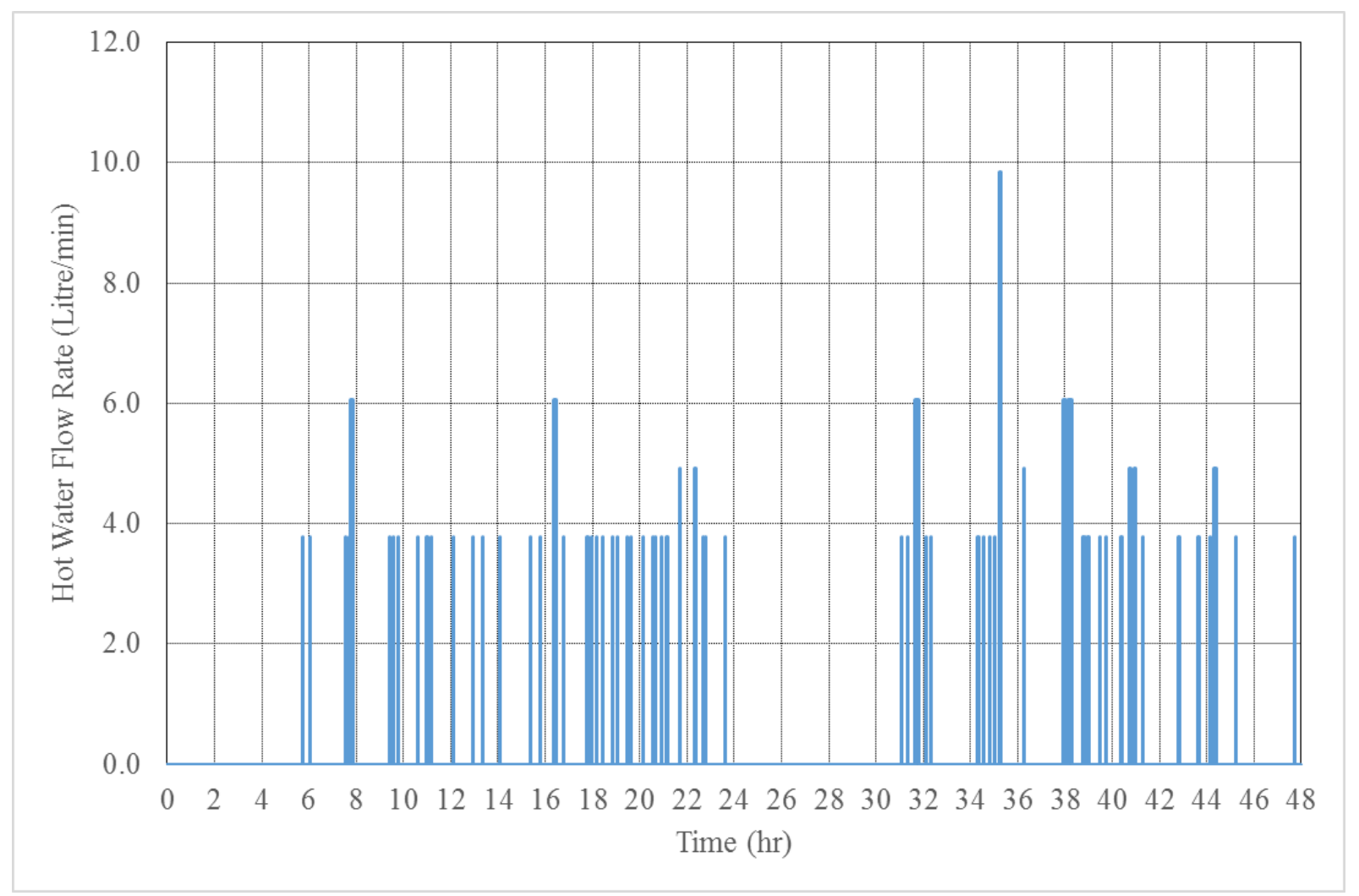

Figure 3-6: Water draw profile based on 1-minute time step (Knight et al., 2007) 


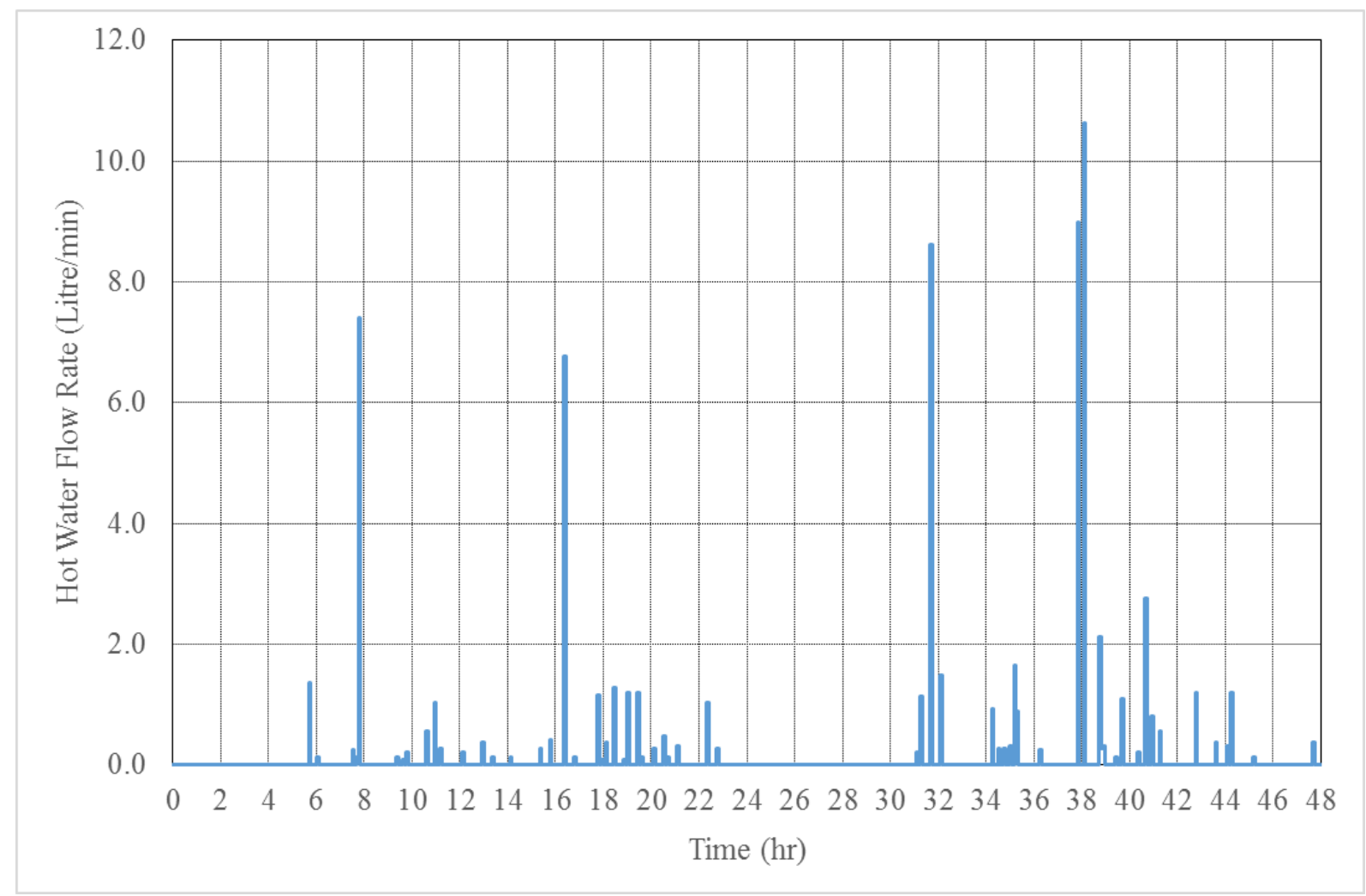

Figure 3-7: Water draw profile based on 5-minutes time step

TRCA Archetype houses use local well for water supply. Figure 3-8 shows the monthly average supply temperature from August 2014 to July 2015 based on the measured data at TRCA houses. The average monthly water supply temperatures were used for the TRNSYS simulation of a typical year. 


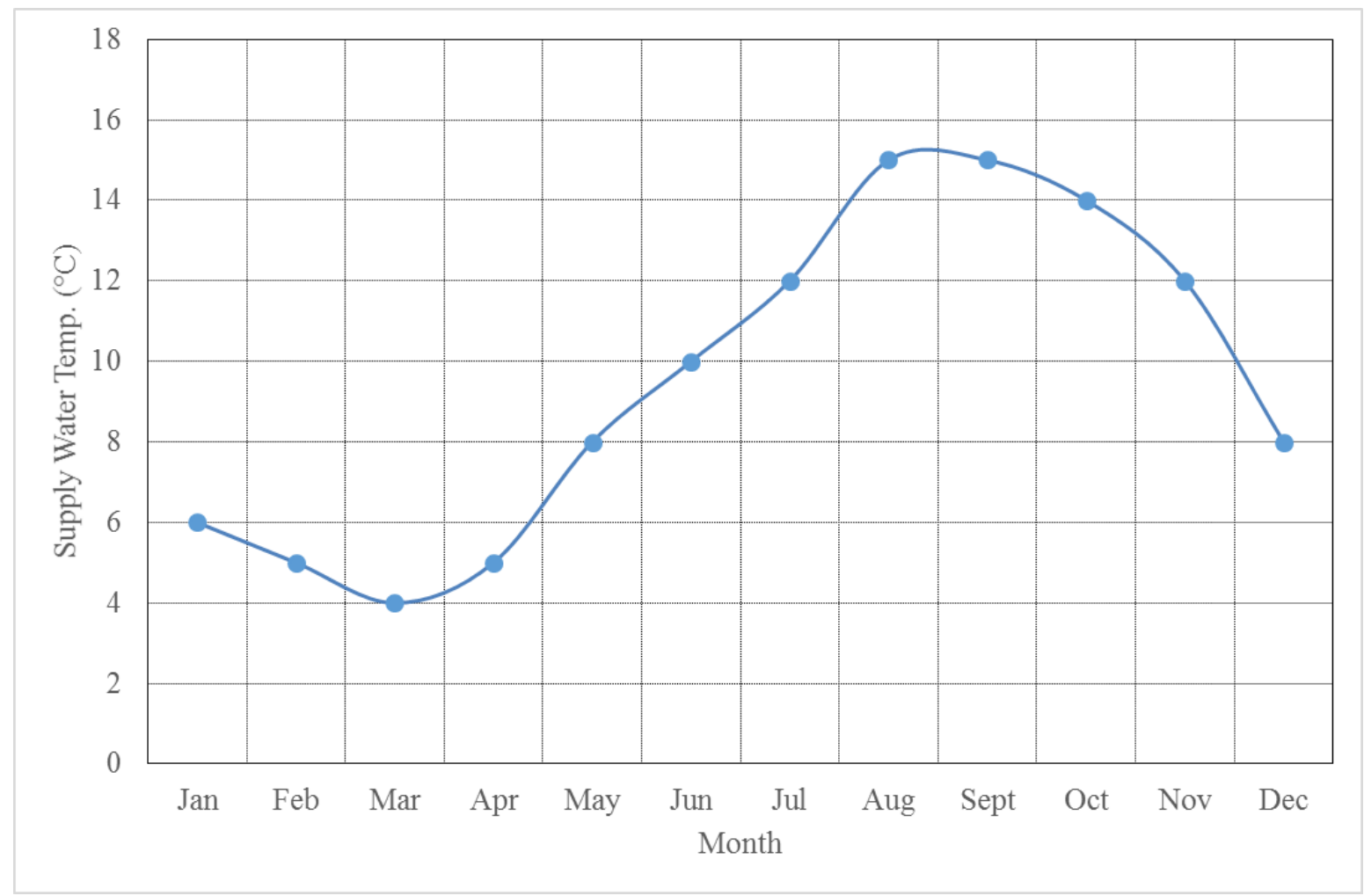

Figure 3-8: Average monthly water supply temperature 


\section{Chapter 4: Methodology}

In this chapter, the required heat transfer equations that govern our system will be explained in Sections 4.1 and 4.2. The detailed conditions of the conducted experiments as well as our methodology for calculating the associated measurement error will also be discussed (Sections 4.3 and 4.4). The details of our modelling approach using the TRNSYS package are presented in Sections 4.5-4.7.

Note that the required information for evaluating different components of the energy transfer rates in the system such as the flow rate, temperature and power consumption have been collected by various sensors that have been installed on ASHPWH. The total system error have been calculated based on the individual errors of all the measuring devices and their calibration results. In addition, as listed in Appendix C, several MATLAB scripts have been developed to read the experimental data and analyze the thermal energy and coefficient of performance of the system along with their corresponding total error.

\subsection{Energy Consumption, Generation and COP Equations}

In this section, the basic equations used for thermal energy and coefficient of performance (COP) calculations of the ASHPWH will be described.

\subsubsection{Density of Water}

Water density is a function of temperature and pressure (Shaughnessy et al., 2005). In this research, water pressure inside the tank is assumed to be constant, therefore water density equation is based on temperature, only. Kravchenko (1966) presented the equation for water density, with their uncertainties, in the temperature range $0{ }^{\circ} \mathrm{C}$ to $90{ }^{\circ} \mathrm{C}$. At a pressure of $101.325 \mathrm{kPa}$, the water density equation may be expressed by the following equation:

$$
\rho_{\text {water }}=1000\left[1-\frac{(T-4)^{2}}{119000+1365 T-4 T^{2}}\right]
$$


Where:

\section{T: $\quad$ Temperature of water $\left({ }^{\circ} \mathrm{C}\right)$}

$\rho_{\text {water }}:$ Density of water $\left(\mathrm{kg} / \mathrm{m}^{3}\right)$

Haynes et al. (2015) presented a table for the density of water based on temperature in the range of $0^{\circ} \mathrm{C}$ to $100^{\circ} \mathrm{C}$. By comparing the results from this study with Equation (4-1) and referring to Figure 4-1, it can clearly be acknowledged that there is a suitable agreement between these two studies, therefore Equation (4-1) has been used for water density.

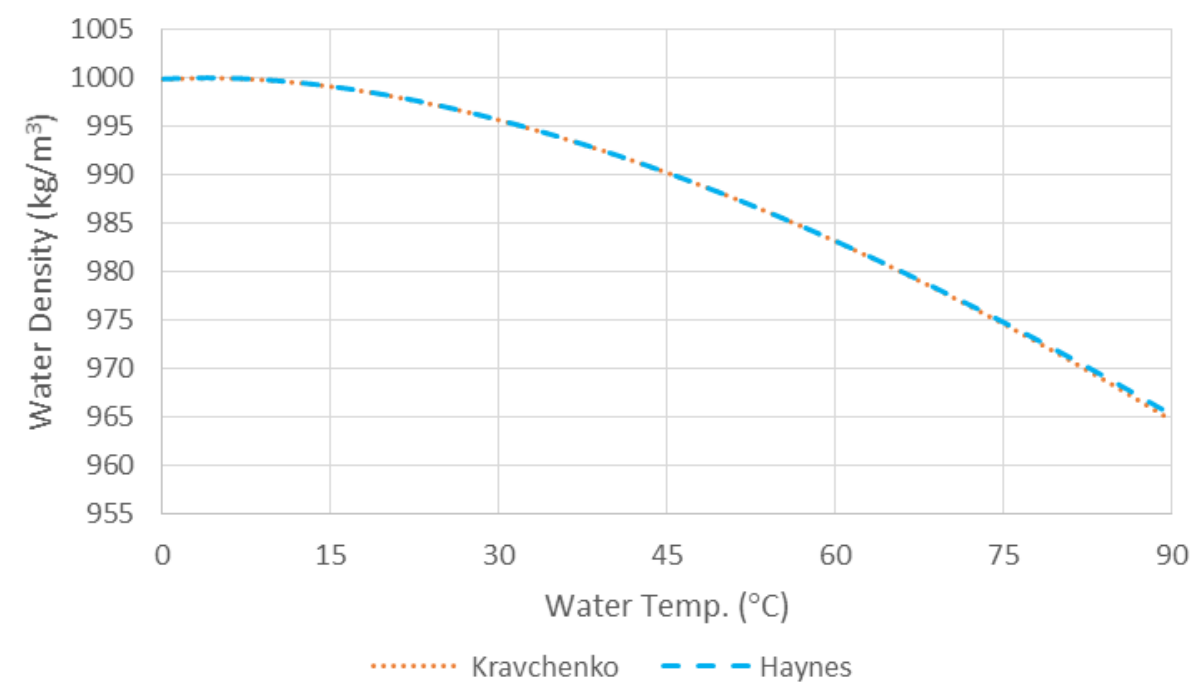

Figure 4-1: Water density trend based on the temperature

\subsubsection{Coefficient of Performance}

As mentioned in the previous chapter, ASHPWH is a system, that by consuming electrical energy in compressor and fan $\left(P_{A S H P}\right)$ as well as in electric resistances $\left(P_{\text {Elec. }}\right)$ transfers the heat from surrounding air $\left(Q_{A S H P}\right)$ and electric resistances $\left(Q_{\text {Elec. }}\right)$ to the water inside the tank as shown in Figure 4-2. In the meantime due to temperature difference between the tank and surrounding air, there is some heat loss $\left(Q_{\text {loss }}\right)$ from tank walls to the environment which depends on the level of wall insulation, tank wall area and temperature difference between the tank water and the room air. The overall effect of these heat fluxes leads to an increase in the tank outlet water temperature as well as the tank average temperature. Equation (4-2) indicates the total heat transfer inside the ASHPWH. 


$$
Q_{\text {Tank }}+\frac{\partial E_{\text {Tank }}}{\partial t}=Q_{A S H P}+Q_{E l e c .}-Q_{\text {loss }}
$$

Where:

$Q_{A S H P}:$ The rate of thermal energy supplied by ASHP $(\mathrm{kJ} / \mathrm{min})$

$Q_{\text {Elec. }}:$ The rate of thermal energy supplied by electric heaters $(\mathrm{kJ} / \mathrm{min})$

$Q_{\text {loss }}:$ The rate of tank heat loss $(\mathrm{kJ} / \mathrm{min})$

$Q_{\text {Tank }}:$ The rate of water draw thermal energy $(\mathrm{kJ} / \mathrm{min})$

$\frac{\partial E_{\text {Tank }}}{\partial t}:$ The rate of change of tank thermal energy $(\mathrm{kJ} / \mathrm{min})$

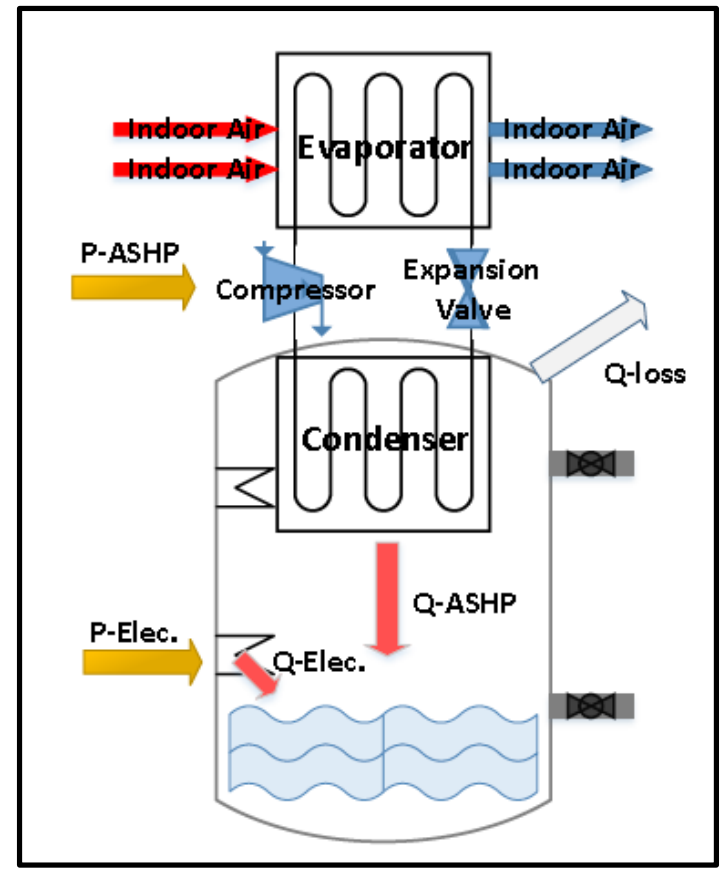

Figure 4-2: Schematic of heat transfer in ASHPWH

In Equation (4-2), all the factors are known except the $Q_{A S H P}$ and $Q_{l o s s}$. In heat loss calculation the U-value is unknown and will be computed in Section 4.1.3. Finally, Equation (4-2) is rearranged to the following order: 
$Q_{A S H P}=Q_{\text {Tank }}+\frac{\partial E_{\text {Tank }}}{\partial t}-Q_{E l e c .}+Q_{\text {loss }}$

Figure 4-3 displays all the sensor locations installed in order to gather the required information for calculating the thermal energy supplied by HP to water and COP of the HP. All the parameters in the following equations are labeled based on the sensor labels.

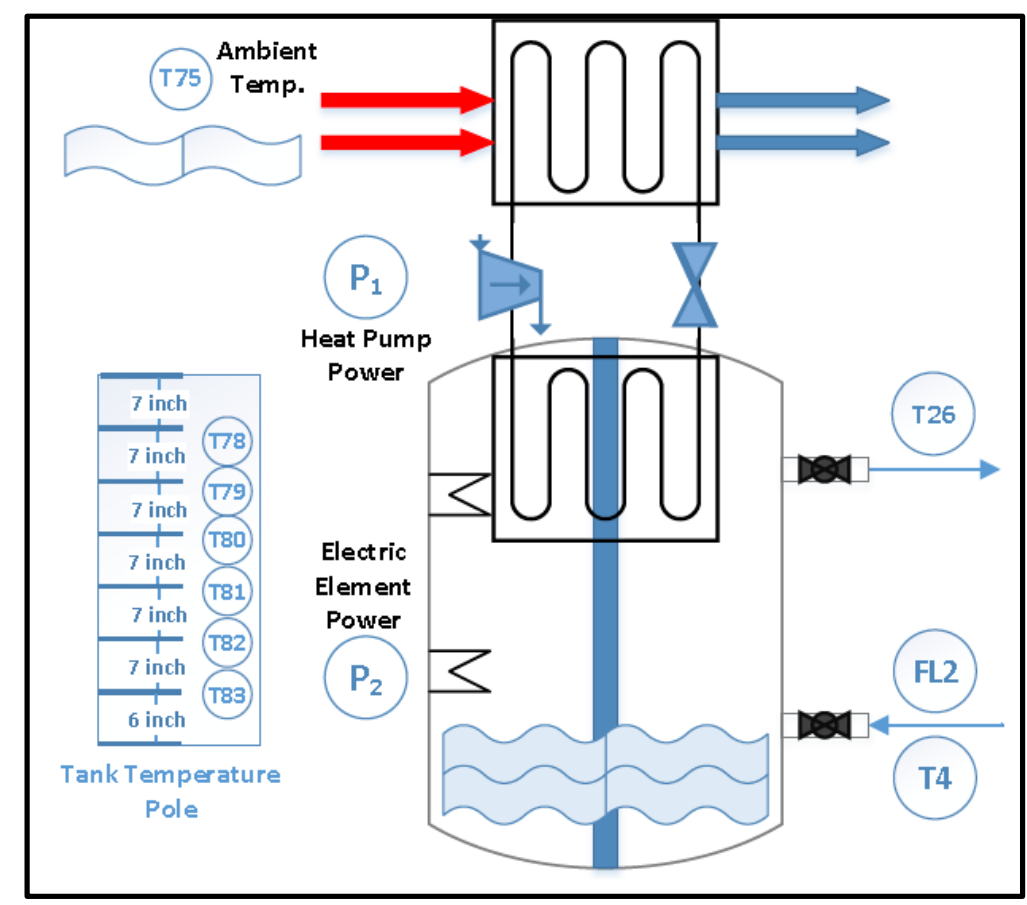

Figure 4-3: Schematic view of ASHPWH with related sensors of House-B

Water draw thermal energy has been calculated using Equation (4-4). In this equation, the specific heat of water is considered to be constant and equal to $4.18 \mathrm{~kJ} / \mathrm{kg}-{ }^{\circ} \mathrm{C}$ (Von Böckh and Wetzel, 2011). Since the volumetric flow rate of inlet water to the tank has been measured therefore the mass flow rate $(\dot{m})$ has been replaced by volumetric flow rate and density of water.

$$
Q_{\text {Tank }}=\dot{m} C\left(T_{4}^{t}-T_{26}^{t}\right)=q \cdot \rho_{\text {water }} \cdot C_{p}\left(T_{4}^{t}-T_{26}^{t}\right)
$$

Where:

$\dot{m}: \quad$ Mass flow rate of water $(\mathrm{kg} / \mathrm{min})$ 
$C_{p}: \quad$ Specific heat of water $\left(\mathrm{kJ} / \mathrm{kg}-{ }^{\circ} \mathrm{C}\right)$

$T_{4}^{t}: \quad$ Tank outlet water temperature $\left({ }^{\circ} \mathrm{C}\right)$

$T_{26}^{t}: \quad$ Tank inlet water temperature $\left({ }^{\circ} \mathrm{C}\right)$

$q$ : Volumetric flow rate of water $\left(\mathrm{m}^{3} / \mathrm{min}\right)$

$\rho_{\text {water }}:$ Density of water $\left(\mathrm{kg} / \mathrm{m}^{3}\right)$

$F L_{2}: \quad$ Tank inlet water flow rate $(\mathrm{GPM})$

Flow rate data read from sensors are in U.S. gallon per minutes, therefore after unit conversion and replacing density with Equation (4-1), Equation (4-4) can be rewritten as followed:

$$
Q_{\text {Tank }}=15.83 F L_{2}^{t}\left(\left[1-\frac{\left(T_{4}^{t}-4\right)^{2}}{119000+1365 T_{4}^{t}-4\left(T_{4}^{t}\right)^{2}}\right] T_{4}^{t}-\left[1-\frac{\left(T_{26}^{t}-4\right)^{2}}{119000+1365 T_{26}^{t}-4\left(T_{26}^{t}\right)^{2}}\right] T_{26}^{t}\right)
$$

Equation (4-6) is used in order to compute the tank water thermal energy variations during a time period of $\Delta t$. The time step for sensor data recordings is 0.5 second. Since the temperature variation during this time period is too small, the chosen time step for calculating the energy variation is set to be 15 minutes (i.e. $\Delta t=15 \mathrm{~min}$ ). The water mass is constant over time and can be replaced by the density and volume of the tank mentioned in Table 4-1. Average tank water temperature is the average of six temperature sensors inside the tank based on Equation (4-7).

$$
\frac{\partial E_{\text {Tank }}}{\partial t}=m C\left(\frac{\partial\left(T_{\text {avg }}^{t+\Delta t}-T_{\text {avg }}^{t}\right)}{\Delta t}\right)=V \cdot \rho_{\text {water }} \cdot C\left(\frac{\partial\left(T_{\text {avg }}^{t+\Delta t}-T_{\text {avg }}^{t}\right)}{\Delta t}\right)
$$

Where:

$m: \quad$ Water mass $(\mathrm{kg})$

$C: \quad$ Specific heat of the water $\left(\mathrm{kJ} / \mathrm{kg}-{ }^{\circ} \mathrm{C}\right)$

$T_{a v g}^{t+\Delta t}$ : Average water temperature at time $t+\Delta t\left({ }^{\circ} \mathrm{C}\right)$

$T_{\text {avg }}^{t}$ : Average water temperature at time $t\left({ }^{\circ} \mathrm{C}\right)$ 


$$
T_{\text {avg }}=\frac{\sum_{78}^{83} T_{i}}{6}
$$

Table 4-1: ASHPWH tank specification

\begin{tabular}{|l|c|}
\hline Capacity (L) & 189 \\
\hline Diameter (m) & 0.56 \\
\hline Water Tank Height (m) & 1.22 \\
\hline Total area of tank $\left(\mathrm{m}^{2}\right)$ & 2.65 \\
\hline U-value $\left(\mathrm{W} / \mathrm{m}^{2}{ }^{\circ} \mathrm{C}\right)$ & $0.877 \sim \mathrm{R}-5$ \\
\hline $\begin{array}{l}\text { Electric Element } \\
\text { Efficiency }(\%)\end{array}$ & 100 \\
\hline
\end{tabular}

By replacing tank volume from Table 4-1 and water density from Equation (4-1) and $\Delta t=$ $15 \mathrm{~min}$ in Equation (4-6), the final formula for the change of water thermal energy over time based on water temperature difference can be expressed as:

$$
\frac{\Delta E_{\text {Tank }}}{\Delta t}=52.67\left[\left[1-\frac{\left(T_{\text {avg }}^{t+\Delta t}-4\right)^{2}}{119000+1365 T_{\text {avg }}^{t+4 t}-4\left(T_{\text {avg }}^{t+\Delta t}\right)^{2}}\right] T_{\text {avg }}^{t+\Delta t}-\left[1-\frac{\left(T_{\text {avg }}^{t}-4\right)^{2}}{119000+1365 T_{\text {avg }}^{t}-4\left(T_{\text {avg }}^{t}\right)^{2}}\right] T_{\text {avg }}^{t}\right]
$$

Due to temperature difference between the water and the surrounding air, a portion of the transferred heat to the tank will be lost to the surrounding air and which may be estimated by Equation (4-9). U-value of the tank will be estimated by experiment presented in Section 4.2. Finally the heat loss unit is converted to $\mathrm{kJ} / \mathrm{min}$ after multiplying by 0.06 .

$$
Q_{\text {loss }}=0.06 U A\left(T_{\text {avg }}^{t}-T_{75}^{t}\right)
$$

Where: 
$\mathrm{U}: \quad$ Overall heat transfer coefficient $\left(\mathrm{W} / \mathrm{m}^{2 \circ} \mathrm{C}\right)$

A: $\quad$ Total area of the tank wall $\left(\mathrm{m}^{2}\right)$

$T_{\text {avg }}^{t}: \quad$ Average tank water temperature $\left({ }^{\circ} \mathrm{C}\right)$

$T_{75}^{t}: \quad$ Ambient temperature $\left({ }^{\circ} \mathrm{C}\right)$

Using the information presented in Table 4-1 and Equation (4-7) for the average water temperature, the final formula for heat loss is obtained.

$$
Q_{\text {loss }}=0.14\left(T_{\text {avg }}^{t}-T_{75}^{t}\right)
$$

By rearranging the efficiency formula of the electric elements, the generated heat from them can be computed by Equation (4-11).

$$
Q_{\text {Elec. }}=\eta \times P_{2}^{t}=(100 \%) P_{2}^{t}=P_{2}^{t}
$$

Where:

$\eta: \quad$ Electric elements efficiency $(\%)(100 \%)$

$P_{2}^{t}: \quad$ Electric elements power input $(\mathrm{kJ} / \mathrm{min})$

Using Equations (4-5), (4-8), (4-10) and (4-11), the final equation for the $Q_{A S H P}$ based on the collected data from sensors is expressed as:

$$
\begin{aligned}
& Q_{A S H P}=15.83 F L_{2}^{t}\left[\left[1-\frac{\left(T_{4}^{t}-4\right)^{2}}{119000+1365 T_{4}^{t}-4\left(T_{4}^{t}\right)^{2}}\right] T_{4}^{t}-\left[1-\frac{\left(T_{26}^{t}-4\right)^{2}}{119000+1365 T_{26}^{t}-4\left(T_{26}^{t}\right)^{2}}\right] T_{26}^{t}\right] \\
& +52.67\left[\left[1-\frac{\left(T_{\text {avg }}^{t+\Delta t}-4\right)^{2}}{119000+1365 T_{\text {avg }}^{t+\Delta t}-4\left(T_{\text {avg }}^{t+\Delta t}\right)^{2}}\right] T_{\text {avg }}^{t+\Delta t}-\left[1-\frac{\left(T_{\text {avg }}^{t}-4\right)^{2}}{119000+1365 T_{\text {avg }}^{t}-4\left(T_{\text {avg }}^{t}\right)^{2}}\right] T_{\text {avg }}^{t}\right]-P_{2}^{t}+ \\
& 0.14\left(T_{\text {avg }}^{t}-T_{75}^{t}\right)
\end{aligned}
$$


One of the objectives in this research is to estimate the coefficient of performance (COP) for the equipment. Using Equation (4-12) and the data obtained from the power sensors, the COP of the HP of ASHPWH is equivalent to:

$$
C O P=\frac{Q_{A S H P}}{P_{1}^{t}}
$$

Where:

$Q_{\text {ASHP }}:$ Total thermal energy supplied by the HP of ASHPWH $(\mathrm{kJ} / \mathrm{min})$

$P_{1}^{t}: \quad$ HP power input $(\mathrm{kJ} / \mathrm{min})$

COP: HP coefficient of performance

\subsection{Calculating Tank Heat Transfer Coefficient (U-value)}

Due to lack of information about the tank wall insulation material, an experiment was performed in order to determine the overall heat transfer coefficient (U-value) for Equations (4-9) and (4-10). The heat transfer coefficient is a function of material properties and temperatures (Von Böckh and Wetzel, 2011) but in this research, it is assumed that the U-value is constant for different temperatures. Since the overall contribution of heat loss to COP is usually negligible, the assumption of constant U-value is expected not to affect our COP results at different tank temperatures. In this experiment, performed for indoor condition of $30{ }^{\circ} \mathrm{C}$ and $60 \% \mathrm{RH}$, there was no water draw from the tank, therefore the rate of water draw thermal energy in Equation (4-4) is equal to zero $\left(Q_{\text {Tank }}=0\right)$. In addition, since the variations of the tank water average temperature, as shown in Figure 4-4, was within the tank control temperature range, the electric elements and heat pump were not working during the time period of 1214.2min ( 72850s). Therefore, the thermal energy supplied by electric heaters and heat pump is zero during this period based on the sensors data. 


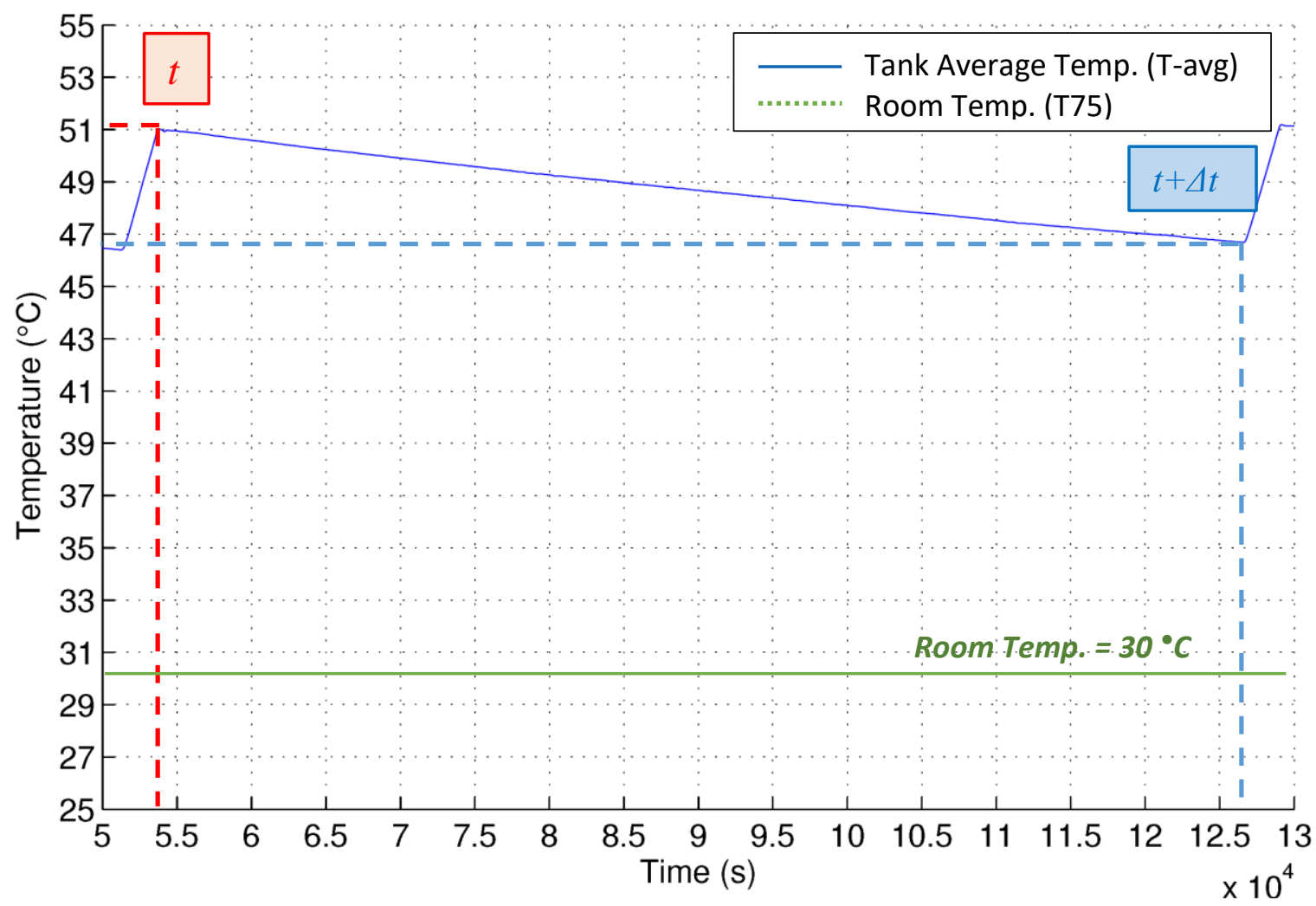

Figure 4-4: $U$-value calculation (Indoor condition: $30{ }^{\circ} \mathrm{C} \& 60 \% \mathrm{RH}$ )

Considering all the experiment conditions, Equation (4-3) will be changed to Equation (4-14) in the following:

$\frac{\partial E_{\text {Tank }}}{\partial t}+Q_{\text {loss }}=0$

By replacing Equations (4-8) and (4-10) in Equation (4-14) and replacing the total area of the tank wall from Table 4-1, it will be converted to Equation (4-15).

$$
\begin{aligned}
& \frac{790.05}{\Delta t}\left[\left[1-\frac{\left(T_{\text {avg }}^{t+\Delta t}-4\right)^{2}}{119000+1365 T_{\text {avg }}^{t+\Delta t}-4\left(T_{\text {avg }}^{t+\Delta t}\right)^{2}}\right] T_{\text {avg }}^{t+d t}-\left[1-\frac{\left(T_{\text {avg }}^{t}-4\right)^{2}}{119000+1365 T_{\text {avg }}^{t}-4\left(T_{\text {avg }}^{t}\right)^{2}}\right] T_{\text {avg }}^{t}\right]+ \\
& 0.159 U\left(T_{\text {avg }}^{t}-T_{75}^{t}\right)=0
\end{aligned}
$$


Figure 4-4 and Table 4-2 display the result from experiment. By replacing all the measured data in Equation (4-15), the estimated overall $\mathrm{U}$-value is equal to $0.877 \mathrm{~W} / \mathrm{m}^{2}-{ }^{\circ} \mathrm{C}(\mathrm{R}$-value $=6.475)$.

Table 4-2: Extracted data for U-value calculation

\begin{tabular}{|c|c|c|}
\hline Parameters & Description & Value \\
\hline$T_{a v g}^{t}\left({ }^{\circ} \mathrm{C}\right)$ & Average Water Temperature at Time $\mathrm{t}$ & 51.23 \\
\hline$T_{a v g}^{t+\Delta t}\left({ }^{\circ} \mathrm{C}\right)$ & Average Water Temperature at Time $\mathrm{t}+\Delta \mathrm{t}$ & 46.5 \\
\hline$T_{75}^{t}\left({ }^{\circ} \mathrm{C}\right)$ & Indoor Temperature at Time $\mathrm{t}$ & 29.9 \\
\hline$\Delta t(\mathrm{~min})$ & Time period between ASHPWH Operations & 1214.2 \\
\hline
\end{tabular}

\subsection{Error Propagation}

The uncertainties of measured variables should be considered in the system error propagation. In this research the Taylor Series Method (TSM) (Coleman and Steele, 2009) has been employed in order to calculate the general uncertainty of the COP as well as the supplied thermal energy. In this study the following equation will be used (Coleman and Steele, 2009):

$$
U_{r}^{2}=\sum_{i=1}^{J}\left(\frac{\partial r}{\partial X_{i}}\right)^{2} U_{X_{i}}^{2}
$$

Where:

$U_{r}: \quad$ Uncertainty in the estimated variables $r$

$U_{X_{i}}: \quad$ Uncertainty in the measured variables $X_{i}$

$r$ : $\quad$ Experimental result function based on measured variables $X_{i}$

The uncertainty is a function of systematic error and random error. Since the random error is related to the repeatability of a single measurement, this error has been neglected in this analysis in which measurements were made only once for each experiment. Therefore the variable uncertainty of the system is equal to systematic error. As explained in Section 3.4, the systematic error should be estimated for each variable based on the available information such as manufacturer specification and analytical estimate. In this research the systematic errors have been collected from calibration process and manuals as organized in Table 4-3. In order to combine 
different systematic uncertainties of each variables the root-sum-square (RSS) method (Coleman and Steele, 2009), as presented in Equation (4-17), has been employed.

$$
E_{\text {sys }}=\sqrt{A_{\text {Sen }}^{2}+A_{\text {Cal }}^{2}}
$$

Where:

$E_{\text {sys }}: \quad$ Systematic error

$A_{\text {Sen }}:$ Sensor accuracy

$A_{\text {Cal }}:$ Calibrator accuracy

Table 4-3: Sensors and calibrator accuracy

\begin{tabular}{|l|l|l|l|c|c|}
\hline \multicolumn{1}{|c|}{ Sesnor Name } & \multicolumn{1}{|c|}{ Sensor Type } & \multicolumn{1}{|c|}{ Manufacturer } & \multicolumn{1}{|c|}{ Model Number } & $\begin{array}{c}\text { Sensor } \\
\text { Accuracy (\%) }\end{array}$ & $\begin{array}{c}\text { Calibrator } \\
\text { Accuracy (\%) }\end{array}$ \\
\hline Metering flow switch & Flow rate & Proteus Industries Inc. & 800 Series & 0.057 & \\
\hline Wattnode & Power & Continental Control Systems & WNB-3Y-208-P & 1.00 & \\
\hline TRD Pt.100 & Temperature & Omega & RTD-2-F3105-36-T-B & 0.12 & 0.18 \\
\hline
\end{tabular}

Using Equations (4-13), (4-14) and (4-17) and the calculated systematic errors for different parameters, the overall error for the HP thermal energy and COP are calculated and are equal to $6.2 \%$ and $2.8 \%$, respectively. It means if $\mathrm{COP}=2.5 \pm 0.07$ and $Q_{A S H P}=3820 \mathrm{kWh} \pm 236.8$, therefore the results are $95 \%$ confident. The details of the calculation is presented in Appendix B.

\subsection{Experimental Conditions}

In order to analyze the thermal performance of the ASHPWH using the monitoring systems, data for various indoor conditions, as shown in Table 4-4, was obtained. During cold start experiments, the tank started to heat up from around $16{ }^{\circ} \mathrm{C}$ outlet temperature to set point temperature of $55{ }^{\circ} \mathrm{C}$ while there was no water draw from the tank. Then these experiments followed by two days of scheduled water draw experiment. Each of the mentioned conditions for indoor temperature and relative humidity, representative of the standard test condition, has been determined by using the psychometric chart as explained in the following:

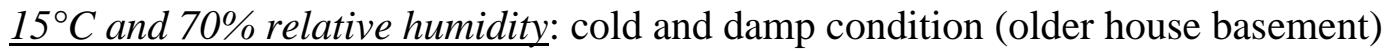


* $20^{\circ} \mathrm{C}$ and $35 \%$ relative humidity: winter comfort zone (popular conditioned indoor environment)

* $25^{\circ} \mathrm{C}$ and $50 \%$ relative humidity: summer comfort zone (popular conditioned indoor environment)

* $30^{\circ} \mathrm{C}$ and $60 \%$ relative humidity: hot and humid summer condition (without cooling)

During the period of testing, the indoor air temperature and humidity were maintained at approximately the specified values. For example the relative humidity was maintained by using three humidifiers (Figure 4-5-a) and one dehumidifier (Figure 4-5-b) with dead band of $\pm 1^{\circ} \mathrm{C}$ and $2 \%$ respectively. It is noted that the experiment for the $30{ }^{\circ} \mathrm{C}$ and $60 \% \mathrm{RH}$ could not be completed due to the mold growth inside the house, therefore the required data could not be collected and this condition was removed from the data.

Table 4-4: Experimental conditions

\begin{tabular}{|c|c|c|c|c|}
\hline \multicolumn{2}{|c|}{ Indoor Conditions } & \multirow{2}{*}{ System Modes } & \multirow{2}{*}{ Operating Conditions } & \multirow{2}{*}{ Exp. No. } \\
\hline Temperature & Relative Humidity & & & \\
\hline \multirow{6}{*}{$15^{\circ} \mathrm{C}$} & \multirow{6}{*}{$70 \%$} & \multirow{2}{*}{ Hybrid Mode } & 1-day Cold Start Tank & Exp. 1 \\
\hline & & & 2-days Water Draw & Exp. 2 \\
\hline & & \multirow{2}{*}{ HP Mode } & 1-day Cold Start Tank & Exp. 3 \\
\hline & & & 2-days Water Draw & Exp. 4 \\
\hline & & \multirow{2}{*}{ Elec. Mode } & 1-day Cold Start Tank & Exp. 5 \\
\hline & & & 2-days Water Draw & Exp. 6 \\
\hline \multirow{4}{*}{$20^{\circ} \mathrm{C}$} & \multirow{4}{*}{$35 \%$} & \multirow{2}{*}{ Hybrid Mode } & 1-day Cold Start Tank & Exp. 7 \\
\hline & & & 2-days Water Draw & Exp. 8 \\
\hline & & \multirow{2}{*}{ HP Mode } & 1-day Cold Start Tank & Exp. 9 \\
\hline & & & 2-days Water Draw & Exp. 10 \\
\hline \multirow{4}{*}{$25^{\circ} \mathrm{C}$} & \multirow{4}{*}{$50 \%$} & \multirow{2}{*}{ Elec. Mode } & 1-day Cold Start Tank & Exp. 11 \\
\hline & & & 2-days Water Draw & Exp. 12 \\
\hline & & \multirow{2}{*}{ HP Mode } & 1-day Cold Start Tank & Exp. 13 \\
\hline & & & 2-days Water Draw & Exp. 14 \\
\hline
\end{tabular}




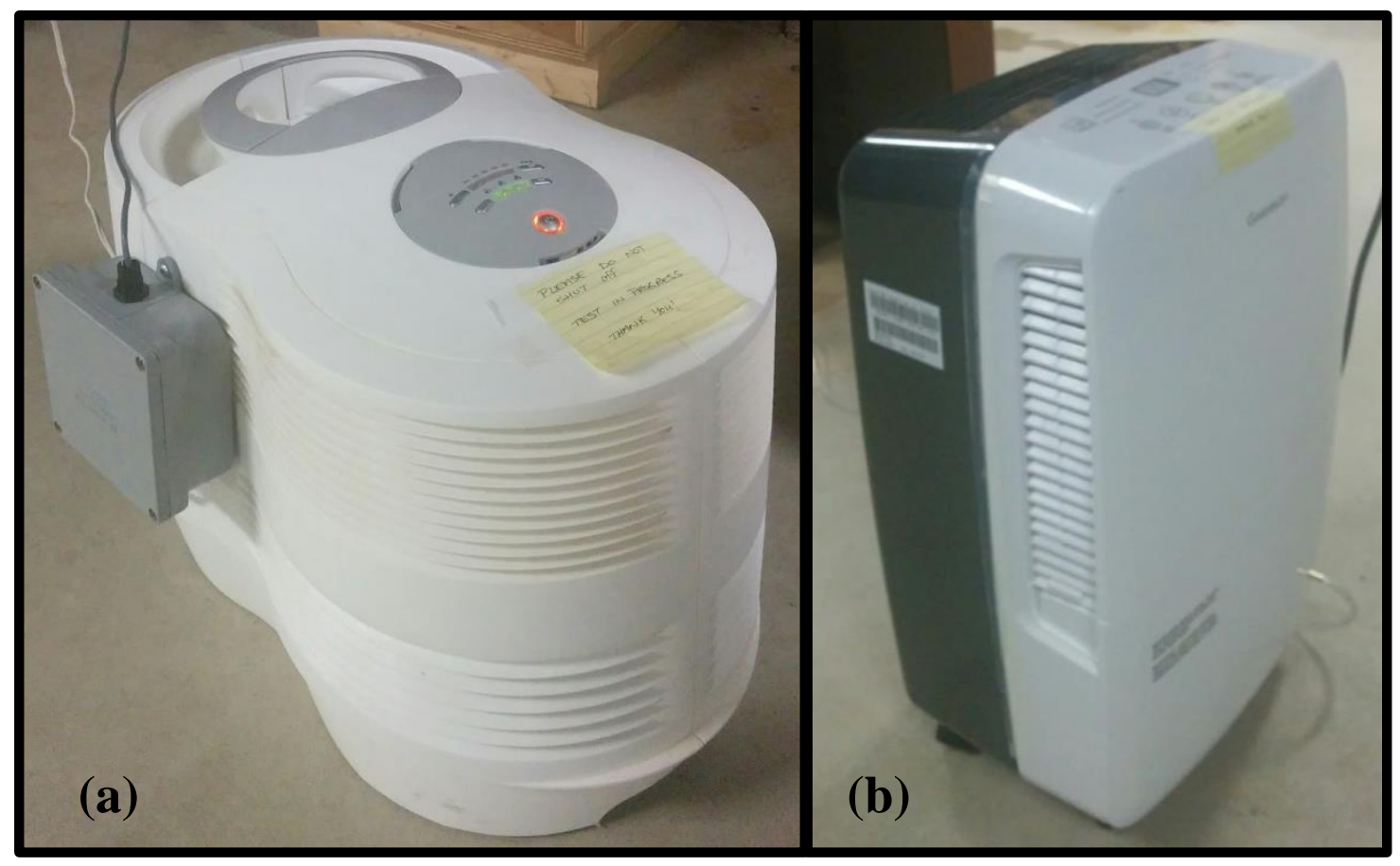

Figure 4-5: Humidifier and dehumidifier

\subsection{Ontario Electricity Rate}

In Ontario the residential electricity rate, so-called time of use (TOU) pricing, changes in different seasons and times of the day in a year. Under this pricing scheme, consumers pay higher prices for electricity when the production price for electricity is high and vice versa. In fact, this pricing framework provides opportunity for customers to lower electricity costs by shifting their usage to less expensive times of the day (IESO, 2016). In order to estimate the total potential of electricity saving from the experimental data as well as simulation results, TOU electricity rates and residential delivery charges are employed. Tables 4-5, 4-6 and 4-7 summarize the Ontario TOU electricity rates (IESO, 2016) and delivery charges (Hydro One, 2016) for further analysis in Chapters 5 and 6. Figure 4-6 illustrates the variation of Ontario electricity rate in different times. The calculated rates in this figure are the summation of TOU rate, distribution volume charge, transmission conecction charge and transmission network charge. 
Table 4-5: Ontario TOU electricity rates (IESO, 2016)

\begin{tabular}{|c|c|c|c|c|}
\hline \multirow{2}{*}{ Time } & \multicolumn{2}{|c|}{ Summer } & \multicolumn{2}{c|}{ Winter } \\
\cline { 2 - 5 } & Rates $(\phi / \mathrm{kWh})$ & & Rates $(\phi / \mathrm{kWh})$ & \\
\hline 1a.m. to 7a.m. & 8.7 & Off-peak & 8.7 & Off-peak \\
\hline 7a.m. to 11a.m. & 13.2 & Mid-peak & 18 & On-peak \\
\hline 11a.m. to 5p.m. & 18 & On-peak & 13.2 & Mid-peak \\
\hline 5p.m. to 7p.m. & 13.2 & Mid-peak & 18 & On-peak \\
\hline 7p.m. to 12a.m. & 8.7 & Off-peak & 8.7 & Off-peak \\
\hline \multirow{2}{*}{ Time } & \multicolumn{4}{|c|}{ Holiday } \\
\cline { 2 - 5 } & \multicolumn{2}{|c|}{ Rates $(\phi / \mathrm{kWh})$} & \\
\hline Sat.\&Sun. & \multicolumn{2}{|c|}{8.7} & Off-peak \\
\hline
\end{tabular}

Table 4-6: Electricity delivery rate (Hydro One, 2016)

\begin{tabular}{|l|c|}
\hline Delivery Rates & Urban Medium Density \\
\hline $\begin{array}{l}\text { Distribution volume charge } \\
\text { (metered usage }-\phi / \mathrm{kWh} \text { ) }\end{array}$ & $2.98 \varnothing$ \\
\hline $\begin{array}{l}\text { Transmission connection charge } \\
\text { (adjusted usage }-\phi / \mathrm{kWh} \text { ) }\end{array}$ & $0.48 \phi$ \\
\hline $\begin{array}{l}\text { Transmission network charge } \\
\text { (adjusted usage }-\phi / \mathrm{kWh} \text { ) }\end{array}$ & $0.68 \varnothing$ \\
\hline Adjustment Factor & 1.076 \\
\hline
\end{tabular}

Table 4-7: Total electricity rate

\begin{tabular}{|c|c|c|c|c|}
\hline \multirow{2}{*}{ Time } & \multicolumn{2}{|c|}{ Summer } & \multicolumn{2}{c|}{ Winter } \\
\cline { 2 - 5 } & Rates $(\phi / \mathrm{kWh})$ & Rates $(\phi / \mathrm{kWh})$ \\
\hline 1a.m. to 7a.m. & 13.82 & Off-peak & 13.82 & Off-peak \\
\hline 7a.m. to 11a.m. & 18.66 & Mid-peak & 23.82 & On-peak \\
\hline 11a.m. to 5p.m. & 23.82 & On-peak & 18.66 & Mid-peak \\
\hline 5p.m. to 7p.m. & 18.66 & Mid-peak & 23.82 & On-peak \\
\hline 7p.m. to 12a.m. & 13.82 & Off-peak & 13.82 & Off-peak \\
\hline \multirow{2}{*}{ Time } & \multicolumn{4}{|c|}{ Holiday } \\
\cline { 2 - 5 } & \multicolumn{3}{|c|}{ Rates $(\phi / \mathrm{kWh})$} & \\
\hline Sat.\&Sun. & \multicolumn{4}{|c|}{ Off-peak } \\
\hline
\end{tabular}




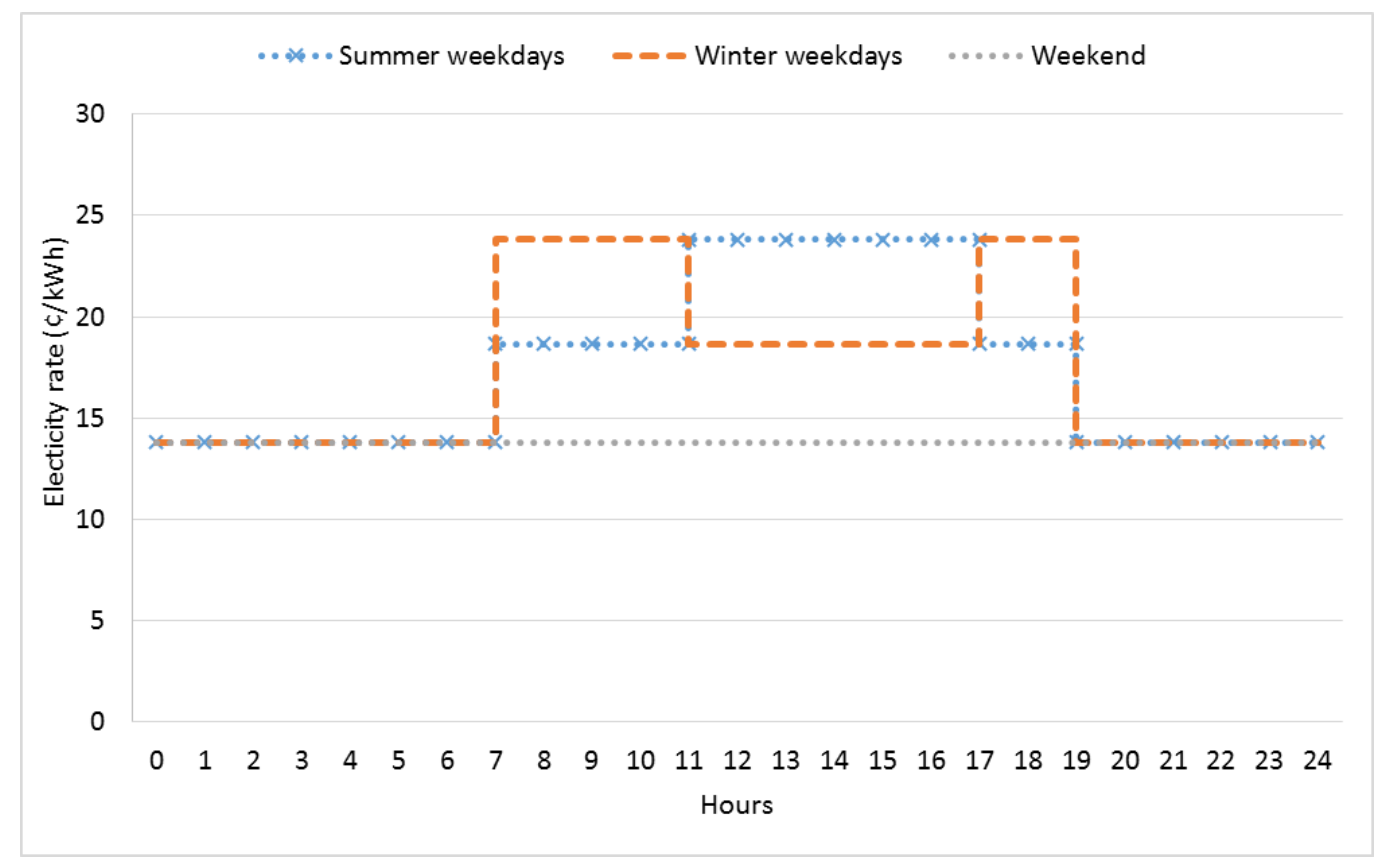

Figure 4-6: Total electricity rates

\subsection{House A TRNSYS Model}

In prevoius research (Safa et al., 2015), TRNSYS model of House A with the heating and cooling system was developed and verified by the experimental data. In this model the cooling season was assumed to begin on May 22 ( $3408 \mathrm{hr})$ and end on September $30(6575 \mathrm{hr})$. The heating season was assumed to begin October 1 (6576 hr) to May 21 (3407 hr). Type 665 in TRNSYS was employed to simulate the ASHP for cooling/heating system. The heating or cooling was delivered through a direct expansion air handling unit which supplied conditioned air to all floors of the house. The ASHP module is controlled by a thermostat, located on the first floor, with a set point dead band of $1.5^{\circ} \mathrm{C}$. Table 4-8 summarized the specification of House A model for 5-minute time step. 
Table 4-8: Model's specification of House A (Safa et al., 2015)

\begin{tabular}{|l|c|}
\hline Features & House A \\
\hline $\begin{array}{l}\text { Peak heating } \\
\text { capacity }\end{array}$ & $13.4 \mathrm{~kW}$ \\
\hline $\begin{array}{l}\text { Peak cooling } \\
\text { capacity }\end{array}$ & $5.74 \mathrm{~kW}$ \\
\hline $\begin{array}{l}\text { Winter set point } \\
\text { temperature }\end{array}$ & $21^{\circ} \mathrm{C}$ \\
\hline $\begin{array}{l}\text { Summer set point } \\
\text { temperature }\end{array}$ & $23^{\circ} \mathrm{C}$ \\
\hline $\begin{array}{l}\text { ASHP heating } \\
\text { energy consumption }\end{array}$ & $4804 \mathrm{kWh}$ \\
\hline $\begin{array}{l}\text { ASHP cooling } \\
\text { energy consumption }\end{array}$ & $383 \mathrm{kWh}$ \\
\hline $\begin{array}{l}\text { Total annual } \\
\text { heating load }\end{array}$ & $16094 \mathrm{kWh}$ \\
\hline $\begin{array}{l}\text { Total annual } \\
\text { cooling load }\end{array}$ & $1986 \mathrm{kWh}$ \\
\hline
\end{tabular}

\subsection{ASHPWH TRNSYS Model}

In this research, a TRNSYS model was developed for the ASHPWH which included three separate TRNSYS subroutines. Namely, (1) vertical cylindrical storage tank with wrap aound heat exchanger (HX), (2) heat pump water heater, and (3) tank auxiliary heating device. Finally, the developed ASHPWH model, shown in Figure 4-7, was integrated with the House A model. It should be noted that for winter and summer two different models were developed. Model 1 is for the ASHPWH, shown in Figure 4-7, including heat pump water heater and two auxiliary electric elements. Model 2 includes two electric water heaters, shown in Figure 4-8, which is considered as a conventional electric water heater in order to compare the two different systems.

The required input and parameters in the model types were established based on the provided system information from the manufacturer, system manuals as well as the collected experimental data. Refrigerant and water properties, such as density, specific heat and thermal conductivity, extracted from their standard tables (Moran and Shapiro, 2006) are summarized in Table 4-9. 
Table 4-9: Properties of refrigerant and water in $T=27^{\circ} \mathrm{C}$ (Moran and Shapiro, 2006)

\begin{tabular}{|l|c|c|c|}
\hline & $\begin{array}{c}\text { Specific } \\
\text { Heat } \\
\mathrm{C}_{\mathrm{p}} \\
\left(\mathrm{kJ} / \mathrm{kg}-{ }^{\circ} \mathrm{C}\right)\end{array}$ & $\begin{array}{c}\text { Density } \\
\rho \\
\left(\mathrm{kg} / \mathrm{m}^{3}\right)\end{array}$ & $\begin{array}{c}\text { Thermal } \\
\text { Conductivity } \\
\mathrm{k} \\
\left(\mathrm{W} / \mathrm{m}-{ }^{\circ} \mathrm{C}\right)\end{array}$ \\
\hline R134a & 1.43 & 1199.7 & 0.081 \\
\hline Water & 4.179 & 996.5 & 0.613 \\
\hline
\end{tabular}

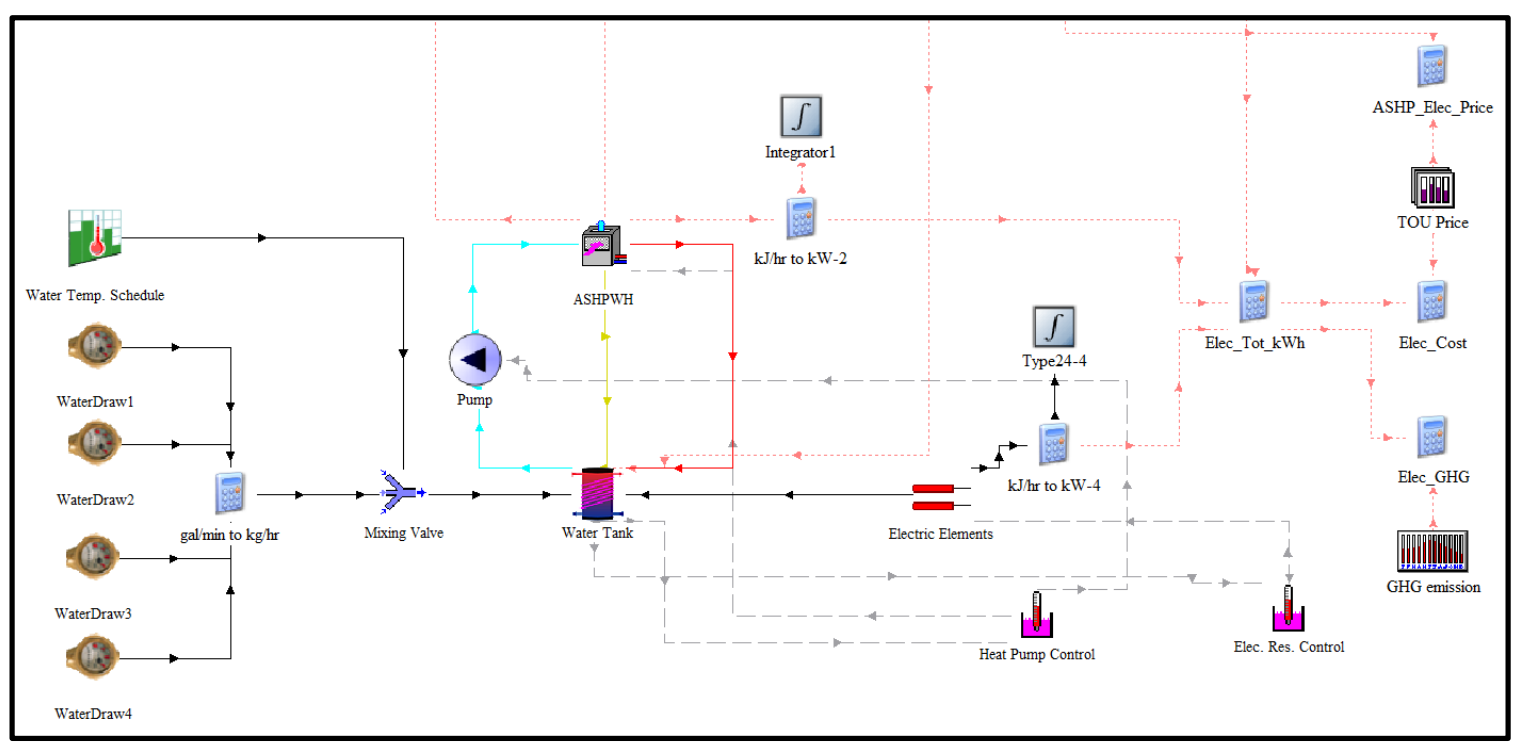

Figure 4-7: ASHPWH model in TRNSYS (Model 1)

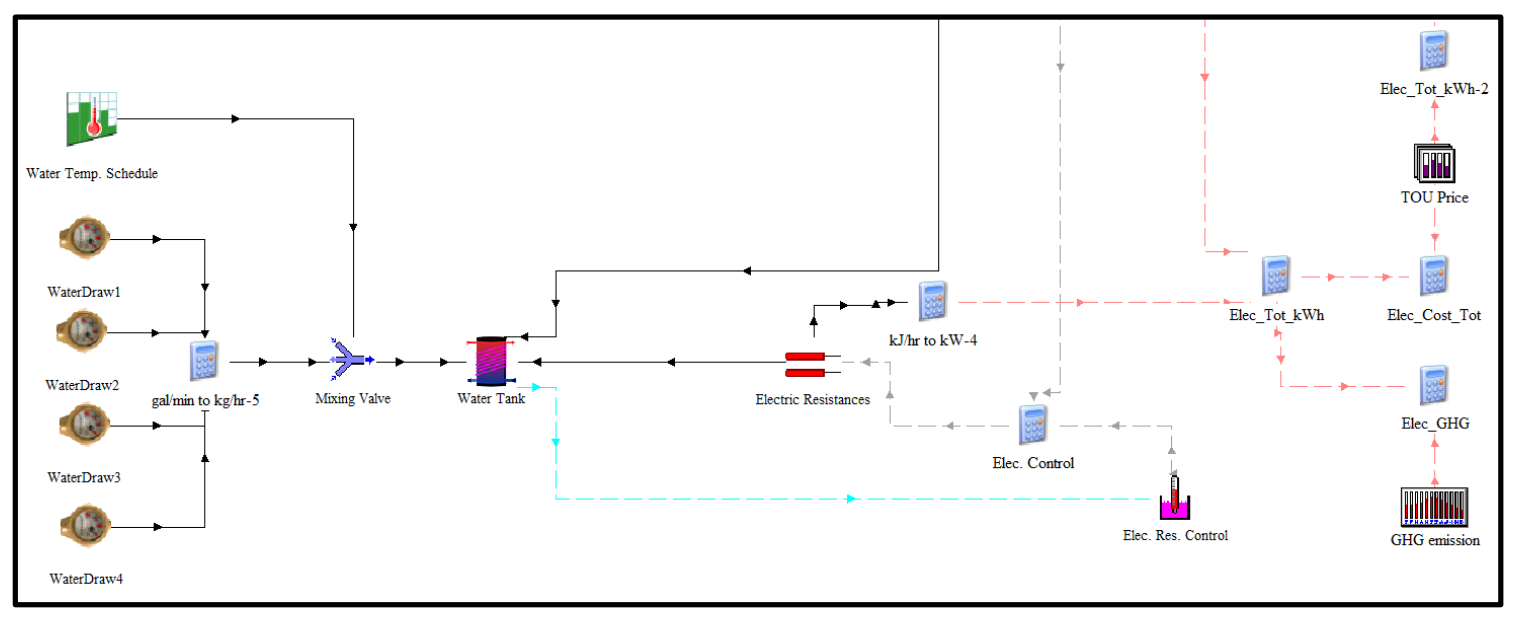

Figure 4-8: Electric water heater model in TRNSYS (Model 2)

In order to reduce the complexity of the model, some parameters like inlet air temperature, relative humidity, air pressure as well as water and refrigerant properties were set as constants. Since the heating and cooling thermostat for the house is located on the first floor, therefore we 
assume that the ASHPWH is also located on the first floor in order to investigate the cooling effect of the system on the overall impact of heating and cooling demand of the ASHP. In addition, latent heat is assumed to be zero inside the heat pump cycle. Another considered assumption for modelling is that the transferred energy from air to refrigerant and from refrigerant to water is equal. It means that loss of energy in refrigerant cycle is assumed to be zero.

\subsubsection{ASHPWH TRNSYS Models Types}

Due to complexity of the ASHPWH system, the use of advanced TRNSYS components from the TESS component library is necessary. These component types include heat pump water heater (Type 938), the wrap-around coil condenser tank (Type 1237), tank auxiliary heating device (Type 2270) and aquastat (Type 1502). Additional components which are also used in the models are

forcing functions, mixing valve and printer. All the mentioned components are assisted by calculators and integrators wherever necessary. Figures 4-9 and 4-10 show the schematics of two developed TRNSYS models. 


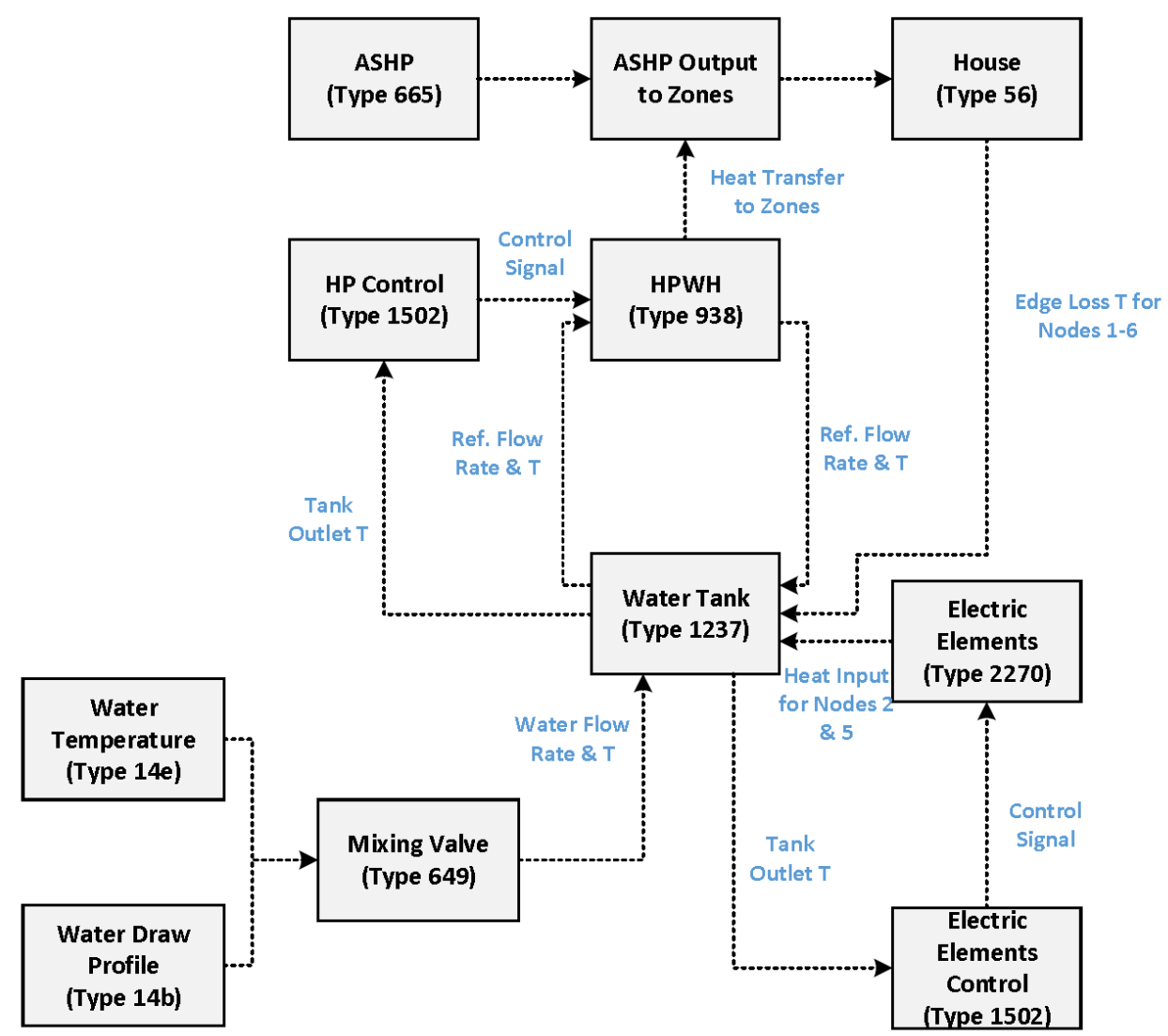

Figure 4-9: ASHPWH (Model 1) model schematic

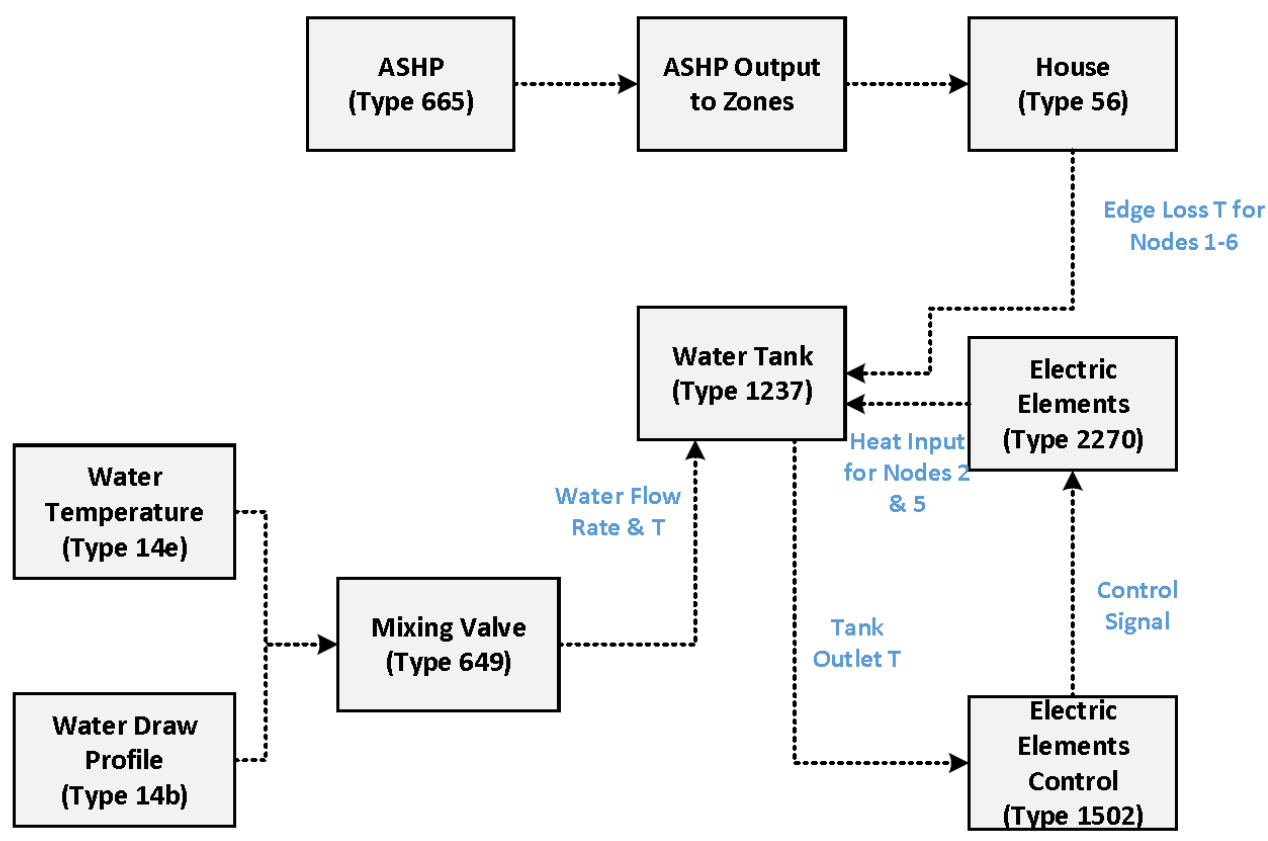

Figure 4-10: Electric water heater (Model 2) model schematic 
For heat pump water heater Type 938 which is specifically developed as a water heater unit. This Type models a single-stage ASHP that is created to heat a liquid stream while cooling and dehumidifying an air stream (TESS Component Library, 2012). The liquid stream in this Type is refrigerant (R134a) which flow through condenser coil around the water tank in order to transfer the heat to the water.

Water tank is modeled by using Type 1237, named Vertical Cylindrical Storage Tank with Wrap-Around HX, which is connected to the HP. The water heater tank includes two electric elements that heat the water when the heat pump cannot produce enough energy. These two supplementary electric heaters are applied to the tank using Type 2270, named Tank Heating Device. In this Type, the transferred energy to the fluid is the product of the three inputs including: capacity, efficiency and control signal (TESS Component Library, 2012). Type 2270 has two modes of operation. In mode 0 there is no master-slave operation, and both elements can function simultaneously based on their control signal from the aquastat. When in operation mode 1 , the dual element system operates in the reverse time which means that the lower element has the ability to be activated only when the upper element is off and has the appropriate control signal. In this research since based on the equipment manual, both of the electric heater operate at the same time, operation mode 0 has been set.

One of the inputs of the heat pump and electric heaters is control signal. Because their operating temperature ranges are different so two control Types are used in the model. Type 1502, an N-stage heating aquastat, is employed and the output of two controls applied to the heat pump and electric heaters. The setpoint temperature for the tank outlet is $54{ }^{\circ} \mathrm{C}$ with the deadband temperature of $\pm 1.7^{\circ} \mathrm{C}$ and these are verified by the experimental result presented in Section 6.1. Therefore when the tank outlet temperature is less than $52.3^{\circ} \mathrm{C}$, it is expected that heat pump starts to heat up the water. Based on the information provided by the manufacturer, the set point temperature of the electric heaters is $5^{\circ} \mathrm{C}$ less than the set point temperature of the HP and the starting temperature for the electric elements to work is $15^{\circ} \mathrm{C}$. Therefore, in special conditions when the heat pump cannot meet the water heating demand with outlet water temperature drops below $50{ }^{\circ} \mathrm{C}$, two electric elements start to work. For the Model 2, conventional electric water heater, all the model elements of model are assumed to be the same except that the HP water heater being removed from the model. The considered setpoint temperature for the electric water heater 
for Model 2 is the same as ASHPWH, Model 1, and equal to $54{ }^{\circ} \mathrm{C}$ with the same deadband temperature of $\pm 1.7^{\circ} \mathrm{C}$.

To integrate the water draw schedule in to the models, two time dependent forcing function (Type 14b and 14e) having repeated patterns for water flow rate and temperature, are employed. These functions include a set of discrete data points based on different times (TRNSYS 17 Component Library). In this research the cycle of flow rate points repeats every 48 hours based on two days of water draw schedule described in Section 3.5. Due to numerous flow rate input points, the schedule is divided into four parts and defined in separate forcing functions. Finally, a mixing valve, is combining all the flow rate and temperature data together, is used to transfer the information to the tank as input data.

Other kind of forcing function employed in the model is the hourly scheduler (Type 516). This Type is used in order to enter the time of use electricity rate and calculate the total electricity consumption cost. Type 516 allows different schedules to be set for weekdays, Saturdays and Sundays. Since the monthly GHG emission factors as explained in the future chapters are employed to compute the total emission, therefore another monthly forcing function scheduler (Type 518) is employed in the model. Table 4-10 summarizes the required parameters in Models 1 and 2. 
Table 4-10: Types' parameters of TRNSYS model

\begin{tabular}{|c|c|c|c|}
\hline Equipments & Types & Parameters & Models \\
\hline HPWH & 938 & $\begin{array}{l}\text { Density of ref.: } 1199.7 \mathrm{~kg} / \mathrm{m}^{3} \\
\text { Specific heat of ref.: } 1.43 \mathrm{~kJ} / \mathrm{kg} . \mathrm{K} \\
\text { Blower power: } 50 \mathrm{~W} \\
\text { Controller power: } 50 \mathrm{~W}\end{array}$ & Model 1 \\
\hline Water Tank & 1237 & $\begin{array}{l}\text { Number of tank nodes: } 6 \\
\text { Tank volume: } 0.189 \mathrm{~m}^{3} \\
\text { Tank height: } 1.17 \mathrm{~m} \\
\text { Water specific heat: } 4.179 \mathrm{~kJ} / \mathrm{kg} . \mathrm{K} \\
\text { Water density: } 996.5 \mathrm{~kg} / \mathrm{m}^{3} \\
\text { Fluid thermal conductivity: } 0.613 \mathrm{~W} / \mathrm{m} . \mathrm{K} \\
\text { Ref. specific heat: } 1.43 \mathrm{~kJ} / \mathrm{kg} . \mathrm{K} \\
\text { Ref. density: } 1199.7 \mathrm{~kg} / \mathrm{m}^{3} \\
\text { Ref. thermal conductivity: } 0.081 \mathrm{~W} / \mathrm{m} . \mathrm{K} \\
\text { Top loss coefficient: } 0.877 \mathrm{~W} / \mathrm{m}^{2} . \mathrm{K} \\
\text { Edge loss coefficient for node- } 1: 0.877 \mathrm{~W} / \mathrm{m}^{2} . \mathrm{K} \\
\text { Edge loss coefficient for node- } 2: 0.877 \mathrm{~W} / \mathrm{m}^{2} . \mathrm{K} \\
\text { Edge loss coefficient for node- }-3: 0.877 \mathrm{~W} / \mathrm{m}^{2} . \mathrm{K} \\
\text { Edge loss coefficient for node- } 4: 0.877 \mathrm{~W} / \mathrm{m}^{2} . \mathrm{K} \\
\text { Edge loss coefficient for node- }-5: 0.877 \mathrm{~W} / \mathrm{m}^{2} . \mathrm{K} \\
\text { Edge loss coefficient for node- } 6: 0.877 \mathrm{~W} / \mathrm{m}^{2} . \mathrm{K} \\
\text { Bottom loss coefficient: } 0.877 \mathrm{~W} / \mathrm{m}^{2} . \mathrm{K} \\
\text { HX loss coefficient: } 0.877 \mathrm{~W} / \mathrm{m}^{2} . \mathrm{K} \\
\text { Fraction of HX length for HX node-1 (top): } 0.02 \\
\text { Fraction of HX length for HX node- } 2: 0.02 \\
\text { Fraction of HX length for HX node- } 3: 0.02 \\
\text { Fraction of HX length for HX node- } 4: 0.36 \\
\text { Fraction of HX length for HX node- } 5: 0.29 \\
\text { Fraction of HX length for HX node- } 6: 0.29 \\
\text { Exit node: } 1 \\
\text { Fraction of inlet flow to node- } 6: 1\end{array}$ & $\begin{array}{c}\text { Models } 1 \\
\& 2\end{array}$ \\
\hline Electric Elements & 2270 & $\begin{array}{l}\text { Thermal efficiency - upper: } 100 \% \\
\text { Thermal efficiency - lower: } 100 \% \\
\text { Heating capacity - upper: } 1500 \mathrm{~W} \\
\text { Heating capacity - lower: } 1500 \mathrm{~W}\end{array}$ & $\begin{array}{c}\text { Models } 1 \\
\& 2\end{array}$ \\
\hline $\begin{array}{l}\text { Electric } \\
\text { Elements } \\
\text { Control }\end{array}$ & 1502 & $\begin{array}{l}\text { Number of heating stages: } 1 \\
\# \text { oscillations permitted: } 5 \\
\text { Temperature dead band: } 0{ }^{\circ} \mathrm{C} \\
\text { Setpoint temperature for stage: } 50^{\circ} \mathrm{C}\end{array}$ & $\begin{array}{c}\text { Models } 1 \\
\& 2\end{array}$ \\
\hline HPWH Control & 1502 & $\begin{array}{l}\text { Number of heating stages: } 1 \\
\# \text { oscillations permitted: } 5 \\
\text { Temperature dead band: } 3.4{ }^{\circ} \mathrm{C} \\
\text { Setpoint temperature for stage: } 54{ }^{\circ} \mathrm{C}\end{array}$ & Model 1 \\
\hline
\end{tabular}




\section{Chapter 5: Data Analysis}

In order to read and analyze the recorded data at every 0.5 second, MATLAB scripts have been written (see Appendix C). All the equations presented in Section 4.1.2 are programmed and the COP as well as the thermal energy supplied by the HP of ASHPWH have been computed for a time interval of 15 minutes. Finally, the performance curve was verified with the provided information by the manufacturer to ensure the accuracy of results. In this chapter, the data for tank water temperature, condensation on the evaporator coil, COP analysis and Energy Factor for different operation modes and indoor conditions will be discussed. At the end, the result from the experimental data will be combined with the Ontario Time of Use (TOU) electricity price in order to investigate the financial aspect of the system during two days of water draw.

\subsection{Experimental Data Verification}

In order to validate the experimental results, an experiment was performed in heat pump mode during the cold start tank stage with an indoor temperature of $19.7^{\circ} \mathrm{C}$ and relative humidity (RH) of 50\%. Figure 5-1 compares the calculated coefficient of performance (COP) from the experimental data to the manufacturer's performance curve. Based on the error propagation analysis, the calculated error for the COP is about $2.8 \%$ as it is shown in the error bars in Figure 5-1. It is comprehensible from the figure that the experimental data is aligned with a technical lab result from ASHPWH manufacturer and they are reliable. 


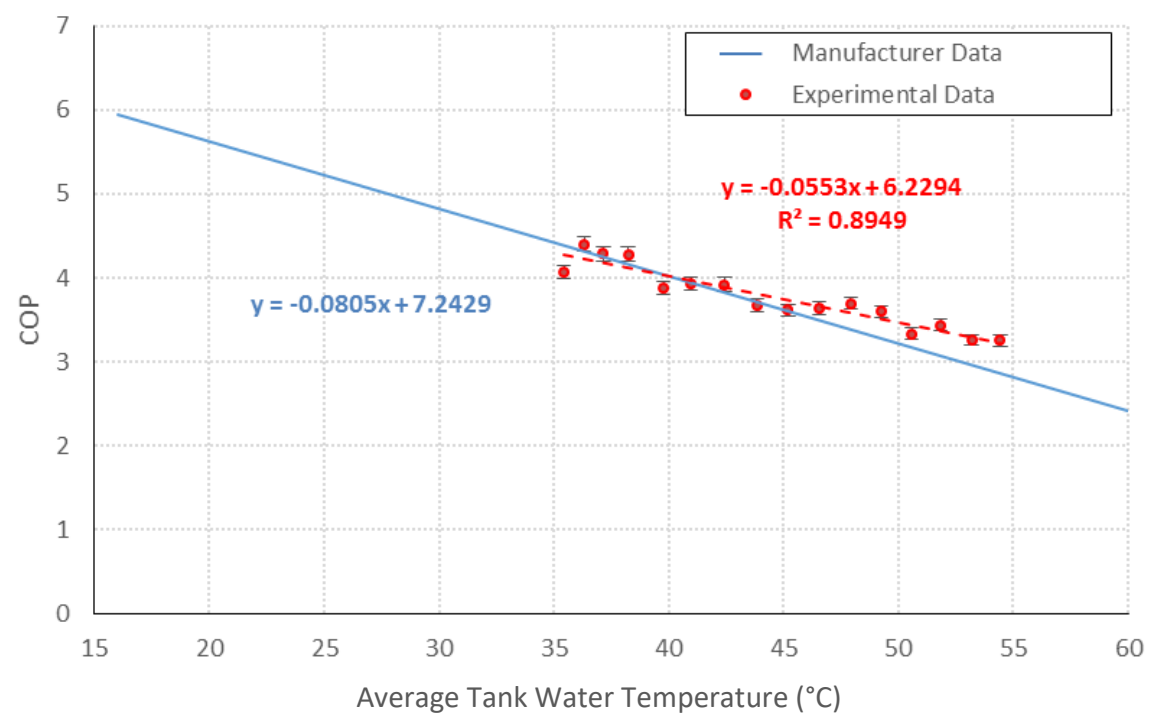

Figure 5-1: Manufacturer and experimental result in cold start tank stage of $19.7{ }^{\circ} \mathrm{C}$ and $50 \% \mathrm{RH}$

\subsection{Water Temperature}

Six temperature sensors have been installed inside the tank in order to estimate the average water temperature based on the average reading of these six nodes. As mentioned in Section 3.2, the electric heaters are located at nodes 2 and 5. The sensors that measure the tank control temperature in order to change the equipment modes between electric and HP in the hybrid mode, are located at nodes 3 and 6 . The set point temperature for all the experiments are $55{ }^{\circ} \mathrm{C}$. Figures 5-2, 5-3 and 5-4 display the temperatures for the six nodes as well as the estimated average temperature of water for two days of water draw. The data is averaged for every $150 \mathrm{~s}$ in order to smooth out the plot and remove the noises. In all modes, the peak values illustrate the stop time of the electric elements and heat pump.

Figure 5-2 shows that the temperatures in nodes 4 and 5 (i.e. $\mathrm{T}_{5}, \mathrm{~T}_{4}$ ) are higher than the other nodes which is due to the electric heater locations in node 5 and flow mixing in node 4 . Moreover, in electric mode, peak temperatures at node 2 are greater than peak temperatures at node 3 because presence of electric heaters. Since there is no electric element at node 1 (bottom of the tank) with water inlet, the temperature at this node is less than expected, compared to the other modes. The peak of average water temperature in electric mode is around $45^{\circ} \mathrm{C}$. 

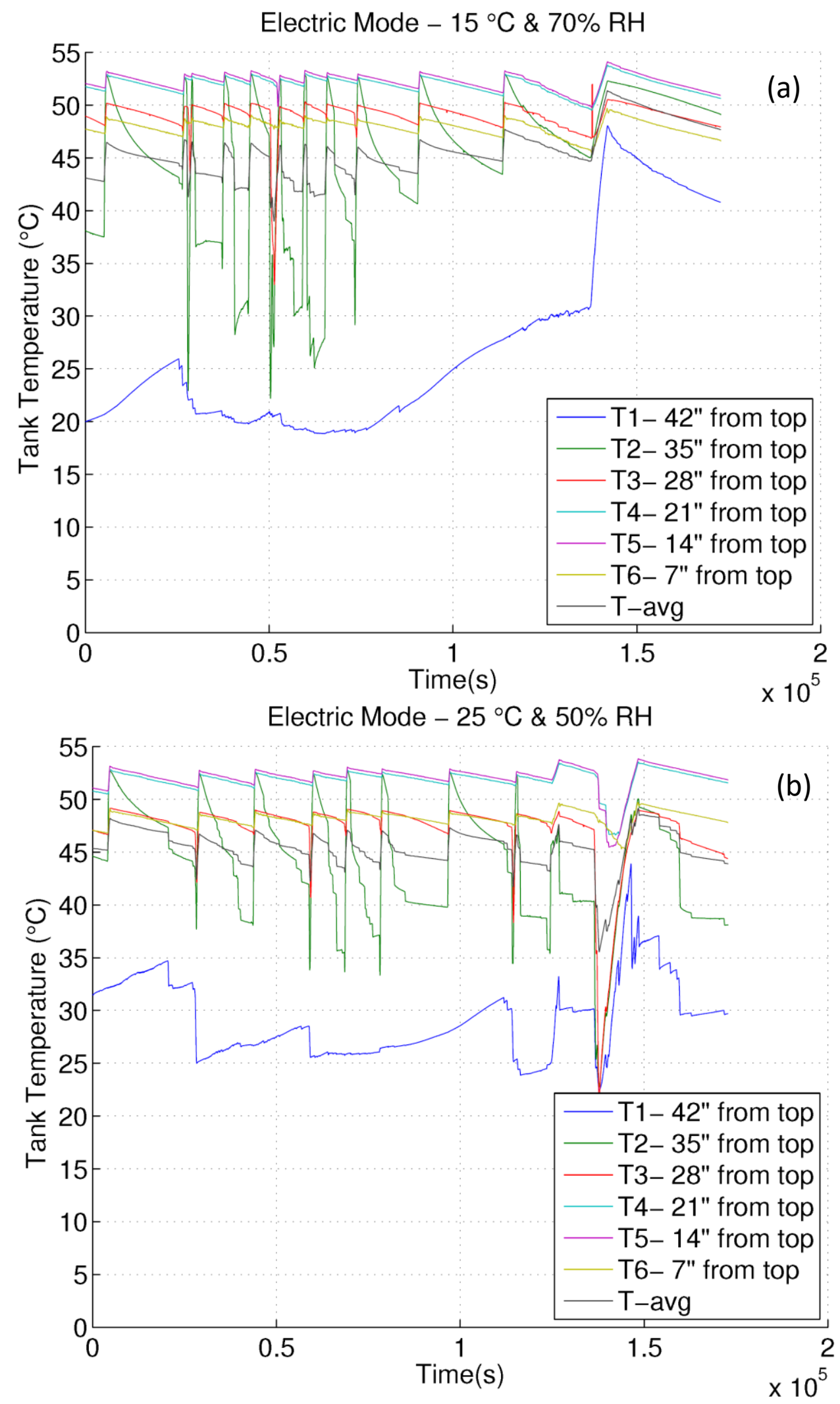

Figure 5-2: Tank nodes temperature for electric mode during water draw stage 

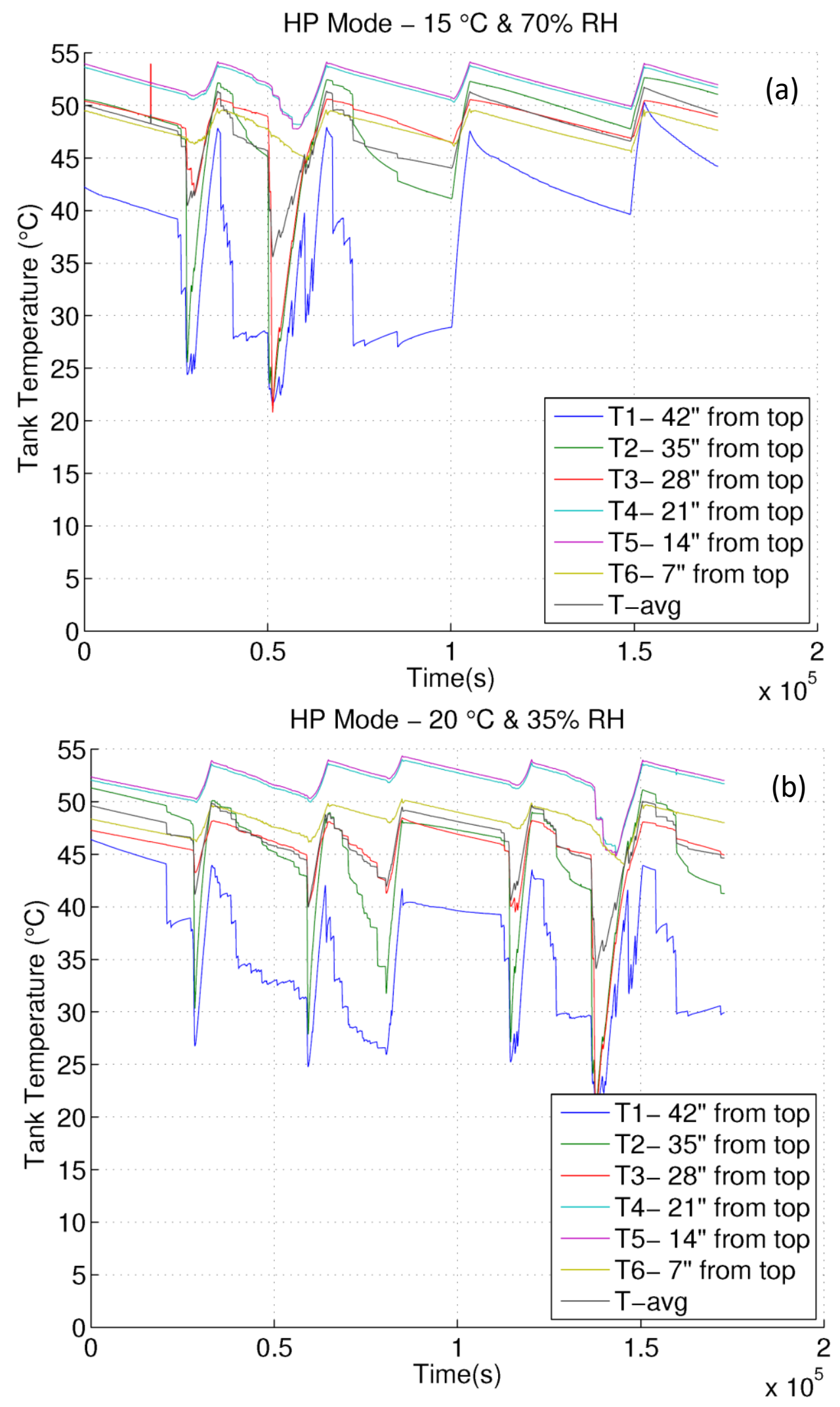


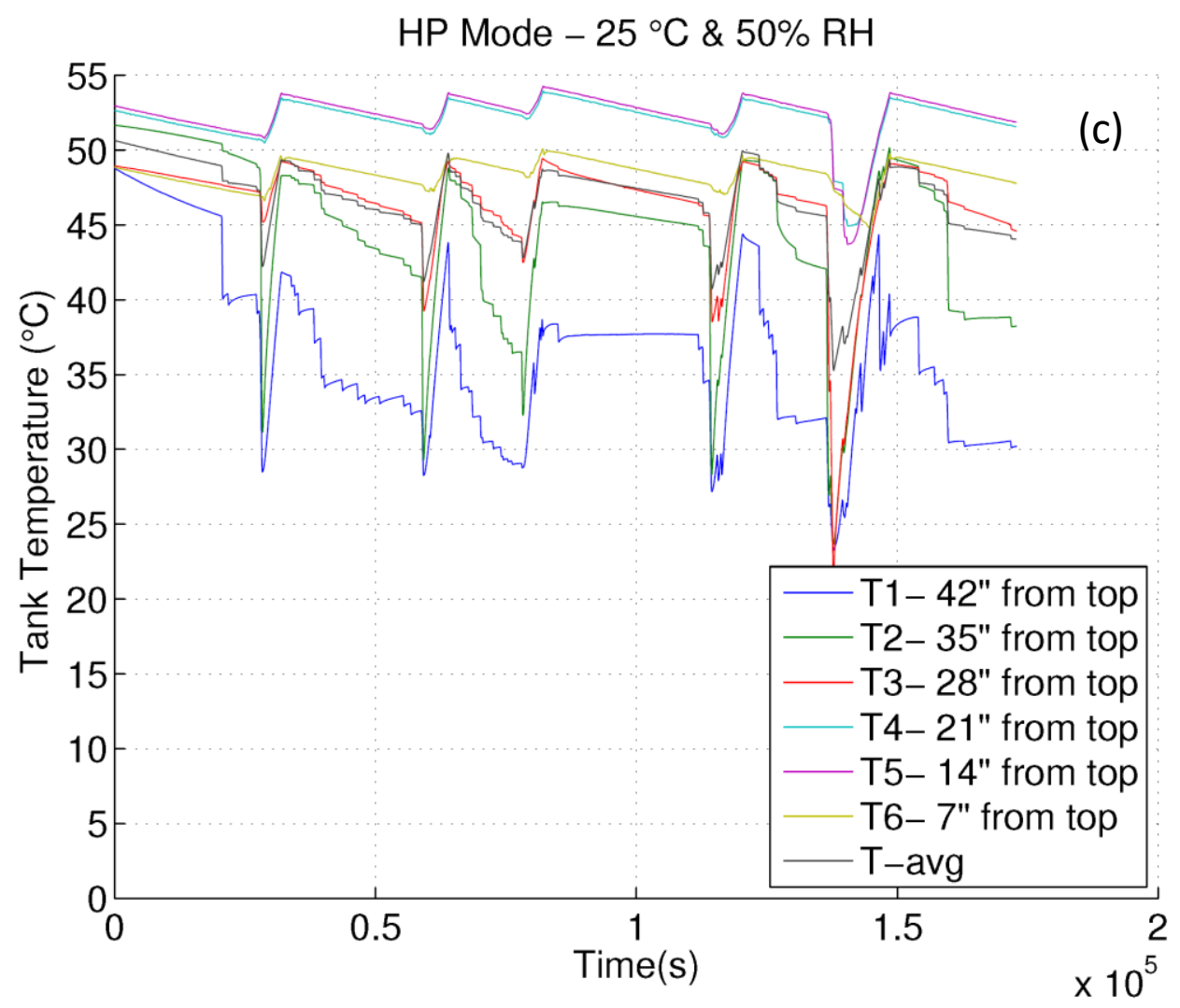

Figure 5-3: Tank nodes temperature for HP mode during water draw stage

Note that as shown in Figure 5-2 (a), the water inlet temperature is lower than that in Figure 5-2 (b). As a result, the temperature drop in (a) is higher than (b).

Based on Figures 5-3 and 5-4, the peak of the average water temperature in HP and hybrid modes is about of $50{ }^{\circ} \mathrm{C}$, which is greater than the peak of the average water temperature in the electric mode. As shown in Table 3-2, distribution of the heat exchanger around the tank in node $3(36 \%)$ is almost equal to node $2(29 \%)$. Therefore, in HP and hybrid modes, unlike the electric mode, the variation of $T_{3}$ during water heater operation is almost similar to the variation of $T_{2}$. Since there is a fraction of $29 \%$ of the heat exchanger wrapped around at node 1 , the temperature of supplied water in HP and hybrid mode can be increased faster than electric mode during water draw. Comparing graphs in the electric mode (Figure 5-2) and other modes (Figures 5-3 and 5-4), the peak temperatures happen more frequently in electric mode and it shows the cycling operation of the electric elements. 

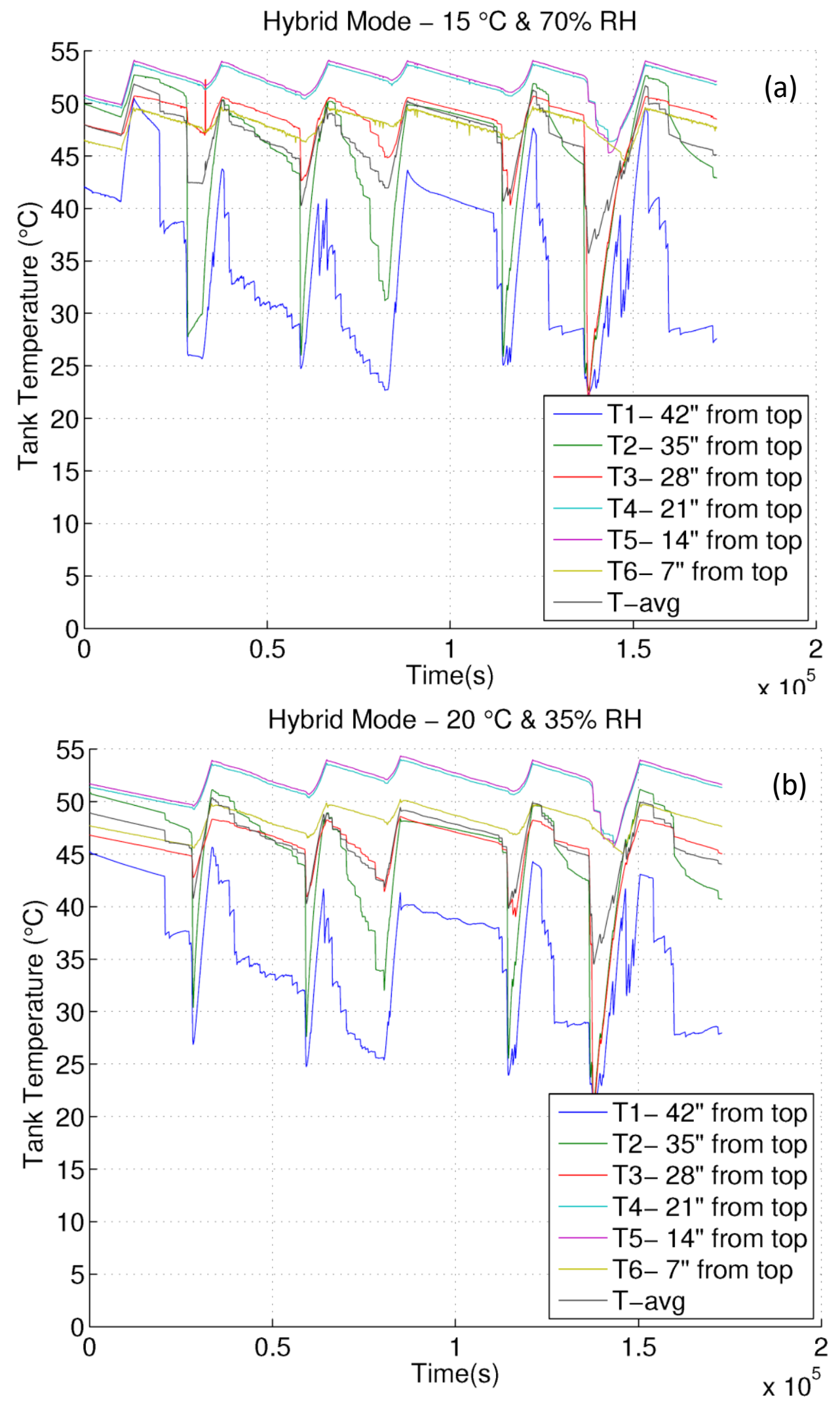

Figure 5-4: Tank nodes temperature for hybrid mode during water draw stage 


\subsection{Condensation on Evaporator Coil Surface}

The ASHPWH is located inside the house and therefore it may extract the indoor latent heat by condensation that occurs on the surface of the evaporator coil. When the temperature of the coil is higher than the dew point of the environment, there is no condensation. The calculated dew point temperatures for $15^{\circ} \mathrm{C}$ and $70 \% \mathrm{RH}, 20{ }^{\circ} \mathrm{C}$ and $35 \% \mathrm{RH}$, and $25^{\circ} \mathrm{C}$ and $50 \% \mathrm{RH}$ are $10{ }^{\circ} \mathrm{C}, 4^{\circ} \mathrm{C}$ and $14{ }^{\circ} \mathrm{C}$, respectively. During the experiments, the sensor for the coil temperature was located at the end of the coil and not on the fin at the middle of the coil; therefore there was a temperature difference between the actual coil temperature and the sensor data as shown in Figure 5-5-a and 55-b. Note that, due to calibration issues, the recorded temperature and the sensor data do not match precisely. Therefore, in contrast to our expectation, the temperature of the coil surface was higher than the indoor temperature during HP operation time.

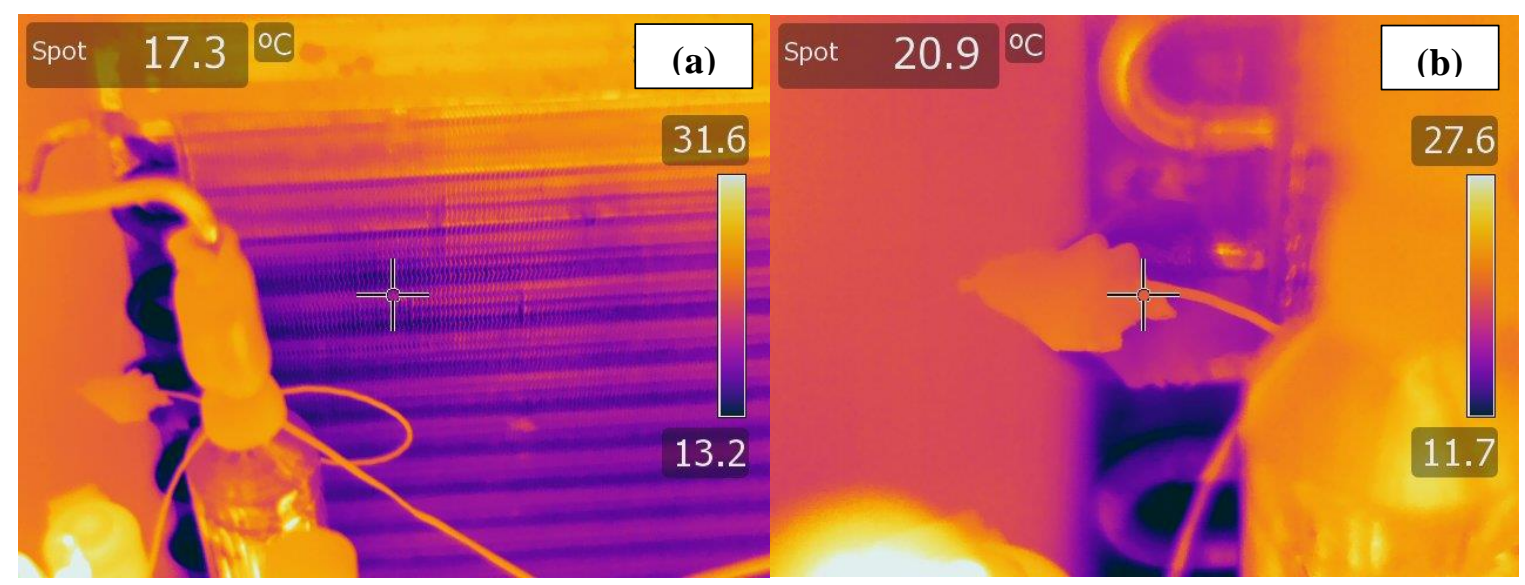

Figure 5-5: Visualization of (a) the actual temperature of the coil surface and (b) the sensor temperature

In order to resolve this inconsistency the following adjustment was made. First, the temperatures of the located sensor and the coil fin were measured by a thermometer which were then compared to the DAQ sensor temperature that had been read simultaneously. The ratio of the recorded and the actual temperature was then calculated and thus all the data were corrected by multiplication to the inverse of this ratio.

The adjusted coil surface temperatures are showed in Figures 5-6, 5-7 and 5-8. These figures illustrate the temperature of the coil during two days of water draw experiments with different indoor conditions. Since the temperatures of the coil surface in $20{ }^{\circ} \mathrm{C}$ and $35 \% \mathrm{RH}$ and $25^{\circ} \mathrm{C}$ and 
$50 \% \mathrm{RH}$ were higher than the specified dew point temperatures, condensation did not occur on the coil in these two indoor conditions. Nevertheless, in $15{ }^{\circ} \mathrm{C}$ and $70 \% \mathrm{RH}$, the coil temperature was close to the dew point temperature at some times during its operation and hence the condensation might have happened.

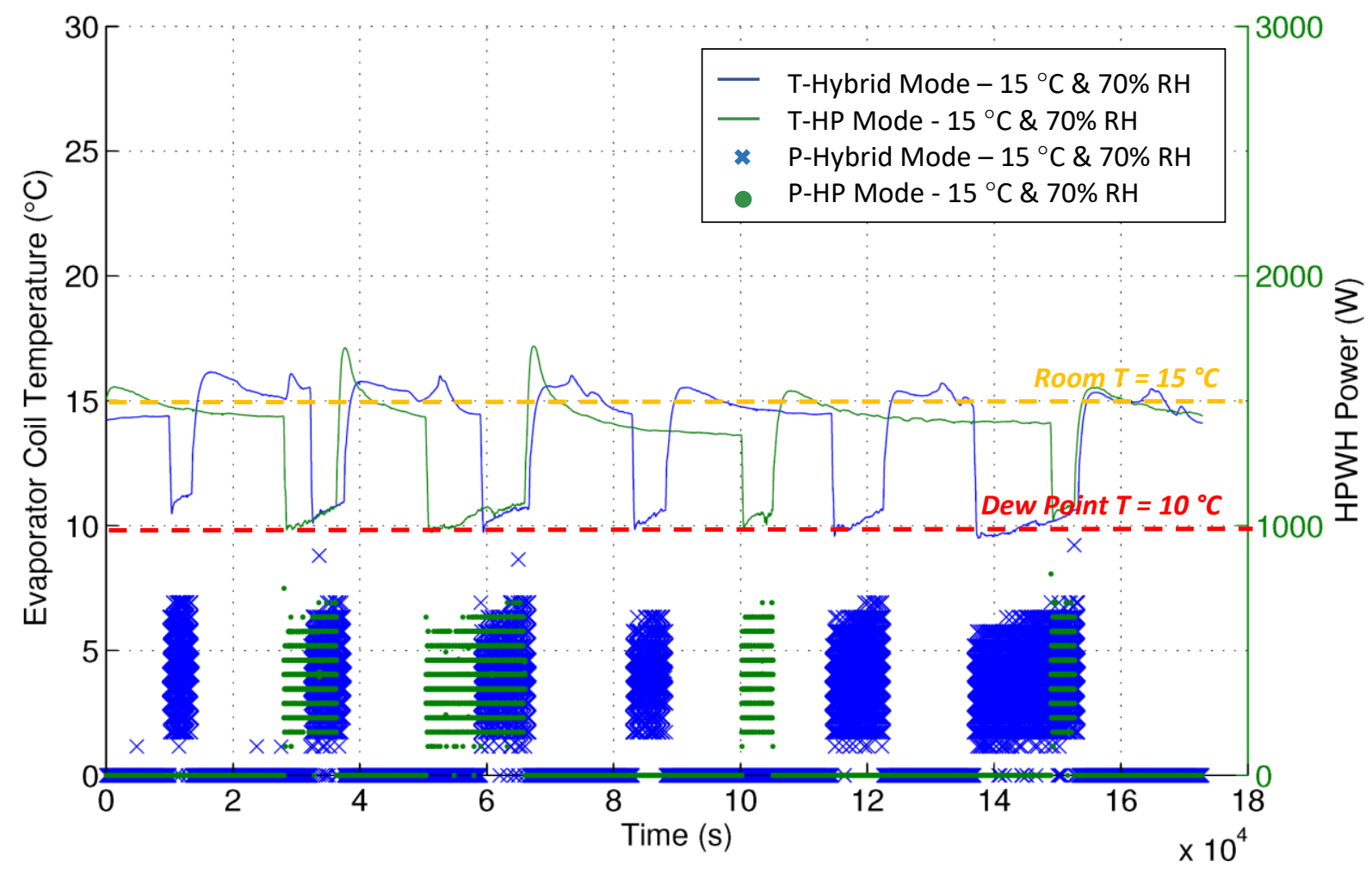

Figure 5-6: Evaporator coil temperature variation in $15{ }^{\circ} \mathrm{C}$ and $70 \% \mathrm{RH}$ 


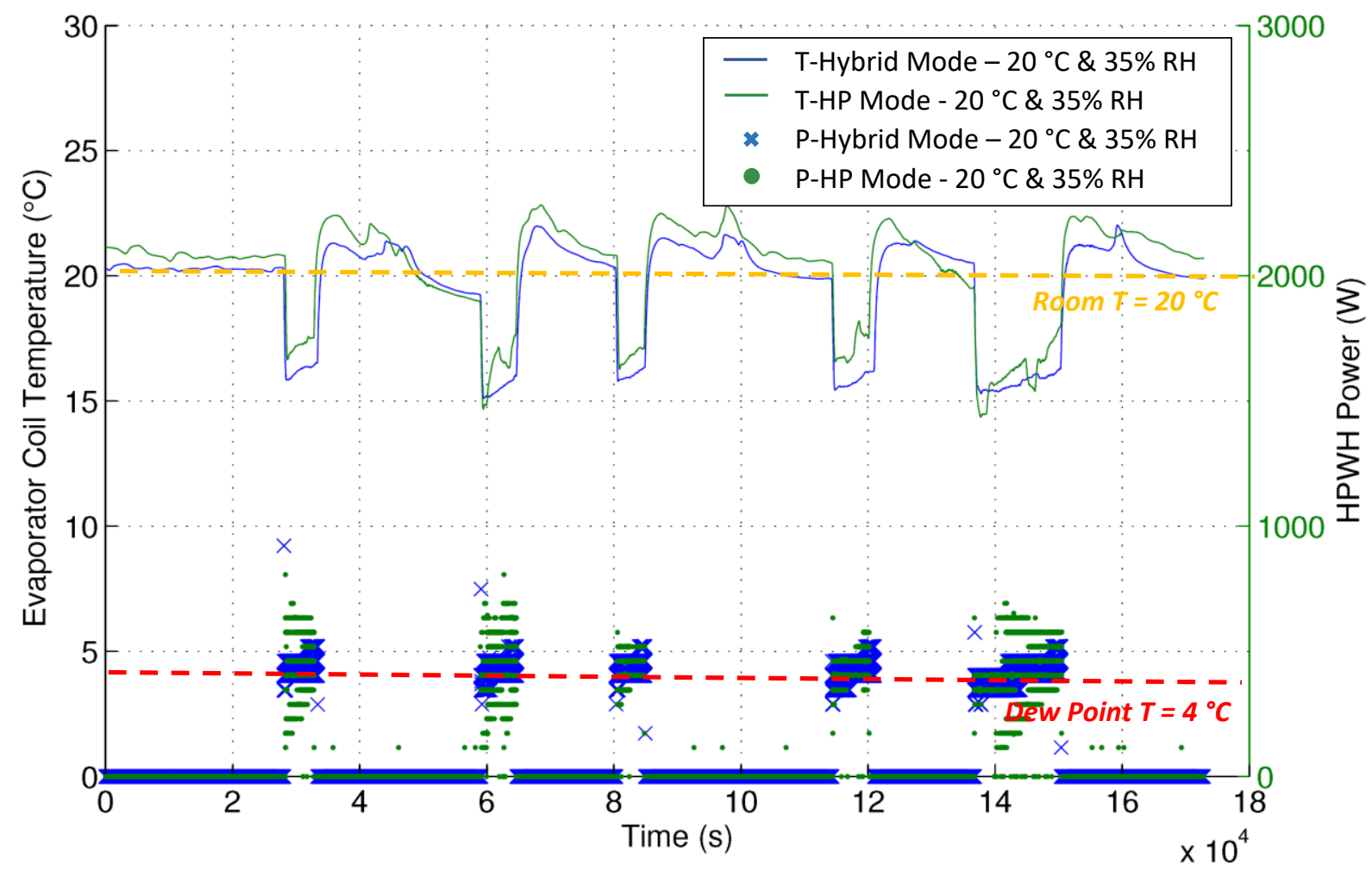

Figure 5-7: Evaporator coil temperature variation in $20^{\circ} \mathrm{C}$ and $35 \% \mathrm{RH}$

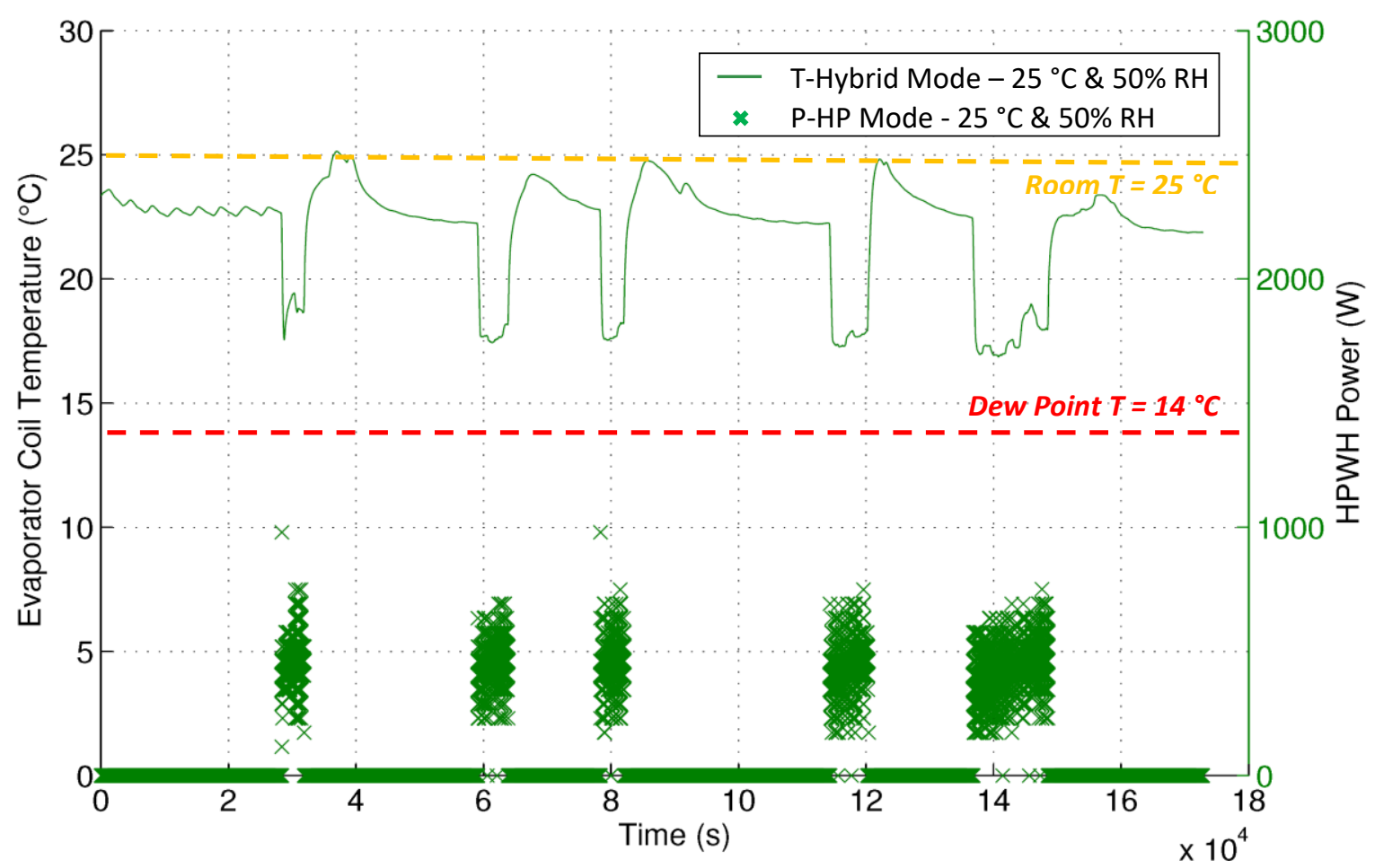

Figure 5-8: Evaporator coil temperature variation in $25^{\circ} \mathrm{C}$ and $50 \% \mathrm{RH}$ 


\subsection{Coefficient of Performance Analysis}

All the analysis in this section is based on Equations (4-12) and (4-13) presented in Section 4.1.2 and for the time step of 15 minutes. Due to fluctuating operation of HP during the experiments, the HP power is approximately zero most of the time. Therefore, the corresponding COP of HP during these periods is infinity or a large number and thus has been removed from the final results. There are two important variables that influence the COP of HP if the water draw flow rates are kept constant during the experiments. These two variables are the inlet water temperature of the tank and the air temperature surrounding the tank. For example, when the temperature of the indoor air is reduced, the COP of the system is expected to decrease due to the reduced energy absorption from the environment which leads to higher power consumption of HP (i.e. lower COP). On the other hand, when the water supply temperature is reduced, the HP generates more thermal energy and hence, the COP of the system is expected to increase.

\subsubsection{Two Days of Water Draw}

The variation of COP for different average water temperatures are shown for different ambient temperatures of HP mode in Figure 5-9. As the average tank water temperature increases, the COP of HP decreases in all three experiments which is expected. Furthermore, it appears that the COP variation is more linear at the temperature range of $45{ }^{\circ} \mathrm{C}$ to $52{ }^{\circ} \mathrm{C}$. As shown in Figure 5-10, the temperature of the inlet water for indoor condition of $15^{\circ} \mathrm{C}$ and $70 \% \mathrm{RH}$ is lower than that of 20 ${ }^{\circ} \mathrm{C}$ and $35 \% \mathrm{RH}$, and $25{ }^{\circ} \mathrm{C}$ and $50 \% \mathrm{RH}$. The variations in the tank inlet water temperature, as shown in Figure 5-10, are due to the water that is remained in the pipes inside the house which causes the water to warm up in contact with the indoor temperature. Therefore in one case the inlet water temperature is around $13{ }^{\circ} \mathrm{C}$ to $15^{\circ} \mathrm{C}$ while in the other two they are about $15^{\circ} \mathrm{C}$ to $25^{\circ} \mathrm{C}$.

Figure 5-9 suggests high values of COP for indoor condition of $20{ }^{\circ} \mathrm{C}$ and $35 \% \mathrm{RH}$ that are even higher than those for $25{ }^{\circ} \mathrm{C}$ and $50 \% \mathrm{RH}$ and thus does not agree with the expected trend described previously based on the indoor air temperature (see also Equations (4-12) and (4-13)). However, notice that the water draw flow rate during this experiment (i.e. $20^{\circ} \mathrm{C}$ and $35 \% \mathrm{RH}$ ) was

found to be more than the set values for the other two experiments. As a result, $Q_{\text {Tank }}$ was 
significantly increased leading to a higher COP (see Equation (4-12)). For this reason and for consistency, this experiment was not used to design the input parameters of the numerical model and will not be further discussed in this chapter.

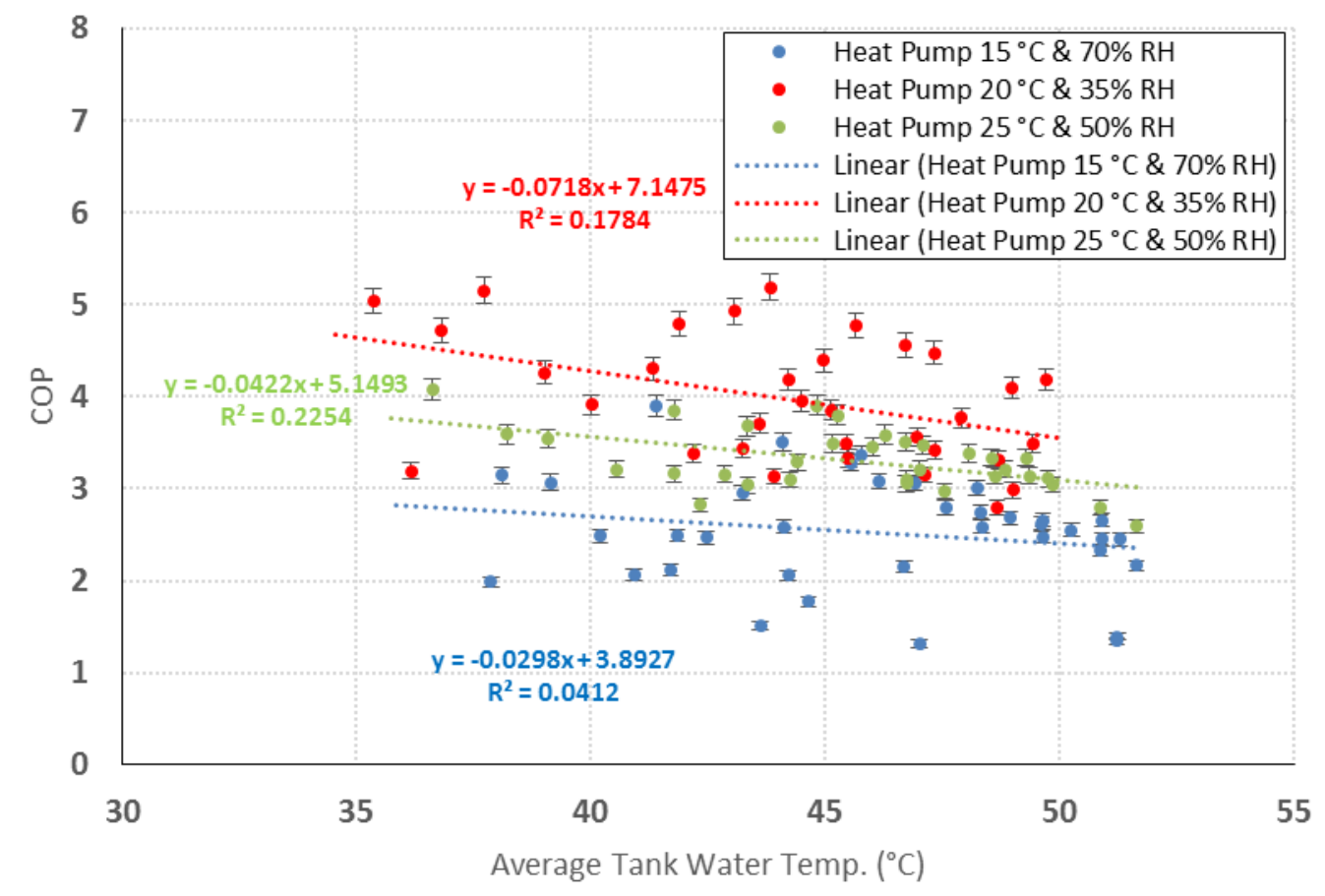

Figure 5-9: HP mode coefficient of performance in three indoor conditions 


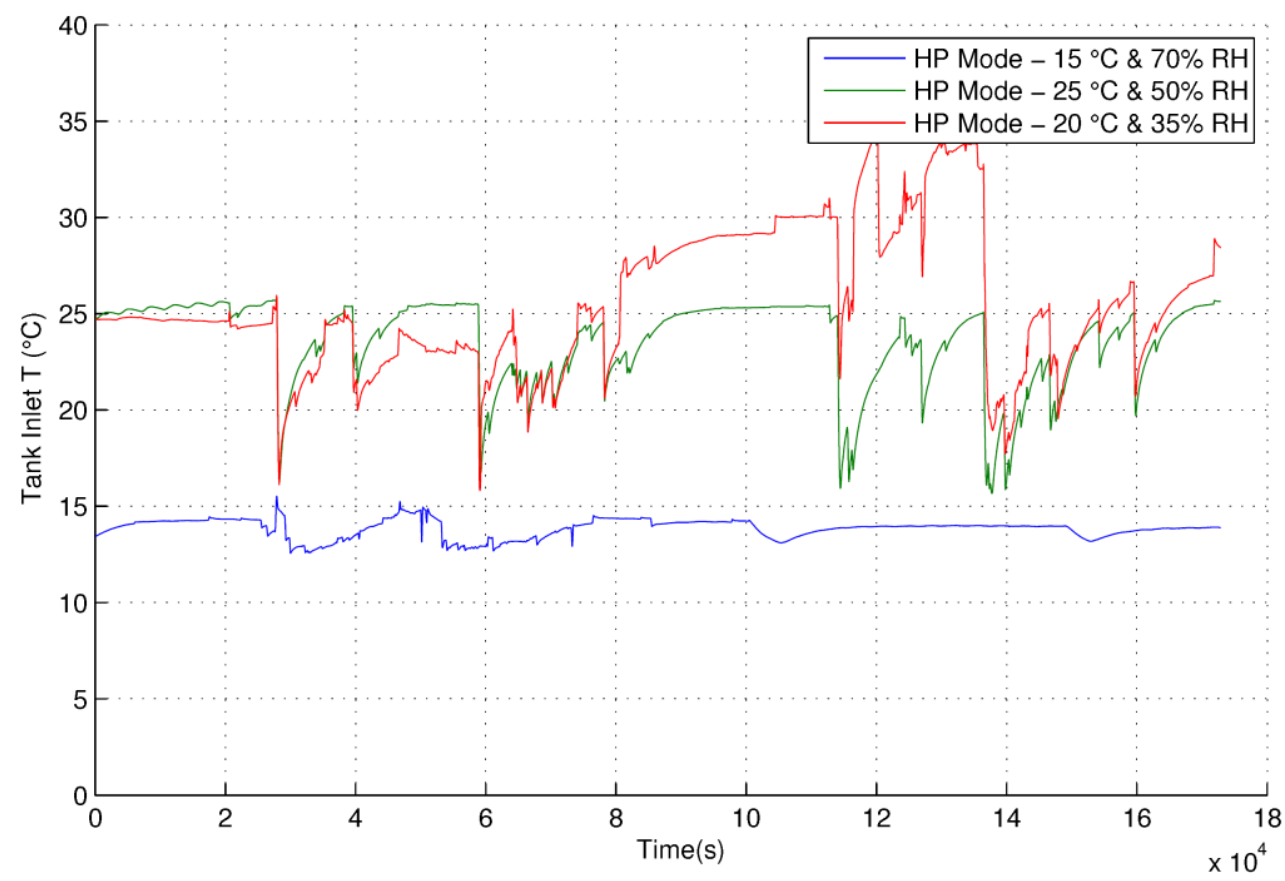

Figure 5-10: Tank inlet temperature for three indoor conditions in HP mode

Figure 5-11 shows the calculated COP for two experiments in the hybrid mode. As expected, by increasing the average tank temperature, the $\mathrm{COP}$ of HP reduces in both experiments and the $\mathrm{COP}$ variation is more linear at the temperature range of $45^{\circ} \mathrm{C}$ to $52^{\circ} \mathrm{C}$. Based on these results, the COP of $20{ }^{\circ} \mathrm{C}$ and $35 \% \mathrm{RH}$ is higher than that of $15{ }^{\circ} \mathrm{C}$ and $70 \% \mathrm{RH}$, but the difference is reduced because the tank inlet water is warmer at $20{ }^{\circ} \mathrm{C}$ and $35 \% \mathrm{RH}$ compared to that at $15{ }^{\circ} \mathrm{C}$ and 70\% RH based on Figure 5-12. In general, it may be concluded that even in cold and humid basement conditions, the A.O. Smith heat pump water heater operates efficiently in both hybrid and HP modes with the COP ranges between 1.5 and 5 depending on the water supply temperature. 


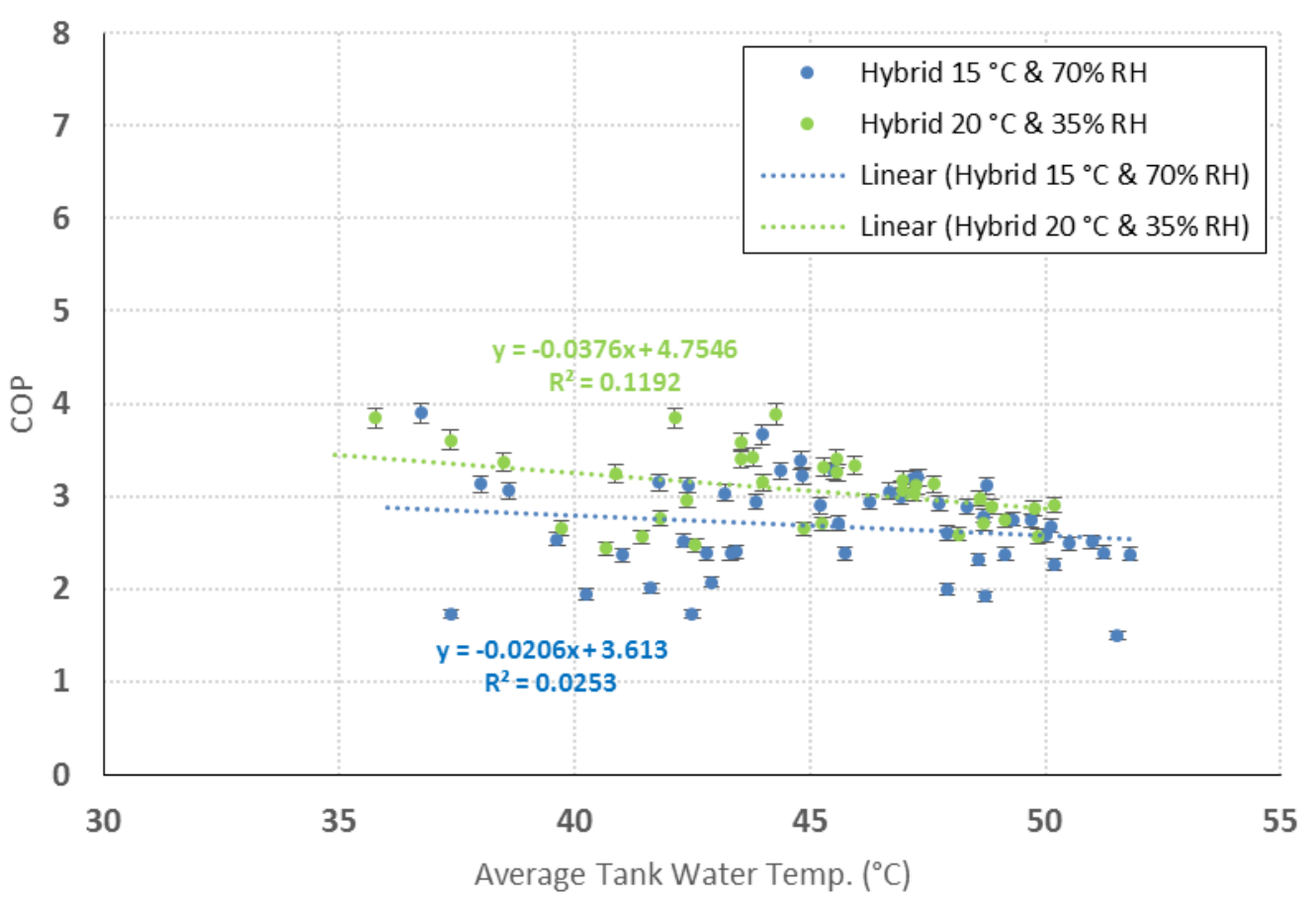

Figure 5-11: Hybrid mode coefficient of performance in two indoor conditions

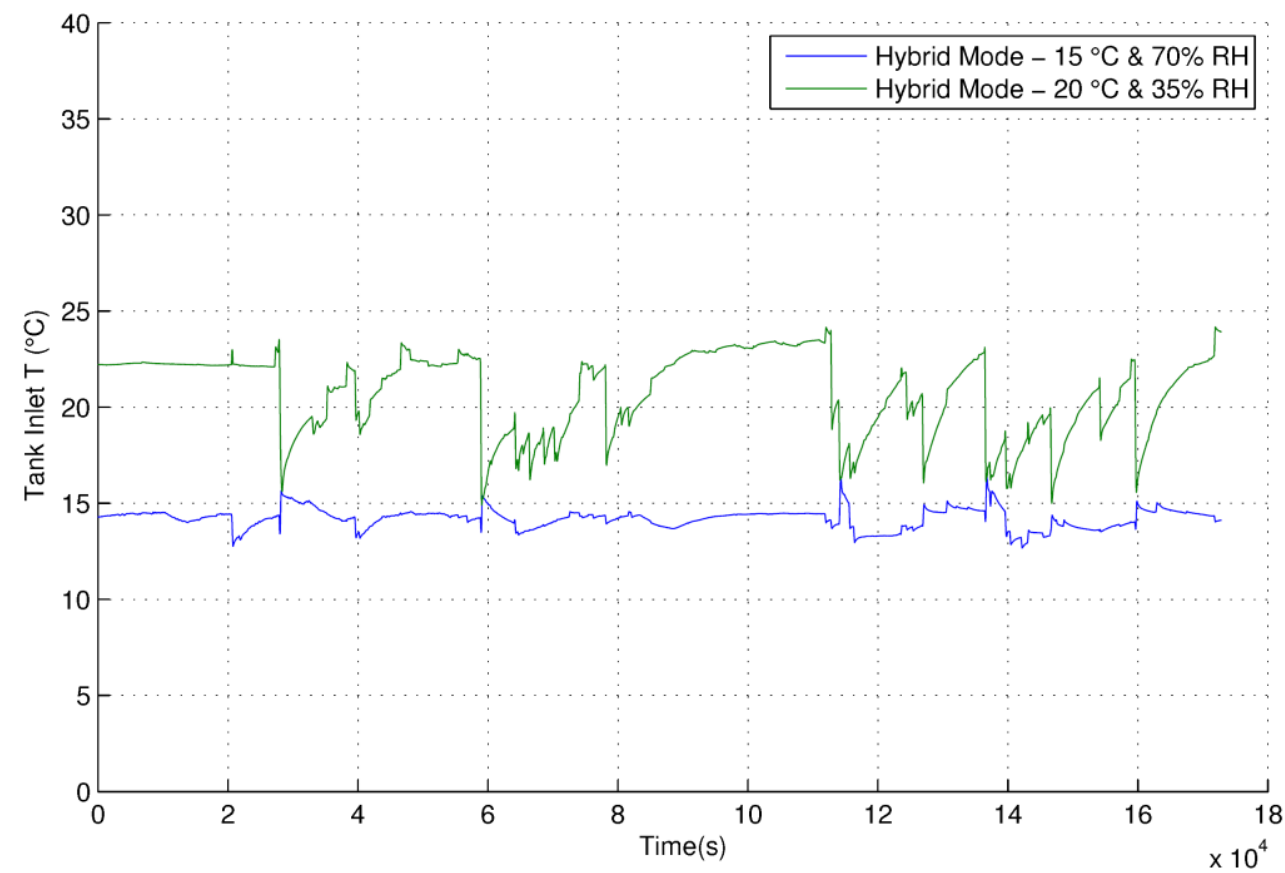

Figure 5-12: Tank inlet temperature for two indoor condition in hybrid mode 


\subsubsection{Cold Start Tank}

The process of heating up the tank from cold start takes about 4 to 8 hours for different experiments. In this process, since the electric elements start to work at $15^{\circ} \mathrm{C}$, the tank has been unloaded until the tank temperature decreased to $16{ }^{\circ} \mathrm{C}$ to avoid the electric heaters' operation during the HP mode operation. Then the cold start stage began to heat up water to $55^{\circ} \mathrm{C}$, the system's set point temperature. Figure 5-13 depicts the COP of ASHPWH during the cold start tank stage for the HP mode.

Although the experiments started at the average tank temperature of $16{ }^{\circ} \mathrm{C}$, in HP mode the electric element works at the beginning of the heating cycle until the tank average water temperature reaches about $30^{\circ} \mathrm{C}$. By comparing Figures 5-13 and 5-14, it is evident that the COP becomes relevant as soon as the electric heaters terminate their operation. However, due to the presence of these hot electric heaters, the temperature of the tank continues to increase, especially in areas that are located at the top of the tank near the electric heaters. During this recovery time, the HP COP increases as the average tank temperature increases. Based on Figure 5-13, the higher the ambient temperature the faster the recovery time for HP COP will be. Therefore, the maximum COP of the $\mathrm{HP}$ of ASHPWH at $25{ }^{\circ} \mathrm{C}$ and $50 \% \mathrm{RH}, 20^{\circ} \mathrm{C}$ and $35 \% \mathrm{RH}$, and $15{ }^{\circ} \mathrm{C}$ and $70 \% \mathrm{RH}$ occur in temperatures of about $36.5^{\circ} \mathrm{C}, 38.5^{\circ} \mathrm{C}$ and $39^{\circ} \mathrm{C}$, respectively. 


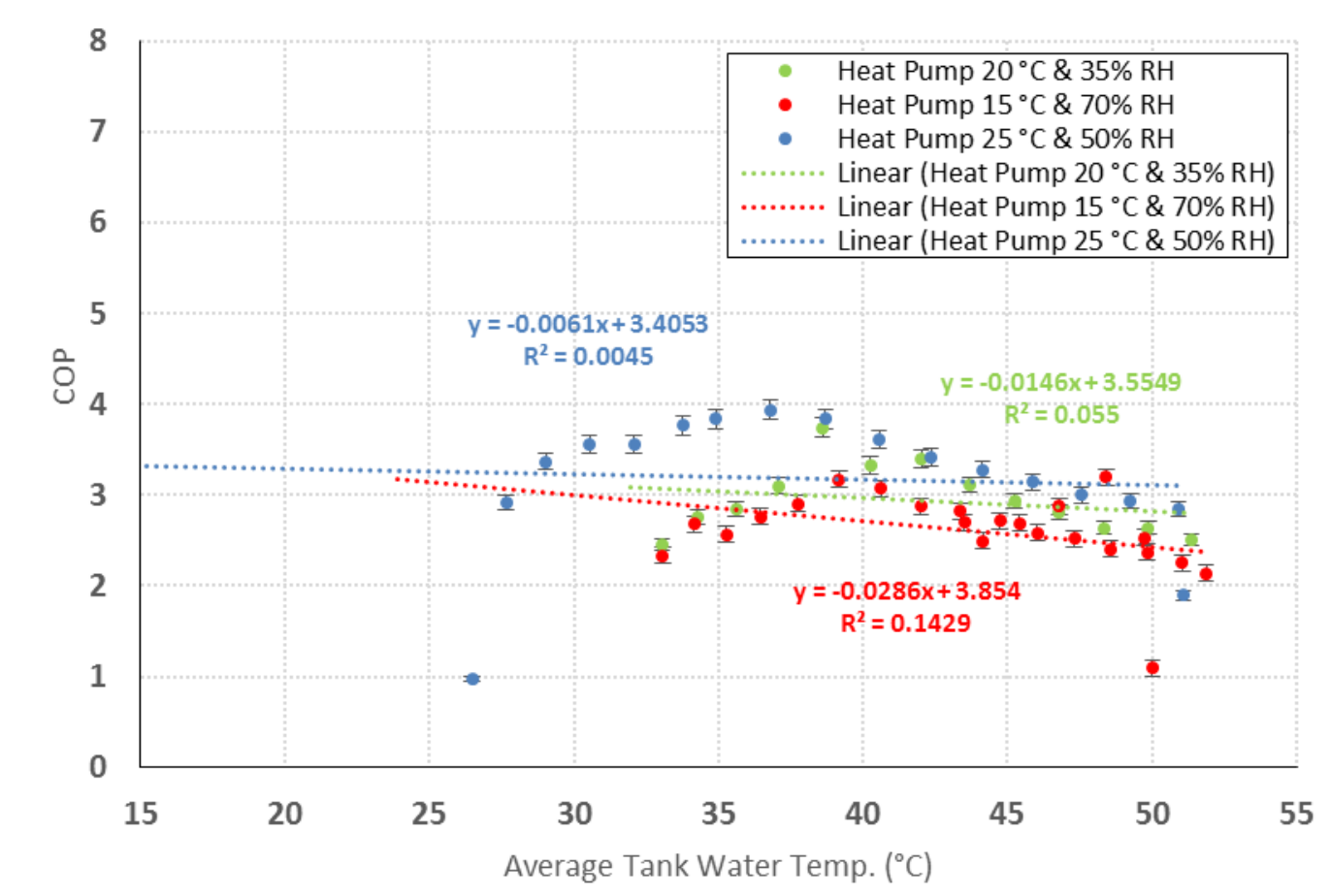

Figure 5-13: Performance curve for heat pump mode during heating up the tank from $16{ }^{\circ} \mathrm{C}$

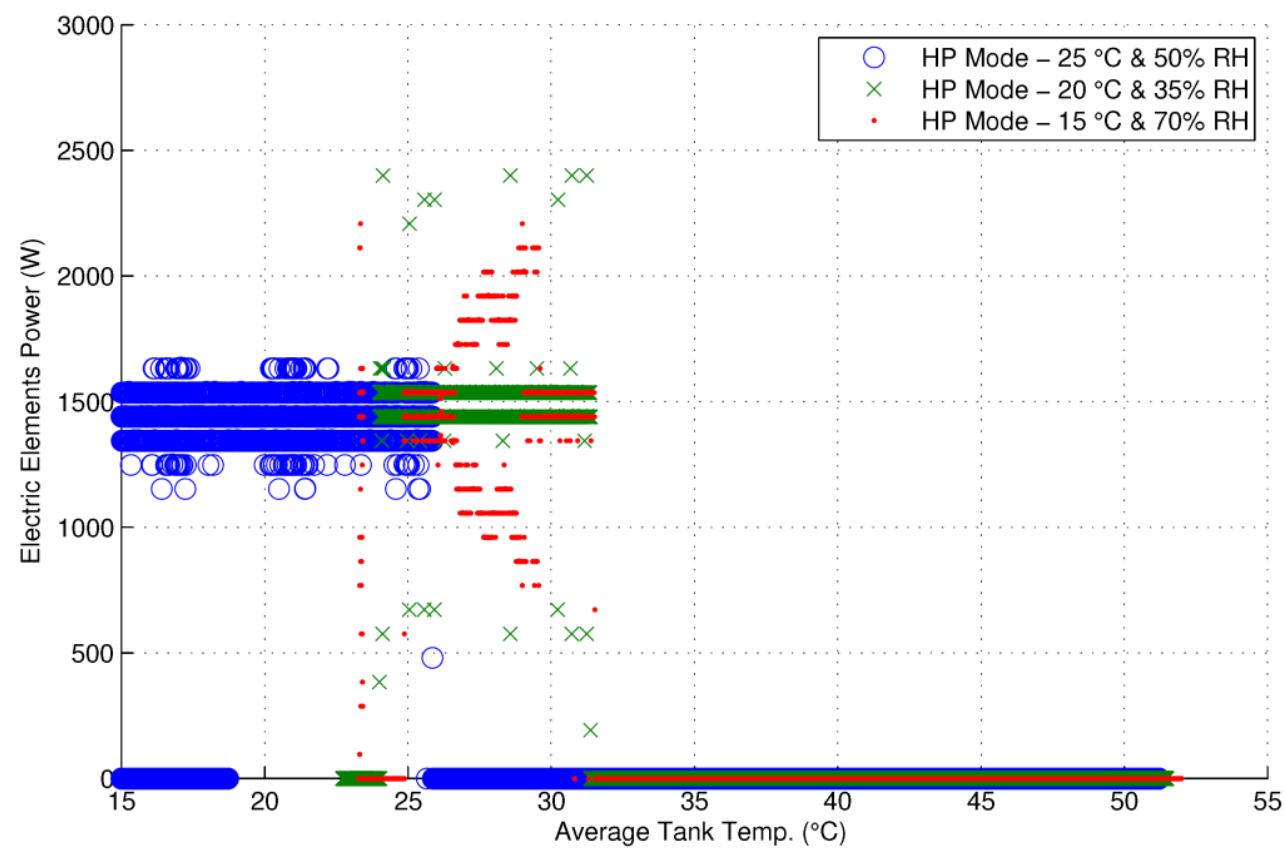

Figure 5-14: Electric element operation in HP mode

In hybrid mode (Figure 5-15), the heat pump is the primary heating source, however if the demand exceeds the predetermined level which causes the outlet water temperature drops $5{ }^{\circ} \mathrm{C}$ 
below the set point temperature or the staring temperature is less than $15^{\circ} \mathrm{C}$, the electric elements will heat up the water. At the beginning of HP operation, the consumed power of HP is a small value due to electric elements operation to the average tank temperature of $38{ }^{\circ} \mathrm{C}$, based on Figure 5-16. Therefore during this period, the ratio of transferred energy to the consumed power of the HP, i.e. COP, based on Equations (4-12) and (4-13) is a large number. Compared to the HP mode, in hybrid mode the electric elements operate for a wider range of temperature and until the water warms up to $38{ }^{\circ} \mathrm{C}$.

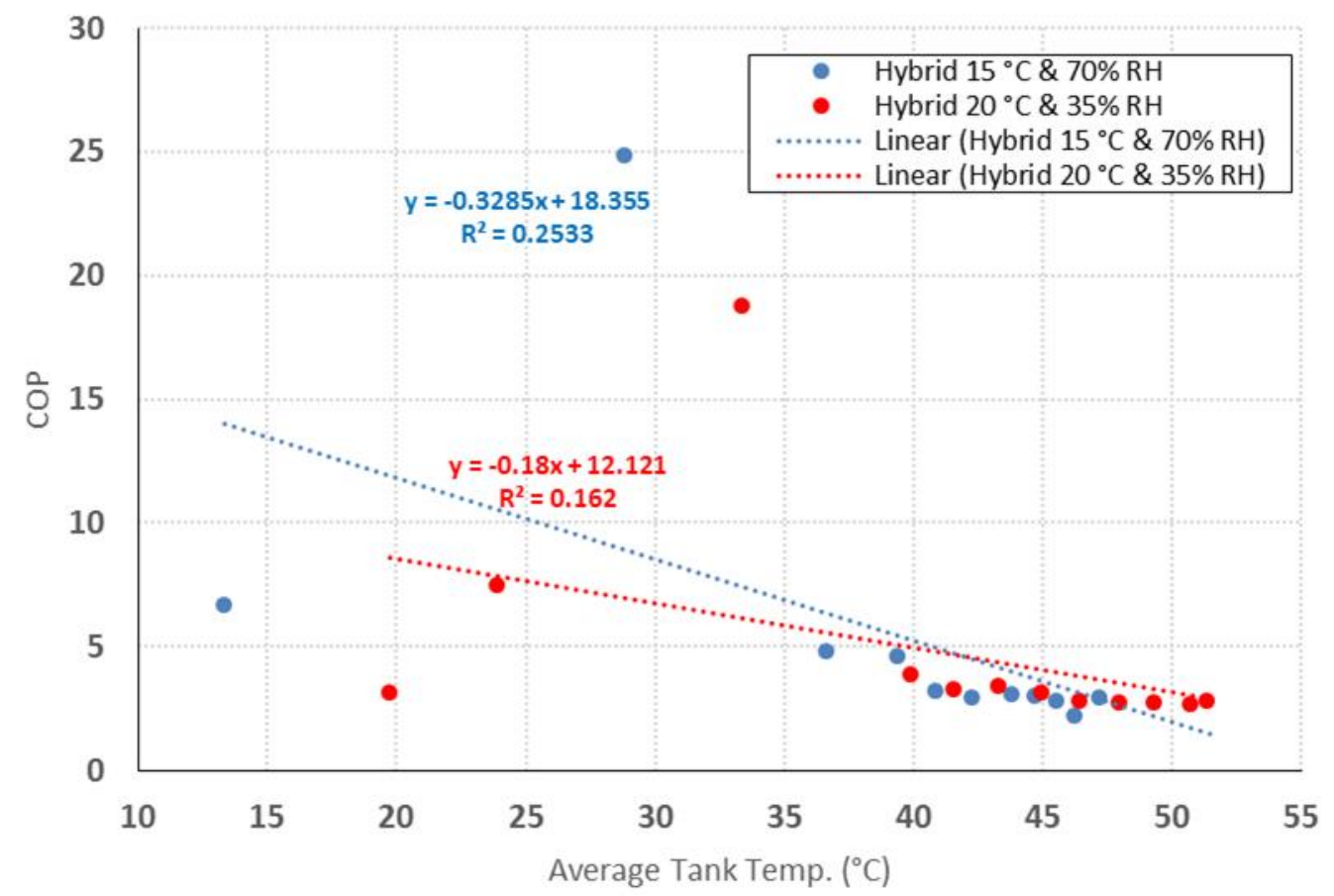

Figure 5-15: Performance curve for hybrid mode during heating the tank from $16{ }^{\circ} \mathrm{C}$ 


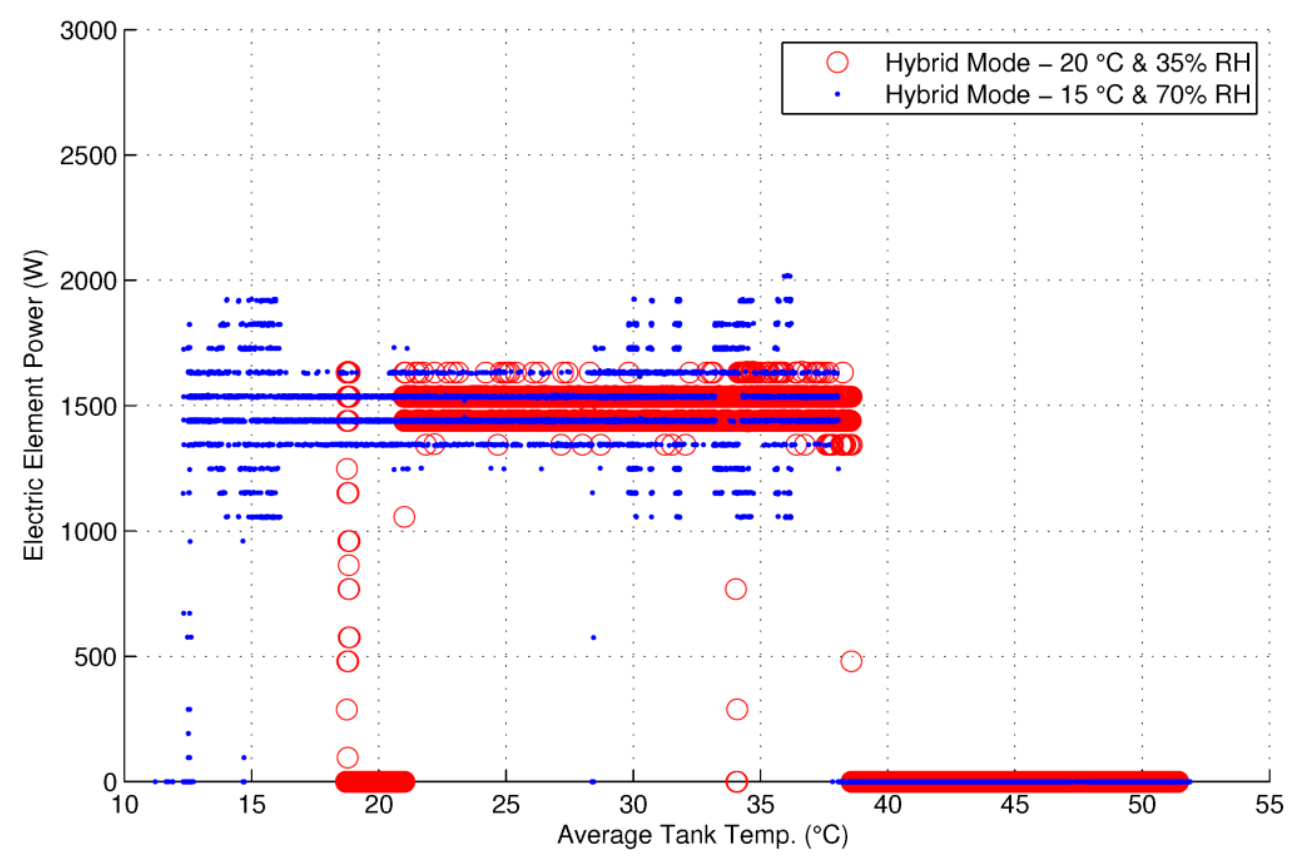

Figure 5-16: Electric element operation in hybrid mode

\subsection{Energy Factor}

Energy Factor (EF) is the added energy content of the water heater's water draw divided by the energy required to heat and maintain the water at set point temperature of the water heater (US DOE, 2000a, Aguilar et al., 2005). Therefore, the greater the EF the more efficient the system is based on the Natural Resources Canada Water Heater Guide (2012). Equations (5-1) and (5-2) express the method (Lutz et al., 1998) of calculating EF in this study using Equation (4-4).

$$
\begin{aligned}
& E F=\frac{\text { added energy content of water draw }}{\text { required energy to heat the water }}=\frac{\dot{m}_{\text {water. }} \cdot C_{p}\left(T_{\text {out }}-T_{\text {in }}\right)}{P_{A S H P}+P_{\text {Elec }}} \\
& E F=\frac{q \cdot \rho_{\text {water. }} \cdot C_{p}\left(T_{4}-T_{26}\right)}{P_{A S H P}+P_{E l e c}}
\end{aligned}
$$




\section{Room Condition: $15^{\circ} \mathrm{C} \& 70 \% \mathrm{RH}$}

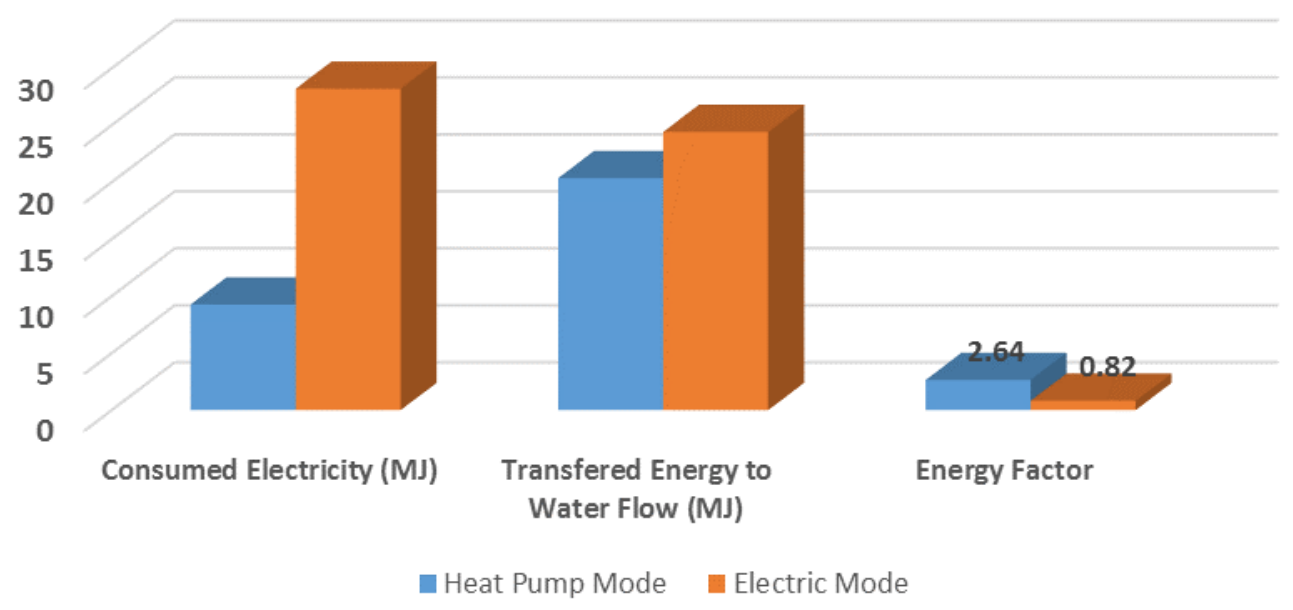

Figure 5-17: Energy Factor in HP and electricity modes in $15^{\circ} \mathrm{C}$ and $70 \% \mathrm{RH}$

Figures 5-17 and 5-18 compare the EF for the electric and HP modes for two different conditions of water draw schedule. Based on the results, the EF for $15{ }^{\circ} \mathrm{C}$ and $70 \% \mathrm{RH}$ is 2.64 for the heat pump mode and 0.82 for the electric mode which, based on the definition of EF, shows that while the useful transferred energy to the supplied water is similar, the value of consumed electrical energy for the electric mode is 2 to 3 times more than in the HP mode. For $25{ }^{\circ} \mathrm{C}$ and $50 \% \mathrm{RH}$, this value is equal to 3.7 for the heat pump mode and 1.35 for the electric mode which is similar to the $15{ }^{\circ} \mathrm{C}$ and $70 \% \mathrm{RH}$ condition. Due to the heat pump operation as shown in Figure 5-18, at some points during the electric mode, unlike the expectation, the EF for the electric mode which was expected to be less than 1 is greater than 1 , at $25{ }^{\circ} \mathrm{C}$ and $50 \% \mathrm{RH}$. In electric mode, $22 \%$ of total electricity is consumed by HP. The HP operates in $8 \%$ of the time while electric elements operate in $3.5 \%$ of the time. 


\section{Room Condition: $25^{\circ} \mathrm{C} \& 50 \% \mathrm{RH}$}

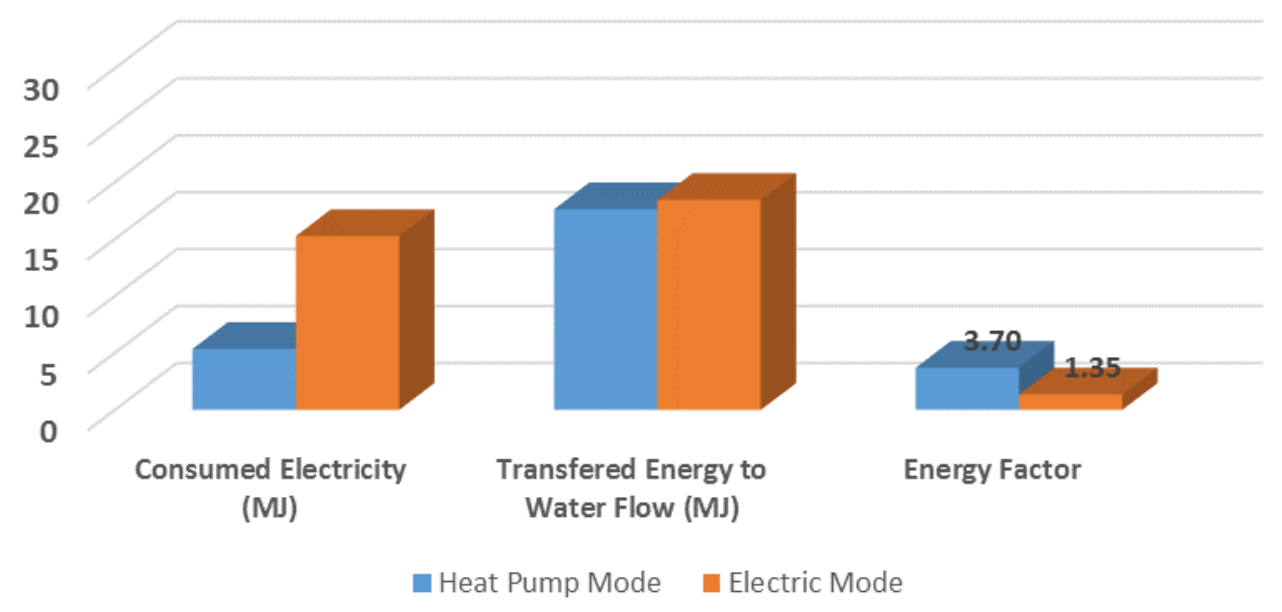

Figure 5-18: Energy Factor in HP and electricity modes in $25^{\circ} \mathrm{C}$ and $50 \% \mathrm{RH}$

\subsection{Electricity Cost Reduction}

In this research, the electric mode was considered as a representative of traditional electric water heater. In this section the cost associated with consumed electricity for each mode will be calculated. The electricity price used in the analysis is based on the total Ontario time of use rates presented in Figure 4-6. Tables 5-1 summarizes the results for the energy consumption and Table 5-2 summarizes electricity cost during two days of water draw for different modes in summer and winter using the experimental data. It is comprehensible from the results for $15{ }^{\circ} \mathrm{C}$ and $70 \% \mathrm{RH}$, in the hybrid and HP modes the electricity cost will be reduced by $64 \%$ and $51 \%$ on summer weekdays and $64 \%$ and $49 \%$ on winter weekdays, respectively. In hybrid mode compared to the HP mode, electric elements operate for longer times to achieve higher water temperature, therefore the saved electricity in hybrid mode is less than HP mode and consequently, the saved cost. Figure 5-20 shows the distribution of the water draw schedule in various TOU electricity price zones. 
Table 5-1: Energy consumption $(k W h)$ in 2-days water draw

\begin{tabular}{|l|c|c|c|}
\hline $\begin{array}{l}\text { Energy } \\
\text { Consumption } \\
(\mathrm{kWh})\end{array}$ & $\begin{array}{c}\text { Electric } \\
\text { Mode }\end{array}$ & HP Mode & $\begin{array}{c}\text { Hybrid } \\
\text { Mode }\end{array}$ \\
\hline $15^{\circ} \mathrm{C} \& 70 \% \mathrm{RH}$ & 9.34 & 3.56 & 5.05 \\
\hline $20^{\circ} \mathrm{C} \& 35 \% \mathrm{RH}$ & N/A & 3.98 & 4.19 \\
\hline $25^{\circ} \mathrm{C} \& 50 \% \mathrm{RH}$ & 7.66 & 3.60 & N/A \\
\hline
\end{tabular}

N/A: No experimental data is available.

Table 5-2: Water heater electricity cost (\$) in 2-days water draw

\begin{tabular}{|l|c|c|c|c|c|c|}
\hline & $\begin{array}{c}\text { Electric } \\
\text { Mode } \\
\text { (Summer) }\end{array}$ & $\begin{array}{c}\text { Electric } \\
\text { Mode } \\
\text { (Winter) }\end{array}$ & $\begin{array}{c}\text { HP Mode } \\
\text { (Summer) }\end{array}$ & $\begin{array}{c}\text { HP Mode } \\
\text { (Winter) }\end{array}$ & $\begin{array}{c}\text { Hybrid } \\
\text { Mode } \\
\text { (Summer) }\end{array}$ & $\begin{array}{c}\text { Hybrid } \\
\text { Mode } \\
\text { (Winter) }\end{array}$ \\
\hline $15^{\circ} \mathrm{C} \& 70 \% \mathrm{RH}$ & 2.04 & 1.96 & 0.74 & 0.71 & 1.00 & 0.99 \\
\hline $20^{\circ} \mathrm{C} \mathrm{\&} \mathrm{35 \%} \mathrm{RH}$ & N/A & N/A & 0.84 & 0.79 & 0.88 & 0.83 \\
\hline $25^{\circ} \mathrm{C} \mathrm{\&} \mathrm{50 \%} \mathrm{RH}$ & 1.57 & 1.53 & 0.75 & 0.71 & N/A & N/A \\
\hline
\end{tabular}

N/A: No experimental data is available.

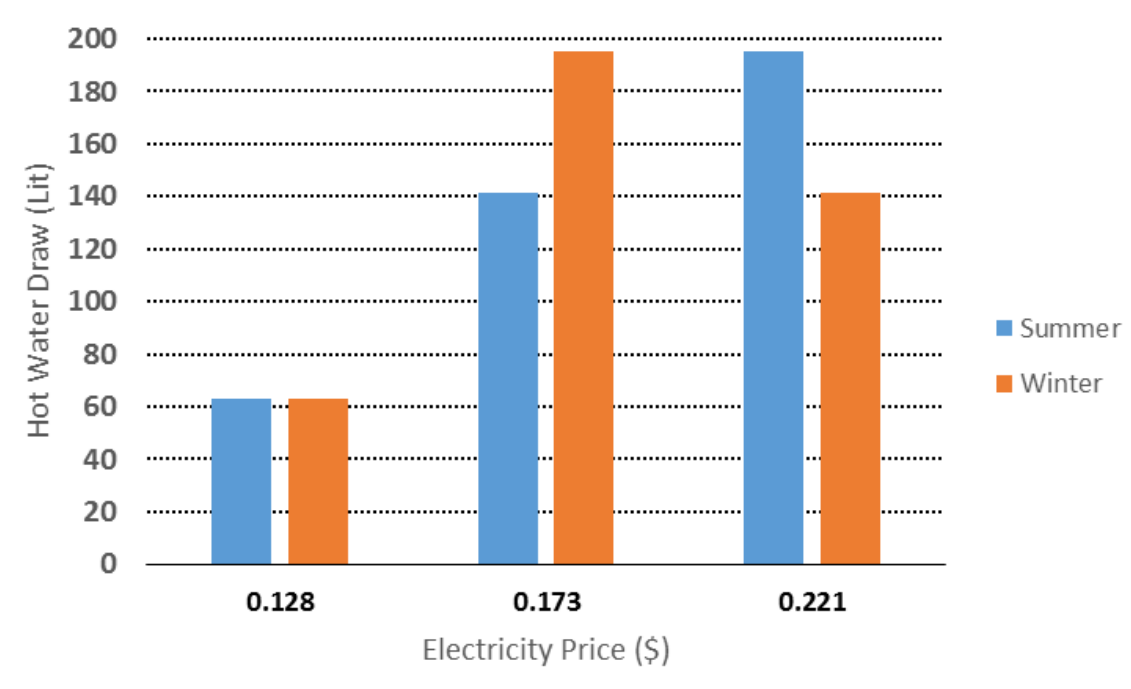

Figure 5-19: The price distribution of the experiment's water draw schedule 


\section{Chapter 6: TRNSYS Simulation}

TRNSYS is a software package for the transient simulation of systems including multi-zone buildings, control strategies, alternative energy systems, etc. (TRNSYS 17 manual, 2012). In this chapter, the results of two TRNSYS models will be presented. Namely, a model of ASHPWH with electric elemetns (Model 1) and a model of an electric water heater (Model 2). Both these models are connected to a house model as will be explained in what follows. Once the models are validated with the experimental results, the simulations associated with summer and winter seasons will be discussd. These simulations were required to investigate the potential benefits of ASHPWH in lowering the required annual energy consumption, its corresponding costs and GHG emissions. Finally, the potential of using this system in five major Canadian cities will be investigated.

\subsection{Model Verification}

In order to characterize the heat pump water heater performance (including heat pump without electric elements) in the model, COP results from different experiments were used as inputs for the water heater type in the Simulation Studio. The input file includes the thermal energy input and output of the heat pump water heater based on air temperature and relative humidity as well as average water temperature of the tank. For verification purposes, Figures 6-1, 6-2 and 6-3 compare the results of various simulations with those analyzed based on the experimental data, in which COP has been calculated every 15 minutes. At the beginning of the heat pump operation, it takes time for the HP to reach to its highest power capacity and therefore its power consumption was small. As a result the values of the calculated COP were unphysically large and thus have been excluded from these plots. Yet, a few outliers with higher COP values may be detected in these figures which might be due to an abrupt increase in the water draw from the tank. As suggested by Figures 6-1 and 6-2, there is a slight difference between the experiment and simulation graphs which may be a consequence of $2.8 \%$ error in the experimental data, as well as the simplifications of the model due to assumptions mentioned in Section 4.6. 


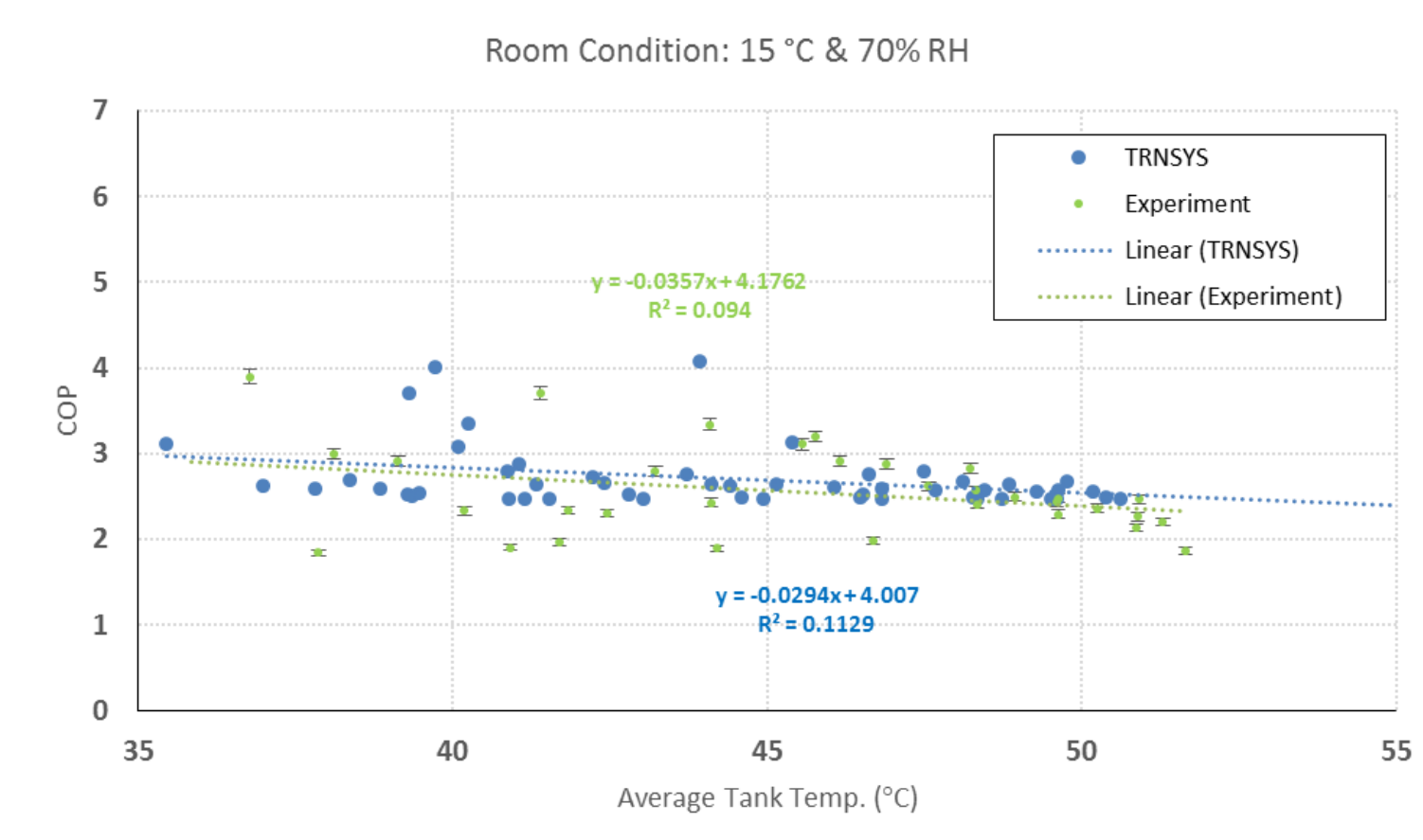

Figure 6-1: Performance curve at $15{ }^{\circ} \mathrm{C}$ and $70 \% \mathrm{RH}$ for two days of water draw

Room Condition: $20^{\circ} \mathrm{C} \& 35 \% \mathrm{RH}$

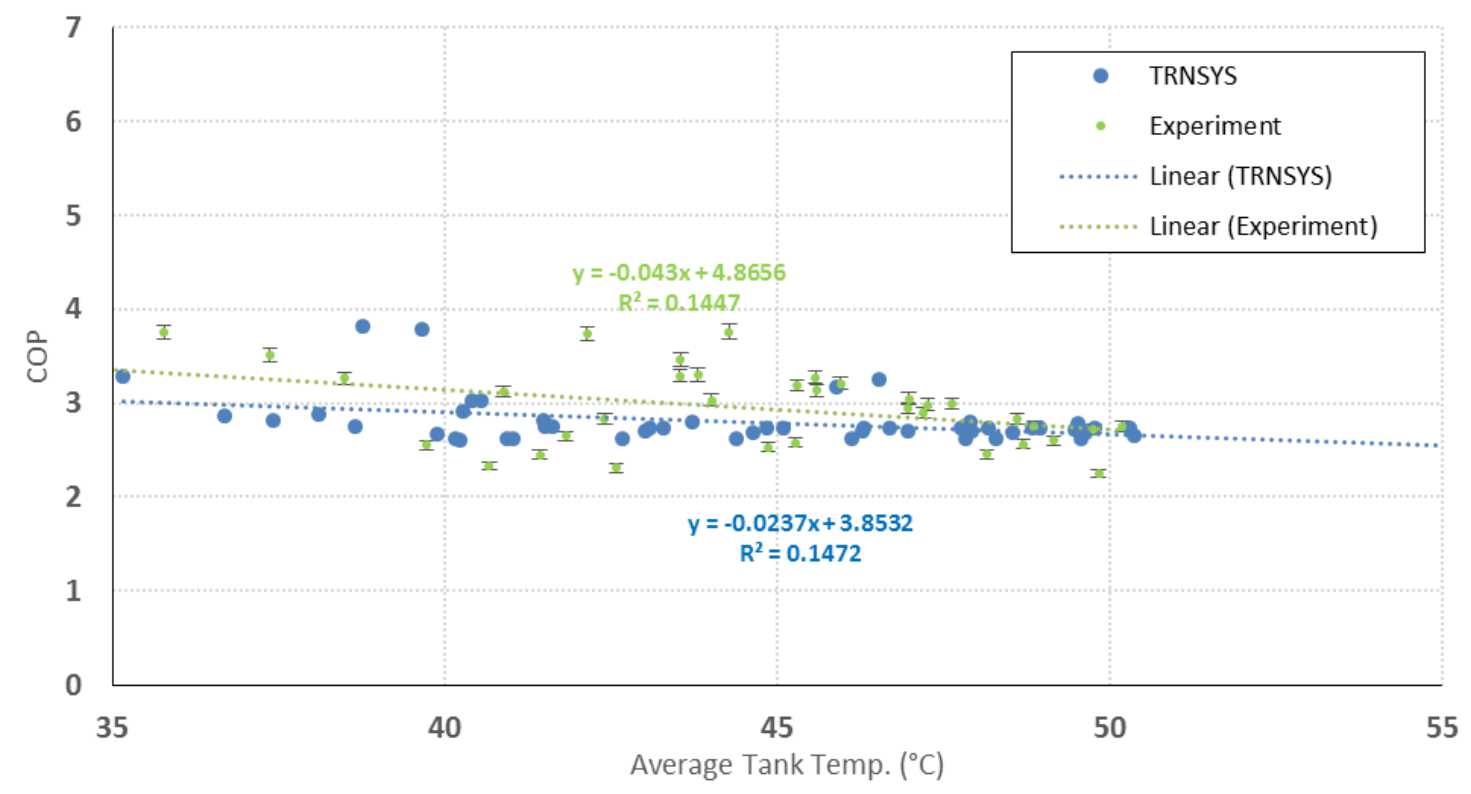

Figure 6-2: Performance curve at $20^{\circ} \mathrm{C}$ and $35 \% \mathrm{RH}$ for two days of water draw 


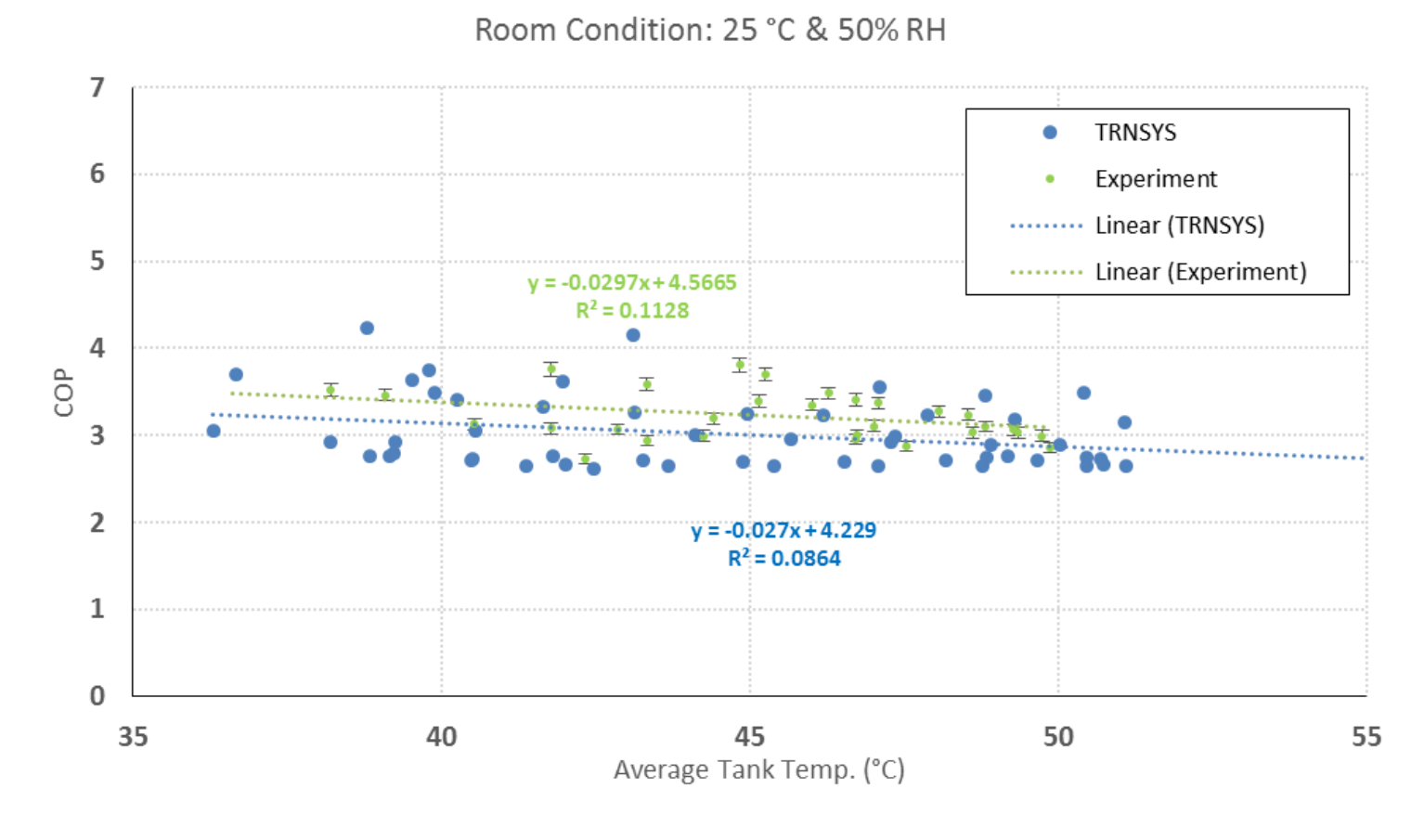

Figure 6-3: Performance curve at $25{ }^{\circ} \mathrm{C}$ and $50 \% \mathrm{RH}$ for two days of water draw

Another parameter that needs to be validated in the model by the experimental data is outlet temperature of the water tank and the selected control temperature range. By considering the provided information by the manufacturer, different set point temperatures as well as dead bands for heat pump water heater and electric elements were tested. The purpose of these tests was to ensure that the outlet water temperature in the model lies within the experimental range. Finally, the setpoint temperature for the HP and electric heaters were set to $54{ }^{\circ} \mathrm{C}$ and $50{ }^{\circ} \mathrm{C}$ respectively with dead bands of $1.7{ }^{\circ} \mathrm{C}$ and $0{ }^{\circ} \mathrm{C}$ respectively. As it is shown in Figures 6-4, 6-5 and 6-6, the outlet temperature of the tank in different indoor conditions is indeed in the range of the experimental data $\left(49.5^{\circ} \mathrm{C}\right.$ to $\left.55.9^{\circ} \mathrm{C}\right)$. Therefore the selected set point temperatures as well as their corresponding dead bands are acceptable in the TRNSYS model. It should be noted that the time steps between experiment and TRNSYS model are different which implies that the water draws are also based on different time steps as explained previously in Section 3.5. The minimum model temperature happens when the maximum water draw flow rate (10.64 litre/min) occurs in 5-minute time steps associated with the water draw in the simulations. In the experiment, the water draw value is less (6.06 litre/min) at the same time. As a result of these differences in the flow 
rates, there apprears to be a relatively large inconsistency between the experiment and simulation temperature at the simulation time of $3446.5 \mathrm{hr}$.

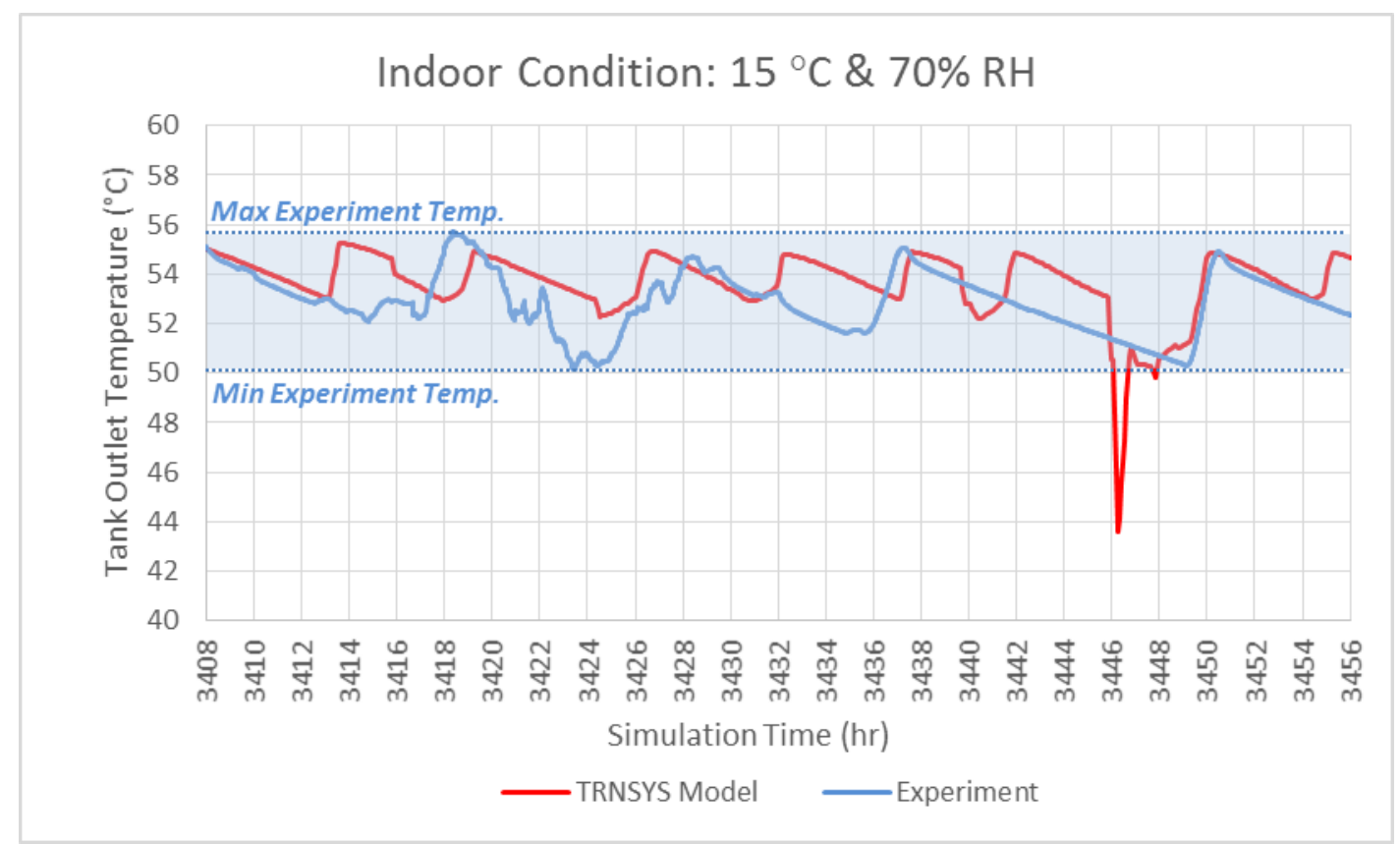

Figure 6-4: Temperature of outlet water at $15{ }^{\circ} \mathrm{C}$ and $70 \% \mathrm{RH}$ for two days of water draw

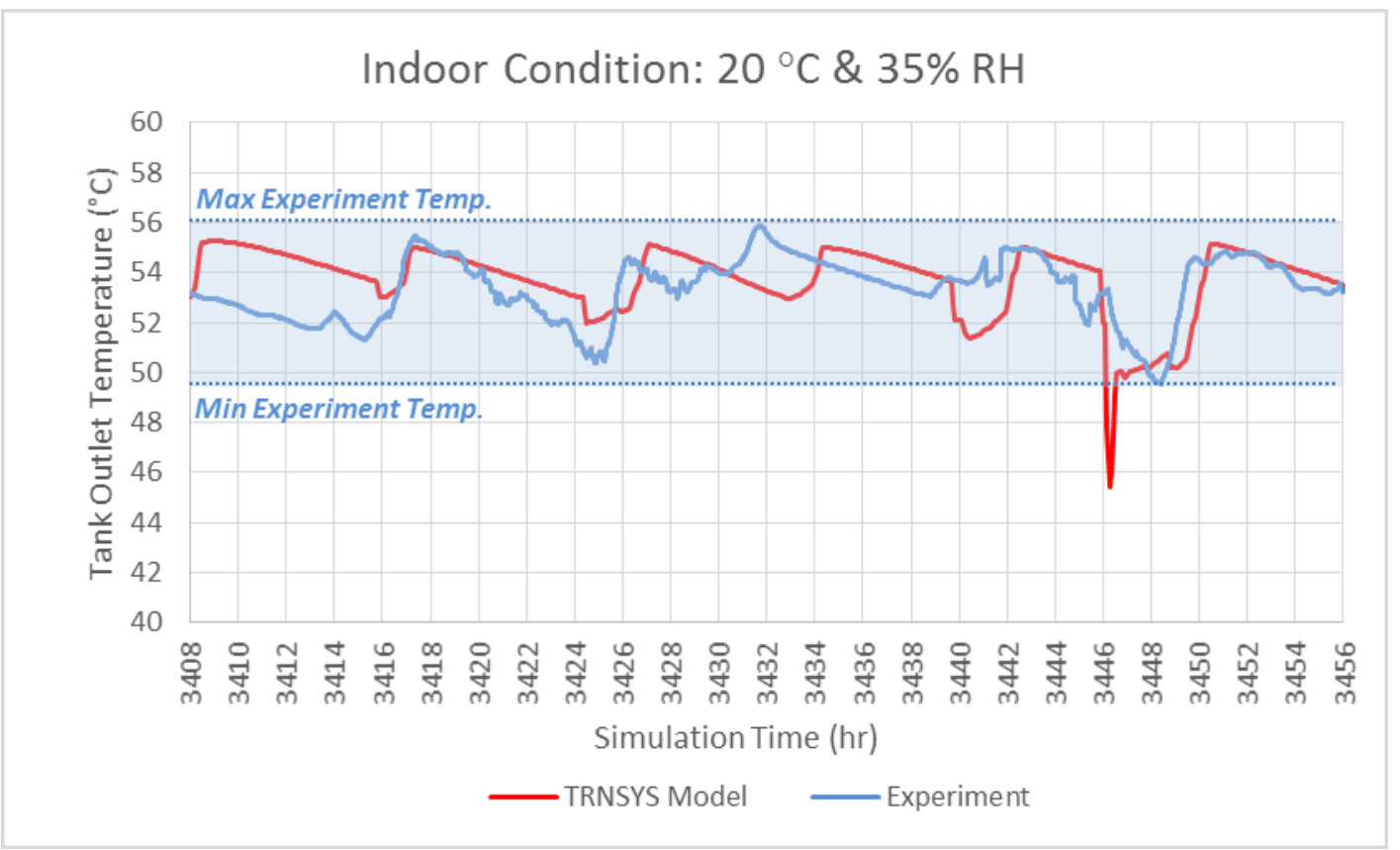

Figure 6-5: Temperature of outlet water at $20^{\circ} \mathrm{C}$ and $35 \% \mathrm{RH}$ for two days of water draw 


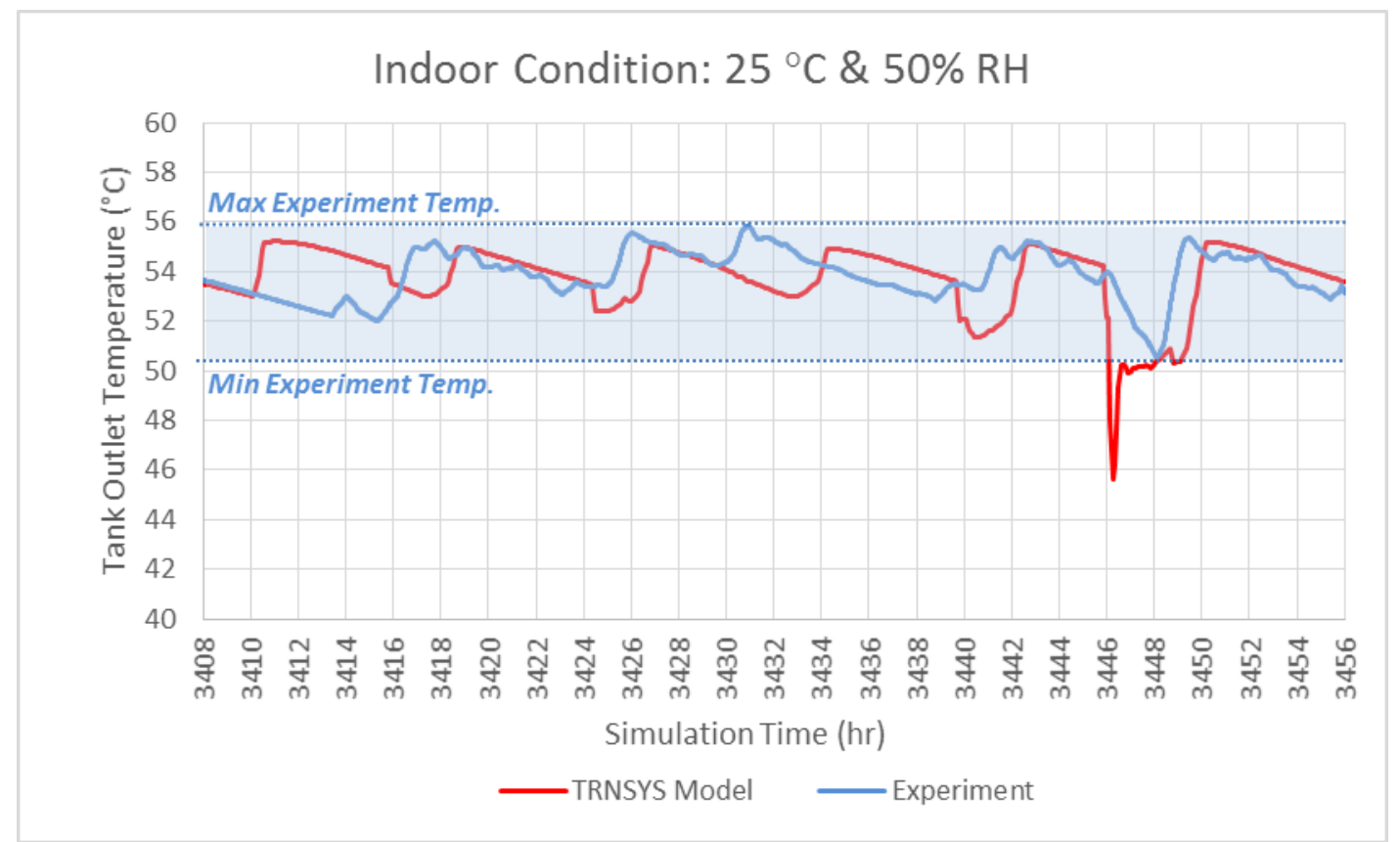

Figure 6-6: Temperature of outlet water at $25{ }^{\circ} \mathrm{C}$ and $50 \% \mathrm{RH}$ for two days of water draw

\subsection{Outlet Temperature and Thermal Energy}

In order to evaluate the capability of the system in keeping the water temperature at a defined set point, the model ran for March and September, which have the coldest and warmest inlet water temperatures during the year based on Figure 3-8. The initial temperatures for all the 6 nodes were inputed as $55^{\circ} \mathrm{C}$ in order to start modelling the system from a steady state condition. Figures 6-7 and 6-8 show the results for outlet water temperature and the working schedule of the electric heaters and HP in March and September respectively. As the graphs display, when the maximum water draw (10.64 litre/min) happens in the second day of draw schedule, the temperatures drop below the setpoint temperature of the electric heater, and the system can recover the tank outlet temperature by using electric resistances in addition to the HP. Excluding the maximum water draw, the system works close to the control range in other draws which shows the acceptable HP operation. Since the inlet water temperature in March $\left(4{ }^{\circ} \mathrm{C}\right)$ is lower than in September $\left(15^{\circ} \mathrm{C}\right)$, the minimum temperature as well as the fluctuation of water temperature is larger in March. The typical power draw for HP and each electric element are about $630 \mathrm{~W}$ and 1500W. The system can recover the tank outlet temperature by using the HP and electric elements for $25.5 \%$ and $1.04 \%$ of the time in September, and 35.9\% and 1.4\% in March respectively. 


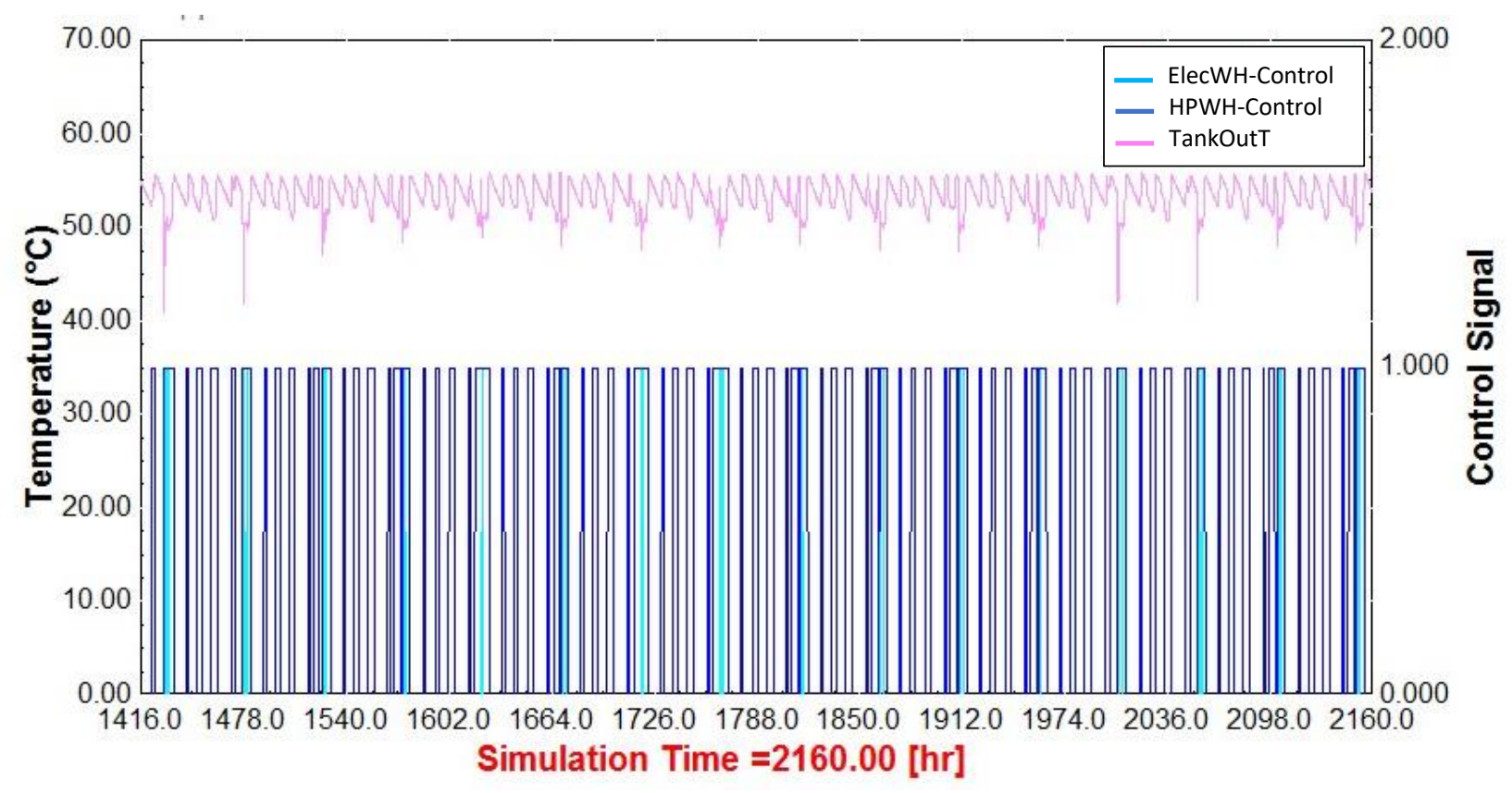

Figure 6-7: Tank outlet temperature and control signals in March

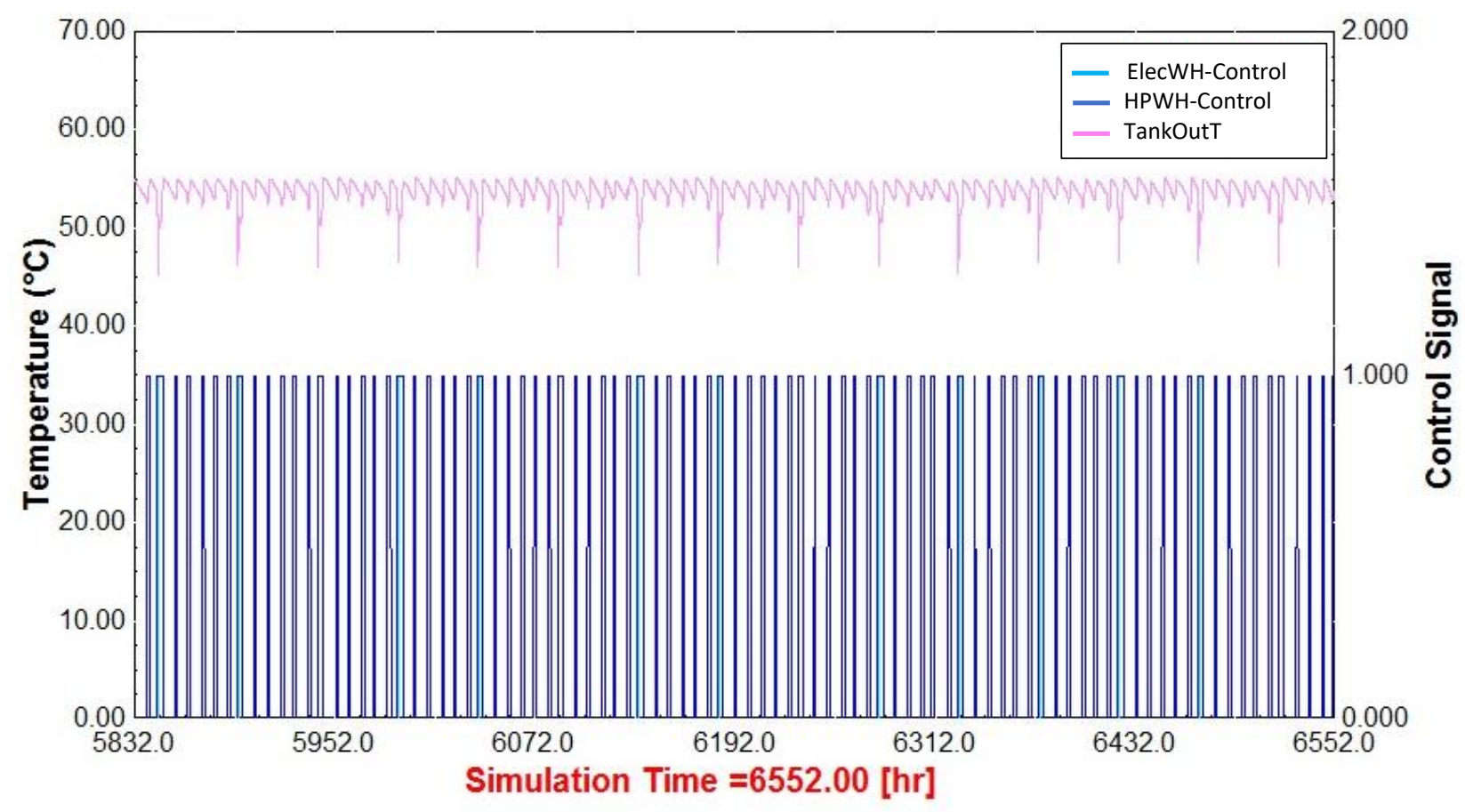

Figure 6-8: Tank outlet temperature and control signals in September

Figure 6-9 illustrates the distribution of thermal energy generation and electrical energy consumption between the electric heaters and HP annually. The maximum and minimum of the thermal energy output and input for both electric elements and HP happen in March and September 
respectively. The difference between maximum and minimum of the ASHPWH thermal output and input will be increased by $27 \%$ and $42 \%$ respectively in March compared to September. The results show that the electric heaters only generate between $7 \%$ to $13 \%$ of total required thermal demand and the major part is produced by the HP. By analysing the control data for two different electric heaters' set point temperatures, $40{ }^{\circ} \mathrm{C}$ and $50{ }^{\circ} \mathrm{C}$, the percentages of each component's operation time are summarized in Table 6-1. Based on the results, for electric heaters' set point temperature of $40{ }^{\circ} \mathrm{C}$, the operation of the electric heater can be completely eliminated, and the ASHPWH can individually heat up the water to the required set point temperature.

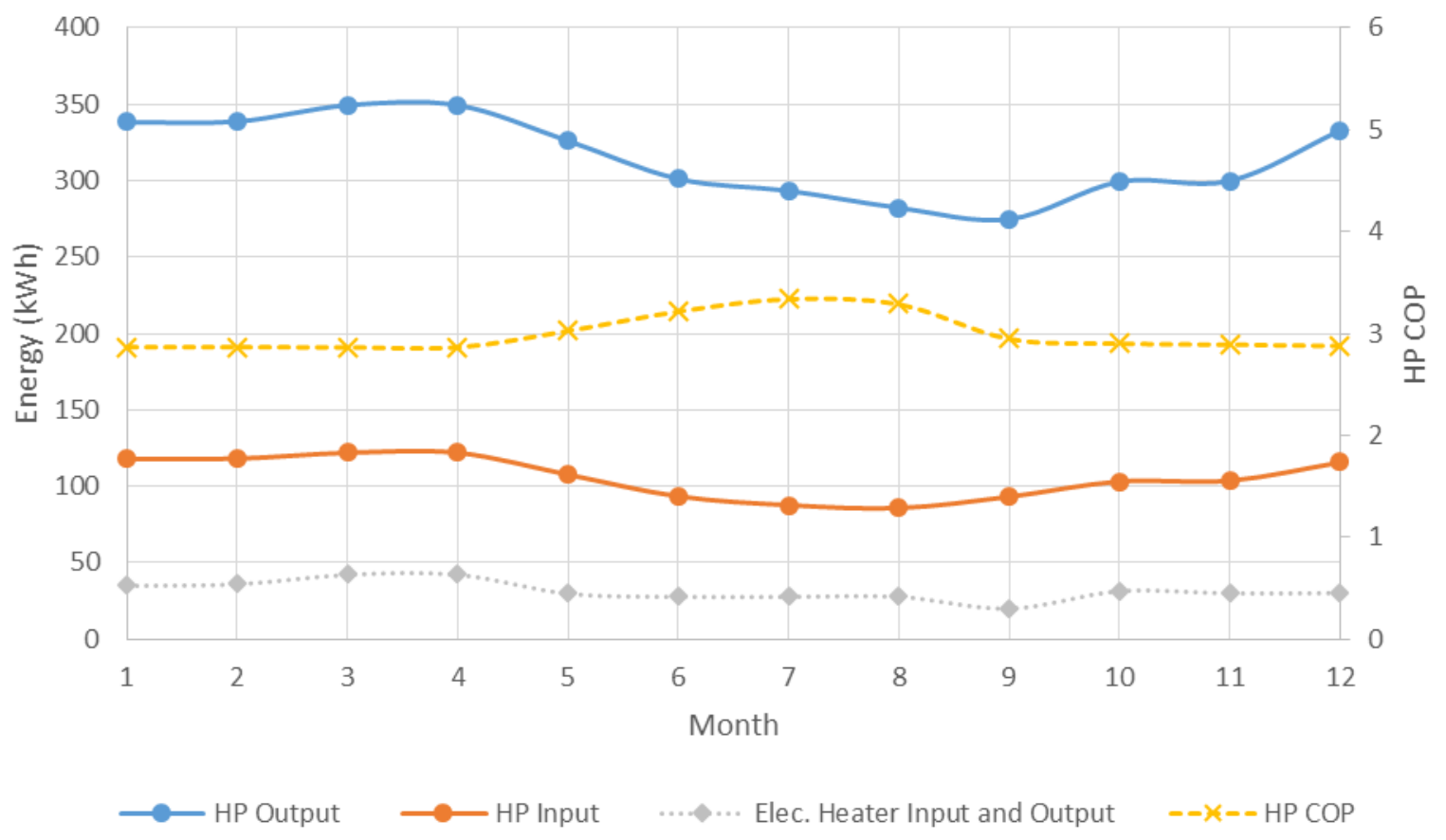

Figure 6-9: ASHPWH thermal energy generation and electrical energy consumption

Table 6-1: Percentages of HP and electric heaters operation time in one year

\begin{tabular}{|c|c|c|c|c|c|c|c|}
\hline \multicolumn{2}{|c|}{ Electric Heaters Set Point T $=5{ }^{\circ} \mathbf{C}$} & \multicolumn{3}{c|}{ Electric Heaters Set Point T $=\mathbf{4 0}^{\circ} \mathbf{C}$} \\
\hline \multicolumn{2}{|c|}{ Summer } & \multicolumn{2}{|c|}{ Winter } & \multicolumn{2}{c|}{ Summer } & \multicolumn{2}{c|}{ Winter } \\
\hline HP & Electric & HP & Electric & HP & Electric & HP & Electric \\
\hline $25.3 \%$ & $1.1 \%$ & $30.9 \%$ & $1.6 \%$ & $27.3 \%$ & $0.0 \%$ & $34.1 \%$ & $0.3 \%$ \\
\hline
\end{tabular}




\subsection{Tank Insulation}

The overall heat transfer coefficient of the tank, calculated in Section 4.2 based on the experimental data, is equal to $0.877 \mathrm{~W} / \mathrm{m}^{2}-{ }^{\circ} \mathrm{C}(\mathrm{R}$-value=6.475). By decreasing the U-value, it is expected that the heat loss from the tank reduces and consequently the ASHPWH consumes less electricity. The simulation for the ASHPWH (Model 1) was performed for different R-values of R-10, R-15 and R-20 in order to calculate the potential energy saving from reducing U-value (increasing R-value) compared to the existing R-value (6.475 h. ${ }^{\circ}$ F.ft $\left.{ }^{2} / \mathrm{BTU}\right)$. Table 6-2 summarizes the ASHPWH power consumption with different R-values. The results in Table 6-3 shows that by increasing the R-value from 6.475 to R-20 (h. $\left.{ }^{\circ} \mathrm{F} . \mathrm{ft}^{2} / \mathrm{BTU}\right)$ the consumed electricity for heating up the required water can be reduced up to $8.85 \%$ and $9.89 \%$ in summer and winter respectively.

Table 6-2: Power consumption for different $R$-values

\begin{tabular}{|l|l|c|c|c|c|}
\hline \multicolumn{2}{|l|}{ Tank Insulation $\left(\mathrm{h} .{ }^{\circ} \mathrm{F}^{\mathrm{ft}}{ }^{2}\right) / \mathrm{BTU}$} & 6.475 & $\mathrm{R}-10$ & $\mathrm{R}-15$ & $\mathrm{R}-20$ \\
\hline \multirow{2}{*}{$\begin{array}{l}\text { ASHPWH Power } \\
\text { Consumption }(\mathrm{kWh})\end{array}$} & Summer & 486 & 473 & 461 & 443 \\
\cline { 2 - 6 } & Winter & 1153 & 1083 & 1041 & 1039 \\
\cline { 2 - 6 } & Annual & 1639 & 1556 & 1502 & 1482 \\
\hline
\end{tabular}

Table 6-3: Power consumption reduction due to increased $R$-value

\begin{tabular}{|l|l|c|c|c|}
\hline \multicolumn{2}{|l|}{ Tank Insulation (h. ${ }^{\circ} \mathrm{F}_{\mathrm{fft}}{ }^{2}$ )/BTU } & $\mathrm{R}-10$ & $\mathrm{R}-15$ & $\mathrm{R}-20$ \\
\hline \multirow{2}{*}{$\begin{array}{l}\text { ASHPWH Power } \\
\text { Consumption Reduction (\%) }\end{array}$} & Summer & 2.67 & 5.14 & 8.85 \\
\cline { 2 - 5 } & Winter & 6.07 & 9.71 & 9.89 \\
\cline { 2 - 5 } & Annual & 5.06 & 8.36 & 9.58 \\
\hline
\end{tabular}

\subsection{Electricity Saving}

As mentioned in the previous chapters, ASHPWH absorbs the heat from indoor air, therefore it can affect the overall heating/cooling load of the house. By integrating both the ASHPWH model as well as electric water heater in two separate models with the same House A cooling/heating system, the overall change in electricity consumption result from ASHPWH operation has been investigated for House A by using Toronto weather data.

The result, tabulated in Table 6-4, shows that as expected, using the ASHPWH can reduce cooling electricity and increase the heating electricity consumption compared to the model with 
electric water heater. However, the overall ASHP combined heating and cooling electricity consumption will be increased anually by $3 \%$. Since the hot water production related electricity consumption in both summer and winter will be reduced, the results show that overall the annual combined space heating, cooling and DHW heating electricity consumption can be reduced by $21.3 \%$ (1891 kWh) for a sustainable house with an average 200 litre/day hot water demand located in Toronto. The difference in DHW energy consumption of Model 1 and 2 (1309 kWh in winter and $739 \mathrm{kWh}$ in summer) is equal to the absorbed heat from the indoor air by ASHPWH. In order to compensate this absorbed heat, the air source heat pump should operate more during winter (299 $\mathrm{kWh})$ and less during summer $(142 \mathrm{kWh})$. Hence the ratio of the reduction in the DHW electricity consumption to the change in the heating/cooling energy consumption yields the approximate COP of ASHP.

Table 6-4: House A electricity consumption breakdown in Toronto weather

\begin{tabular}{|l|c|c|c|c|}
\hline \multirow{2}{*}{} & \multicolumn{2}{|c|}{ Electricity Consumption (kWh) } & Electricity Reduction \\
\cline { 2 - 5 } & $\begin{array}{c}\text { Model 2 (Electric } \\
\text { Water Heater) }\end{array}$ & Model 1 (ASHPWH) & Saved Electricity $(\%)$ \\
\hline Summer Cooling & 383 & 241 & 142 & 37.1 \\
\hline Winter Heating & 4804 & 5103 & -299 & -6.2 \\
\hline Annual Heating/Cooling & 5187 & 5344 & -157 & -3.0 \\
\hline Summer DHW & 1225 & 486 & 739 & 60.3 \\
\hline Winter DHW & 2462 & 1153 & 1309 & 53.2 \\
\hline Annual DHW & 3687 & 1639 & 2048 & 55.5 \\
\hline Total Consumed Electricity & $\mathbf{8 8 7 4}$ & $\mathbf{6 9 8 3}$ & $\mathbf{1 8 9 1}$ & $\mathbf{2 1 . 3}$ \\
\hline
\end{tabular}

The heat transfer from the ASHPWH including the HP and electric elements to the water inside the tank will be devided in two parts. One part is heat loss from the tank to the environment and the other part is the heat transfer to the water inside the tank. EF, as described in Section 5.5, is the ratio of energy delivered to hot water via HP and electric elements to the total electricity consumption by both HP and electric heaters. Tables 6-5 and 6-6 summarize respectively the heat loss, delivered energy to water and Energy Factros for ASHPWH and electric water heater during both summer and winter. Based on these tables, the EF for summer is larger than for winter and it is a result of different indoor set point temperatures as well as water supply temperature in different seasons. The total heat loss is $6 \%$ and $11 \%$ of total generated energy by ASHPWH in summer and winter respectively. For Model 2 (electric water heater) the total heat loss is $7 \%$ and $5 \%$ of the total generated energy by the electric water heater in summer and winter, respectively. The difference between two models in terms of their heat loss is due to the heat loss of the heat pump 
coil. In addition, the temperature of the top wall of the tank in ASHPWH is in contact with the outlet air of evaporator which is colder than indoor air.

Table 6-5: Energy Factor and heat loss of ASHPWH

\begin{tabular}{|l|c|c|c|}
\hline Model 1 (ASHPWH) & Summer & Winter & Annual \\
\hline Heat Loss (kWh) & 71 & 268 & 339 \\
\hline $\begin{array}{l}\text { Energy Delivered to Water in } \\
\text { Tank (kWh) }\end{array}$ & 1169 & 2483 & 3652 \\
\hline $\begin{array}{l}\text { Heat Transfer to Tank via HP } \\
\text { and Elec. Heater (kWh) }\end{array}$ & 1240 & 2489 & 3729 \\
\hline Electricity Consumption $(\mathrm{kWh})$ & 486 & 1153 & 1639 \\
\hline Energy Factor & 2.41 & 2.15 & 2.23 \\
\hline
\end{tabular}

Table 6-6: Energy Factor and heat loss of electric water heater

\begin{tabular}{|l|c|c|c|}
\hline Model 2 (Electric WH) & Summer & Winter & Annual \\
\hline Heat Loss (kWh) & 85 & 120 & 205 \\
\hline $\begin{array}{l}\text { Energy Delivered to Water in } \\
\text { Tank (kWh) }\end{array}$ & 1140 & 2342 & 3482 \\
\hline $\begin{array}{l}\text { Heat Transfer to Tank via HP } \\
\text { and Elec. Heater (kWh) }\end{array}$ & 1225 & 2462 & 3687 \\
\hline Electricity Consumption $(\mathrm{kWh})$ & 1225 & 2462 & 3687 \\
\hline Energy Factor & 0.93 & 0.95 & 0.94 \\
\hline
\end{tabular}

\subsection{Electricity Cost Saving}

The total electricity savings calculated in this research have been caused by the reduction in heating/cooling as well as hot water heater energy consumption. The TOU electricity rates and delivery rates, described in Section 4.5, have been entered in the model by adding an hourly forcing function scheduler type. The calculated annual electricity cost as well as savings comparing the electric water heater and the ASHPWH can be seen in Table 6-7. The space heating electricity consumption increased in winter compared to the scenario with electric heaters; therefore, the electricity costs related to the winter heating have also risen, but in total it is evident from the simulation results that using ASHPWH can reduce the annual electricity bills for customers. Besides the performance improvement, the financial aspect of using this system can motivate the customers to replace their conventional equipment with this relatively new system. If we assume 
the prices of electric water heater and ASHPWH are $\$ 600$ and $\$ 1850$ (CAD) respectively, the payback period for returning the initial investement for ASHPWH is 3.7 years.

Table 6-7: Cost reduction breakdown

\begin{tabular}{|c|c|c|c|c|}
\hline & \multicolumn{2}{|c|}{ Electricity Cost (\$) } & \multirow[b]{2}{*}{$\begin{array}{l}\text { Electricity Cost } \\
\text { Reduction (\$) }\end{array}$} & \multirow[b]{2}{*}{ Saved Cost (\%) } \\
\hline & $\begin{array}{l}\text { Model } 2 \text { (Electric } \\
\text { Water Heater) }\end{array}$ & Model 1 (ASHPWH) & & \\
\hline Summer Cooling & 70 & 44 & 26 & 37.1 \\
\hline Winter Heating & 783 & 834 & -51 & -6.5 \\
\hline Annual Heating/Cooling & 853 & 878 & -25 & -2.9 \\
\hline Summer DHW & 217 & 87 & 130 & 59.9 \\
\hline Winter DHW & 434 & 208 & 226 & 52.1 \\
\hline Annual DHW & 651 & 295 & 356 & 54.7 \\
\hline Total Electricity Cost & 1504 & 1173 & 331 & 22.0 \\
\hline
\end{tabular}

At the moment, natural gas water heater $(\mathrm{NGWH})$ is most commonly used for the domestic hot water production in typical Canadian houses (NRCan, 2011). Here the potential electricity cost saving associated with replacing the natural gas water heater with a heat pump water heater will be estimated. We will consider a typical Canadian house with a natural gas boiler-furnace for heating and central air conditioner for cooling in which the daily hot water demand is assumed to be 200 litre/day. The parameters for this estimation are listed in Table 6-8. If the ASHPWH studied in this research with the COP of around 3 in winter and 3.5 in summer is employed instead of NGWH with an assumed efficiency of 0.55 , the overall natural gas consumption cost would be increased by $16 \%$ in winter and it would be decreased by $90 \%$ in summer (note that all the cooling effect is assumed to be used for cooling down the house). The results for the electricity cost reduction are summarized in Table 6-9. If we further assume that the price of NGWH and ASHPWH are $\$ 700$ and $\$ 1850$ (CAD) respectively, the payback period for returning the initial investement for ASHPWH is approximately 22 years. This relatively long payback period is primarily due to the current cheap costs of natural gas. 
Table 6- 8: Assumed parameters for NGWH and ASHPWH

\begin{tabular}{|l|r|}
\hline Electric price $(\$ / \mathrm{kWh})$ & 0.15 \\
\hline Natural gas price $\left(\$ / \mathrm{m}^{3}\right)$ & 0.40 \\
\hline Daily hot water draw $(\mathrm{Lit} /$ day $)$ & 200 \\
\hline Delta temp. $\left({ }^{\circ} \mathrm{C}\right)$ & 45 \\
\hline COP of HPWH in summer & 3.5 \\
\hline COP of HPWH in winter & 3.0 \\
\hline Natural gas boiler-furnace efficiency & 0.80 \\
\hline Natural gas water heater efficiency & 0.55 \\
\hline Central AC EER & 10.25 \\
\hline
\end{tabular}

Table 6- 9: Estimated cost reduction for NGWH and ASHPWH

\begin{tabular}{|c|c|c|c|c|}
\hline & $\begin{array}{c}\text { NGWH } \\
\text { electricity } \\
\text { cost }(\$)\end{array}$ & $\begin{array}{c}\text { ASHPWH } \\
\text { electricity } \\
\text { cost }(\$)\end{array}$ & $\begin{array}{c}\text { Cost } \\
\text { reduction } \\
(\$)\end{array}$ & $\begin{array}{c}\text { Cost } \\
\text { reduction } \\
(\%)\end{array}$ \\
\hline Summer & 88.7 & 9.0 & 79.7 & 89.8 \\
\hline Winter & 177.5 & 206.7 & -29.3 & -16.5 \\
\hline Annual & 266.2 & 215.8 & 50.4 & 19.0 \\
\hline
\end{tabular}

\subsection{GHG Emission Reduction}

Gordon and Fung (2011) determined the monthly time dependent emission factors for Ontario (shown in Table 6-10) based on the hourly electricity consumption data and hourly GHG emission factors. The mentioned monthly factors were entered into the model by adding the monthly forcing function scheduler type, and the type was connected with the electricity consumption calculator. The results from the GHG emission computation can be viewed in Table 6-11. Based on the results, by using the ASHPWH, the overall GHG emission from space heating/cooling as well as domestic water heating systems can be reduced by $21.7 \%$.

Table 6-10: Monthly average GHG emission factors in Ontario

\begin{tabular}{|c|c|c|c|c|c|c|c|c|c|c|c|c|}
\hline gr of & January & February & March & April & May & June & July & August & September & October & November & December \\
\hline $\begin{array}{c}\mathrm{CO}_{2} / \mathrm{kWh} \\
\text { in } 2006\end{array}$ & 215.1 & 1988 & 1808 & 125.5 & 1648 & 216.9 & 233.9 & 2 & 188 & 193.6 & 191.1 & 155 \\
\hline
\end{tabular}

Table 6-11: GHG emission analysis

\begin{tabular}{|l|c|c|c|c|}
\hline \multirow{2}{*}{} & \multicolumn{2}{|c|}{ Annual GHG emission $(\mathrm{kg})$} & Annual GHG emission \\
\cline { 2 - 5 } & $\begin{array}{c}\text { Model 2 (Electric } \\
\text { Water Heater) }\end{array}$ & Model 1 (ASHPWH) & $\begin{array}{c}\text { Annual GHG emission } \\
\text { reduction }(\%)\end{array}$ \\
\hline Toronto & 1661 & 1301 & 360 & 21.7 \\
\hline
\end{tabular}




\subsection{System Performance in Major Canadian Cities}

In order to investigate the effect of weather conditions on the ASHPWH system performance and energy saving potential, the models were used for five major Canadian cities, including Halifax, Montreal, Toronto, Edmonton and Vancouver, using the weather data files of TRNSYS. Another necessary input file for this part of the research is the inlet water temperature for the five cities. Tanha et al. (2015) has presented the monthly inlet water temperature for five major cities in Canada as shown in Figure 6-10 which has been used in the model. Based on Tanha's data Vancouver has the highest monthly inlet water average temperature and Edmonton has the lowest.

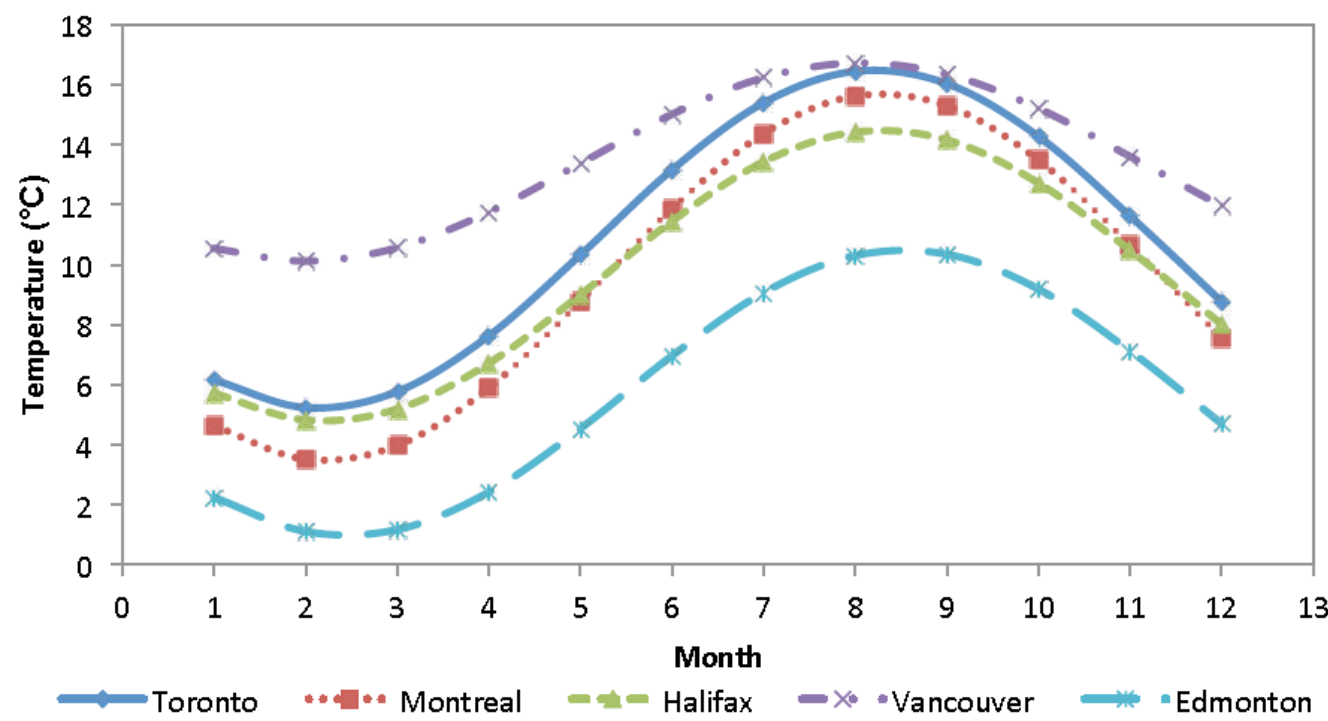

Figure 6-10: Monthly water main temperature (Tanha et al., 2015)

The summary of the annual electricity usage by the electric water heater and ASHPWH as well as the reduced electricity when comparing two systems for the five aforementioned cities are listed in Table 6-10. For both systems, Edmonton has the highest values for electricity consumptions due to colder monthly ambient temperatures and lower water main temperatures, as seen in Figure 6-12. The minimum saving happens in Edmonton. However the maximum saving that can be achieved is in Vancouver where $28.3 \%$ of electricity (1932 kWh) can be saved by using ASHPWH instead of the electric water heater. 
Table 6-12: Annual saved electricity in five major Canadian cities

\begin{tabular}{|l|c|c|c|c|}
\hline & $\begin{array}{c}\text { Elec. Water Heater+HP } \\
(\mathrm{kWh})\end{array}$ & $\begin{array}{c}\text { ASHPWH+HP } \\
(\mathrm{kWh})\end{array}$ & $\begin{array}{c}\text { Annual Saved } \\
\text { Electricity }(\mathrm{kWh})\end{array}$ & $\begin{array}{c}\text { Annual Saved } \\
\text { Electricity }(\%)\end{array}$ \\
\hline Halifax & 8795 & 7022 & 1773 & 20.2 \\
\hline Montreal & 10694 & 8916 & 1778 & 16.6 \\
\hline Toronto & 8874 & 6983 & 1891 & 21.3 \\
\hline Edmonton & 12644 & 10954 & 1690 & 13.4 \\
\hline Vancouver & $\mathbf{6 8 3 1}$ & $\mathbf{4 8 9 9}$ & $\mathbf{1 9 3 2}$ & $\mathbf{2 8 . 3}$ \\
\hline
\end{tabular}

In order to compute the annual electricity cost reduction, the average 2014 electricity prices for different cities (Hydro Quebec, 2010) except Toronto, shown in Table 6-13, have been employed. Using the GHG emission factors per kilogram equivalent $\mathrm{CO}_{2}$ for electricity (Environment Canada, 2013), shown in Table 6-14, the annual GHG emissions from two systems and the overall reduction in GHG emissions have been calculated and the result has been demonstrated in Table 6-14. Similar to electricity reduction, the maximum cost reduction and GHG emission reduction happens in Vancouver and the minimum in Edmonton.

Table 6-13: Annual electricity cost reduction in five major Canadian cities

\begin{tabular}{|l|c|c|c|c|c|}
\hline & $\begin{array}{c}\text { Cost of Electricity per } \\
\mathrm{kWh}(\mathbb{C})\end{array}$ & $\begin{array}{c}\text { Elec. Water } \\
\text { Heater+HP }(\$)\end{array}$ & ASHPWH+HP (\$) & $\begin{array}{c}\text { Annual Electricity } \\
\text { Cost Reduction }(\$)\end{array}$ & $\begin{array}{c}\text { Annual Saved } \\
\text { Electricity }(\%)\end{array}$ \\
\hline Halifax & 16.83 & 1480 & 1182 & 298 & 20.2 \\
\hline Montreal & 8.12 & 868 & 724 & 144 & 16.6 \\
\hline Toronto & Time of Use Rates & 1504 & 1173 & 331 & 22.0 \\
\hline Edmonton & 12.47 & 1577 & 1366 & 211 & 13.4 \\
\hline Vancouver & $\mathbf{1 0 . 3 9}$ & $\mathbf{7 1 0}$ & $\mathbf{5 0 9}$ & $\mathbf{2 0 1}$ & $\mathbf{2 8 . 3}$ \\
\hline
\end{tabular}

Table 6-14: Annual GHG emission reduction in five major Canadian cities

\begin{tabular}{|l|c|c|c|c|c|}
\hline & $\begin{array}{c}\text { GHG Emission Factor } \\
\text { per kWh }(\mathrm{kg})\end{array}$ & $\begin{array}{c}\text { Elec. Water } \\
\text { Heater+HP }(\mathrm{kg})\end{array}$ & $\begin{array}{c}\text { ASHPWH+HP } \\
(\mathrm{kg})\end{array}$ & $\begin{array}{c}\text { Annual GHG } \\
\text { Emission Reduction } \\
(\mathrm{kg})\end{array}$ & $\begin{array}{c}\text { Annual GHG } \\
\text { Emission Reduction } \\
(\%)\end{array}$ \\
\hline Halifax & 0.69 & 6069 & 4845 & 1223 & 20.2 \\
\hline Montreal & 0.002 & 21 & 18 & 4 & 16.6 \\
\hline Toronto & Monthly Hourly Factors & 1661 & 1301 & 360 & 21.7 \\
\hline Edmonton & 0.82 & 10368 & 8982 & 1386 & 13.4 \\
\hline Vancouver & $\mathbf{0 . 1 5}$ & $\mathbf{1 0 2 5}$ & $\mathbf{7 3 5}$ & $\mathbf{2 9 0}$ & $\mathbf{2 8 . 3}$ \\
\hline
\end{tabular}




\section{Chapter 7: Summary and Conclusion}

The main focus of this research was to investigate the performance of the air source heat pump water heater system in cold climate condition of Canada. The related experiments were performed in the TRCA Archetype House B in three different indoor conditions (dry bulb temperature and relative humidity) and three system modes (hybrid, HP and electric). Each of indoor conditions was representative of the typical house condition encounter in Canada. Every experiment included two stages. In the stage 1 , the tank water was heated up from $16{ }^{\circ} \mathrm{C}$ to the set point temperature $\left(55^{\circ} \mathrm{C}\right)$ in one day. This stage was followed by the stage 2 which included two days of water draw based on the International Energy Agency water draw schedule. Using the data acquisition system, the data from temperature, power and flow rate sensors were recorded for every 0.5 second.

While the required data was collecting, MATLAB scripts were developed in order to read and analyze the data. The values of coefficient of performance, heating capacity of HP, energy consumption and Energy Factor were determined. Then, the experimental results were verified by the manufacturer data. The fluctuation in the water temperature was examined by calculating the average tank temperature from six temperature poles data installed inside the tank. Using Ontario Time of Use electricity rates for residential customers, the electricity costs for different experiment modes were estimated.

The ASHPWH system model (Model 1), including the heat pump and two auxiliary electric heaters, as well as the electric water heater model (Model 2) were developed in TRNSYS 17. Then, both models were integrated to the existing TRCA House A model for simulation in both heating and cooling seasons. The heat pump water heater in the Model 1 was verified by the performance curves obtained from the experimental data. In addition, the variation in the water outlet temperature from the simulation was validated by the experimental results. By simulating the system, the changes in hot water production energy consumption, heating and cooling energy consumption, GHG emission and electricity cost in summer and winter were compared between Model 1 and Model 2. In addition, the effect of ASHPWH system energy consumption with different R-value increase of the tank insulation was investigated. Finally, Models 1 and 2 were used to simulate the hot water production systems in four major Canadian cities other than Toronto, including Montreal, Edmonton, Vancouver and Halifax in order to investigate the potential 
reduction in domestic hot water energy consumption, heating and cooling energy consumption, GHG emission and electricity cost in different Canadian weather conditions.

Considering results from the experiments, it can be concluded that the COP of the system is changing mostly between 1.5 to 4.5 depending on the indoor dry bulb temperature, average water temperature and water inlet temperature. As expected, by increasing the water average temperature, the COP reduces while in most of the cases the COP was higher for the experiments with higher indoor temperature in both Hybrid and HP modes. Although this system can operate more efficiently in warmer environments, the cold and humid condition of room does not deteriorate the performance of the system.

Another parameter investigated is the tank average temperature. Based on the obtained results, the system in both HP and hybrid modes can keep temperature in the acceptable range. However, because of the control strategy of the system, electric elements started to work at some points even during the heat pump mode unlike the expectation. Generally by comparing different modes, the average tank temperature in the electric mode is about 5 degrees below HP and hybrid modes as it was expected based on the provided information by the manufacturer.

One of the parameters in the evaluation of energy efficiency of the water heater is Energy Factor. The calculated Energy Factor from the experiments for the HP mode are 2.64 and 3.7 and for the electric mode are 0.82 and 1.35 which show that the value of consumed electrical energy for the electric mode is 2 to 3 times more than in the HP mode. The estimation of cost for different modes for two days of water draw shows that the electricity cost of the water heating system can be reduced up to $64 \%$ in hybrid and HP modes respectively compared to the electric mode.

By comparing the result from Model 1 and experiment, the best set point temperature for the ASHPWH and the auxiliary electric heater is about $54^{\circ} \mathrm{C}$ and $50{ }^{\circ} \mathrm{C}$ respectively. The results from Model 1 show that by the mentioned control strategy for the HP and the auxiliary electric heaters, the electric heaters only generate between $7 \%$ to $13 \%$ of the total required thermal demand and the majority is produced by the HP. By reducing the two electric heaters' set point temperatures, from $50{ }^{\circ} \mathrm{C}$ to $40{ }^{\circ} \mathrm{C}$, their usage can be completely eliminated and the HP can individually heat up the required hot water demand to the set point temperature. The total heat loss form the tank and HP 
evaporator coil is $6 \%$ and $11 \%$ of total generated energy by ASHPWH in summer and winter respectively. After increasing the R-value from 6.475 to 20 (h. ${ }^{\circ} \mathrm{F} \mathrm{ft}^{2} / \mathrm{BTU}$ ) in the ASHPWH model the required electricity for heating up the same amount of water can be reduced up to $8.85 \%$ and $9.89 \%$ in summer and winter respectively.

The simulation results from the ASHPWH model and the electric water heater model show that by using the ASHPWH in a typical three story house in Toronto with an average of 200 litre/day of hot water demand, the hot water production energy consumption can be reduced by $60.3 \%$ and $53.2 \%$ in summer and winter respectively. While the summer cooling decreases, the winter heating increases. The net effects leads to $21.3 \%$ reduction in the total electricity consumption of the house. The electricity price and the GHG emission reduce by $22 \%$ and $21.7 \%$ respectively. The payback period for the ASHPWH compared to electric water heater is about 3.7 years. By using the model for other major Canadian cities, the minimum and maximum electricity and cost saving as well as the GHG emission reduction happen in Edmonton and Vancouver respectively. It shows that even in one of the coldest cities in Canada (i.e. Edmonton) we can have the annual electricity saving of $13.4 \%$ by using ASHPWH while the maximum saving can be achieved up to $28.3 \%$ in Vancouver.

The following recommendations are made based on the results of this study:

- Although, based on the manufacturer information it was expected that during the HP mode only ASHPWH operates and during the electric mode only electric elements operate but in some experiments we observed that both of them were operating in both modes. It is recommended to perform more experiments to find the strategy to eliminate the operation of electric elements in the heat pump mode and also ASHPWH in the electric mode to investigate their performance more precisely.

- During different experiments, the water supply temperature to the tank was different. Reducing this difference, as one of the two factors that influence the COP of the ASHPWH, can show the effect of another factor, indoor temperature, more clearly. Dumping more water at the start of each experiment can help to reduce the effect of warming up the water in the house piping system and may reduce the water supply temperature difference. 
- The ASHPWH system absorbs the heat from indoor air. By connecting the evaporator part to the return air of the ventilation system, it can eliminate the effect of the system on the winter heating consumption of the house and also recover the heat that dump to the outside. Simulating the system with absorbing the required heat from return air of the ventilation system can reveal the potential energy saving and it might have a convincing result for the manufacturer to customize their design in order to make this connection possible.

- Since the control strategy of the system can influence the overall ASHPWH efficiency and temperature distribution inside the tank, it is beneficial to investigate different control strategies. One of the strategies is to include the starting point for operation of HP and electric elements which can be based on the average temperature of different nodes. Another option is the investigation of operating electric elements at different set point temperatures.

- Distribution of heat exchanger coil around the water tank can affect the temperature distribution inside the tank. This factor along with the control strategy can have an important role in using the consumed electricity efficiently in the ASHPWH. One of the potential studies is simulation of different options for distribution fraction of heat exchanger coils with different control strategies in order to optimize the overall performance. 


\section{Appendix A: Water Draw Profile}

The water draw profile with 1-min time step that was used in experiments are for two days and the schedule is shown in Table B-1.

Table B-1: Water Draw schedule

\begin{tabular}{|c|c|c|c|c|c|}
\hline Start Time & Duration (sec) & $\begin{array}{c}\text { Flow Rate (Hot } \\
\text { Only) (gpm) }\end{array}$ & Start Time & Duration (sec) & $\begin{array}{c}\text { Flow Rate (Hot } \\
\text { Only) (gpm) }\end{array}$ \\
\hline Day 1 & & & Day 2 & & \\
\hline 5:43:00 & 108 & 1 & 7:05:00 & 16 & 1 \\
\hline 6:03:00 & 10 & 1 & 7:19:00 & 89 & 1 \\
\hline 7:34:00 & 19 & 1 & 7:40:00 & 427 & 1.6 \\
\hline 7:43:00 & 10 & 1 & 8:06:00 & 117 & 1 \\
\hline $7: 45: 00$ & 367 & 1.6 & $8: 18: 00$ & 70 & 1 \\
\hline $9: 24: 00$ & 10 & 1 & 10:19:00 & 73 & 1 \\
\hline 9:35:00 & 6 & 1 & 10:33:00 & 22 & 1 \\
\hline 9:47:00 & 16 & 1 & 10:49:00 & 22 & 1 \\
\hline 10:37:00 & 44 & 1 & 11:02:00 & 25 & 1 \\
\hline 10:59:00 & 82 & 1 & $11: 14: 00$ & 100 & 1.3 \\
\hline $11: 10: 00$ & 22 & 1 & $11: 15: 00$ & 54 & 1.3 \\
\hline 12:07:00 & 16 & 1 & $12: 16: 00$ & 15 & 1.3 \\
\hline 12:56:00 & 29 & 1 & 13:54:00 & 445 & 1.6 \\
\hline 13:20:00 & 10 & 1 & 14:07:00 & 527 & 1.6 \\
\hline 14:06:00 & 10 & 1 & 14:46:00 & 168 & 1 \\
\hline 15:23:00 & 22 & 1 & 14:51:00 & 22 & 1 \\
\hline 15:46:00 & 32 & 1 & 14:59:00 & 25 & 1 \\
\hline 16:21:00 & 335 & 1.6 & $15: 28: 00$ & 10 & 1 \\
\hline 16:47:00 & 10 & 1 & 15:44:00 & 86 & 1 \\
\hline $17: 47: 00$ & 19 & 1 & $16: 23: 00$ & 16 & 1 \\
\hline $17: 49: 00$ & 73 & 1 & $16: 42: 00$ & 100 & 1.3 \\
\hline 17:57:00 & 6 & 1 & 16:44:00 & 68 & 1.3 \\
\hline 18:09:00 & 29 & 1 & 16:57:00 & 49 & 1.3 \\
\hline 18:25:00 & 78 & 1.3 & $17: 16: 00$ & 44 & 1 \\
\hline 18:51:00 & 6 & 1 & $18: 48: 00$ & 95 & 1 \\
\hline 19:02:00 & 73 & 1.3 & 19:39:00 & 29 & 1 \\
\hline 19:29:00 & 73 & 1.3 & 20:08:00 & 25 & 1 \\
\hline 19:36:00 & 10 & 1 & $20: 19: 00$ & 73 & 1.3 \\
\hline $20: 09: 00$ & 22 & 1 & 20:21:00 & 100 & 1.3 \\
\hline 20:34:00 & 38 & 1 & 21:14:00 & 10 & 1 \\
\hline 20:41:00 & 10 & 1 & 23:43:00 & 29 & 1 \\
\hline 20:56:00 & 10 & 1 & & & \\
\hline 21:09:00 & 25 & 1 & & & \\
\hline 21:41:00 & 93 & 1.3 & & & \\
\hline $22: 20: 00$ & 63 & 1.3 & & & \\
\hline $22: 40: 00$ & 19 & 1 & & & \\
\hline 22:47:00 & 22 & 1 & & & \\
\hline $23: 37: 00$ & 16 & 1 & & & \\
\hline
\end{tabular}




\section{Appendix B: Error Propagation}

The error propagation has been done for the hybrid mode at $15 \mathrm{C}$ and $70 \% \mathrm{RH}$ between time $32400 \mathrm{~s}$ to $33300 \mathrm{~s}(\Delta \mathrm{t}=15 \mathrm{~min})$. The parameters values were shown in Table B-1 an the detail calculations are as the following.

Table B-2: Used parameters for error calculation

\begin{tabular}{|l|c|c|}
\hline & Value & Error \\
\hline$F L_{2}(G P M)$ & 0.72 & 0.040 \\
\hline$T_{a v g}^{t}\left({ }^{\circ} \mathrm{C}\right)$ & 42.5 & 0.092 \\
\hline$T_{a v g}^{t+d t}\left({ }^{\circ} \mathrm{C}\right)$ & 44 & 0.095 \\
\hline$T_{26}\left({ }^{\circ} \mathrm{C}\right)$ & 15.2 & 0.032 \\
\hline$T_{4}\left({ }^{\circ} \mathrm{C}\right)$ & 55 & 0.119 \\
\hline$T_{75}\left({ }^{\circ} \mathrm{C}\right)$ & 15 & 0.032 \\
\hline Electric Element Power $(\mathrm{kJ} / \mathrm{min})$ & 0 & 0.000 \\
\hline
\end{tabular}

$\frac{\partial Q}{\partial F L_{2}}=15.83\left[\left[1-\frac{\left(T_{4}^{t}-4\right)^{2}}{119000+1365 T_{4}^{t}-4\left(T_{4}^{t}\right)^{2}}\right] T_{4}^{t}-\left[1-\frac{\left(T_{26}^{t}-4\right)^{2}}{119000+1365 T_{26}^{t}-4\left(T_{26}^{t}\right)^{2}}\right] T_{26}^{t}\right]$

$=621$

$\frac{\partial Q}{\partial T_{4}} \quad=15.83 F L_{2}\left[1-\frac{\left(3 T_{4}^{2}-18 T_{4}+16\right)\left(119000+1365 T_{4}-4 T_{4}^{2}\right)-\left(1365-8 T_{4}\right)\left(T_{4}^{3}-8 T_{4}^{2}+16 T_{4}\right)}{\left(119000+1365 T_{4}-4 T_{4}^{2}\right)^{2}}\right]$

$=30.38$

$\frac{\partial Q}{\partial T_{26}}=-15.83 F L_{2}\left[1-\frac{\left(3 T_{26}^{2}-18 T_{26}+16\right)\left(119000+1365 T_{26}-4 T_{26}^{2}\right)-\left(1365-8 T_{26}\right)\left(T_{26}^{3}-8 T_{26}^{2}+16 T_{26}\right)}{\left(119000+1365 T_{26}-4 T_{26}^{2}\right)^{2}}\right]$

$=-31.63$

$\frac{\partial Q}{\partial P_{2}} \quad=-1$

$\frac{\partial Q}{\partial T_{a v g}^{t}}=52.67[1-$ 


$$
\begin{aligned}
& \left.\frac{\left(3\left(T_{\text {avg }}^{t}\right)^{2}-18 T_{\text {avg }}^{t}+16\right)\left(119000+1365 T_{\text {avg }}^{t}-4\left(T_{\text {avg }}^{t}\right)^{2}\right)-\left(1365-8 T_{\text {avg }}^{t}\right)\left(\left(T_{\text {avg }}^{t}\right)^{3}-8\left(T_{\text {avg }}^{t}\right)^{2}+16 T_{\text {avg }}^{t}\right)}{\left(119000+1365 T_{\text {avg }}^{t}-4\left(T_{\text {avg }}^{t}\right)^{2}\right)^{2}}\right] \\
& =47.35 \\
& \frac{\partial Q}{\partial T_{a v g}^{t+\Delta t}} \quad=52.67[1- \\
& \left.\frac{\left(3\left(T_{a v g}^{t+\Delta t}\right)^{2}-18 T_{a v g}^{t+\Delta t}+16\right)\left(119000+1365 T_{a v g}^{t+\Delta t}-4\left(T_{a v g}^{t+\Delta t}\right)^{2}\right)-\left(1365-8 T_{a v g}^{t+\Delta t}\right)\left(\left(T_{a v g}^{t+\Delta t}\right)^{3}-8\left(T_{a v g}^{t+\Delta t}\right)^{2}+16 T_{a v g}^{t+\Delta t}\right)}{\left(119000+1365 T_{a v g}^{t+\Delta t}-4\left(T_{a v g}^{t+\Delta t}\right)^{2}\right)^{2}}\right] \\
& =38.74 \\
& \frac{\partial Q}{\partial T_{75}} \quad=-0.14 \\
& U_{Q}^{2}=\left[\frac{\partial Q}{\partial F L_{2}}\right]^{2} \times U_{F L_{2}}^{2}+\left[\frac{\partial Q}{\partial T_{4}}\right]^{2} \times U_{T_{4}}^{2}+\left[\frac{\partial Q}{\partial T_{26}}\right]^{2} \times U_{T_{26}}^{2}+\left[\frac{\partial Q}{\partial T_{a v g}^{t}}\right]^{2} \times U_{T_{a v g}^{t}}^{2}+\left[\frac{\partial Q}{\partial T_{a v g}^{t+d t}}\right]^{2} \\
& \times U_{T_{a v g}^{t+d t}}^{2}+\left[\frac{\partial Q}{\partial P_{2}}\right]^{2} \times U_{P_{2}}^{2}+\left[\frac{\partial Q}{\partial T_{75}}\right]^{2} \times U_{T_{75}}^{2} \\
& U_{Q} \quad=0.062=6.2 \% \\
& \frac{\partial C O P}{\partial P_{1}} \quad=-\frac{Q}{P_{1}^{2}}=-0.007 \\
& \frac{\partial C O P}{\partial Q} \quad=\frac{1}{P_{1}}=0.0022 \\
& U_{C O P}^{2} \quad=\left[\frac{\partial C O P}{\partial Q}\right]^{2} \times U_{Q}^{2}+\left[\frac{\partial C O P}{\partial P_{1}}\right]^{2} \times U_{P_{1}}^{2} \\
& U_{C O P}=0.028=2.8 \%
\end{aligned}
$$




\section{Appendix C: MATLAB Code for Analyzing Experimental Data}

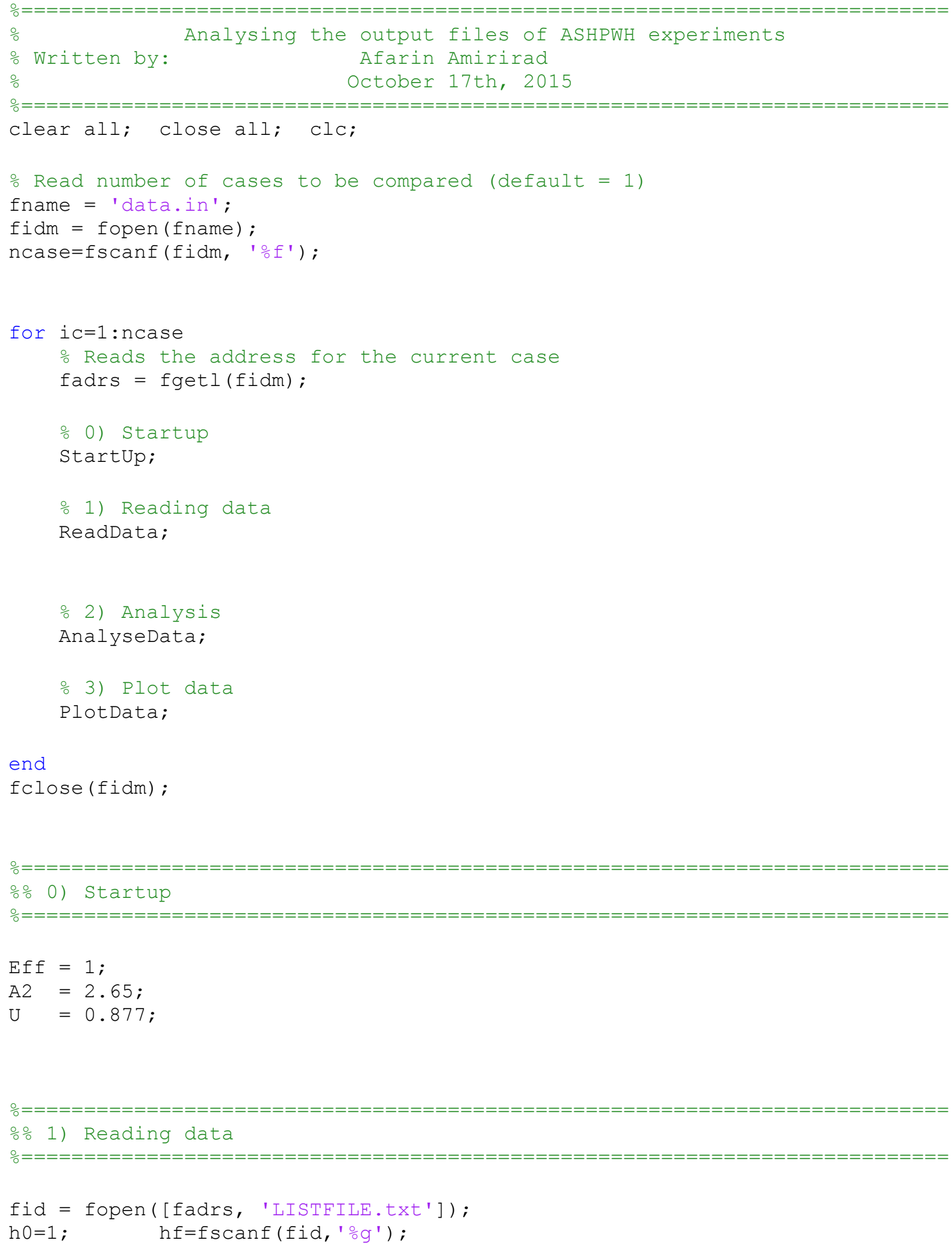




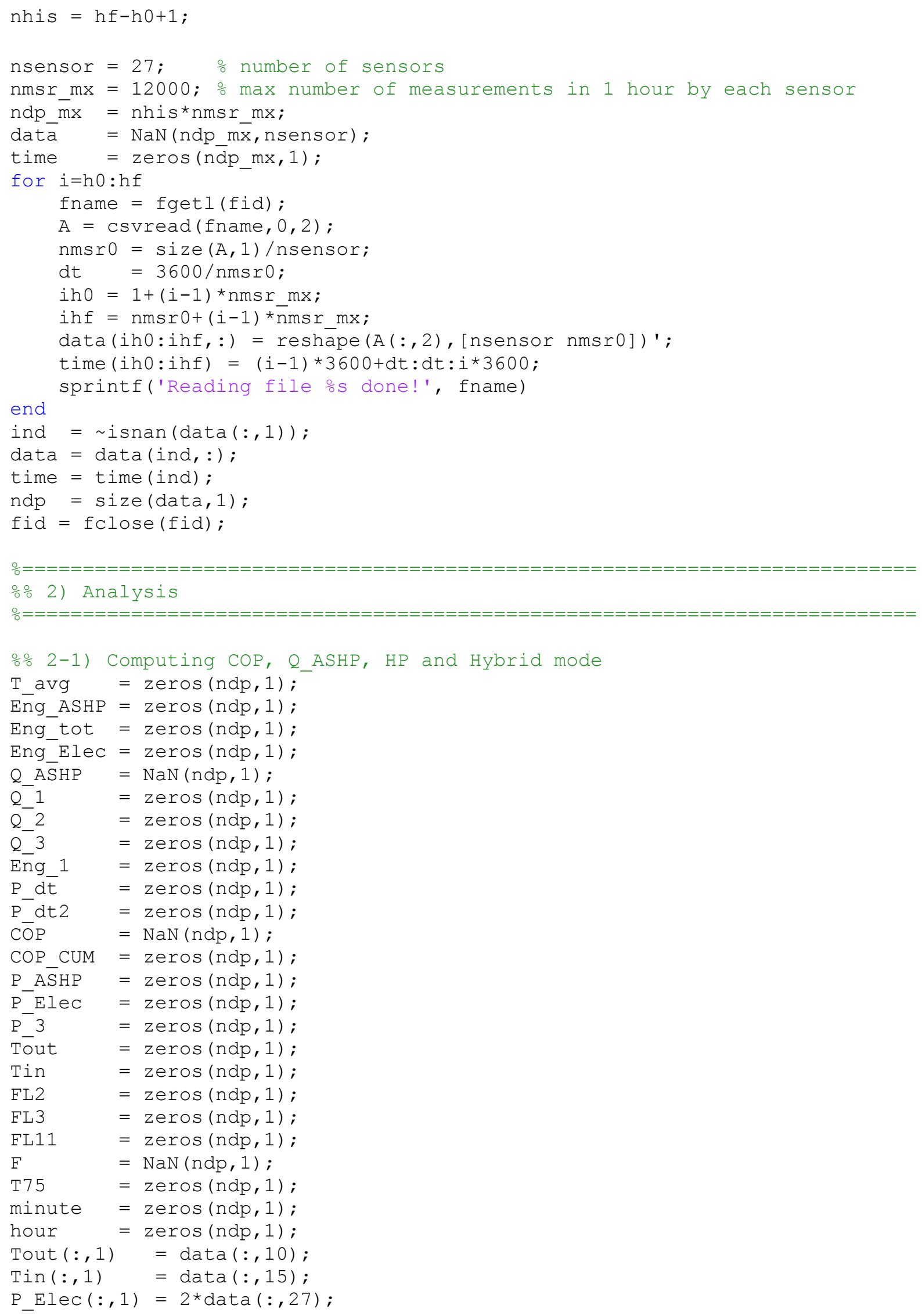




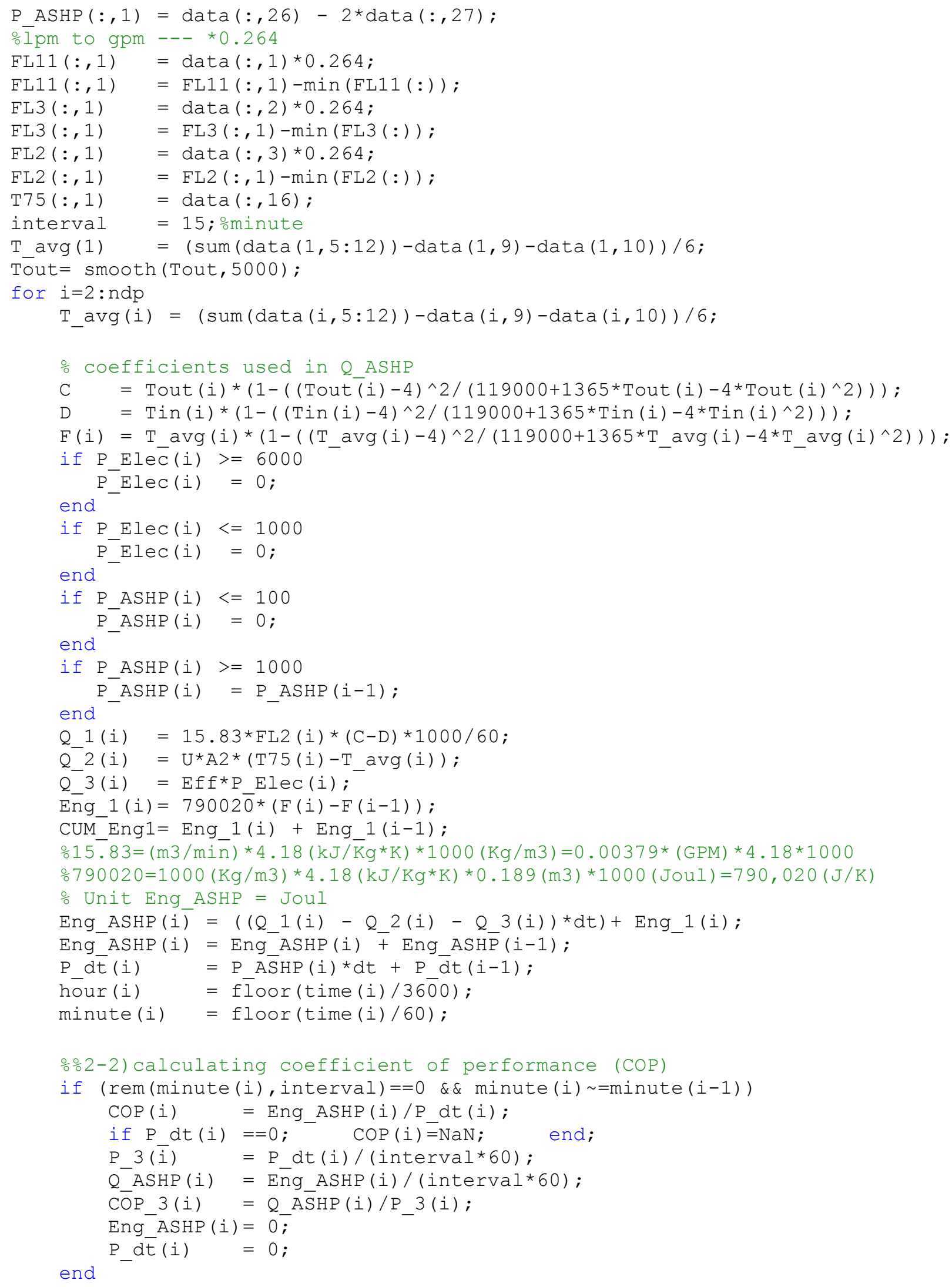




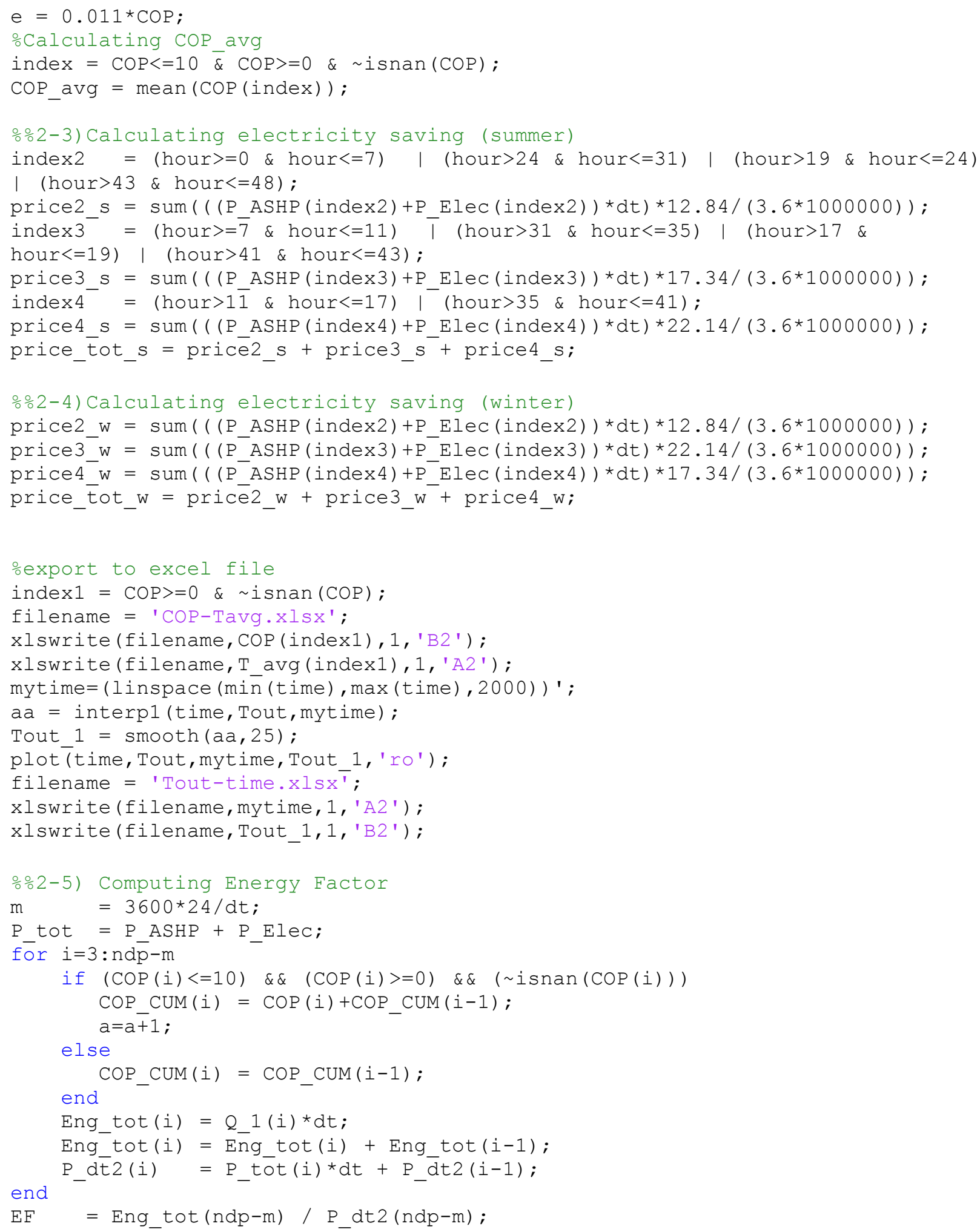




\section{References}

Aguilar, C., White, D. J., \& Ryan, D. L. (2005). Domestic water heating and water heater energy consumption in Canada. Canadian Building Energy End-Use Data and Analysis Centre.

Amponsah, N. Y., Troldborg, M., Kington, B., Aalders, I., \& Hough, R. L. (2014). Greenhouse gas emissions from renewable energy sources: A review of lifecycle considerations. Renewable and Sustainable Energy Reviews, 39, 461-475.

ASHRAE Handbook (2009). ASHRAE Handbook-fundamentals. Atlanta, GA.

Aste, N., Adhikari, R. S., \& Manfren, M. (2013). Cost optimal analysis of HP technology adoption in residential reference buildings. Renewable energy, 60, 615-624.

Austin, B. T., \& Sumathy, K. (2011). Transcritical carbon dioxide HP systems: A review. Renewable and Sustainable Energy Reviews, 15(8), 4013-4029.

Bertsch, S. S., \& Groll, E. A. (2008). Two-stage air-source HP for residential heating and cooling applications in northern US climates. International Journal of Refrigeration, 31(7), 12821292.

Bursill, J., \& Cruickshank, C. A. (2016). Heat Pump Water Heater Control Strategy Optimization for Cold Climates. Journal of Solar Energy Engineering, 138(1), 011011.

Byrne, P., Miriel, J., \& Lénat, Y. (2012, September). Modelling and simulation of a HP for simultaneous heating and cooling. Building Simulation (Vol. 5, No. 3, pp. 219-232). Tsinghua Press.

Calabrese, N., Mastrullo, R., Mauro, A. W., Rovella, P., \& Tammaro, M. (2015). Performance analysis of a rooftop, air-to-air HP working with $\mathrm{CO}$ 2. Applied Thermal Engineering, 75, 1046-1054.

Coleman, H. W., \& Steele, W. G. (2009). Experimentation, validation, and uncertainty analysis for engineers. John Wiley \& Sons. 
Dembo, A., Fung, A., Ringo NG, K., \& Pyrka, A. (2010). The Archetype Sustainable House: Investigating its Potentials to Achieving the Net-Zero Energy Status Based on the Results of a Detailed Energy Audit. International High Performance Buildings Conference. Purdue, Indiana.

Ding, Y., Chai, Q., Ma, G., \& Jiang, Y. (2004). Experimental study of an improved air source HP. Energy Conversion and Management, 45(15), 2393-2403.

Dongellini, M., Naldi, C., \& Morini, G. L. (2015). Seasonal performance evaluation of electric airto-water HP systems. Applied Thermal Engineering.

Environment Canada, "National Inventory Report 1990-2013: Greenhouse Gas Sources and Sinks in Canada-Part 3", Retrieved May 31, 2016, from: https://www.ec.gc.ca/gesghg/default.asp?lang=En\&n=83A34A7A-1.

Fu, H. D., Pei, G., Ji, J., Long, H., Zhang, T., \& Chow, T. T. (2012). Experimental study of a photovoltaic solar-assisted heat-pump/heat-pipe system. Applied Thermal Engineering, 40, 343-350.

Fung, A. S., \& Gill, G. S. (2011). Energy and Environmental Analysis of Residential Hot Water Systems: A Study for Ontario, Canada. ASHRAE Transactions, 117(2).

Ghoubali, R., Byrne, P., Miriel, J., \& Bazantay, F. (2014). Simulation study of a HP for simultaneous heating and cooling coupled to buildings. Energy and Buildings, 72, 141-149.

Gordon, C., \& Fung, A. (2011). Analysis of Time Dependent Valuation of Emission Factors from the Electricity Sector. INTECH Open Access Publisher.

Greening, B., \& Azapagic, A. (2012). Domestic HPs: Life cycle environmental impacts and potential implications for the UK. Energy, 39(1), 205-217.

Haynes, W. M. (Ed.). (2015). CRC handbook of chemistry and physics. CRC press.

Hepbasli, A., \& Kalinci, Y. (2009). A review of heat pump water heating systems. Renewable and Sustainable Energy Reviews, 13(6), 1211-1229. 
Honari, H., Makhyoun, M., Sridhar, V., \& Hoover, K. (2014). Economic Analysis of Ground Source HPs in North Carolina. ASHRAE Transactions, 120, 1 D.

Hydro One, "Residential Delivery Rate”, Retrieved March 21, 2016, from: http://www.hydroone.com/MyHome/MyAccount/UnderstandMyBill/Pages/ResidentialDeli veryRates.aspx

Ibrahim, O., Fardoun, F., Younes, R., \& Louahlia-Gualous, H. (2014). Air source HP water heater: Dynamic modeling, optimal energy management and mini-tubes condensers. Energy, 64, 1102-1116.

Independent Electricity System Operator (IESO), "Residential and Small Business Consumers", Retrieved March 21, 2016, from: http://www.ieso.ca/Pages/Ontario's-Power$\underline{\text { System/Electricity-Pricing-in-Ontario/Residential-and-Small-Business-Consumers.aspx. }}$

Jenkins, D., Tucker, R., Ahadzi, M., \& Rawlings, R. (2008). The performance of air-source HPs in current and future offices. Energy and Buildings, 40(10), 1901-1910.

Ji, J., Liu, K., Chow, T. T., Pei, G., He, W., \& He, H. (2008). Performance analysis of a photovoltaic HP. Applied Energy, 85(8), 680-693.

Kamel, R. S., \& Fung, A. S. (2014). Modeling, simulation and feasibility analysis of residential BIPV/T+ ASHP system in cold climate-Canada. Energy and Buildings, 82, 758-770.

Kamel, R. S., Fung, A. S., \& Dash, P. R. (2015). Solar systems and their integration with HPs: A review. Energy and Buildings, 87, 395-412.

Kim, M., Kim, M. S., \& Chung, J. D. (2004). Transient thermal behavior of a water heater system driven by a heat pump. International journal of refrigeration, 27(4), 415-421.

Knight, I., Kreutzer, N., Manning, M., Swinton, M., \& Ribberink, H. (2007). European and Canadian non-HVAC Electric and DHW Load Profiles for Use in Simulating the Performance of Residential Cogeneration Systems. International Energy Agency (IEA Annex 42). 
Kravchenko, V. S. (1966). Empirical equation derived for temperature dependence of density of heavy water. Atomic Energy, 20(2), 212-212.

Liang, C. H., Zhang, X. S., Li, X. W., \& Zhu, X. (2011). Study on the performance of a solar assisted air source HP system for building heating. Energy and Buildings, 43(9), 2188-2196.

Li, G. (2015). Comprehensive investigations of life cycle climate performance of packaged air source HPs for residential application. Renewable and Sustainable Energy Reviews, 43, 702710.

Li, H., Sun, L., \& Zhang, Y. (2014). Performance investigation of a combined solar thermal HP heating system. Applied Thermal Engineering, 71(1), 460-468.

Lutz, J., Whitehead, C. D., Lekov, A., Winiarski, D., \& Rosenquist, G. (1998). Wham: A simplified energy consumption equation for water heaters (No. CONF-980815--). Lawrence Berkeley National Lab., CA (US).

Ma, G. Y., \& Chai, Q. H. (2004). Characteristics of an improved heat-pump cycle for cold regions. Applied energy, 77(3), 235-247.

Mattinen, M. K., Nissinen, A., Hyysalo, S., \& Juntunen, J. K. (2015). Energy Use and Greenhouse Gas Emissions of Air-Source HP and Innovative Ground-Source Air HP in a Cold Climate. Journal of Industrial Ecology, 19(1), 61-70.

Madonna, F., \& Bazzocchi, F. (2013). Annual performances of reversible air-to-water HPs in small residential buildings. Energy and Buildings, 65, 299-309.

Ministry of the Environment and Climate Change, "Ontario's Climate Change Update, 2014", Retrieved 20 Mar. 2016, from: https://dr6j45jk9xcmk.cloudfront.net/documents/3618/climate-change-report-2014.pdf

Moran, M. J., Shapiro, H. N., (2006). Fundamentals of engineering thermodynamics. $5^{\text {th }}$ ed. John Wiley \& Sons. 
Morrison, G. L., Anderson, T., \& Behnia, M. (2004). Seasonal performance rating of HP water heaters. Solar Energy, 76(1), 147-152.

Nam, Y., Ooka, R., \& Shiba, Y. (2010). Development of dual-source hybrid HP system using groundwater and air. Energy and Buildings, 42(6), 909-916.

Natural Resources Canada, Office of Energy Efficiency, (2011), "Energy Efficiency Trends in Canada 1990-2009”, energy publication.

Natural Resources Canada, Office of Energy Efficiency, "Residential Sector Ontario Table 10: Water Heating Secondary Energy Use and GHG Emissions by Energy Source”, Retrieved 20 March 2016, from: http://oee.nrcan.gc.ca/corporate/statistics/neud/dpa/showTable. $\underline{\mathrm{cfm}}$ ?type $=\mathrm{CP} \&$ sector $=$ res $\&$ juris $=$ on $\& \mathrm{rn}=10 \&$ page $=0$

Natural Resources Canada, Office of Energy Efficiency (2012), “Water Heater Guide”, energy publication, Retrieved 20 April 2016, from: https://www.nrcan.gc.ca/sites/www.nrcan.gc.ca /files/energy/pdf/energystar/WaterHeaterGuide_e.pdf

Nekså, P., Rekstad, H., Zakeri, G. R., \& Schiefloe, P. A. (1998). CO 2-HP water heater: characteristics, system design and experimental results. International Journal of refrigeration, 21(3), 172-179.

Nekså, P. (2002). CO 2 HP systems. International Journal of refrigeration, 25(4), 421-427.

Papadaki, A., \& Stegou-Sagia, A. (2015). Exergy analysis of CO2 HP systems. Journal homepage: www. IJEE. IEEFoundation.org, 6(2), 165-174.

Poulet, P., \& Outbib, R. (2015). Energy production for dwellings by using hybrid systems based on HP variable input power. Applied Energy, 147, 413-429.

Quebec, Hydro. (2010). Comparison of electricity prices in major North American cities. Montréal: Hydro Québec.

Renedo, C. J., Ortiz, A., Manana, M., \& Delgado, F. (2007). A more efficient design for reversible air-air HPs. Energy and Buildings, 39(12), 1244-1249. 
Safa, A. A., Fung, A. S., \& Kumar, R. (2015). Comparative thermal performances of a ground source HP and a variable capacity air source HP systems for sustainable houses. Applied Thermal Engineering, 81, 279-287.

Safa, A. A., Fung, A. S., \& Kumar, R. (2015). Performance of two-stage variable capacity air source HP: Field performance results and TRNSYS simulation. Energy and Buildings, 94, $80-90$.

Shaughnessy, E. J., Katz, I. M., \& Schaffer, J. P. (2005). Introduction to fluid mechanics (Vol. 8). New York: Oxford University Press.

Tanha, K. (2012). Evaluating the performance of two solar domestic hot water systems of the archetype sustainable houses. MASc thesis. Toronto, ON, Canada: Ryerson University.

Tanha, K., Fung, A. S., \& Kumar, R. (2015). Performance of two domestic solar water heaters with drain water heat recovery units: Simulation and experimental investigation. Applied Thermal Engineering, 90, 444-459.

Tanha, K., Fung, A. S., \& Kumar, R. (2015). Simulation and experimental investigation of two hybrid solar domestic water heaters with drain water heat recovery. International Journal of Energy Research, 39(14), 1879-1889.

Thermal Energy System Specialists. TESS Libs. 17 (2012). Component Libraries for the TRNSYS Simulation Environment, Volume 11. Storage Tank Library Mathematical Reference.

Thygesen, R., \& Karlsson, B. (2013). Economic and energy analysis of three solar assisted HP systems in near zero energy buildings. Energy and Buildings, 66, 77-87.

Tran, C. T., Rivière, P., \& Waide, P. (2016). Energy Efficiency Modelling of Residential Air Source HP Water Heater. Journal of Sustainable Development of Energy, Water and Environment Systems, 4(1), 69-88. 
University of Wisconsin--Madison. Solar Energy Laboratory, \& Klein, S. A. (2012). TRNSYS, a transient system simulation program. Solar Energy Laboratory, University of Wisconsin-Madison.

U.S. Department of Energy (2000a), “Technical Support Document: Energy Efficiency Standards for Consumer Products: Residential Water Heaters, Including: Regulatory Impact Analysis", (Washington. DC: Energy Efficiency \& Renewable Energy)

Vieira, A. S., Stewart, R. A., \& Beal, C. D. (2015). Air source HP water heaters in residential buildings in Australia: Identification of key performance parameters. Energy and Buildings, 91, 148-162.

Von Böckh, P., \& Wetzel, T. (2011). Heat transfer: basics and practice. Springer Science \& Business Media.

Yang, J. L., Ma, Y. T., Li, M. X., \& Hua, J. (2010). Modeling and simulating the transcritical CO 2 HP system. Energy, 35(12), 4812-4818.

Zhang, D., Barua, R., \& Fung, A. S. (2011). TRCA-BILD Archetype Sustainable House-Overview of Monitoring System and Preliminary Results for Mechanical Systems. ASHRAE Transactions, 117(2).

Zhang, J., Wang, R. Z., \& Wu, J. Y. (2007). System optimization and experimental research on air source HP water heater. Applied thermal engineering, 27(5), 1029-1035. 